\author{
UNIVERSIDADE DE SÃO PAULO \\ INSTITUTO DE ASTRONOMIA, GEOFÍSICA E CIÊNCIAS \\ ATMOSFÉRICAS \\ DEPARTAMENTO DE GEOFÍSICA
}

GELVAM ANDRÉ HARTMANN

\title{
A Anomalia Magnética do Atlântico Sul: Causas e Efeitos
}

SÃO PAULO

2005 


\section{A Anomalia Magnética do Atlântico Sul: Causas e Efeitos}

Dissertação apresentada ao Instituto de Astronomia, Geofísica e Ciências Atmosféricas da Universidade de São Paulo para obtenção do Grau de Mestre em Ciências Geofísicas.

Área de Concentração: Geofísica Orientador: Prof. Dr. Igor Ivory Gil Pacca

SÃO PAULO 2005 


\section{DEDICATÓRIA}

Dedico este trabalho aos meus pais, João e Dóris, com amor e carinho, por tudo. 


\section{AGRADECIMENTOS}

Agradeço ao Prof. Igor, que aceitou o desafio de orientar-me neste assunto e que durante este período de convivência, muito me ensinou e contribuiu para o meu crescimento científico e intelectual.

Ao programa de pós-graduação em Geofísica do IAG/USP, pela oportunidade de realização do mestrado.

Aos funcionários do IAG/USP, pela disposição em sempre atender as necessidades que surgiram durante o transcorrer desta pesquisa, em especial às secretárias do Departamento (Teca e Virgínia) e a Rose da SPG.

À CAPES, pela concessão da bolsa de mestrado.

Aos colegas da pós-graduação: Afonso Lopes, Ahmad Meguid, Alanna Dutra, Alexandre Lopes, Claudia de Oliveira, Daniel Franco, Daniele Brandt, Danilo Oliveira, Deborah Souza, Dionisio Uendro, Eduardo Viana, Emilson Leite, Eric Font, Erika Reyes, Everton Bonfim, Fabio Lucas, Francisca de Souza, George Caminha, Ivan Mamede, Lucieth Vieira, Luiz Gustavo, Marcelo Peres, Marcelo Teles, Marcus Lima, Mario Rosales, Manuelle Góis, Miguel Carminatti, Nilton Silva, Oleg Bokhonok, Robson Santos, Selma Rodrigues e Welitom Borges, pelo apoio, pelas dicas e discussões sempre valiosas e, principalmente, pela amizade.

À minha família, pelo incentivo dado desde o início, em especial aos meus pais, pela compreensão e carinho que tiveram comigo durante todo esse tempo, que foram de grande importância para realização deste trabalho. 


\section{Resumo}

HARTMANN, G. A. A Anomalia Magnética do Atlântico Sul: Causas e Efeitos. 153 pp. Dissertação de Mestrado. Departamento de Geofísica, Instituto de Astronomia, Geofísica e Ciências Atmosféricas, Universidade de São Paulo, 2005.

Este trabalho tem por objetivo descrever a Anomalia Magnética do Atlântico Sul (SAMA) utilizando os modelos para o período histórico (1600-1890) e também os modelos para o último século (DGRF e IGRF). Como a SAMA apresenta características de baixa intensidade do campo total e coincide com a região de intenso fluxo de partículas cósmicas, muitos problemas com objetos que orbitam a Terra (por exemplo, satélites) são detectados nessa região. São descritos os efeitos provocados pela SAMA em fenômenos espaciais. Através da análise dos modelos na forma de mapas, foram extraídos os dados de mínima intensidade para o centro da SAMA e a posição destes pontos, possibilitando conhecer a trajetória e as taxas de deriva. Os modelos foram testados na interface manto-núcleo através da componente vertical, para encontrar correlação com anomalias em superfície. Os resultados mostraram deriva para Oeste constante e variações em latitude. Foi observado que as intensidades acompanham a diminuição de todo o campo, embora a SAMA apresente caráter predominantemente não-dipolar, evidenciada pela razão entre o campo não-dipolar e o campo total no Atlântico Sul. A comparação de intensidades da SAMA com as medidas de intensidade realizadas pelos observatórios mostrou que a influência da SAMA aparece na forma de sobreposição ou amplificação de fenômenos com menor comprimento de onda, como os impulsos de variação secular (jerks geomagnéticos). A continuação para baixo dos modelos se mostrou satisfatória quando comparada com o método de inversão estocástica. $A$ comparação da SAMA com outras anomalias em superfície mostrou independência na trajetória, porém, quando comparadas com os lóbulos principais na interface manto-núcleo, indicam que estas anomalias possam estar interligadas. Os lóbulos do núcleo foram interpretados com base nos mecanismos de geração, sugerindo que a SAMA possa ser originada através de movimentos combinados entre duas colunas de convecção e regiões de fluxo reverso no núcleo externo.

Palavras chave: Anomalia Magnética do Atlântico Sul, geomagnetismo. 


\section{Abstract}

\section{HARTMANN, G. A. The South Atlantic Magnetic Anomaly: Causes and}

Consequences. $153 \mathrm{pp}$. Dissertation for a Master's Degree. Department of Geophysics, Institute of Astronomy, Geophysics and Atmospheric Sciences, University of São Paulo, 2005.

The object of this dissertation is to describe the South Atlantic Magnetic Anomaly (SAMA) using geomagnetic models for the historical period from 1600 to 1890 and also the IGRF and DGRF models for the past century. Since the SAMA presents low intensities of the total geomagnetic field that correspond to a region of intense cosmic ray particle flux, many problems with objects that orbit along this region (eg. Satelites) have been detected. The SAMA effects on space vehicles are described. The field models led to the definition of the SAMA center as the locus of minimum total field intensity and how the anomaly drifted and varied in intensity for the past four centuries. The vertical component at the Core Mantle Boundary (CMB) was used to find correlations with anomalies at the surface the Earth surface. Results have shown a rather constant westward drift and also latitude variations. It was observed that intensities follow the general decrease of the total field although the SAMA displays a predominantly non-dipolar character that is evident in the non-dipolar/total field ratios for the South Atlantic. The comparison of geomagnetic measurements by nearby Southamerican Observatories show that the SAMA influence appears as a superposition or amplification of lower wavelength phenomena such as the secular variation impulses (jerks). A downward continuation of the models was found satisfactory when compared to the stochastic inversion method. The comparison of the SAMA with other surface anomalies showed a rather independent behavior however, a comparison with the main radial component lobes at the CMB showed that all these anomalies may be interconnected. The nucleus lobes have been interpreted under the light of field generation processes, suggesting that the SAMA may originate from the combined motion of two convection columns and reverse flux regions in the outer core.

Key words: South Atlantic Magnetic Anomaly, geomagnetism. 


\section{Lista de figuras}

Figura 2.1:Localização dos pólos geográficos, geomagnéticos e magnéticos; do equador geográfico e geomagnético.

Figura 2.2: As diferentes regiões da magnetosfera no plano do meridiano meio-dia meia-noite (fonte:

http://ssdoo.gsfc.nasa.gov/education/lectures/magnetosphere/index.html)

Figura 2.3: Movimentos de carga elétrica na presença do campo magnético (modificado de Kirchhoff, 1991)...

Figura 2.4: Campo magnético total para o ano de 2000. O contorno de 28000nT destaca a região da SAMA e o triângulo vermelho, o centro da SAMA para a época. Nota-se também o contorno de 60000nT na região do Pólo Sul e do Alto da Sibéria. 20

Figura 2.5: Deriva do centro da SAMA para o período de 1973 e 1995. Em (a) a deriva para oeste em (b) o deslocamento para o norte (compilado de Badhwar et al., 2002).

Figura 2.6: Dosagem média em função do tempo de ativação do TEPC (compilado de Badhwar, 2002).

Figura 2.7: Distribuição geográfica de DSEs no MOPITT. A SAMA pode ser claramente identificada pela densidade de pontos (compilado de Nichitiu et al., 2004).

Figura 3.1: Representação das coordenadas esféricas.

Figura 3.2: Representação geométrica de dois harmônicos esféricos zonais.......... 36

Figura 3.3: Representação geométrica de dois harmônicos esféricos setoriais....... 37

Figura 3.4: Representação geométrica de dois harmônicos esféricos tesserais...... 37

Figura 4.1: Variação secular para a época de 2000. Em (a) modelo do IGRF e (b) modelo WMM. Em ambos o intervalo de contorno é de 5nT/ano. Os contornos em vermelho indicam variação positiva e os contornos em azul indicam variação negativa.

Figura 4.2: Variação secular da componente $Y$ do campo geomagnético de 37 observatórios europeus mostrando os jerks de 1969, 1978 e 1991 (compilado de LeHuy et al., 1998). 
Figura 4.3: Variação secular da componente $Y$ do campo geomagnético para dois observatórios distintos: Niemegk (Alemanha) e Macquarie Island (Austrália) mostrando os jerks de 1969, 1978, 1991 e 1999. As cruzes são as diferenças entre as médias anuais, a linha pontilhada representa a variação secular prevista pela parte regular do fluxo na superfície do núcleo e, a linha contínua é a variação secular prevista pela dinâmica do núcleo - dependente do tempo e do fluxo zonal equatorial (na forma de oscilações torsionais). (compilado de Bloxham et al., 2002).

Figura 4.4: Mapas para o campo não-dipolar. Em (a) para o ano de 1950 e (b) 2000. O intervalo de contorno de 16000nT mostra a variação dos focos de maior intensidade para o campo não-dipolar.

Figura 4.6: Variação do momento dipolar de 1600 a 2005 considerando os coeficientes de Gauss $g_{1}^{0}, g_{1}^{1}$ e $h_{1}^{1}$.

Figura 4.7: Momento do dipolo em função do tempo obtido em intervalos médios de 500 e 1000 anos. A barra de erros mostra um nível de confiança de 95\% (compilado de Merrill et al., 1998). 57

Figura 4.8: Velocidades de deslocamento dos pólos Norte e Sul obtidos através dos modelos do campo geomagnético para o período de 1900 a 2000. A linha em vermelho é a curva do pólo Norte magnético e a curva em azul o pólo Sul magnético (compilado de Mandea e Dormy, 2003). 58

Figura 5.1: Dínamo duplo de Rikitake. 60

Figura 5.2: llustração do efeito $\alpha$. Modificado de Merrill et al. (1998). 68

Figura 5.3: Geração de um campo magnético toroidal no núcleo. Em (a), a linha do campo magnético poloidal, $\mathbf{S}_{\mathbf{1}}^{\mathbf{0}}$, atravessa o núcleo da Terra e, um campo de velocidades cilíndrica $\mathbf{T}_{1}^{0}$. Em (b), a interação entre os campos magnético e de velocidade, em três períodos sucessivos, sendo que quando o circuito se completa, um novo campo toroidal $\left(\mathbf{T}_{2}^{0}\right)$ de sinal oposto é gerado. Modificado de Merrill et al. (1998).

Figura 5.4: Geração de um campo poloidal a partir de um upwelling. Modificado de Merrill et al. (1998).

Figura 5.5: Relação entre o número de Ekman $(E)$ e o número de Rayleigh $(R a)$ em vários modelos de geodínamo. As linhas mais espessas indicam números de Rayleigh críticos e as linhas finas representam valores do número de Rayleigh 
modificado $\left(R a_{M}=E R a\right)$. O valor para a Terra é baseado numa viscosidade de $1 \mathrm{~m}^{2} \mathrm{~s}^{-1}$ (compilado de Kono e Roberts, 2002).

Figura 5.6: Componente radial do campo magnético mapeada na superfície e na CMB. Os focos tendendo para o vermelho indicam saída e os focos tendendo para o azul indicam entrada de fluxo magnético. A escala de cores na superfície foi multiplicada por 10 para se obter contrastes equivalentes (compilado de Roberts e Glatzmaier, 2000).

Figura 5.7: Mapas da componente radial do campo na CMB (à esquerda), e um corte longitudinal do núcleo (à direita) com os contornos do campo toroidal à esquerda e linhas de campo magnético poloidal à direita. O conjunto superior é do modelo de Kuang e Bloxham (1999) e o modelo inferior de Glatzmaier e Roberts (2000), (compilado de Roberts e Glatzmaier, 2000).

Figura 6.1: Localização geográfica das três aproximações para o centro da SAMA para o período de 1945 a 2000 (compilado de Henderickx, 1996).

Figura 6.3: Mapas do campo total que mostram a variação da SAMA. Para o período histórico: em (a) para a época de 1600 e (b) para a época de 1800; o intervalo de contorno é de 1000nT. Para o último século: em (c) para 1900 e em (d) para 2000; o intervalo de contorno é de 200nT e os pontos representam a malha dos dados calculados, espaçados em $1^{\circ}$. Em todos os mapas a cruz em azul representa a localização geográfica para o valor da intensidade mais baixa do campo.

Figura 7.1: Trajetória do centro da SAMA em função do tempo. A curva em vermelho é um ajuste polinomial de grau 6 , o valor de R-quadrado é adequado para o ajuste.

Figura 7.2: Trajetória do centro da SAMA em função do tempo e a localização de quatro observatórios geomagnéticos: Vassouras (VSS), Las Acacias (LAS), La Quiaca (LQA) e Pilar (PIL).

Figura 7.3: Intensidade total do centro da SAMA para o período de 405 anos. A curva em vermelho é um ajuste polinomial de grau 6 e o valor de R-quadrado é adequado para o ajuste. 95

Figura 7.4: Intensidades do centro da SAMA para os últimos 105 anos. ................ 96

Figura 7.5: Segunda derivada para os dados de intensidade da SAMA. 96

Figura 7.6: Variação em módulo dos coeficientes dipolares e não-dipolares em função do tempo. 
Figura 7.7: Razão entre o campo não-dipolar (Bndip) e total (Btotal) em função do tempo.

Figura 7.8: Razão entre o campo não-dipolar (Bndip) e o campo total (Btotal) em função do tempo para o foco de máximo campo não-dipolar no Atlântico Sul. . 99 Figura 7.9: Intensidade total para a SAMA e para observatórios VSS, PIL, LAS e

LQA em função do tempo. 100

Figura 7.10: Segunda derivada dos dados de intensidade total da SAMA, VSS, PIL,

LAS e LQA em função do tempo. 101

Figura 7.11: Variação de intensidade total dos observatórios em função da distância ao centro da SAMA. Em (a) para Vassouras, (b) para Pilar, (c) Las Acacias e (d) La Quiaca. 102

Figura 7.12: Primeira derivada da componente Y em VSS, PIL, LAS e LQA em função do tempo. 103

Figura 7.13: Intensidade total para a SAMA e para os pólos Norte e Sul em função do tempo. 104

Figura 7.14: Deriva da SAMA e dos pólos Norte e Sul em função do tempo. 105

Figura 7.15: Intensidades para as quatro anomalias do campo em função do tempo.

Figura 7.16: Segunda derivada das intensidades para as quatro anomalias do campo em função do tempo. 107

Figura 7.17: Localização geográfica para as quatro anomalias do campo em função do tempo. 108

Figura 7.18: Mapas da componente radial na CMB. Em (a), modelo de Jackson et al. (2000), truncado até $n=14$ e em (b) usando a continuação para baixo, truncado até $n=10$. Os gradientes de intensidades são compatíveis. Ambos os mapas estão na projeção Aitoff.

Figura 7.19: Razão entre as intensidades dos lóbulos principais do núcleo em função do tempo. 112

Figura 7.20: Distância aproximada entre os lóbulos principais do núcleo em função do tempo. 


\section{Lista de Tabelas}

Tabela 5.1: Propriedades do núcleo da Terra. ............................................ 72

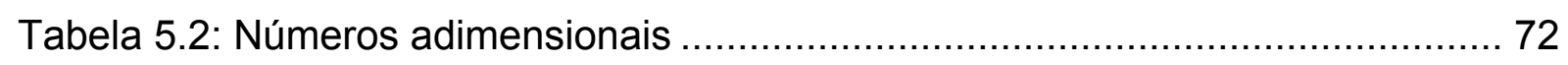

Tabela 5.3: Grupos de simulações tridimensionais do geodínamo (compilado de

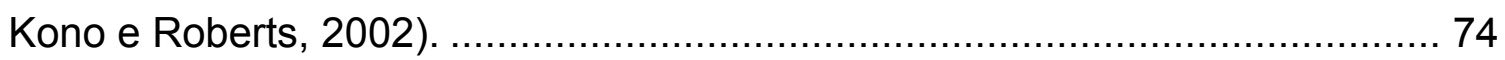

Tabela 7.1: Taxas de deriva aproximadas para o centro da SAMA...................... 92

Tabela 7.2: Taxas de deriva do centro da SAMA para os últimos 105 anos. ........... 93

Tabela 7.3: Variação de intensidade do centro da SAMA para os últimos 400 anos.

95

Tabela 7.4: Variação em intensidade do centro da SAMA para os últimos 105 anos. 


\section{Sumário}

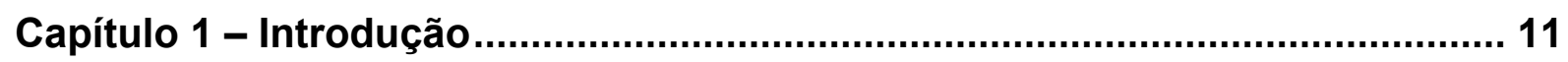

Capítulo 2 - Fenomenologia da Anomalia Magnética do Atlântico Sul ............. 15

2.1 Aspectos do Campo Magnético da Terra ............................................... 15

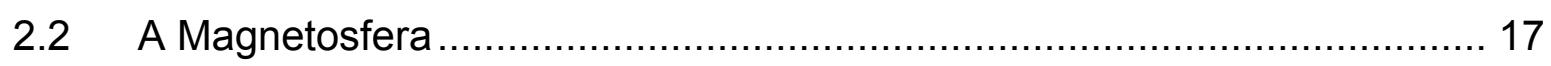

2.3 A Anomalia Magnética do Atlântico Sul............................................... 20

2.4 Os efeitos produzidos pela SAMA na atmosfera terrestre........................ 21

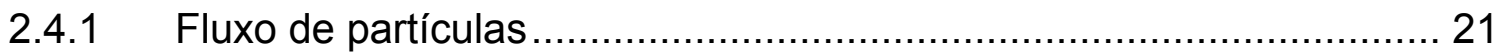

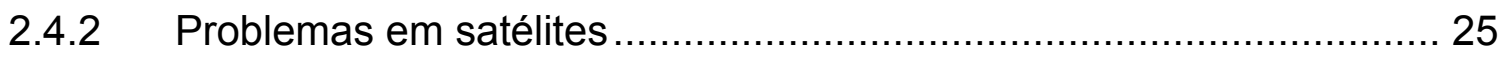

2.4.3 Correntes geomagneticamente induzidas ........................................ 27

Capítulo 3 - Representação e Modelagem do Campo Magnético da Terra....... 31

3.1 Representação do Campo Magnético da Terra por Harmônicos Esféricos 31

3.1.1 Separação do Campo Interno e Externo ............................................ 40

3.1.2 Separação dos campos dipolar e não-dipolar ..................................... 41

3.2 Modelagem do Campo Geomagnético ............................................... 42

Capítulo 4 - Variação Secular do Campo Magnético Terrestre........................... 45

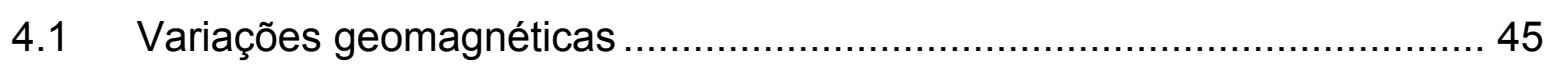

4.2 Os impulsos de variação secular e a blindagem do manto ......................... 47

4.3 A deriva para oeste e as variações em intensidade .................................. 53

4.3.1 A deriva do campo não-dipolar .................................................. 54

4.3.2 Variações do campo dipolar em função do tempo .............................. 56

Capítulo 5 - A geração do campo geomagnético no núcleo externo ................. 59

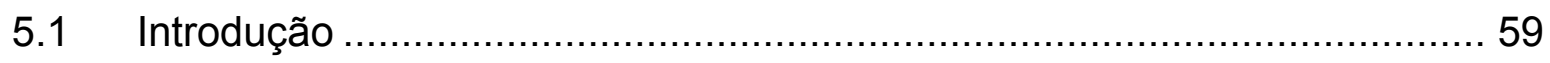

5.2 O problema do geodínamo.............................................................. 61

5.2.1 Os efeitos $\alpha$ e $\omega$ na teoria do Geodínamo ..................................... 67

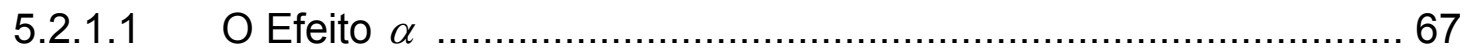

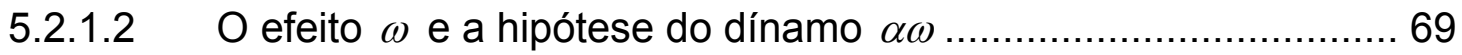

5.2.2 Propriedades do núcleo da Terra e números adimensionais .............. 71

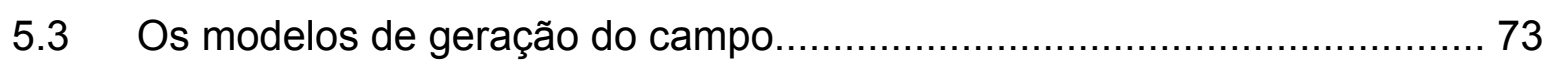

Capítulo 6 - Metodologia de Análise dos Dados ................................................ 79

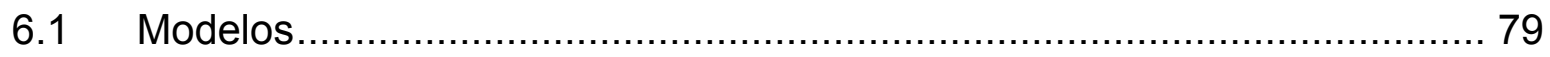

6.1.1 Modelos do campo para o período histórico .................................... 79 
6.1.2 Modelos do campo para os últimos 105 anos ................................... 83

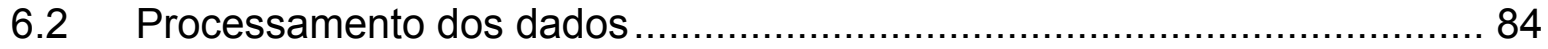

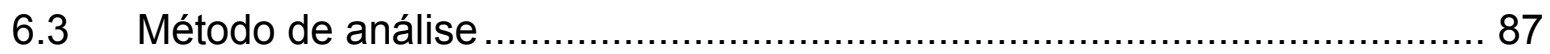

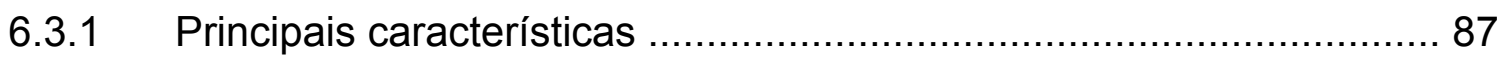

6.3.2 Continuação para baixo do campo geomagnético ………................. 90

Capítulo 7 - Análise dos Resultados: Discussão e Conclusões......................... 91

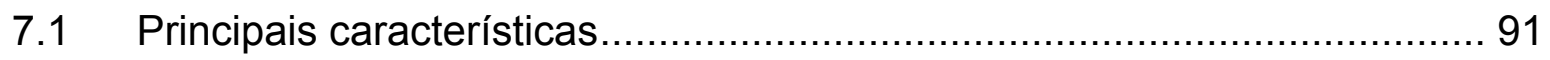

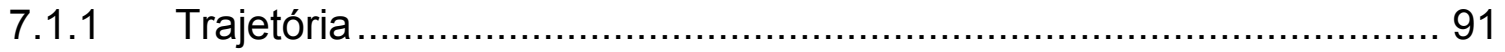

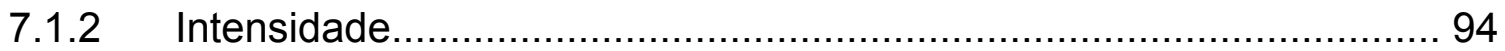

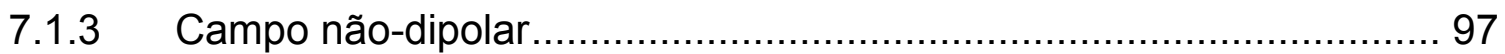

7.1.4 Comparação com observatórios geomagnéticos …………................ 99

7.1.5 Comparação com outras anomalias do campo .................................104

7.2 Anomalias do campo magnético na interface manto-núcleo ....................108

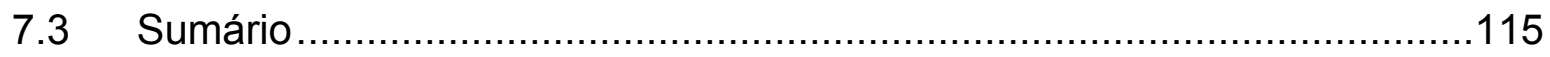

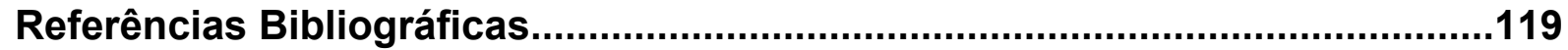

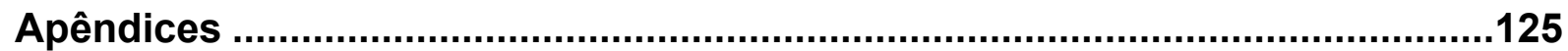

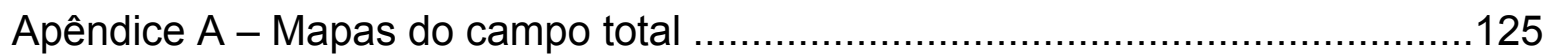

Apêndice B - Mapas da razão entre os campos não-dipolar e total ....................133

Apêndice C - Mapas do campo radial na interface manto-núcleo ......................139

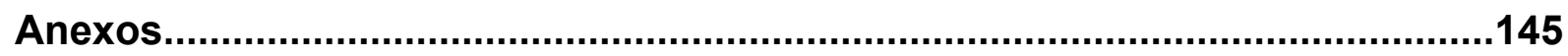

Anexo A - Tabela dos coeficientes de Gauss para o período histórico (modelos de

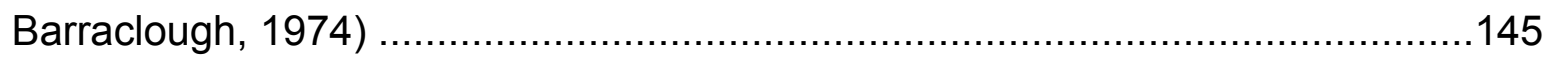

Anexo B - Tabela dos modelos do DGRF e IGRF a partir de 1900 ....................146 


\section{Introdução}

O campo magnético da Terra é variável no tempo e no espaço. Para tanto, modelos são construídos com o objetivo de melhor descrever este campo. A principal forma de representação do campo magnético é através de harmônicos esféricos, que permitem descrevê-lo em função de um potencial, que pode ser analisado separando-o por fontes produtoras, sendo estas: o campo interno (núcleo), o campo crustal (crosta) e o campo externo (magnetosfera). Pode-se separar também pelos elementos magnéticos medidos em superfície e pelas diferentes componentes multipolares.

Se o campo na superfície terrestre fosse descrito perfeitamente por um dipolo geocêntrico, os pólos geomagnéticos (representam o melhor ajuste para o dipolo) e magnéticos (representam os pólos observados) deveriam coincidir. Entretanto, uma fração do campo superficial restaria, caso o campo dipolar de melhor ajuste fosse removido. Esta fração é conhecida como campo não-dipolar.

A compilação de dados obtidos por navegadores possibilitou a elaboração de modelos a partir de 1550. Estes modelos dão uma idéia do comportamento do campo no passado mais recente. Barraclough (1974) realizou uma compilação destes dados e elaborou modelos de 1600 a 1910. Com a melhoria dos equipamentos de medida e o aumento do número de observatórios no início do século passado, foi possível elaborar modelos mais precisos do campo e truncados até grau e ordem maiores. Os modelos de campo mais utilizados atualmente são o IGRF (International Geomagnetic Reference Field) e o WMM (World Magnetic Model). Dependendo das hipóteses fundamentais e do grau e ordem da análise, obtêm-se diferentes valores para os coeficientes do modelo, conhecidos como coeficientes de Gauss.

A partir de 1850, aproximadamente, quando medidas da intensidade do campo começaram a ser realizadas, os modelos revelam feições mais detalhadas para o campo geomagnético. A Anomalia Magnética do Atlântico Sul (comumente indicada pela sigla em inglês SAMA - South Atlantic Magnetic Anomaly) é uma das feições mais notáveis do campo, caracterizando-se por apresentar baixas 
intensidades do campo geomagnético total. A origem da SAMA está no núcleo externo da Terra, onde movimentos do fluido condutor produzem o campo observado na superfície.

A região de abrangência da SAMA coincide com uma região de intensa radiação no espaço próximo à Terra. Isto ocorre porque as baixas intensidades da SAMA facilitam a entrada de partículas cósmicas na magnetosfera. O aumento do fluxo cósmico pode provocar problemas em objetos que orbitam a Terra, tais como satélites e estações espaciais. Os efeitos são percebidos também em superfície como por exemplo, problemas na transmissão e recepção de dados via satélite e, em correntes elétricas produzidas em dutos e linhas de transmissão por variações do campo. Os efeitos oriundos da SAMA tem sido motivadores para o desenvolvimento de pesquisas.

As causas da SAMA constituem um problema fundamental em Geomagnetismo. No entanto, os modelos de geração do campo fornecem indícios sobre os possíveis mecanismos de geração e, quando são comparados com os modelos do campo na interface manto-núcleo, podem sugerir como os processos físicos responsáveis pela geração do campo, atuam para o surgimento das principais feições observadas na superfície.

Este trabalho tem como principais objetivos: descrever as características da SAMA com base nos modelos para o período histórico (modelos de Barraclough, 1974) e para o último século (modelos do DGRF e IGRF); realizar um levantamento dos efeitos produzidos pela SAMA nas pesquisas espaciais; com a análise por harmônicos esféricos, das cartas e modelos do campo, comparar a variação temporal e espacial da SAMA, de outras anomalias do campo geomagnético e de alguns observatórios na América do Sul; analisar as diferentes componentes do campo buscando processos físicos que possam ser individualizados e, com base nos modelos de geodínamo buscar interpretações para os resultados obtidos através da continuação do campo para a interface manto-núcleo.

Este trabalho está estruturado em 7 capítulos: após a Introdução, o Capítulo 2 faz uma explanação sobre os principais aspectos do campo e os efeitos da SAMA em fenômenos espaciais. O Capítulo 3 mostra a descrição do campo por harmônicos esféricos e como é realizada a modelagem do campo. A variação secular é importante para identificar a influência da SAMA no campo (Capítulo 4), além da influência em fenômenos de menor comprimento de onda como os impulsos 
de variação secular (jerks geomagnéticos). O Capítulo 5 trata do problema do geodínamo e de como os modelos de geração contribuem para o estudo de questões fundamentais do Geomagnetismo. A descrição dos modelos para o período histórico e para o último século utilizados no trabalho e, os métodos de análise são apresentados no Capítulo 6. O Capítulo 7 discute e conclui os resultados obtidos como: as principais características da SAMA, a comparação com outras anomalias do campo total e com observatórios, além das análises dos resultados (obtidos pela continuação para baixo) através dos mecanismos de geração. 


\section{Fenomenologia da Anomalia Magnética do Atlântico Sul}

Este capítulo apresenta as principais características do campo magnético terrestre, e as principais características da Anomalia Magnética do Atlântico Sul. Muitos trabalhos têm sido voltados ao estudo da Anomalia com ênfase nos efeitos e problemas produzidos pela Anomalia no campo externo.

\subsection{Aspectos do Campo Magnético da Terra}

O campo magnético da Terra (CMT) é bastante complexo, variável no tempo e no espaço apresentando uma orientação predominantemente na direção aproximada da linha Norte-Sul geográfica. Dependendo da localização em latitude, as linhas de campo orientam-se para cima ou para baixo. O CMT assemelha-se, de uma forma geral, ao campo gerado por um ímã dipolar que estivesse localizado no centro da Terra. Os eixos do dipolo estariam inclinados aproximadamente de $11,5^{\circ}$ em relação ao eixo de rotação da Terra [CHAPMAN e BARTELS, 1940].

Se o campo tivesse a configuração exata de um dipolo inclinado, seria idêntico ao esquema da figura 2.1. A linha que passa pelo centro da Terra junto ao eixo do dipolo, intercepta a superfície em dois pontos chamados de pólos geomagnéticos. Estes pólos diferem dos pólos magnéticos de inclinação, que são os pontos médios das regiões sobre a superfície da Terra onde o campo é vertical. Os pólos geomagnéticos e os pólos magnéticos deveriam coincidir se o campo fosse dipolar e geocêntrico. Mas este não é o caso e cerca de $10 \%$ a $20 \%$ do campo na superfície da Terra permanece depois que o campo dipolar de melhor ajuste é removido [MERRILL et al., 1998], este campo é chamado de campo não-dipolar. Assim, o campo dipolar pode responder por até $90 \%$ da intensidade total do campo terrestre. O equador geomagnético é aquele obtido pelo melhor ajuste a um dipolo ideal e, o equador magnético é definido pela linha cuja inclinação do vetor magnético é nula, variando de maneira não uniforme em função da complexidade do campo terrestre.

O campo geomagnético, em qualquer posição da superfície da Terra é a soma de três origens distintas: 
- O campo interno, cuja produção ocorre no núcleo externo da Terra;

- O campo crustal, cujas fontes são os materiais magnetizados e induzidos encontrados na crosta e,

- O campo externo, produzido na magnetosfera.

A observação do magnetismo associado às manchas solares levou Joseph Larmor, em 1919, à idéia de que o campo era produzido por fluidos condutores com movimentos convectivos em um processo de dínamo auto-sustentado.

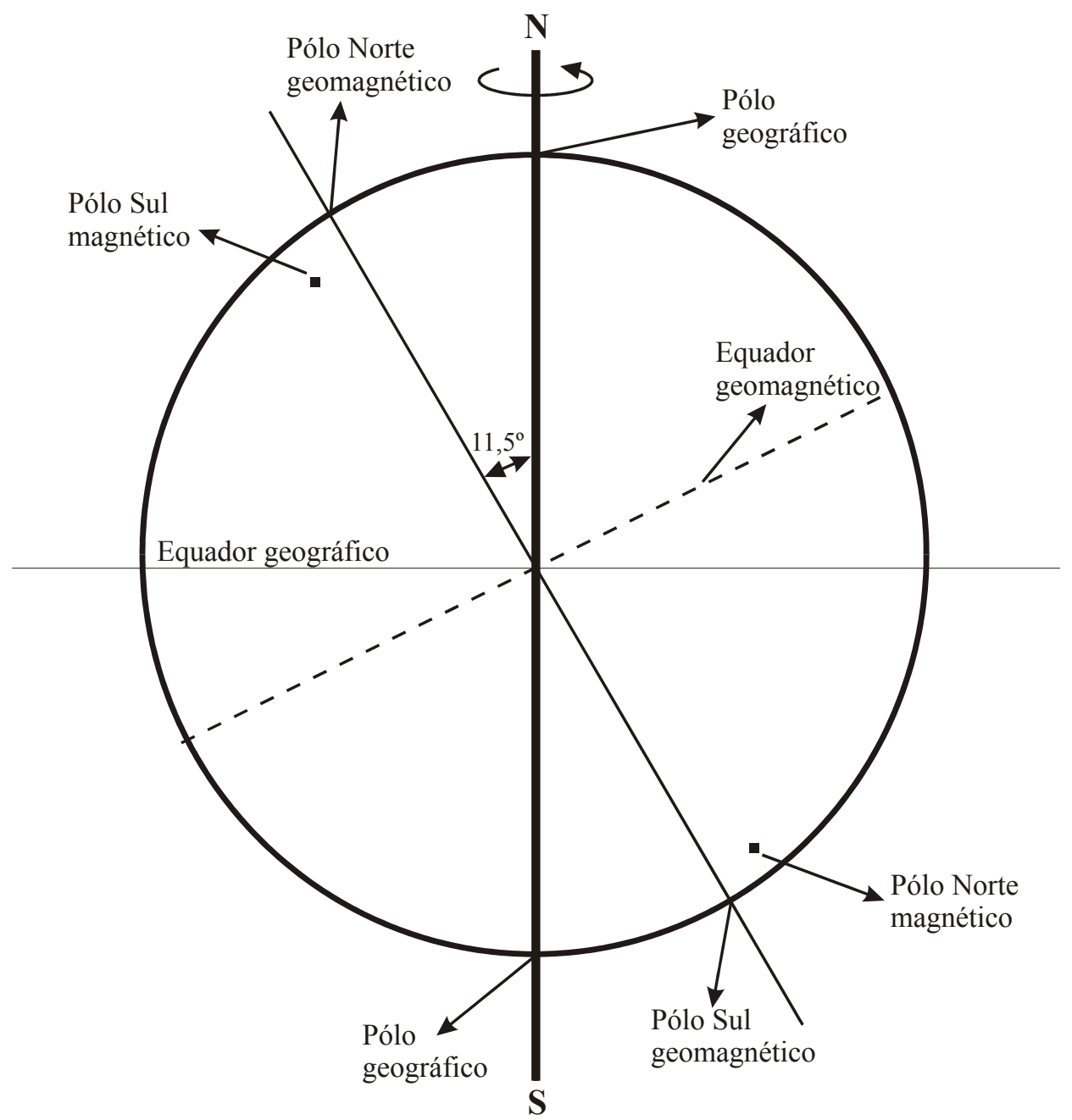

Figura 2.1:Localização dos pólos geográficos, geomagnéticos e magnéticos; do equador geográfico e geomagnético.

Estas idéias moldaram a moderna hipótese do dínamo auto-excitado como gerador do CMT, bem como o das manchas solares, levadas adiante de forma independente por W. M. Elsasser e E. C. Bullard [KONO e ROBERTS, 2002]. Segundo a hipótese do dínamo, o CMT seria a manifestação do campo magnético gerado pela circulação de correntes na região entre o manto inferior e o núcleo 
externo da Terra a aproximadamente $2900 \mathrm{~km}$ de profundidade (Capítulo 5). O movimento necessário à manutenção do mecanismo do dínamo seria fornecido pela convecção causada pelo calor latente de solidificação e convecção composicional do material do núcleo [ROBERTS e GUBBINS, 1987].

O campo magnético principal (CMP) apresenta variações de longo período em sua magnitude, orientação e posição, de tal forma, que as posições dos pólos magnéticos oscilam irregularmente, com pequena amplitude, com um centro aproximado sobre os pólos de rotação da Terra. Esta variação irregular tem sido registrada ao longo da história e é chamada de variação secular. A variação secular também se manifesta na forma de um deslocamento contínuo para oeste do padrão geomagnético (Capítulo 4).

Em períodos geológicos, com intervalos irregulares, o CMT sofre reversões em seus pólos. Este fenômeno é utilizado pelo paleomagnetismo no auxílio a datação de estruturas geológicas e no estudo da expansão dos fundos oceânicos, essencial para a teoria da tectônica de placas. Provavelmente origina-se na metaestabilidade do dínamo auto-excitado, onde condições determinadas no sistema magneto-hidrodinâmico do núcleo, podem chegar a limites críticos, causando mudanças drásticas na circulação das correntes nos fluidos condutores [KONO e ROBERTS, 2002].

As principais fontes internas não-dipolares podem ser as flutuações no dínamo auto-excitado que ocorrem na interface do núcleo interno com o núcleo externo, as variações do manto, e as diferentes propriedades magnéticas das rochas ao longo da crosta terrestre [ROBERTS e GUBBINS, 1987].

\subsection{A Magnetosfera}

A magnetosfera é uma região em que o campo magnético domina o movimento do plasma, constituído principalmente de prótons e elétrons. A forma das linhas do campo magnético é tal que estas são achatadas de frente ao Sol, pela ação do vento solar, sendo alongadas do lado oposto [KIRCHHOFF, 1991].

$\mathrm{Na}$ magnetosfera existem camadas ionizadas formando a ionosfera. A ionosfera é a região onde se movimentam partículas ionizadas e, portanto, qualquer perturbação no campo magnético resulta em modificações nas condições de 
transporte do meio ionizado. A ionosfera é dividida em três regiões: a região $D$ : situada entre 50-90km; região E: 90-120km e; região F: 120-1500km. E na parte superior, a magnetosfera está limitada pela magnetopausa, depois da qual o campo geomagnético é nulo [AKASOFU e CHAPMAN, 1972].

As contribuições externas são geradas essencialmente pelos ventos solares e sua influência sobre a atmosfera da Terra, com variações temporais predominantemente de curto período. O fluxo contínuo de partículas ionizadas do vento solar confina o campo magnético na magnetosfera, deformando-a de maneira a existir uma cauda, como a de um cometa, que se estende por distâncias maiores do que a distância Terra-Lua, no sentido oposto ao Sol. A figura 2.2 apresenta a forma da magnetosfera, num plano meridiano meio-dia - meia-noite.

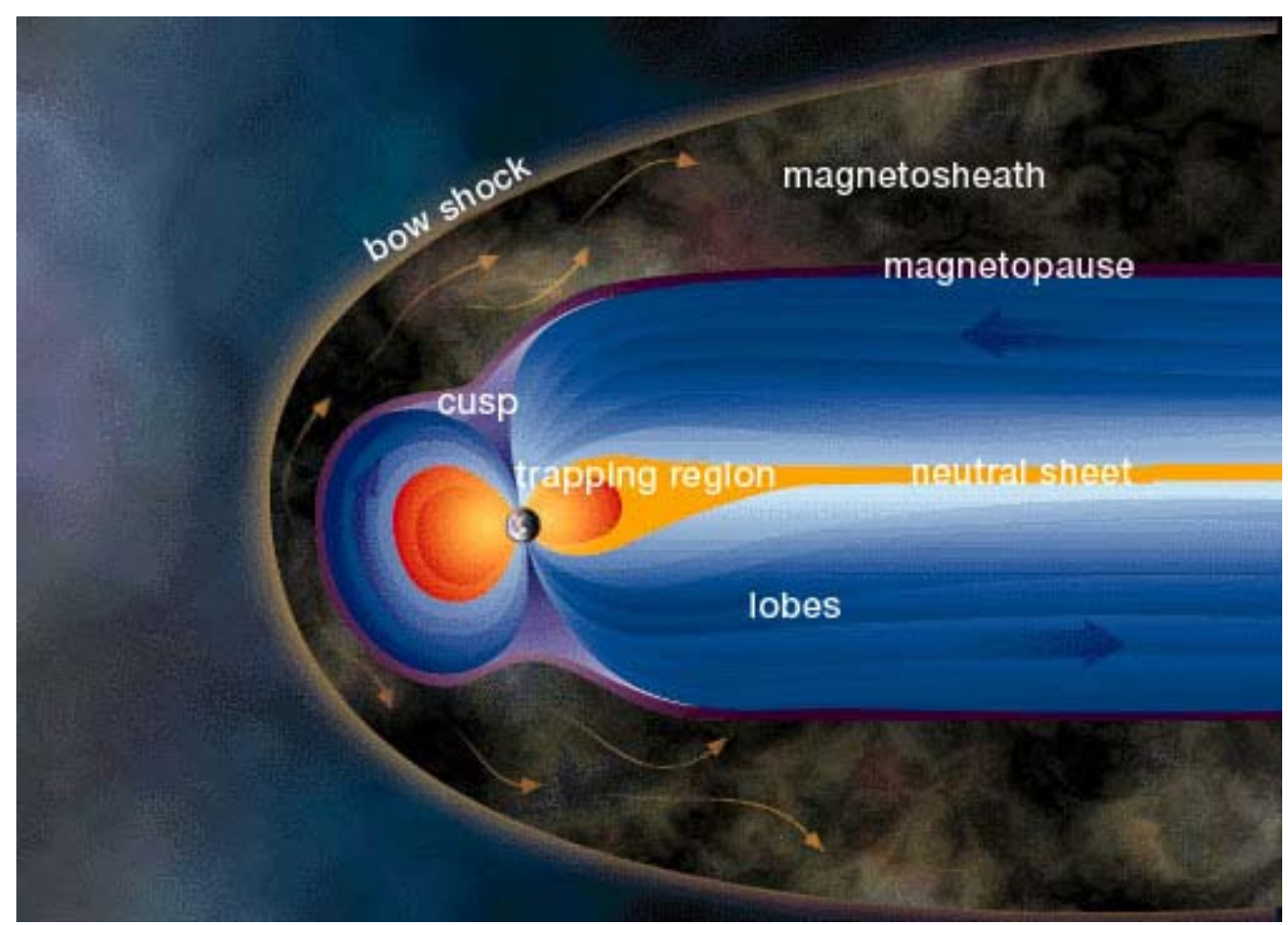

Figura 2.2: As diferentes regiões da magnetosfera no plano do meridiano meio-dia - meia-noite (fonte: http://ssdoo.gsfc.nasa.gov/education/lectures/magnetosphere/index.html).

Um arco de choque (bow shock) é produzido na região onde o vento solar é freado pela interação com o campo terrestre, como mostra a figura 2.2.

Grupos de partículas ionizadas são aprisionados em regiões conhecidas como cinturões de radiação de Van Allen, seguindo em trajetória espiral as linhas de campo polares (figura 2.3).

Mudanças no vento solar eventualmente fazem com que o fluxo de partículas na alta atmosfera aumente, produzindo as Auroras Polares. As mudanças 
da atividade solar podem ser associadas com aumento do número de manchas solares e podem causar flutuações abruptas no campo geomagnético, chamadas de tempestades magnéticas. As tempestades magnéticas representam uma forte influência sobre o planeta, interferindo no clima e em várias atividades tecnológicas. Falhas em circuitos de satélites, interrupções em sistemas de comunicação via rádio, aumento da corrosão em oleodutos por corrente induzida na terra e falhas na distribuição de energia elétrica em longas distâncias, são alguns dos exemplos da ação das tempestades magnéticas.

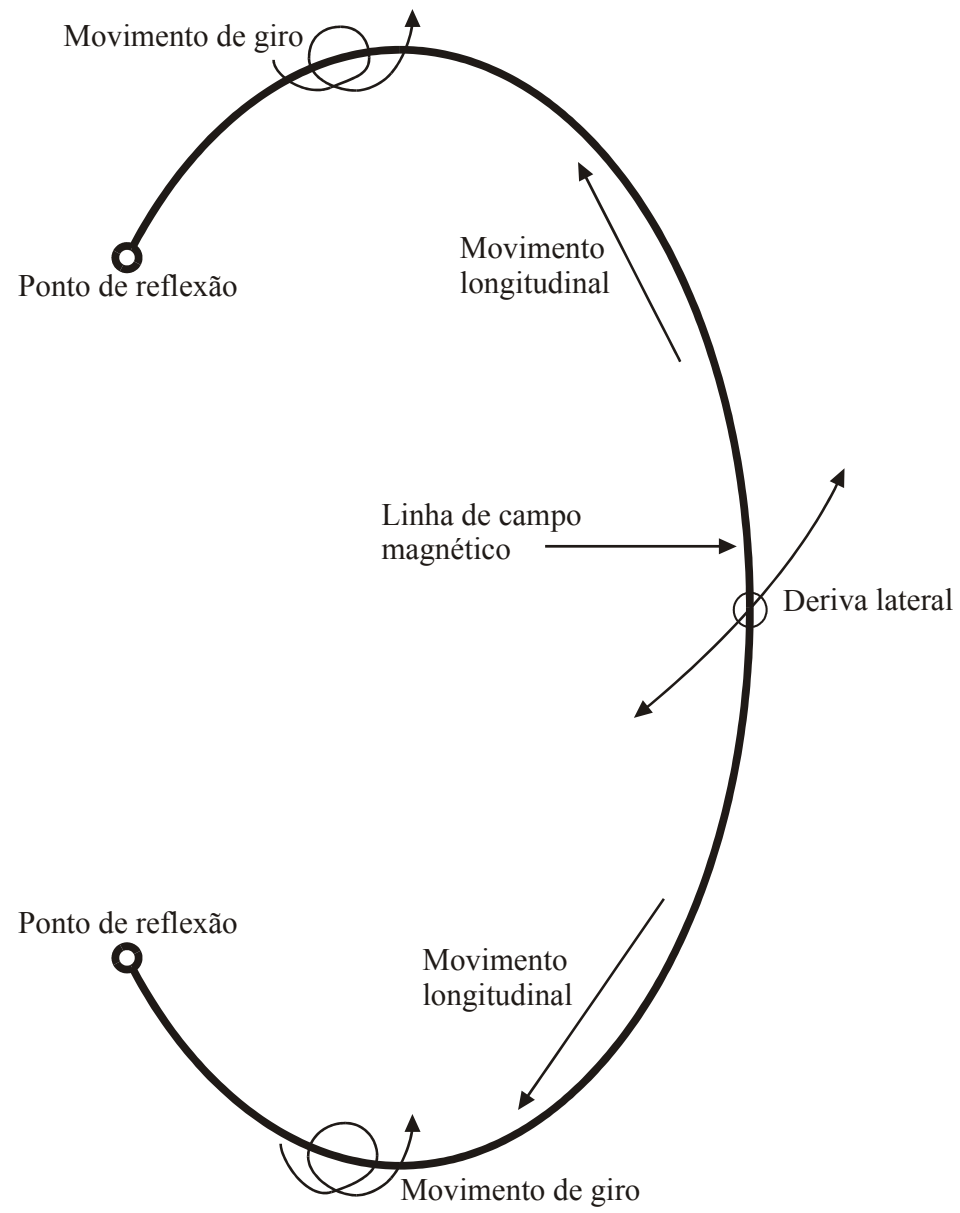

Figura 2.3: Movimentos de carga elétrica na presença do campo magnético (modificado de Kirchhoff, 1991).

O sol também é responsável pela variação diurna do CMT, representando uma variação de até $0,5 \%$ da intensidade total. Mesmo durante os períodos de relativa calmaria das atividades solares, variações significativas ocorrem nas regiões polares e equatoriais, onde fenômenos produzidos por sistemas de correntes na ionosfera estão sempre presentes, tais como o eletrojato equatorial e os eletrojatos aurorais. 


\subsection{A Anomalia Magnética do Atlântico Sul}

A análise dos dados obtidos pela rede de observatórios magnéticos há mais de 170 anos possibilitou a elaboração de cartas e modelos cada vez mais precisos do campo geomagnético e de suas variações. O CMT apresenta algumas anomalias regionais. Uma delas é a Anomalia Magnética do Atlântico Sul (SAMA), que se tornou evidente nos mapas magnéticos do início do século 20 [CHAPMAN e BARTELS, 1940], e é assim chamada porque atualmente estende-se pelo Atlântico Sul.

A região da SAMA caracteriza-se por apresentar baixas intensidades no campo magnético total, coincidindo com uma região de intensa radiação no espaço próximo à Terra, sendo portanto, uma espécie de "janela" à entrada de partículas cósmicas [HEIRTZLER, 2002].
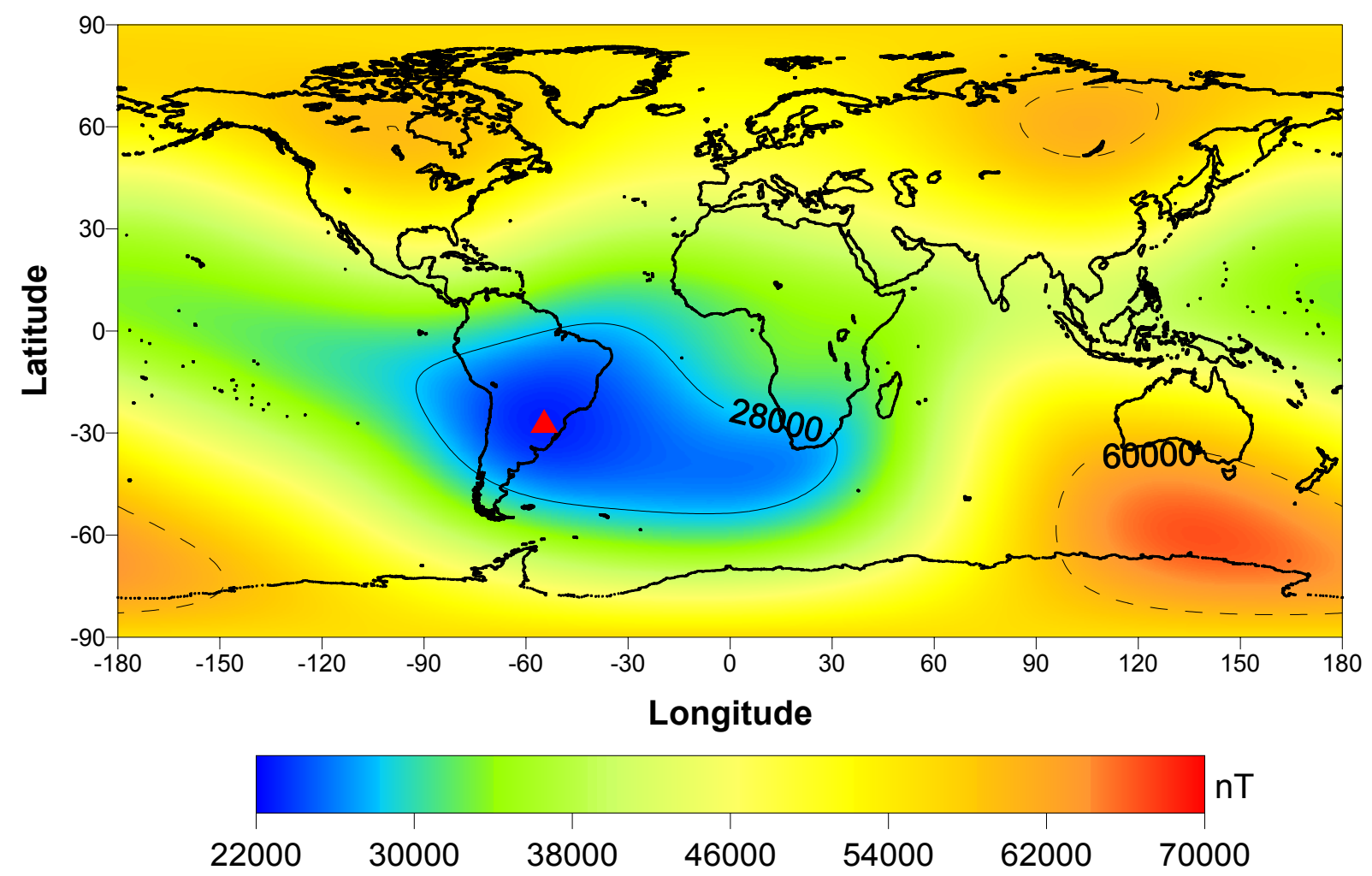

Figura 2.4: Campo magnético total para o ano de 2000. O contorno de 28000nT destaca a região da SAMA e o triângulo vermelho, o centro da SAMA para a época. Nota-se também o contorno de 60000 nT na região do Pólo Sul e do Alto da Sibéria.

Alguns autores interpretam a SAMA como relacionada com a assimetria geomagnética entre os hemisférios Norte e Sul [FRASER-SMITH, 1987; PINTO Jr. et al., 1992; HEYNDERICKX, 1996]. O dipolo excêntrico que melhor representa o 
campo observado está deslocado na direção a noroeste do Pacífico $\left(21,47^{\circ} \mathrm{N}\right.$; $144,77^{\circ} \mathrm{E}$ ) em $527 \mathrm{~km}$ numa direção definida [FRASER-SMITH, 1987].

Nesta aproximação, a SAMA pode ser localizada na direção oposta, sobre o Oceano Atlântico, na costa do Brasil. Entretanto, contrariando simples aproximações, o campo magnético próximo à superfície da Terra difere significativamente do dipolo excêntrico. A região da SAMA é mostrada na figura 2.4 e a sua evolução no tempo, nas figuras do Apêndice $A$.

Embora o modelo de dipolo excêntrico ofereça uma representação satisfatória do campo, ele não explica a origem da SAMA em termos dos processos físicos responsáveis por esta e outras anomalias do campo [PINTO Jr. et al., 1992].

Atualmente, a SAMA possui uma forma alongada estendendo-se da América do Sul até a África, sendo que o centro em função da mínima intensidade do campo localiza-se no interior do Paraguai.

Mapas do campo na interface manto-núcleo externo revelam características pouco conhecidas do campo [BLOXHAM e GUBBINNS, 1985; BLOXHAM, 1987; BLOXHAM e JACKSON, 1989; BLOXHAM et al., 1989; BLOXHAM e JACKSON, 1992]. Neste contexto, a SAMA pode estar associada a uma característica particular de fluxo reverso no material do núcleo externo.

\subsection{Os efeitos produzidos pela SAMA na atmosfera terrestre}

A magnetosfera, em grande parte, protege o planeta de partículas carregadas vindas do espaço, desviando-as através das linhas de campo. Como a SAMA possui baixas intensidades do campo magnético total, esta região oferece menor resistência ao fluxo de partículas.

Desta forma, observa-se que a região apresenta diversos fenômenos produzidos pela interação do fluxo de partículas com as linhas do campo. Alguns destes fenômenos causam problemas em equipamentos e satélites que orbitam a Terra. Vários destes fenômenos são estudados e bem documentados, fornecendo suporte ao estudo da SAMA.

\subsubsection{Fluxo de partículas}

O ambiente espacial próximo à Terra consiste de partículas carregadas aprisionadas no campo magnético, e raios cósmicos solares e até extra-galácticos. 
Além da presença destas partículas primárias, há também partículas secundárias produzidas por interações de partículas primárias com a atmosfera terrestre e mesmo com a estrutura de objetos espaciais que orbitam a Terra [BADHWAR et al., 2002]. O espectro de energia dos raios cósmicos e as partículas secundárias produzidas são dependentes da atividade solar. Os fluxos de partículas provenientes dos cinturões internos de radiação dependem da atividade solar e da altitude dos detectores.

A configuração do CMT determina o aprisionamento e distribuição de partículas energéticas. A entrada de partículas pelo CMT depende em grande parte do tipo de partícula e também da energia. No caso da SAMA, nota-se que há partículas de diversos níveis de energia que interagem com o campo.

As altitudes do ponto de reflexão de partículas aprisionadas nos cinturões de radiação variam em função do valor do campo. Como na região da SAMA o campo é fraco, o ponto de reflexão de partículas aprisionadas nos cinturões de radiação é mais baixo do que em outras regiões [HEIRTZLER, 2002].

O fluxo de partículas no estudo da SAMA pode ser utilizado para encontrar a sua localização. Muitos trabalhos têm revelado fenômenos de fluxos de partículas na região da SAMA. Badhwar (1997) comparou as taxas dos fluxos de prótons da SAMA usando dados do Skylab (de dezembro de 1973 a janeiro de 1974) com as taxas obtidas pela MIR em março de 1995 (figura 2.5). Este período foi escolhido porque tem a vantagem de comparar medidas semelhantes espaçadas num intervalo de 21,2 anos, que corresponde ao intervalo entre dois mínimos solares. Os resultados indicaram uma deriva de $0,28^{\circ} \pm 0,03^{\circ} \mathrm{W} / a n o$ e $0,08^{\circ} \pm 0,03^{\circ} \mathrm{N} / a n o$ para $\mathrm{O}$ centro da SAMA, definido em função do máximo fluxo de partículas. Estas medidas foram consistentes com determinações feitas usando os modelos AP8 para o fluxo de partículas nos cinturões e, em consonância com as taxas de deriva observadas para o campo geomagnético.

Trabalhos mais recentes utilizaram as energias dos prótons para determinar a deriva e outras características do fluxo de prótons na região da SAMA.

De novembro de 1994, a novembro de 1996, o detector REM (Radiation Environment Monitor) da estação orbital MIR, mediu o fluxo de elétrons e prótons energéticos na atmosfera terrestre. Foram investigados vários aspectos do fluxo de prótons na SAMA [BÜHLER et al., 2002]. Este período indicava baixa atividade solar, sendo propício para medir o fluxo de partículas. 
a)

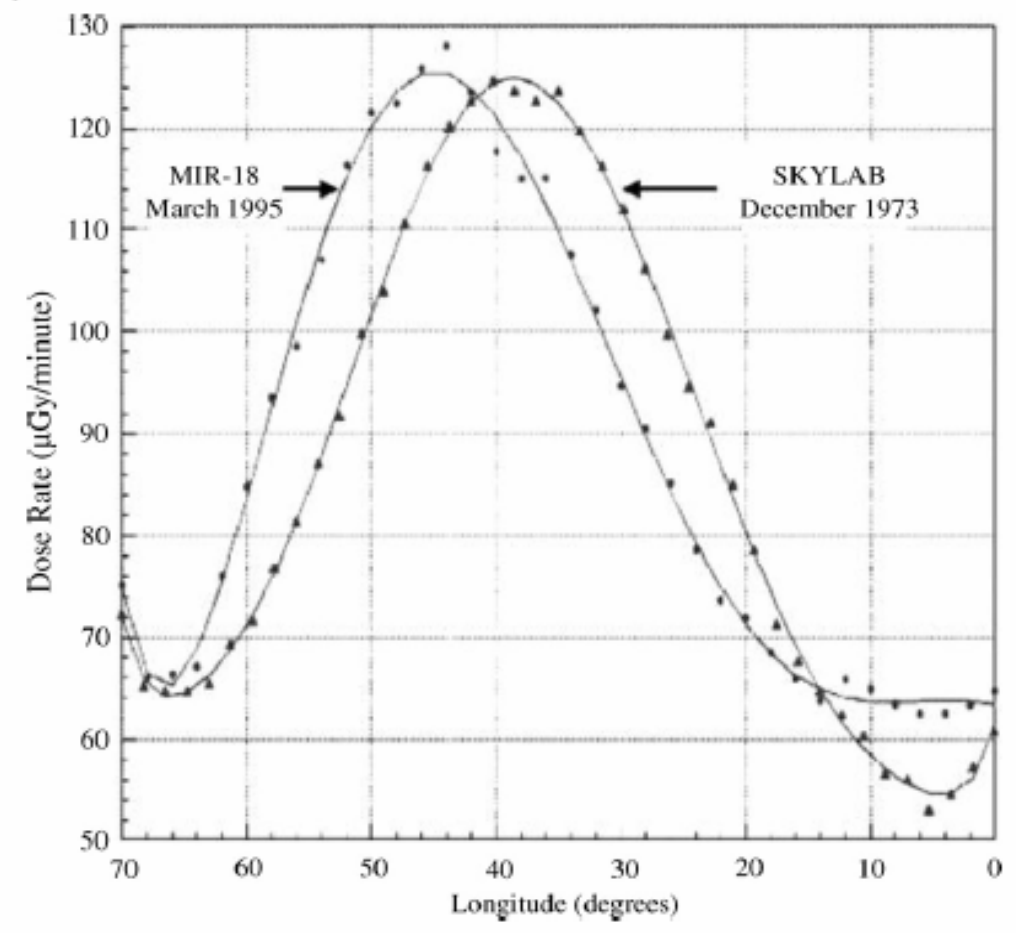

b)

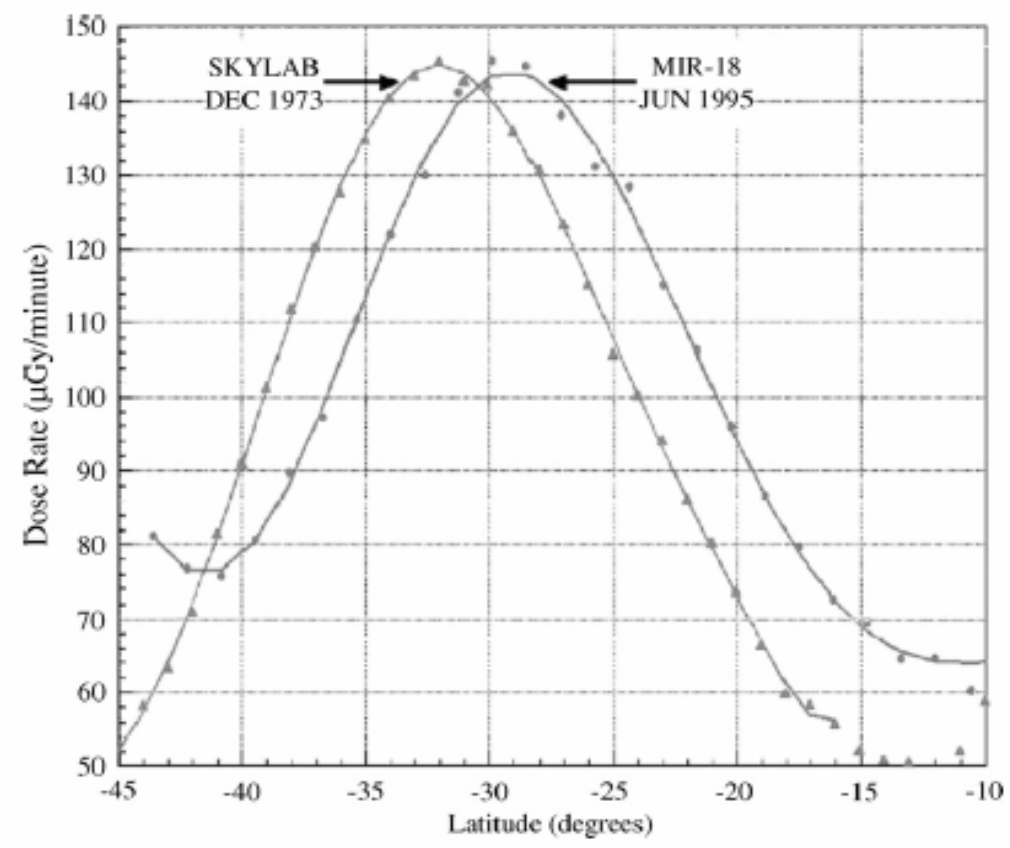

Figura 2.5: Deriva do centro da SAMA para o período de 1973 e 1995. Em (a) a deriva para oeste em (b) o deslocamento para o norte (compilado de Badhwar et al., 2002).

Os resultados indicaram que durante estes dois anos o fluxo de prótons na região da SAMA aumentou em 25\%, quando se aproximou do mínimo solar, indicando que não existe uma relação direta entre o máximo solar e a entrada de prótons na atmosfera. A deriva para oeste da SAMA, usando dados coletados desde 1970, apresentou as seguintes taxas médias: 
- $0,32^{\circ} \pm 0,05^{\circ} \mathrm{W} /$ ano para partículas com energia de $50 \mathrm{MeV}$;

- $0,31^{\circ} \pm 0,05^{\circ} \mathrm{W} /$ ano para partículas com energia de $200 \mathrm{MeV}$;

- e o deslocamento para o norte foi de $0,06^{\circ} \pm 0,05^{\circ}$ /ano.

Fiandrini et al. (2004) apresentaram perfis do fluxo de prótons com energias entre $0,07 \mathrm{GeV}$ e 9,1GeV, para altitudes de $370-390 \mathrm{~km}$, no intervalo geográfico de $\pm 51,7^{\circ} \mathrm{em}$ latitude. Para este estudo, a SAMA foi definida como a região cujo campo magnético total é $B<26000 \mathrm{nT}$, para estas altitudes. As medidas do AMS (Alpha Magnetic Spectrometer) apresentaram duas populações distintas: as populações "Quasi-Trapped" - QT (esta notação foi usada para denotar partículas com tempo de residência nos cinturões na faixa de $0,3 s<T_{f}<30 s$ ), uniformemente distribuídas ao longo da órbita do AMS, e a outra com tempos de residência típicos dos cinturões de Van Allen, as chamadas populações estavelmente aprisionadas (Stably Trapped ST), encontradas somente próximo a SAMA e limitada para baixas energias. As observações suportam a existência de uma zona de transição entre ST, próximo a SAMA (onde $B<26000 \mathrm{nT}$ ), e QT fora da SAMA. Na região de transição, as duas populações coexistem e as frações do fluxo de ST aumentam em direção ao centro da SAMA. Os fluxos QT medidos "dentro" e "fora" dos limites da SAMA apresentam as mesmas características em termos de intensidade do fluxo e da distribuição espacial, indicando que a mesma população foi observada em diferentes pontos. Já as feições das ST são diferentes: o fluxo é limitado para energias relativamente baixas, detectadas na SAMA e exibem um perfil com um mínimo entre duas regiões distintas.

Pinto Jr. e Gonzalez (1989) apontaram os principais processos físicos relacionados à precipitação de elétrons energéticos (PEE) na região da SAMA: espalhamento Coulomb, interações magnetosféricas onda-partícula, relâmpagos ou interações onda-partícula induzidas artificialmente, interações de ressonância de deriva (drift-resonance), e interações onda-partícula geradas por instabilidades do plasma. Duas grandes incertezas quanto a PEE na SAMA foram abordadas: (1) variação temporal e espacial dos períodos magneticamente calmos para períodos magneticamente perturbados; (2) o papel dos processos de precipitação induzidos por ondas. No entanto, medidas de ondas na fase VLF, em relação a sete tempestades magnéticas suportam a idéia da precipitação de elétrons induzidos por ondas [PINTO Jr. et al., 1990]. 
Muitos trabalhos foram realizados sobre medidas de raios $X$ devido à precipitação de elétrons na região da SAMA [PINTO e GONZALEZ, 1986; PINTO et al., 1989]. Os resultados das medidas de raios $X$ foram analisados com o intuito de determinar o aumento do fluxo de raios $X$ na SAMA, bem como as características temporais das medidas e o espectro de elétrons energéticos responsáveis pela produção dos raios $X$ observados.

Pinto Jr. et al. (1997) apresentaram medidas de raios $X$ atmosféricos na faixa de energia de 30 a $150 \mathrm{keV}$, realizadas entre novembro e dezembro de 1992, no hemisfério Sul estendendo-se de $53^{\circ}$ a $81^{\circ}$ em latitude. Os resultados comparados com dados similares obtidos em outras regiões dos hemisférios Norte e Sul indicaram que o fluxo de raios $X$ no hemisfério Sul foi praticamente constante, $a$ partir de altas latitudes até a latitude magnética de $30^{\circ}$, porém, indicou uma queda em torno de $50^{\circ}$ magnéticos, entre os valores medidos e os valores esperados por outros modelos. Esta discrepância pôde ser atribuída a diferentes energias consideradas pelos dados e pelos modelos ou à precipitação de elétrons energéticos do cinturão externo na região da SAMA.

\subsubsection{Problemas em satélites}

Como o fluxo de partículas na região da SAMA é considerável, os satélites sofrem com problemas quando passam por ela. A radiação medida no espaço é complicada pela atividade solar, inclinação, altitude e blindagem dos satélites. Esta radiação apresenta um risco constante para a saúde e segurança de tripulantes, componentes eletrônicos, experimentos rádio-sensíveis e equipamentos de bordo.

Durante quinze anos de atuação no espaço, vários grupos de pesquisa do mundo todo utilizaram a estação MIR para obter uma variedade de medidas de radiação espacial, utilizando para isto diversos equipamentos e detectores [BADHWAR et al., 2002; BARDE et al., 2002]. Este período cobriu aproximadamente dois ciclos solares, incluindo um de grande ejeção de massa coronal, um de grandes tempestades magnéticas e, entre esses dois, um evento com emissões de rádio alcançando $250 \times 10^{4}$ Jansky. Resultados de medidas de dosagem passiva em dois astronautas mostraram que a razão entre a absorção em atividades externas à MIR e a absorção dentro do módulo Núcleo da MIR, foi aproximadamente 3 vezes maior enquanto a MIR encontrava-se sobre a região da SAMA [BADHWAR et al., 2002; 
DEME et al., 1999a; DEME et al., 1999b]. A figura 2.6 mostra medidas dosimétricas ativas, feitas pelo detector TEPC (Tissue Equivalent Proportional Counter). Os picos do gráfico representam as dosagens enquanto a MIR passava sobre a SAMA e os menores valores são os raios cósmicos [BADHWAR et al., 2002].

Vários experimentos utilizando folhas metálicas indicaram uma pequena contribuição da radiação de nêutrons na dosagem total das partículas. A missão registrou uma dosagem média de $247 \pm 14 \mu \mathrm{Gy} /$ dia . Os raios cósmicos contribuíram em média $126 \pm 4 \mu \mathrm{Gy} /$ dia e a região da SAMA em $121 \pm 13 \mu \mathrm{Gy} /$ dia para a dosagem total absorvida. Ou seja, aproximadamente metade da dosagem média de radiação foi devida à passagem da MIR sobre a região da SAMA.

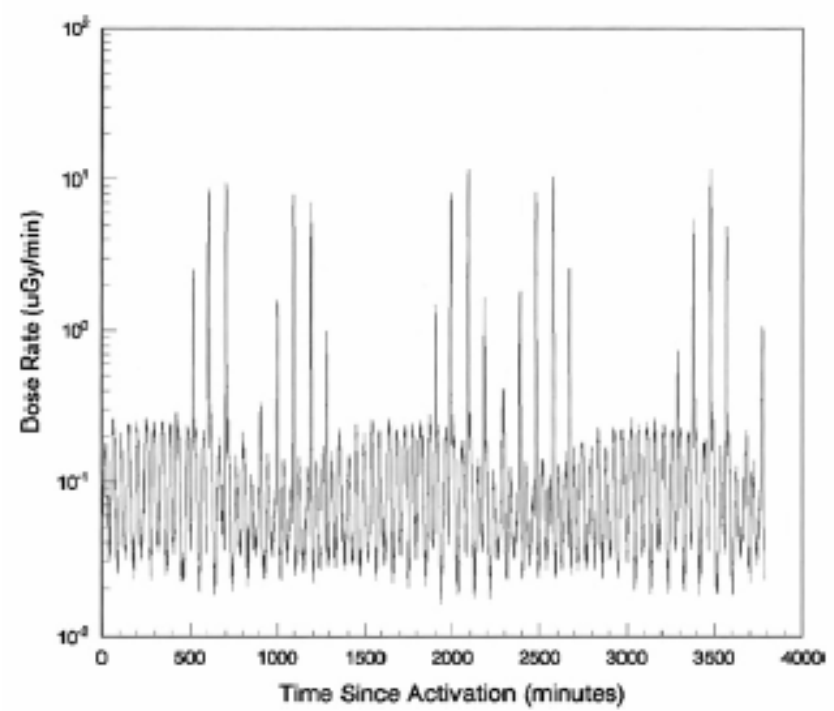

Figura 2.6: Dosagem média em função do tempo de ativação do TEPC (compilado de Badhwar, 2002).

O satélite Jason (da missão TOPEX/Poseidon) lançado em 7 de dezembro de 2001, registrou entre 15 de janeiro de 2002 e 26 de abril de 2003 o comportamento do oscilador do relógio DORIS, quando o satélite passava sobre a SAMA [WILLIS et al., 2004]. O relógio sofreu uma aceleração na passagem sobre a SAMA. Caso este efeito fosse ignorado no posicionamento geodésico das estações do DORIS, a derivada das coordenadas mostraria uma tendência quase linear no tempo, correspondendo a velocidades horizontais e verticais anômalas da ordem de $1 \mathrm{~m} /$ ano. A explicação para o funcionamento anômalo se dá pelo fato de que o DORIS é sensível ao aumento da radiação por prótons, causando sua aceleração. Geralmente os efeitos são pequenos e não fornecem risco aos resultados científicos 
das missões realizadas, entretanto, no caso dos dados do Jason/DORIS os efeitos provocados são importantes para aplicações geodésicas.

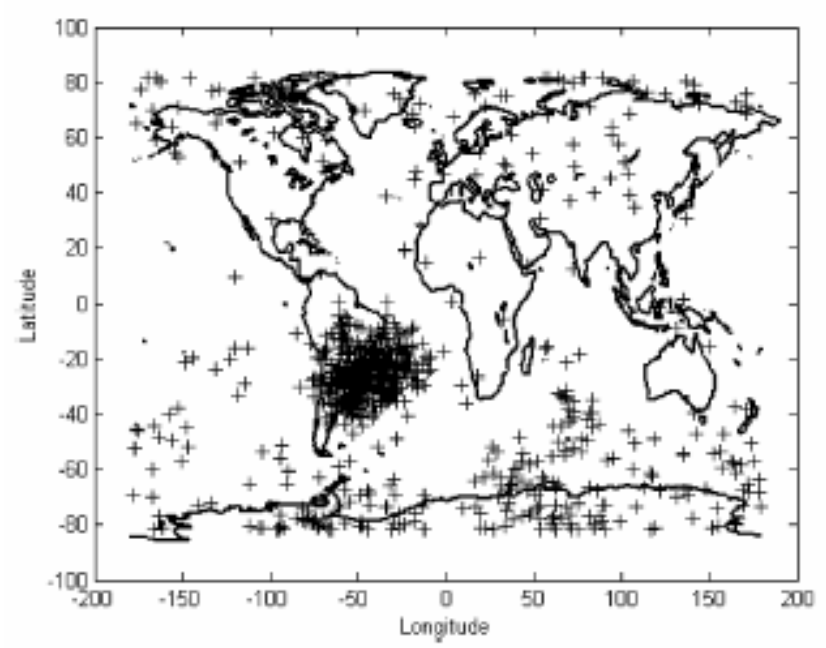

Figura 2.7: Distribuição geográfica de DSEs no MOPITT. A SAMA pode ser claramente identificada pela densidade de pontos (compilado de Nichitiu et al., 2004).

Outro problema detectado foi no MOPITT (Measurements Of Pollution In The Troposphere). A bordo do satélite Terra, os acelerômetros do MOPITT registraram na região da SAMA vários "Evento Único de Aparelho" (DSE - Device Single Event) ou "Evento de Distúrbio Único" (SEU - Single Event Upset) [NICHITIU et al., 2004]. A figura 2.7 mostra a distribuição geográfica de DSEs. Cerca de 54\% dos DSEs no MOPITT ocorrem na região da SAMA, enquanto que apenas $26 \%$ ocorrem nas regiões polares. As fontes que provocam os DSEs foram devidas principalmente a duas fontes de partículas: partículas aprisionadas nos cinturões de radiação e Eventos de Partículas Solares (EPS). A outra fração (cerca de 20\%) é devida aos raios cósmicos.

\subsubsection{Correntes geomagneticamente induzidas}

As cargas de partículas ionizadas em movimento formam correntes elétricas de alta altitude que se fazem acompanhar de severas alterações no campo magnético. Essas correntes iônicas de alta altitude induzem "correntes-imagem" na Terra, assim como nos caminhos artificiais paralelos, incluindo os sistemas telefônicos, linhas de dutos, estradas de ferro e linhas de transmissão de energia elétrica. O fenômeno das correntes geomagneticamente induzidas (Geomagnetically Induced Currents - GICs) é bem estudado no hemisfério Norte, onde já causou, 
reconhecidamente, "blackouts" de grandes proporções. Sabe-se que as correntes são quase contínuas, com freqüências bem inferiores a $1 \mathrm{~Hz}$, e que afetam sistemas de comunicação, operações de satélites e sistemas elétricos de potência. Os países localizados em "altas latitudes" (Canadá, Escandinávia, Estados Unidos) gastam bilhões de dólares em monitoração e prevenção dos possíveis problemas causados por este fenômeno geomagnético [PINTO et al., 2004].

Pelo fato do Brasil encontrar-se numa região tropical, estaria menos sujeito aos fenômenos das GICs. Portanto, pode-se pensar que regiões próximas aos pólos são mais vulneráveis a possíveis "bombardeios" eletromagnéticos. Apenas tempestades magnéticas de grandes proporções atingiriam as latitudes mais baixas, enquanto que tempestades de fracas a moderadas, mais freqüentes, atingem com mais facilidade as latitudes mais altas. Entretanto, o Brasil e boa parte da América do Sul encontram-se na região da SAMA e, assim, sujeitos à ocorrência das GICs.

As características de propagação das GICs variam em função do período (dia ou noite), do sentido (leste - oeste ou vice-versa) e da área de abrangência (podem atingir grande parte do globo). Linhas longas e "horizontais", no sentido da latitude, e situadas sobre rochas ígneas estão mais sujeitas ao fenômeno. Alguns dos principais efeitos provocados pelas GICs em sistemas de transmissão elétrica são:

- Excitação DC (corrente alternada) em transformadores de potência, provocando saturação dos núcleos e conseqüentemente aquecimentos indesejáveis;

- Colapso de tensão: transformadores saturados causam quedas de tensão;

- Um sinal distorcido para um regulador automático de tensão, pode resultar em falhas no controle levando a variações anormais das potências ativas e reativas geradas;

- A introdução de harmônicos em linhas de transmissão pode alterar o nível máximo regulado para a tensão pela ocorrência de picos, tanto positivos quanto negativos, podendo levar à violação de limites préestabelecidos (isolamento, qualidade de energia) e à eventual atuação da proteção ou dano direto a equipamentos (ruptura de isolamentos, envelhecimento precoce de máquinas, etc.); 
- Sistemas interligados: a saturação de um transformador pode injetar harmônicos no sistema, sobrecarregando bancos de capacitores e levando-os ao desligamento, à perda de geradores e ao mau funcionamento dos compensadores estáticos.

Para evitar que as GICs possam provocar efeitos de grandes proporções, é necessário que se façam previsões sobre a ocorrência do fenômeno. Esforços para modelagem das GICs usando dados geomagnéticos estão sendo feitos [TRICHTCHENKO e BOTELER, 2004].

Efeitos em sondagens de MT (Magneto-telúrica) geralmente ocorrem em latitudes aurorais e equatoriais. Entretanto, Padilha (1995) apontou distorções por ruídos em sondagens de MT em dois locais distintos na região da SAMA. Os levantamentos realizados em Blumenau, Santa Catarina e, Cachoeira Paulista, São Paulo, apresentaram freqüências não esperadas para as sondagens. Outras fontes que poderiam influenciar nas medidas como movimento de veículos, ventos e microssismos e linhas de transmissão, foram descartadas pelo fato de que as áreas foram cuidadosamente escolhidas e os equipamentos devidamente instalados. Problemas nos equipamentos de medida puderam ser descartados pelo fato de que as distorções foram similares, tanto para medidas realizadas com equipamentos do INPE (Instituto Nacional de Pesquisas Espaciais), quanto para as medidas realizadas pelo Observatório Nacional. 


\section{Representação e Modelagem do Campo Magnético da Terra}

O CMT representado por harmônicos esféricos é uma importante ferramenta de estudo e avaliação servindo de base para os modelos que descrevem o campo. Este capítulo apresenta a teoria da representação por harmônicos esféricos e descreve como são construídos os modelos.

\subsection{Representação do Campo Magnético da Terra por Harmônicos} Esféricos

O campo geomagnético é um vetor, portanto caracterizado pelo módulo, direção e sentido. No eletromagnetismo, usa-se B para o campo de indução magnética ou fluxo de densidade. Por resolução da IAGA (International Association of Geomagnetism and Aeronomy), de 1973, deve-se usar o vetor B para representar o campo geomagnético. O campo é descrito pelas Equações de Maxwell:

Lei de Ampère

$$
\nabla \times \mathbf{B}=\mu_{0}\left(\mathbf{J}+\frac{\partial \mathbf{D}}{\partial t}\right)
$$

Lei de Faraday

$$
\nabla \times \mathbf{E}=-\frac{\partial \mathbf{B}}{\partial t}
$$

Lei de Gauss

$\nabla \cdot \mathbf{E}=\rho$

Condição solenoidal (Lei de Gauss para o campo magnético)

$\nabla \cdot \mathbf{B}=0$ 
onde $\mu_{0}$ é a permeabilidade magnética no vácuo, $\partial \mathbf{D} / \partial t$ é a corrente de deslocamento, E é o campo elétrico e $\rho$ é a densidade de carga elétrica. Se forem desprezadas as correntes entre a superfície da Terra e a ionosfera, e as variações do campo externo, $\nabla \times \mathbf{B}=0$ e o campo deriva de um potencial escalar. B pode ser representado como gradiente de um potencial escalar $V$ :

$$
\mathbf{B}=-\nabla V
$$

Assim, pela equação (3.4) o divergente de B é nulo e $V$ satisfaz a equação de Laplace:

$$
\nabla^{2} V=0
$$

A equação (3.5) não é válida na região acima dos $95 \mathrm{~km}$, onde os dados de satélites são adquiridos. Pode-se escrever então:

$$
B=B_{i}+B_{e}+B_{j}
$$

onde $B_{i}$ é o campo de origem estritamente interna da Terra; $B_{e}$ é o campo de origem externa, cuja produção ocorre fora da região da ionosfera e $B_{j}$ é o campo cuja produção ocorre dentro da ionosfera, então $B_{i}+B_{e}$ podem ser representados por um potencial escalar. Na prática, os dados usados para determinar $V$ são selecionados para minimizar $B_{j}$ e o $V$ resultante assume uma boa representação de $B_{i}+B_{e}$

As representações de $\mathbf{B}$ satisfazem as equações (3.5) e (3.6). Em 1839, Gauss mostrou que $V$ pode ser escrito como uma série em função dos harmônicos esféricos.

Em termos de coordenadas esféricas $(\theta=$ colatitude, $\lambda=$ longitude, $r=$ raio; as coordenadas estão representadas na figura 3.1), a equação (3.6) pode ser escrita: 


$$
\frac{\partial}{\partial r}\left(r^{2} \frac{\partial V}{\partial r}\right)+\frac{1}{\sin \theta} \frac{\partial}{\partial \theta}\left(\sin \theta \frac{\partial V}{\partial \theta}\right)+\frac{1}{\sin ^{2} \theta} \frac{\partial^{2} V}{\partial \lambda^{2}}=0
$$

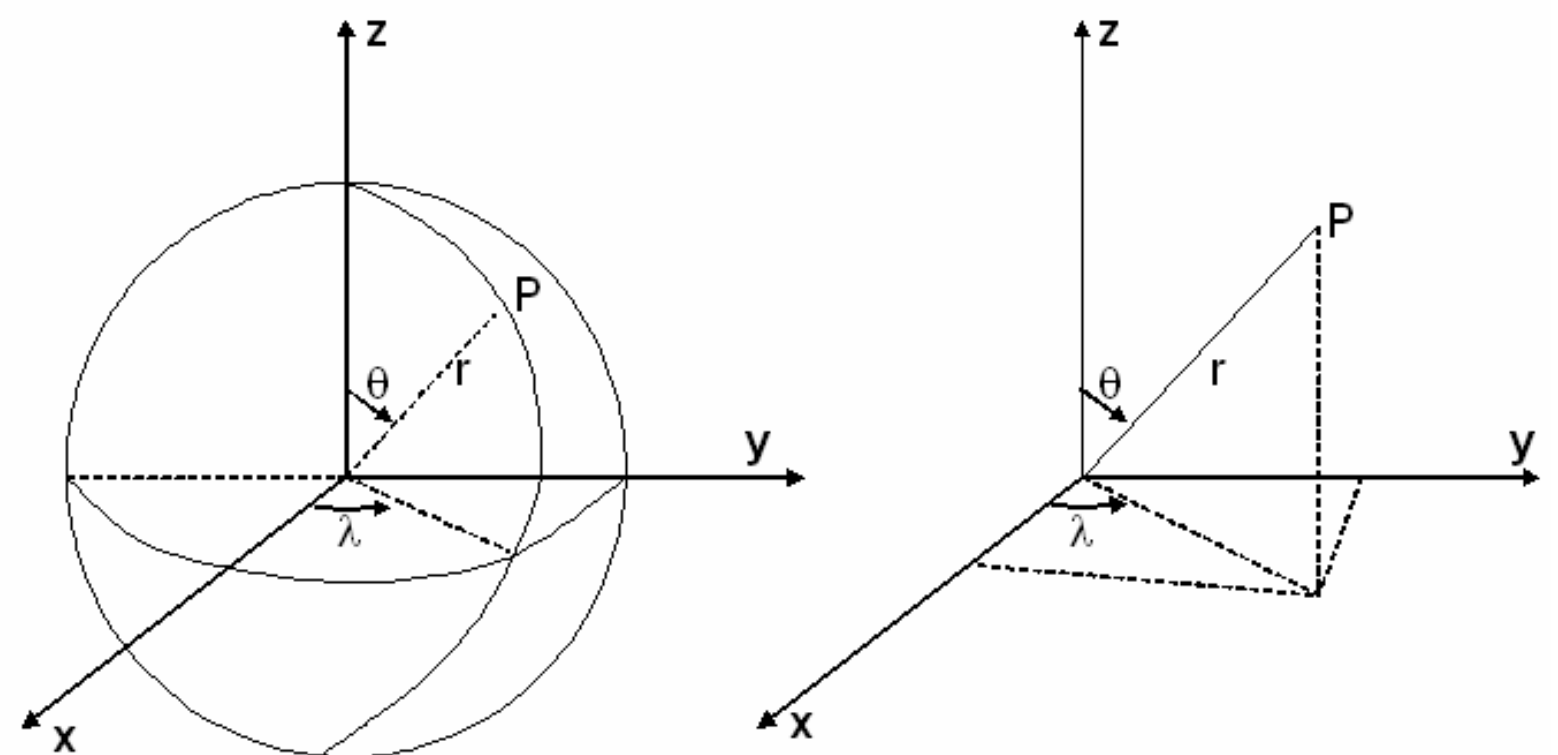

Figura 3.1: Representação das coordenadas esféricas.

A solução da equação (3.8) é encontrada pelo método da separação de variáveis,

$$
V=R(r) \Theta(\theta) \Lambda(\lambda)
$$

Substituindo os termos das equações diferenciais da equação (3.8):

$$
\begin{aligned}
& \frac{\partial V}{\partial r}=\Theta \Lambda \frac{d R}{d r} \\
& \frac{\partial V}{\partial \theta}=R \Lambda \frac{d \Theta}{d \theta} \\
& \frac{\partial^{2} V}{\partial \lambda^{2}}=R \Theta \frac{d^{2} \Lambda}{d \lambda^{2}}
\end{aligned}
$$

Fazendo a substituição e dividindo os termos por $R \Theta \Lambda$ e multiplicando por $\sin ^{2} \theta$ :

$$
\frac{\sin ^{2} \theta}{R} \frac{d}{d r}\left(r^{2} \frac{d R}{d r}\right)+\frac{\sin \theta}{\Theta} \frac{d}{d \theta}\left(\sin \theta \frac{d \Theta}{d \theta}\right)+\frac{1}{\Lambda} \frac{d^{2} \Lambda}{d \lambda^{2}}=0
$$


passando o último termo para o $2^{\circ}$ membro:

$$
\frac{\sin ^{2} \theta}{R} \frac{d}{d r}\left(r^{2} \frac{d R}{d r}\right)+\frac{\sin \theta}{\Theta} \frac{d}{d \theta}\left(\sin \theta \frac{d \Theta}{d \theta}\right)=-\frac{1}{\Lambda} \frac{d^{2} \Lambda}{d \lambda^{2}}
$$

o que só é possível se ambos os membros forem iguais a uma constante:

$$
\frac{1}{\Lambda} \frac{d^{2} \Lambda}{d \lambda^{2}}=-m^{2}
$$

tomando o primeiro membro e dividindo por $\sin ^{2} \theta$ e passando o $2^{\circ}$ termo para o $2^{\circ}$ membro:

$$
\begin{aligned}
& \frac{1}{R} \frac{d}{d r}\left(r^{2} \frac{d R}{d r}\right)=\frac{m^{2}}{\sin ^{2} \theta}-\frac{1}{\sin \theta} \frac{1}{\Theta} \frac{d}{d \theta}\left(\sin \theta \frac{d \Theta}{d \theta}\right)=n(n+1) \\
& \frac{1}{\sin \theta} \frac{d}{d \theta}\left(\sin \theta \frac{d \Theta}{d \theta}\right)+\left[n(n+1)-\frac{m^{2}}{\sin ^{2} \theta}\right] \Theta=0 \\
& \frac{d}{d r}\left(r^{2} \frac{d R}{d r}\right)-n(n+1) R=0
\end{aligned}
$$

A constante de separação foi escrita na forma $n(n+1)$ porque isto será conveniente em seguida. Neste estágio, $n$ é completamente arbitrário.

Para encontrar a função do potencial, deve-se resolver as equações (3.13), (3.14) e (3.15). Assim, as soluções para a equação (3.13) são:

$$
\Lambda=A \cos m \lambda \quad \text { ou } \quad \Lambda=B \sin m \lambda
$$

onde $A$ e $B$ são constantes de integração e $m$ é um número inteiro para que as funções sejam unívocas. A equação (3.15) admite soluções do tipo:

$$
R=C r^{n} \quad \text { ou } \quad R=D r^{-(n+1)}
$$


onde C e D são constantes e $n$ é um número inteiro.

Para solução da equação (3.14) é conveniente fazer uma mudança de variável. Colocando $\mu=\cos \theta$ e $d \theta=-\frac{d \mu}{\sqrt{1-\mu^{2}}}$, temos que

$$
\frac{d}{d \mu}\left[\left(1-\mu^{2}\right)^{n} \frac{d P}{d \mu}\right]+\left[n(n+1)+\frac{m^{2}}{\sin ^{2} \theta}\right] P=0
$$

As soluções desta equação podem ser encontradas expressando $P_{n}$ como uma série infinita de potências de $\mu$. Nos problemas físicos, a condição da série ser convergente impõe um limite superior nas potências permitidas para $\mu$, de modo que a série se reduzirá a um polinômio de grau $n$, onde $n$ é um inteiro positivo. Estes polinômios contêm somente potências pares de $n$, se $n$ for par. Por outro lado, se $n$ for ímpar, $P_{n}(\mu)$ conterá somente potências ímpares de $\mu$. Fazendo $m=0$, a equação (chamada de equação de Legendre) passa a ter soluções que são os polinômios de Legendre:

$$
P_{n}^{0}(\mu)=\frac{1}{2^{n} n !} \frac{d^{n}}{d \mu^{n}}\left[\left(\mu^{2}-1\right)^{n}\right]
$$

onde $\frac{1}{2^{n} n !}$ é o fator de normalização dos polinômios. Os primeiros polinômios, normalizados de maneira que $P_{n}(1)=1$, são dados por:

$$
\begin{aligned}
& P_{0}^{0}(1)=1 \\
& P_{1}^{0}(\mu)=\mu=\cos \theta \\
& P_{2}^{0}(\mu)=\frac{1}{2}\left(3 \mu^{2}-1\right)=\frac{1}{4}(3 \cos 2 \theta+1) \\
& P_{3}^{0}(\mu)=\frac{1}{2}\left(5 \mu^{2}-3 \mu\right)=\frac{1}{8}(5 \cos 3 \theta+3 \cos \theta)
\end{aligned}
$$



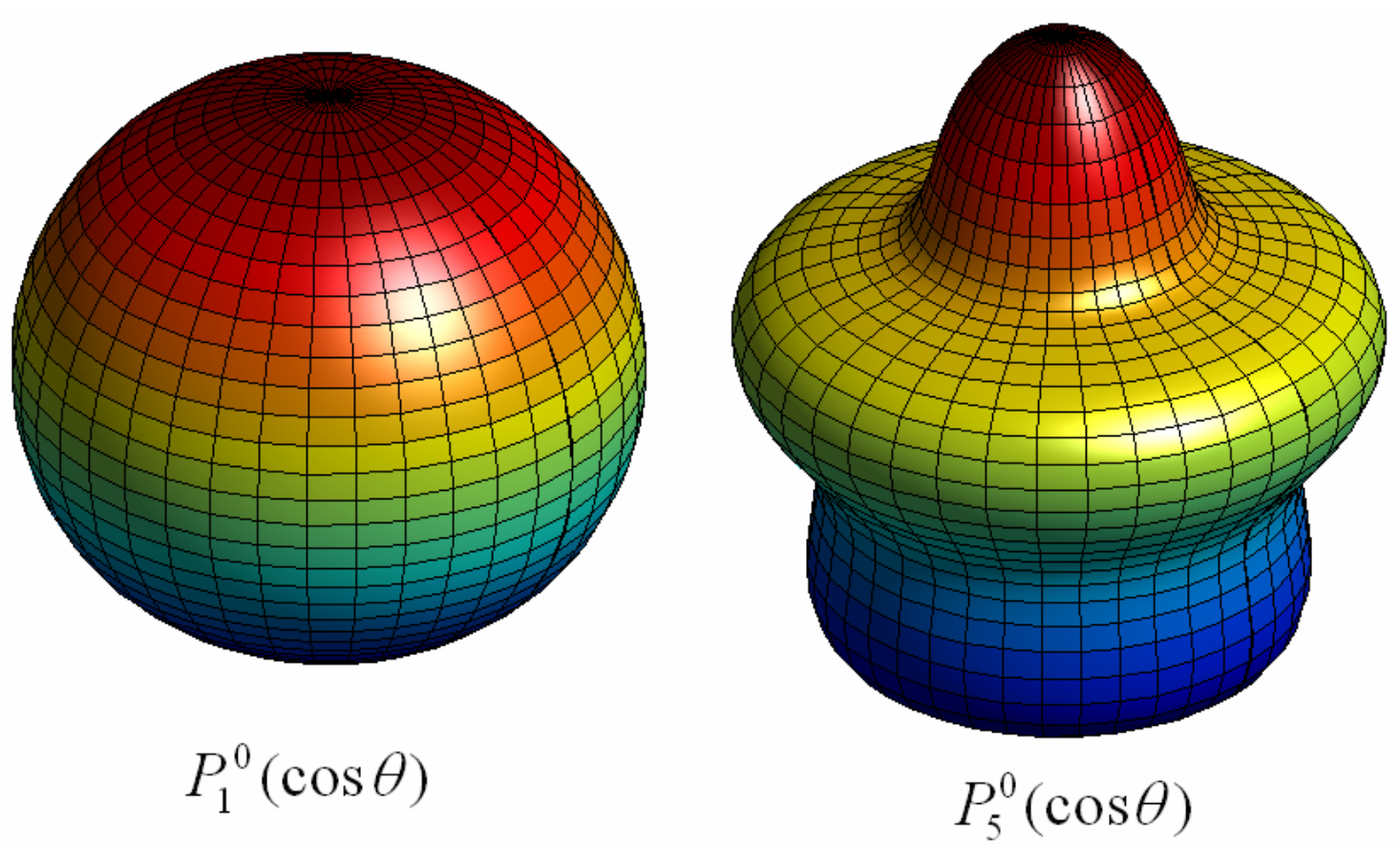

Figura 3.2: Representação geométrica de dois harmônicos esféricos zonais.

Quando $m \neq 0$, há variação com a longitude e a equação chama-se Equação de Legendre Associada e as soluções são os polinômios de Legendre Associados, que se relacionam com os polinômios de Legendre através de:

$$
P_{n}^{m}(\theta)=\sin ^{m} \theta \frac{d^{m} P_{n}^{0}(\mu)}{d(\mu)^{m}}
$$

usando o fator de normalização,

$$
P_{n}^{m}(\theta)=\frac{\left(1-\mu^{2}\right)^{m / 2}}{2^{n} n !} \frac{d^{(n+m)}}{d(\mu)^{(n+m)}}\left[\left(\mu^{2}-1\right)^{n}\right]
$$

Neste caso, a derivada será nula quando $(m+n)>2 n$, portanto, devemos ter $m \leq n$. Para o caso particular de $m=n$, os harmônicos correspondentes chamam-se harmônicos setoriais (são definidos num setor esférico). Os mais simples são:

$$
\begin{aligned}
& P_{1}^{1}(\mu)=\left(1-\mu^{2}\right)^{1 / 2}=\sin \theta \\
& P_{2}^{2}(\mu)=3\left(1-\mu^{2}\right)^{1 / 2}=3\left(1-\cos ^{2} \theta\right) \\
& P_{3}^{3}(\mu)=15 \mu\left(1-\mu^{2}\right)^{1 / 2}=15 \sin ^{3} \theta
\end{aligned}
$$



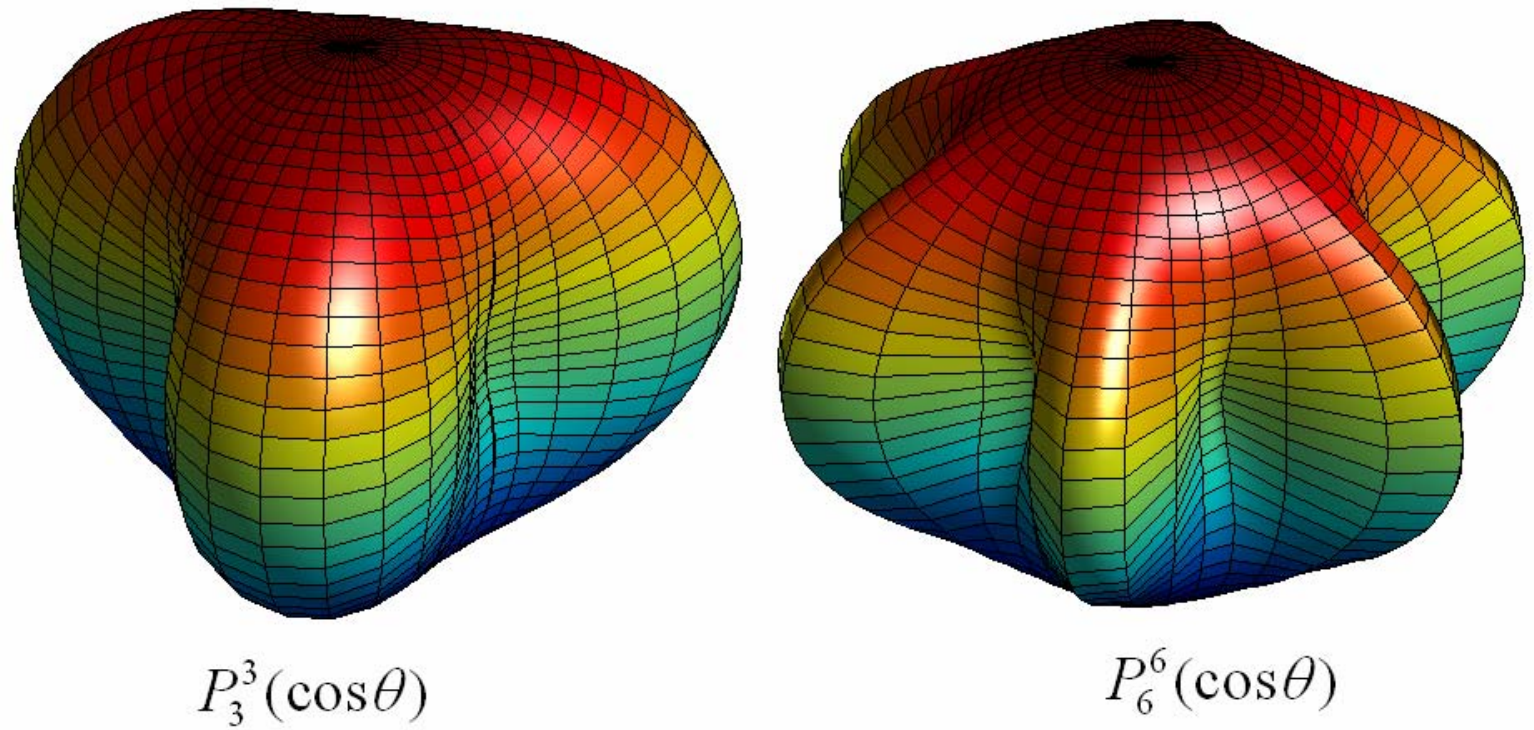

Figura 3.3: Representação geométrica de dois harmônicos esféricos setoriais.
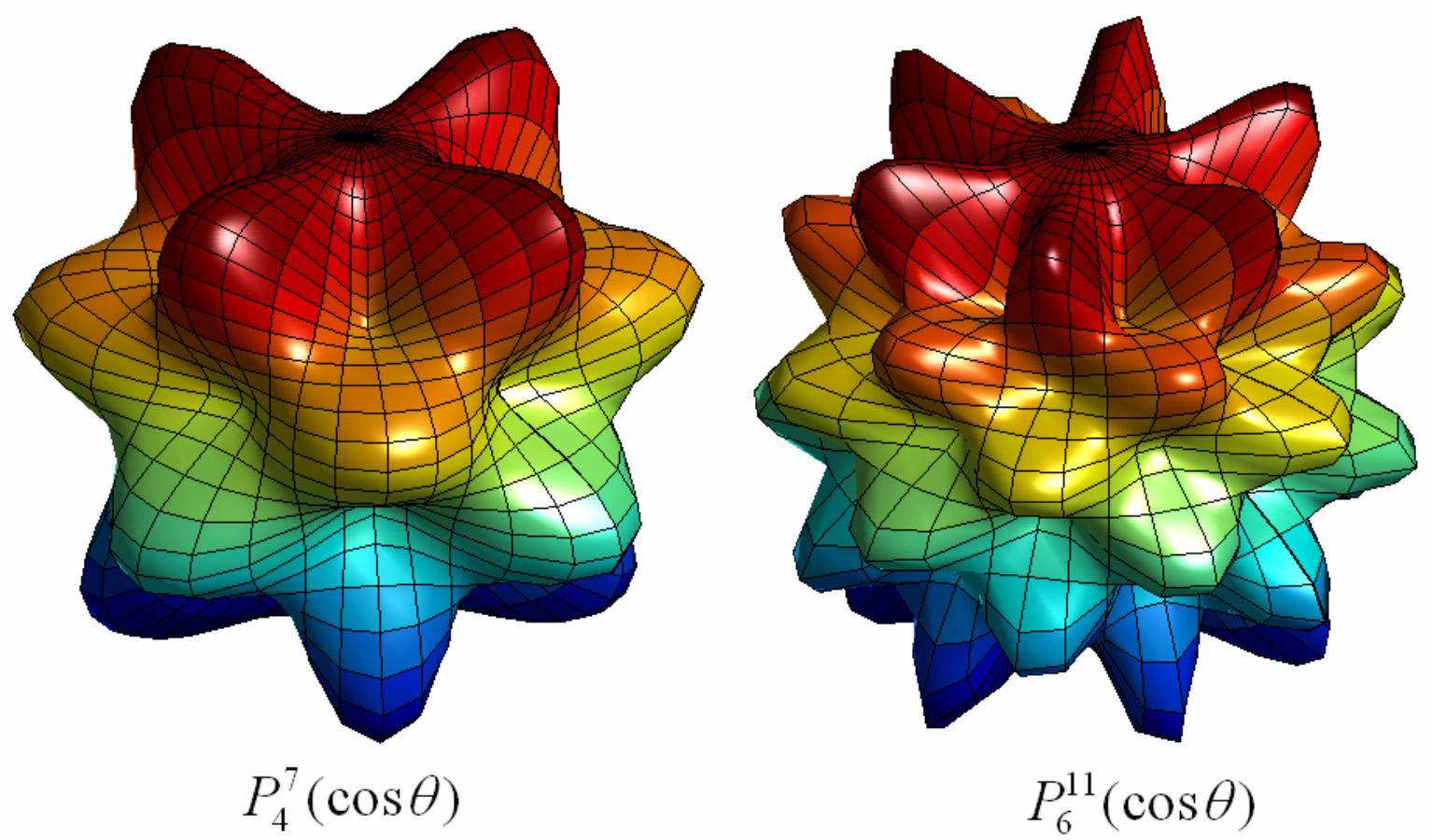

Figura 3.4: Representação geométrica de dois harmônicos esféricos tesserais.

No caso geral de $m \neq n$, com $m \neq 0$, as soluções são os harmônicos tesserais (definidos numa téssera, que é a intersecção entre um setor e uma zona esférica):

$$
\begin{aligned}
& P_{2}^{1}(\mu)=3 \mu\left(1-\mu^{2}\right)^{1 / 2}=3 \sin \theta \cos 2 \theta \\
& P_{3}^{1}(\mu)=\frac{3}{2}\left(1-\mu^{2}\right)^{1 / 2}\left(5 \mu^{2}-1\right) \\
& P_{3}^{2}(\mu)=15 \mu\left(1-\mu^{2}\right)
\end{aligned}
$$


As soluções da parte radial $R$ do tipo $r^{-(n+1)}$, correspondem a fontes na origem. Para soluções do tipo $r^{n}$ correspondentes a fontes no infinito, com $V \rightarrow \infty$ para $r \rightarrow \infty$, portanto, fontes de origem externa à Terra. A solução geral da Equação de Laplace sobre uma esfera é:

$$
V=\sum_{n=1}^{\infty} \sum_{m=0}^{n}\left[C_{n}^{m} r^{n}+D_{n}^{m} r^{-(n+1)}\right]\left[A_{n}^{m} \cos m \lambda+B_{n}^{m} \sin m \lambda\right] P_{n}^{m}(\theta)
$$

onde $A_{n}^{m}, B_{n}^{m}, C_{n}^{m}$ e $D_{n}^{m}$ são os chamados coeficientes dos harmônicos esféricos.

Combinando as constantes e introduzindo a razão $\left(\frac{a}{r}\right)$, onde $a$ é o raio médio da Terra, e se $c$ e $s$ forem as frações de $P_{n}^{m} \cos m \lambda$ e $P_{n}^{m} \sin m \lambda$, devidas a origem externa, a solução geral será:

$$
V=a \sum_{n=1}^{\infty} \sum_{m=0}^{n} P_{n}^{m}(\theta)\left\{\begin{array}{l}
{\left[c_{n}^{m}\left(\frac{r}{a}\right)^{n}+\left(1-c_{n}^{m}\right)\left(\frac{a}{r}\right)^{n+1}\right] A_{n}^{m} \cos m \lambda+} \\
+\left[s_{n}^{m}\left(\frac{r}{a}\right)^{n}+\left(1-s_{n}^{m}\right)\left(\frac{a}{r}\right)^{n+1}\right] B_{n}^{m} \sin m \lambda
\end{array}\right\}
$$

o multiplicador $a$ é adicionado a solução para que os coeficientes tenham a mesma dimensão de B. O potencial $V$ não é diretamente observável, mas sim as componentes do campo medidas na superfície da Terra $(r=a)$. As componentes do campo geomagnético são derivadas direcionais do potencial e dependem dos coeficientes $A_{n}^{m}$ e $B_{n}^{m}$. Utilizando a equação (3.5), pode-se encontrar as componentes:

$$
\begin{aligned}
& X=\frac{-\partial V}{r \partial \theta}=-\sum_{n=1}^{\infty} \sum_{m=0}^{m}\left\{A_{n}^{m} \cos m \lambda+B_{n}^{m} \sin m \lambda\right\} \frac{d P_{n}^{m}(\theta)}{d \theta} \\
& Y=\frac{-1}{r \sin \theta} \frac{\partial V}{\partial \lambda}=\frac{1}{\sin \theta} \sum_{n=1}^{\infty} \sum_{m=0}^{m}\left\{m A_{n}^{m} \sin m \lambda+B_{n}^{m} \cos m \lambda\right\} P_{n}^{m}(\theta)
\end{aligned}
$$




$$
Z=\frac{-\partial V}{\partial r}=\sum_{n=1}^{\infty} \sum_{m=0}^{m}\left\{\begin{array}{l}
{\left[n c_{n}^{m}-\left(1-c_{n}^{m}\right)(n+1)\right] A_{n}^{m} \cos m \lambda+} \\
+\left[n s_{n}^{m}-\left(1-s_{n}^{m}\right)(n+1)\right] B_{n}^{m} \sin m \lambda
\end{array}\right\} P_{n}^{m}(\theta)
$$

Ajustando-se as expressões de $X$ e $Y$ aos valores observados, obtém-se os coeficientes $A_{n}^{m}$ e $B_{n}^{m}$. Numa primeira aproximação, pode-se desprezar o campo externo, supondo que $c_{n}^{m}$ e $s_{n}^{m}$ são muito menores que 1. Então a expressão do potencial fica:

$$
V=a \sum_{n=1}^{\infty} \sum_{m=0}^{n} P_{n}^{m}(\theta)\left[g_{n}^{m} \cos m \lambda+h_{n}^{m} \sin m \lambda\right]\left(\frac{a}{r}\right)^{n+1}
$$

onde $g_{n}^{m}$ e $h_{n}^{m}$ são os chamados coeficientes de Gauss e têm dimensões de campo magnético.

Sobre a superfície da Terra $(r=a)$, as componentes $X, Y$ e $Z$ do campo geomagnético podem ser escritas em termos dos coeficientes de Gauss, como:

$$
\begin{aligned}
& X=\sum_{n=1}^{\infty} \sum_{m=0}^{m}\left\{g_{n}^{m} \cos m \lambda+h_{n}^{m} \sin m \lambda\right\} \frac{d P_{n}^{m}(\theta)}{d \theta} \\
& Y=\frac{1}{\sin \theta} \sum_{n=1}^{\infty} \sum_{m=0}^{m}\left\{m g_{n}^{m} \sin m \lambda+m h_{n}^{m} \cos m \lambda\right\} P_{n}^{m}(\theta) \\
& Z=\sum_{n=1}^{\infty} \sum_{m=0}^{m}\left\{\begin{array}{l}
{\left[n c_{n}^{m}-\left(1-c_{n}^{m}\right)(n+1)\right] g_{n}^{m} \cos m \lambda+\left[n s_{n}^{m}-\left(1-s_{n}^{m}\right)(n+1)\right] h_{n}^{m} \sin m \lambda}
\end{array}\right\} P_{n}^{m}(\theta)
\end{aligned}
$$

O cálculo dos $g_{n}^{m}$ e $h_{n}^{m}$ é feito a partir de medidas realizadas em observatórios e de levantamentos magnéticos todas reduzidas a mesma época. Por exemplo, com os dados da componente $X$, traçam-se linhas de igual valor e por interpolação encontram-se os valores para os nós da rede de colatitude $\theta_{0}$ a $\theta_{p}$, e longitude $\lambda_{0}$ a $\lambda_{p}$. Então, para um $\theta$ fixo, desenvolve-se em série de Fourier ao longo do paralelo: 


$$
f(\theta)=\sum_{m=0}^{\infty}\left(a_{m} \cos m \lambda+b_{m} \sin m \lambda\right)
$$

Nesta série, os valores de $f(\theta)$ são conhecidos para os nós da rede, obtendo-se então os $a_{m}$ e $b_{m}$. Igualando-se a série (3.34) a (3.31), encontram-se os $g_{n}^{m}$ e $h_{n}^{m}$. Como exemplo, segue a solução dos $g_{n}^{0}$ :

$$
\begin{aligned}
& a_{0}\left(\theta_{0}\right)=g_{1}^{0}\left(\frac{d P_{1}^{0}}{d \theta}\right)_{\theta=\theta_{0}}+g_{2}^{0}\left(\frac{d P_{2}^{0}}{d \theta}\right)_{\theta=\theta_{0}}+g_{3}^{0}\left(\frac{d P_{3}^{0}}{d \theta}\right)_{\theta=\theta_{0}}+\ldots \\
& a_{0}\left(\theta_{1}\right)=g_{1}^{0}\left(\frac{d P_{1}^{0}}{d \theta}\right)_{\theta=\theta_{1}}+g_{2}^{0}\left(\frac{d P_{2}^{0}}{d \theta}\right)_{\theta=\theta_{1}}+g_{3}^{0}\left(\frac{d P_{3}^{0}}{d \theta}\right)_{\theta=\theta_{1}}+\ldots \\
& \ldots \\
& a_{0}\left(\theta_{p}\right)=g_{1}^{0}\left(\frac{d P_{1}^{0}}{d \theta}\right)_{\theta=\theta_{p}}+g_{2}^{0}\left(\frac{d P_{2}^{0}}{d \theta}\right)_{\theta=\theta_{p}}+g_{3}^{0}\left(\frac{d P_{3}^{0}}{d \theta}\right)_{\theta=\theta_{p}}+\ldots
\end{aligned}
$$

Os $\frac{d P_{n}^{0}}{d \theta}$ são conhecidos para cada valor de $\theta$, obtendo-se um sistema de $p$ equações em $g_{1}^{0}, g_{2}^{0} \ldots g_{n}^{0}$, solucionáveis desde que se tenha $p \geq n$. O ajuste é feito pelo método dos mínimos quadrados. E os outros $g_{n}^{m}$ e $h_{n}^{m}$ são calculados de forma análoga. Pode-se calcular os coeficientes de Gauss utilizando também a componente $Y$, sendo que os resultados encontrados com as duas componentes deveriam ser iguais, entretanto, isso não ocorre devido a pequenas diferenças devidas a erros nas medidas e interpolação.

\subsubsection{Separação do Campo Interno e Externo}

Encontrados os valores dos coeficientes $g_{n}^{m}$ e $h_{n}^{m}$, usa-se então a expressão de $Z$ para determinar os $c_{n}^{m}$ e $s_{n}^{m}$, ou seja, as frações de cada harmônico correspondentes a origem externa. Gauss utilizou este método pela primeira vez e concluiu que a origem do campo era toda interna e que o campo externo não existia. Sabemos hoje que o campo de origem externa responde por algumas dezenas de 
nT em dias de baixa atividade solar e pode responder por até $30 \%$ do campo total em dias de tempestades magnéticas.

A componente $Z$ pode ser desenvolvida em série de Fourier ao longo de um paralelo:

$$
Z=\sum_{n=1}^{\infty} \sum_{m=0}^{n} P_{n}^{m}(\theta)\left(\alpha_{n}^{m} \cos m \lambda+\beta_{n}^{m} \operatorname{sen} m \lambda\right)
$$

igualando à expressão de $Z$ dos harmônicos esféricos, obtém-se:

$$
\begin{aligned}
& \alpha_{n}^{m}=\left[n c_{n}^{m}-(n+1)\left(1-c_{n}^{m}\right)\right] g_{n}^{m} \\
& \beta_{n}^{m}=\left[n s_{n}^{m}-(n+1)\left(1-s_{n}^{m}\right)\right] h_{n}^{m}
\end{aligned}
$$

Os $\left\{\alpha_{n}^{m}, \beta_{n}^{m}\right\}$ são conhecidos do desenvolvimento de Fourier e os $\left\{g_{n}^{m}, h_{n}^{m}\right\}$ são calculados com as equações de $X$ e $Y$, estando portanto determinados os valores de $\left\{c_{n}^{m}, s_{n}^{m}\right\}$.

\subsubsection{Separação dos campos dipolar e não-dipolar}

A parte do campo de origem interna, obtida subtraindo o campo do dipolo geocêntrico inclinado do campo total (aproximadamente $10 \%$ do campo total, podendo chegar até $20 \%$ ), é chamada de campo não-dipolar. Um mapa de campo não-dipolar consiste num sistema irregular, com anomalias de longo comprimento de onda.

Com o modelo encontrado através da análise por harmônicos esféricos, é possível fazer a separação dos campos dipolar e não-dipolar. Isto é feito isolando-se dos modelos os coeficientes que correspondem ao campo dipolar. Os coeficientes $g_{1}^{0}, g_{1}^{1}$ e $h_{1}^{1}$, coletivamente, representam o campo dipolar. Os harmônicos de grau $n \geq 2$ na análise por harmônicos esféricos do campo principal correspondem às componentes do campo não-dipolar. Os termos de grau $n=2$ na expansão do potencial correspondem aos quadrupolos magnéticos, os termos de grau $n=3$ os octupolos, e assim por diante. 
Em 1940, McNish mostrou que o campo não-dipolar pode ser aproximado por uma distribuição de quatorze pequenos dipolos radiais situados à metade do raio terrestre, isto é, um pouco abaixo da interface manto-núcleo.

Vestine et al. (1947) mapeou a distribuição de correntes elétricas em escudos esféricos de diferentes raios, que produziram em 1945, as componentes não-dipolares do campo principal. Alldredge e Hurwitz (1964) mostraram que o campo geomagnético observado pode ser estritamente reproduzido por nove dipolos no núcleo. O maior momento magnético está localizado no centro da Terra. Os outros tem momentos muito menores e estariam localizados a uma distância geocêntrica de $r / a=0,28$, isto é, dentro dos limites do núcleo.

\subsection{Modelagem do Campo Geomagnético}

Vários modelos do campo vêm sendo propostos, desde a época de Gauss. Dependendo de hipóteses fundamentais e do grau e ordem da análise por harmônicos esféricos, obtêm-se diferentes valores para os coeficientes de Gauss.

A IAGA propôs o IGRF (International Geomagnetic Reference Field), que é um modelo global calculado para o período de cinco anos. É o modelo utilizado em prospecção geofísica, levantamentos e pesquisa.

Outro modelo é o WMM (World Magnetic Model), dos Departamentos de Defesa dos Estados Unidos e da Grã Bretanha. É utilizado em navegação e em aplicações que envolvam curso e altitude. É o modelo utilizado no sistema de GPS. Ambos modelos são atualizados a cada 5 anos.

Para modelar o campo através de medidas feitas por observatórios ou por satélites, utilizamos a função potencial $V(r, \theta, \lambda)$ mas, na realidade, a função é $V(r, \theta, \lambda, t)$ pois o campo geomagnético, e portanto os coeficientes de Gauss, variam com o tempo. O modelo deve especificar a época em que deve ser aplicado.

As componentes medidas do campo geomagnético usadas mais freqüentemente como dados são sete. A notação geomagnética convencional é definida da seguinte maneira:

Norte: $\quad X=-B_{\theta}=\frac{1}{r} \frac{\partial V}{\partial \theta}$ 


$$
\begin{array}{ll}
\text { Leste: } & Y=B_{\phi}=\frac{1}{r(\sin \theta)} \frac{\partial V}{\partial \lambda} \\
\text { Vertical: } & Z=-B_{r}=\frac{\partial V}{\partial r} \\
\text { Horizontal: } & H=\left(X^{2}+Y^{2}\right)^{1 / 2} \\
\text { Total: } & F=\left(X^{2}+Y^{2}+Z^{2}\right)^{1 / 2} \\
\text { Inclinação: } & I=\arctan \left(\frac{Z}{H}\right) \quad-\frac{\pi}{2} \leq I \leq \frac{\pi}{2} \\
\text { Declinação: } & D=\arctan \left(\frac{Y}{X}\right) \quad-\pi \leq D \leq \pi
\end{array}
$$

onde $\left(B_{r}, B_{\theta}, B_{\phi}\right)$ são as componentes de $\mathbf{B}$ em coordenadas polares esféricas. É claro que com três componentes quaisquer pode-se determinar as outras.

O método convencional para determinar os coeficientes geomagnéticos é truncando a equação (3.30) até o grau $N$ (usualmente $4 \leq N \leq 13$ ) e ajustando os coeficientes das observações pelo método dos mínimos quadrados. As equações (3.38), (3.39) e (3.40) tem relações lineares entre $X, Y, Z$ e os coeficientes geomagnéticos; e as equações (3.41) a (3.44) tem relações não-lineares. A solução procede iterativamente para os dados não-lineares de alguns modelos iniciais $\left\{g_{n}^{m}, h_{n}^{m}\right\}$.

Sendo $m$ um vetor $P$ de um modelo de parâmetros, onde $P=N(N+2)$ é o número do modelo de parâmetros, e $\gamma$ é um vetor $D$ de medidas, onde $D$ é um número de dados. As equações (3.31) a (3.33) e a equação (3.30) têm, então, as relações lineares entre $\gamma$ e $m$,

$$
\gamma=A m+e
$$

são as equações da condição para a análise dos mínimos quadrados e e é um vetor erro. As equações (3.41) a (3.44) precisam primeiro ser linearizadas, e a solução encontrada iterativamente. 


\section{Variação Secular do Campo Magnético Terrestre}

Este capítulo abordará os principais aspectos da variação secular. As grandes anomalias do campo geomagnético variam consideravelmente com 0 tempo. Com isto, as variações do campo dipolar, a deriva para oeste do campo nãodipolar e os "impulsos da variação secular" são importantes por se tratar de fenômenos que têm origem no núcleo da Terra e que possivelmente influenciam ou sofrem a influência da SAMA.

\subsection{Variações geomagnéticas}

As variações no campo geomagnético observadas na superfície da Terra ocorrem em escalas de tempo da ordem de milisegundos a milhões de anos. As variações de curto período são devidas principalmente ao fluxo de correntes na ionosfera e magnetosfera, à variação diurna e tempestades magnéticas. Estas rápidas flutuações muitas vezes são sobrepostas pelas variações lentas com períodos de anos a milhões de anos. As variações lentas são chamadas de "variação secular geomagnética". A variação secular tem origem no núcleo da Terra; algumas fontes de origem externa causam variações de longo período no campo e podem contribuir para as variações do campo observado, mas não de forma a definir a variação secular [BLOXHAM et al., 1989]. Alguns períodos de 11 e 21,5 anos são suficientemente próximos dos períodos de atividade solar e podem ser de origem externa, mas estes sinais são relativamente pequenos. Períodos de origem interna menores do que um ano não são observados na superfície da Terra por causa do efeito de blindagem da parte inferior do manto eletricamente condutor. A variação não pode ainda ser prevista á longo prazo, isto é, a derivada segunda de um elemento geomagnético com relação ao tempo não é nula.

Modelos de variação secular começaram a serem construídos a partir de 1900 quando as medidas de intensidade tornaram-se melhores e mais precisas. A figura 4.1 mostra a variação secular do campo total para a época de 2000 . Em (a) a variação foi calculada utilizando-se o IGRF e em (b) o modelo de variação é do 
WMM. Nota-se que os modelos apresentam algumas diferenças, no entanto, os contornos negativos e positivos coincidem.

a)

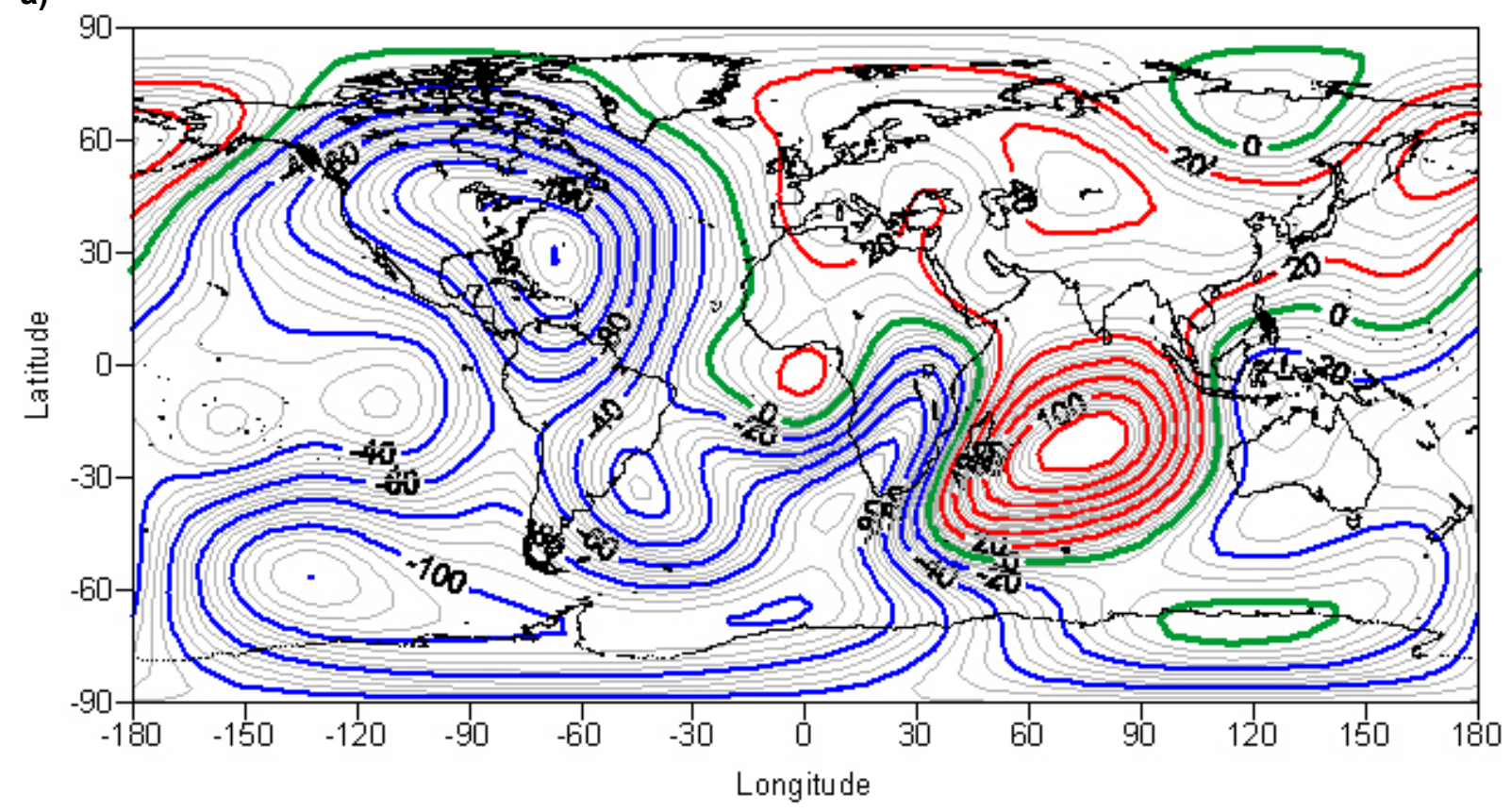

b)

\section{US/UK World Magnetic Chart -- Epoch 2000 Total Intensity - Annual Change (F)}

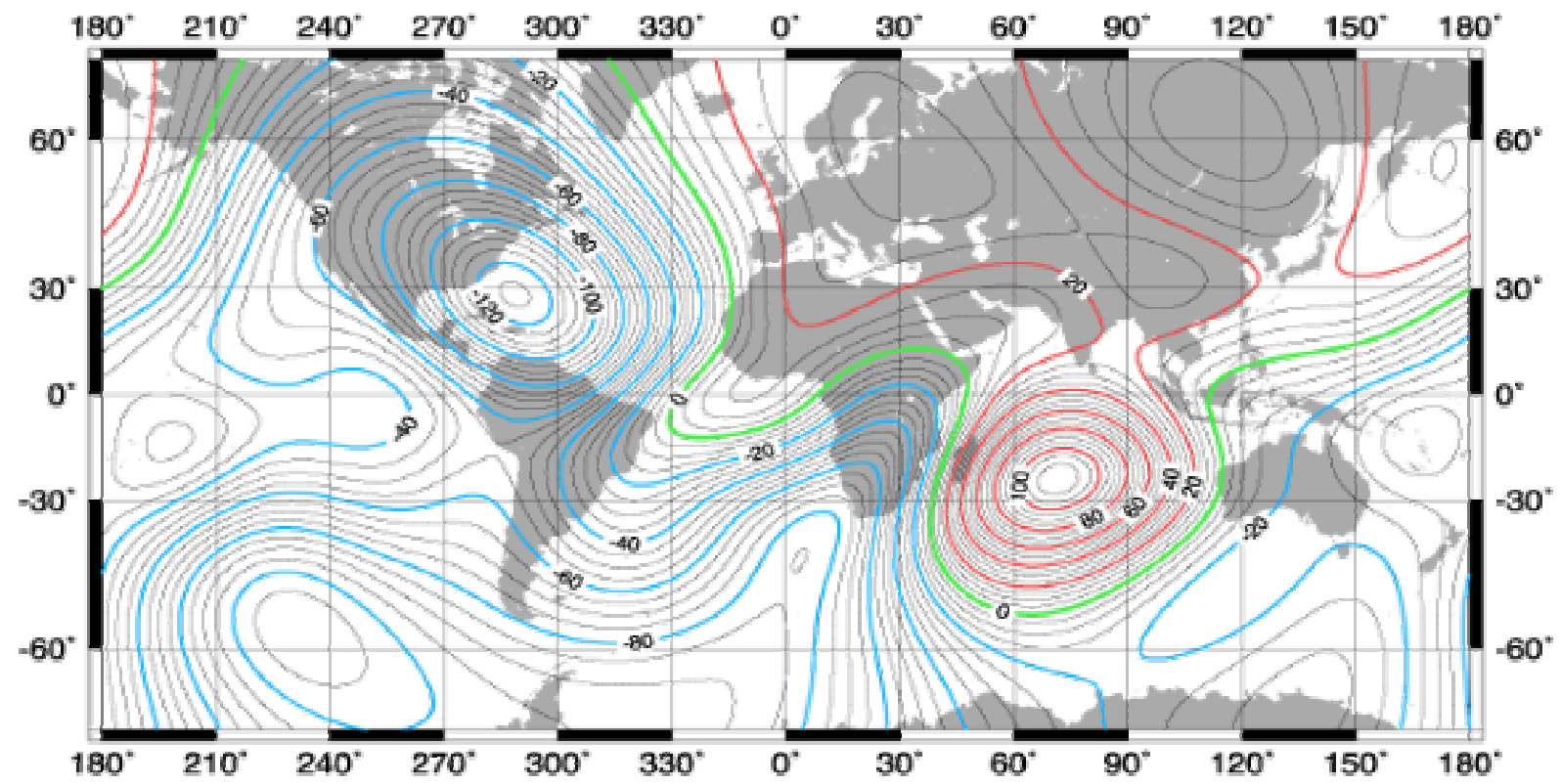

Uhlo : nand Tablasy

cortour inerval i 9 nandesiasty

Figura 4.1: Variação secular para a época de 2000. Em (a) modelo do IGRF e (b) modelo WMM. Em ambos o intervalo de contorno é de $5 n$ T/ano. Os contornos em vermelho indicam variação positiva e os contornos em azul indicam variação negativa. 
Modelos para épocas anteriores a 1900, utilizando dados de navegadores, foram construídos e a variação secular pode ser estimada [BRAGINSKII, 1972; BARRACLOUGH, 1974].

\subsection{Os impulsos de variação secular e a blindagem do manto}

As variações temporais do campo magnético, com origem no núcleo, passam pelo manto e assim as variações observadas na superfície da Terra são uma leitura filtrada. Para prever os efeitos deste filtro é necessário conhecer a distribuição da condutividade elétrica do manto. Campos magnéticos externos são usados para obter estimativas da condutividade do manto superior, enquanto que campos originados no núcleo são usados para obter estimativas da condutividade para o manto inferior.

Variações no campo magnético externo podem induzir anéis de corrente no interior da Terra de acordo com a lei de Lenz. A variação no campo magnético medido na superfície da Terra é uma combinação das variações do campo externo e os campos induzidos associados. Na prática duas séries temporais podem ser usadas (uma para variações externas vistas na superfície da Terra e as outras para os campos induzidos na Terra) e estas séries podem ser separadas usando técnicas de correlação cruzada [MERRILL et al., 1998]. O método magnetotelúrico tem sido usado para estimar a distribuição da condutividade elétrica do manto superior.

Em um condutor magnético uniforme e estacionário, a equação de indução magnética reduzida para o vetor de difusão é:

$$
\frac{\partial \mathbf{B}}{\partial t}=\frac{1}{\sigma \mu} \nabla^{2} \mathbf{B}
$$

em que B é o campo magnético, $\sigma$ é a condutividade elétrica, e $\mu$ é a permeabilidade magnética do meio. Isto mostra que o campo magnético pode propagar-se (como num processo de difusão) dentro de um condutor, que neste caso é a crosta e o manto. Uma equação similar pode ser derivada das Equações de Maxwell para o campo elétrico. Considerando um campo magnético variando com uma freqüência 
$\omega$, difundindo em um meio com condutividade constante, a solução neste caso é dada por:

$$
\begin{aligned}
& \mathbf{B}=\mathbf{B}_{0} \exp \left(-\frac{z}{\delta}\right) \exp \left[i\left(\omega t-\frac{z}{\delta}\right)\right] \\
& \delta=\left(\frac{2}{\omega \mu \sigma}\right)^{1 / 2}
\end{aligned}
$$

onde $z$ é a profundidade e $\delta$ é a profundidade "skin" (profundidade na qual a amplitude do campo se torna igual a $1 / e$ do valor original). Note-se que a profundidade skin é uma função da condutividade e da freqüência, aumentando para sinais de baixa freqüência e para materiais de condutividade menor. Na prática pode-se ter uma cadeia de freqüências examinadas e isto permite a determinação da condutividade em função da profundidade [MERRILL, et al., 1998].

Basicamente, todos os modelos publicados para condutividade elétrica fornecem um valor de condutividade próximo de $1 \mathrm{Sm}^{-1}$ (siemens/metro) para a profundidade da descontinuidade sísmica de $670 \mathrm{~km}$. Isto representa um aumento substancial de condutividades crustais, que geralmente são duas ordens de magnitude menores. Apesar de haver modelos que fornecem valores de condutividades constantes para o manto profundo (com profundidades em torno de $1000 \mathrm{~km}$ ), a resolução abaixo de $670 \mathrm{~km}$ é muito pobre. Geralmente, a condutividade do manto inferior é estimada por outros meios, como, por exemplo, usando a informação associada com variações no campo magnético de origem no núcleo.

A dificuldade em usar esta teoria é que se precisa conhecer a condutividade do manto com o intuito de analisar o espectro geomagnético ou conhecer o espectro geomagnético com o intuito de obter a condutividade do manto. Runcorn (1955), verificou que para um modelo de terra plana, no qual o manto é aproximado a um plano de condutividade constante $\sigma_{0}$ e espessura $L$, a amplitude do espectro na superfície tem a forma,

$$
\mathbf{B}=\mathbf{B}_{0} \exp \left(-\frac{L}{\sqrt{\mu_{0} \sigma_{0} \omega}}\right)
$$


Portanto, assumindo que a variação secular na interface manto-núcleo possa ser descrita por um espectro "branco", Runcorn pôde estimar a condutividade média do manto.

Uma estimativa do período mínimo, que não pode ser significativamente filtrado pelo manto inferior, pode ser obtida assumindo o modelo de blindagem do plano de Runcorn. A profundidade skin em quilômetros é:

$$
\delta=\frac{1}{2}\left(\frac{T_{c}}{\sigma_{0}}\right)^{1 / 2}
$$

onde $T_{c}$ é o período. Para esta estimativa faz-se $\sigma_{0}$ no manto inferior igual a $1 \mathrm{Sm}^{-1}$ e $\delta$ igual a $2000 \mathrm{~km}$, então, $T_{C} \approx 16 \times 10^{6} \mathrm{~s}$, o que corresponde a aproximadamente meio ano. Isto representa uma boa estimativa de primeira ordem do período mínimo para que um campo magnético com origem no núcleo possa ser observado na superfície da Terra. Períodos muito menores que esse, podem certamente ser atribuídos às fontes acima do núcleo da Terra. Em 1957, Mcdonald melhorou este método considerando um modelo esférico e atribuindo uma expansão geométrica no manto em que a condutividade varia de acordo com uma lei exponencial em função do raio.

Entretanto, existe uma restrição sobre a condutividade elétrica do manto inferior. Ela não pode ser alta porque grande parte da variação secular de curto período observada na superfície poderia ser blindada. Os períodos de variação curta, considerados geralmente de origem no núcleo, são chamados de "impulso de variação secular", também conhecidos como "jerks" geomagnéticos. Os jerks são mudanças abruptas na segunda derivada do CMT, ou seja, a chamada aceleração secular. Este fenômeno é bem observado na primeira derivada da componente $Y$ (leste) do campo magnético por observatórios magnéticos do mundo todo [Le MÖUEL et al., 1982]. A variação do campo é muito mais aparente na componente $Y$ do que nas componentes $X$ e $Z$, parcialmente, por que os contornos de igual valor de $Y$ e $d Y / d t$ tendem a estabilizar no plano do meridiano. Outra razão, é que a porção simétrica do campo, descrita pelos coeficientes $g_{n}^{0}$ e $d g_{n}^{0} / d t$, não faz parte de uma simples deriva para Oeste. Esta porção simétrica está ausente na componente $Y$, 
mas é forte nas componentes $X$ e $Z$ que tendem a encobrir qualquer característica de variação mais abrupta [LANGEL, 1987].

O primeiro jerk foi detectado em 1969 a partir de dados de observatórios europeus. A duração de um jerk é da ordem de um ano ou menos [COURTILLOT et al., 1984; BLOXHAM et al., 2002].

Backus (1983) foi quem primeiro realizou análises para o problema da blindagem relacionada à observação de jerks, argumentando que a curta duração do jerk de 1969, observado na Europa, foi devido à combinação dos modos harmônicos. Courtillot et al. (1984), sugeriram que algumas das observações relacionadas ao jerk poderiam ser contaminadas por resquícios dos efeitos do ciclo solar. A presença de fontes externas foi uma explicação alternativa, no entanto, não desenvolvida até este ponto. Se a condutividade do manto não pode ser desprezada, então não se pode assumir que $\mathbf{B}=-\nabla V$. Mas o campo pode ser dividido, nas partes poloidal e toroidal,

$$
\mathbf{B}=\nabla \times(\Lambda p+\Lambda q)
$$

onde $\Lambda p$ corresponde a parte poloidal, $\Lambda q$ a parte toroidal e o operador angular $\Lambda$ é definido por:

$$
\Lambda=\mathbf{r} \times \nabla
$$

Backus (1983) mostrou que na superfície da Terra, com raio $a$,

$$
S_{n}^{m}(a, t)=\left(\frac{c}{a}\right)^{n+1} \int_{0}^{\infty} F_{n}(\tau) P_{n}^{m}(c, t-\tau) d \tau
$$

onde $c$ é o raio do núcleo, $t$ é o tempo e $S_{n}^{m}$ é a função escalar (que depende do grau e ordem dos harmônicos esféricos) do qual o campo magnético poloidal é obtido. O campo poloidal é o único campo de origem no núcleo que é observado na superfície. $F_{n}(t)$ é a função resposta do impulso e depende de $n$ mas não de $m$, porém, desaparece à medida que $\tau$ se aproxima de zero ou infinito. Sendo $\tau_{1}$ a 
média e $\tau_{2}$ o desvio padrão desta função, então, $S_{n}^{m}(a, t)$ pode ser obtido atenuando $P_{n}^{m}$ por $(c / a)^{n+1}$ e calculando sobre o intervalo de tempo de $2 \tau_{2}$ a $\tau_{1}$. O valor de $\tau_{1}$ é aproximadamente duas vezes $\tau_{2}$ e que $\tau_{1}$ está provavelmente entre 1 e 10 anos. Backus (1983) mostrou que o jerk de 1969 (e outros impulsos similares) pode, na verdade, ocorrer de 1 a 10 anos antes, e alegou que a duração de menos de um ano reflete mais uma mudança gradual do que a ocorrida sobre alguns anos. Entretanto, Courtillot et al. (1984) atribuiu á presença de um sinal semelhante às manchas solares nos dados e o fato de que o jerk é um fenômeno mundial e simultâneo. Neste caso, a aplicação da teoria de filtro de Backus deve indicar que $\tau_{1}$ é provavelmente menor que um ano.

A questão dos jerks é central não somente para a compreensão da condutividade do manto, mas também para a teoria do dínamo, porque sendo de origem interna, não podem ser considerados independentemente do mecanismo de geração do CMP. Os jerks podem estar relacionados a grandes mudanças de fluxos responsáveis pela convecção do material do núcleo. Alexandrescu et al. (1995; 1996) desenvolveram análises por ondaletas (wavelets) e detectaram cinco eventos de jerks (1901, 1913, 1925, 1969 e 1978) que possivelmente tiveram extensão global e, dois eventos com características mais locais (1932 e 1949). Porém, a mais importante descoberta destas análises, foi da que rejeita a possibilidade de que o jerk tenha algum sinal externo adicional.

Le Huy et al. (1998), utilizando dados de 160 observatórios, modelaram por harmônicos esféricos, truncando as séries até ordem e grau 4, os jerks de 1969, 1978 e 1991. Os resultados confirmaram a origem interna dos jerks. A figura 4.2 mostra a variação secular da componente $Y$ para 37 observatórios europeus em que ficam evidentes os jerks de 1969, 1978 e 1991.

Os resultados encontrados por estes trabalhos não apresentam grandes mudanças nos valores de condutividade do manto inferior de $3 \times 10^{2} \mathrm{Sm}^{-1}$, um valor que é três ordens de magnitude menor que o do núcleo. Nota-se, entretanto, que regiões locais (descontínuas) de alta condutividade no manto inferior são possíveis. De fato, estas podem ter uma causa para algumas variações geográficas observadas para o jerk de 1969. 


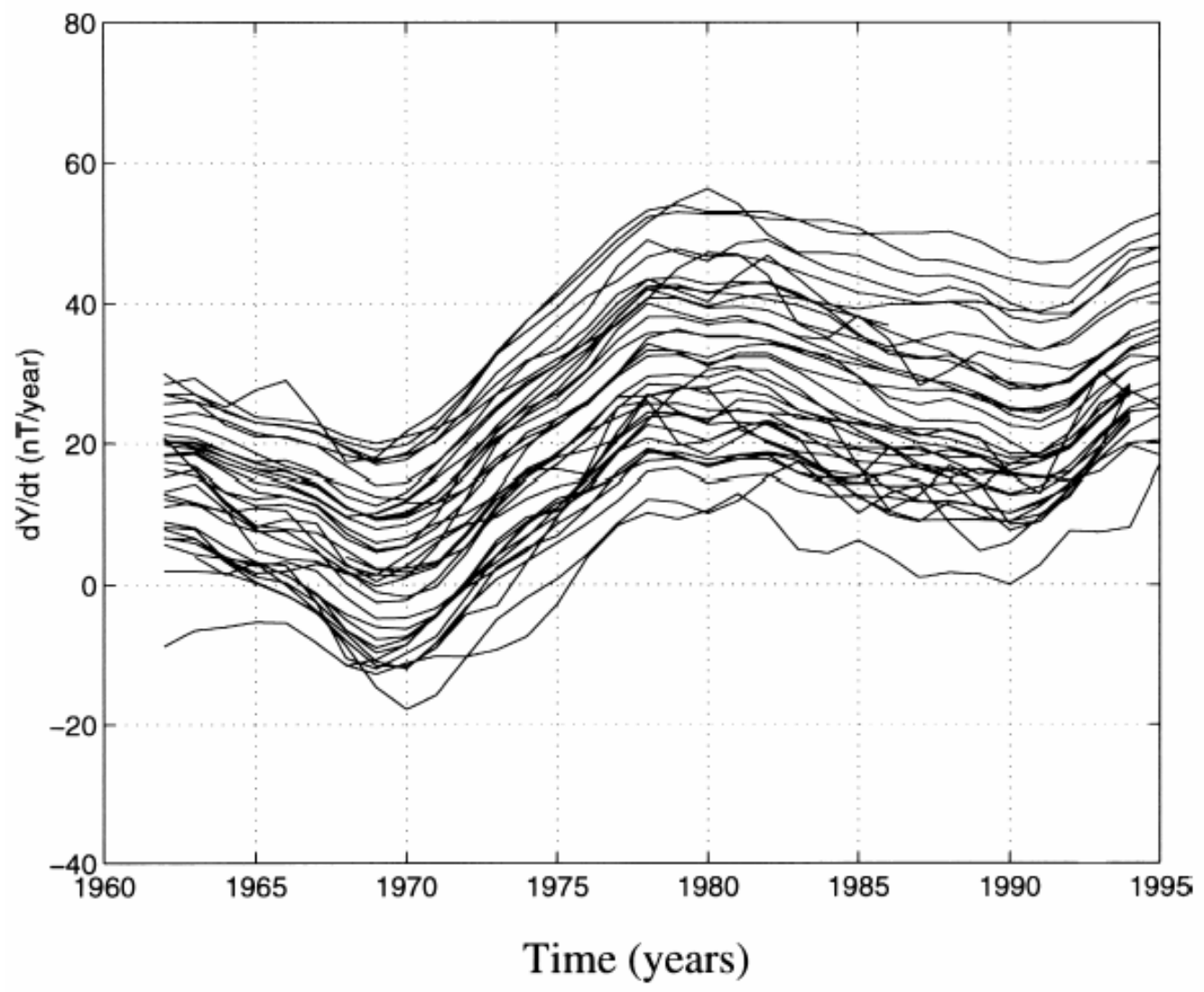

Figura 4.2: Variação secular da componente $Y$ do campo geomagnético de 37 observatórios europeus mostrando os jerks de 1969, 1978 e 1991 (compilado de LeHuy et al., 1998).

\section{a)Niemegk (Alemanha)}
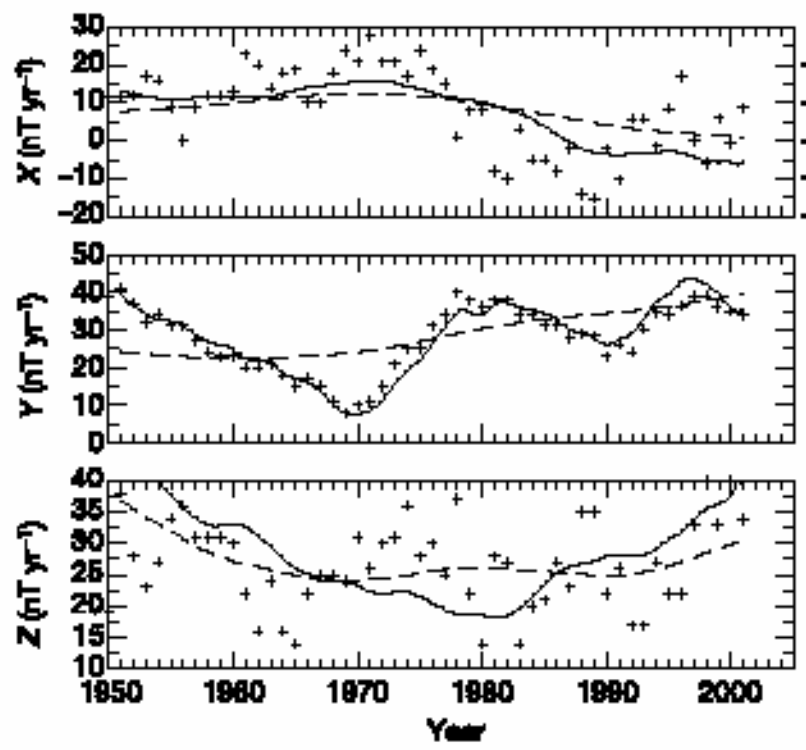

b)Macquarie Island
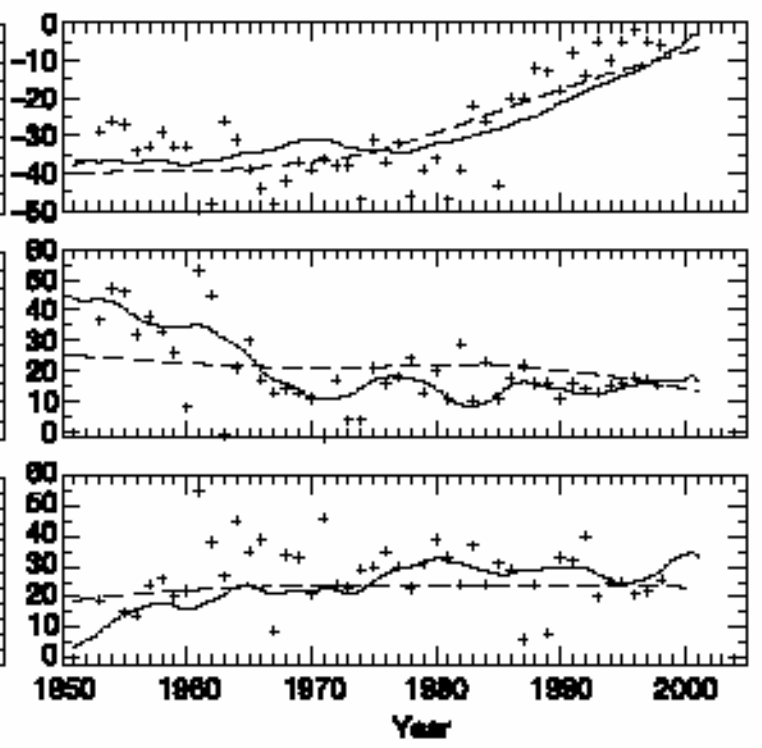

Figura 4.3: Variação secular da componente $Y$ do campo geomagnético para dois observatórios distintos: Niemegk (Alemanha) e Macquarie Island (Austrália) mostrando os jerks de 1969, 1978, 1991 e 1999. As cruzes são as diferenças entre as médias anuais, a linha pontilhada representa a variação secular prevista pela parte regular do fluxo na superfície do núcleo e, a linha contínua é a variação secular prevista pela dinâmica do núcleo - dependente do tempo e do fluxo zonal equatorial (na forma de oscilações torsionais). (compilado de Bloxham et al., 2002). 
Contudo, deve-se notar que o jerk pode não ser um fenômeno global, mas um fenômeno de variação regional. Bloxham et al. (2002) realizaram análises de dados para dois observatórios diferentes, encontrando para o período de 1950-2001 quatro jerks: 1969, 1978, 1991 e 1999. Ao contrário do que Le Möuel et al. (1982) e Alexandrescu et al. (1995; 1996) afirmaram, Bloxham et al. (2002) mostraram que os jerks são fenômenos que não ocorrem em todo o planeta. Os observatórios de Niemegk (Alemanha) e Macquarie Island (Austrália) são quase antípodas um do outro. Os resultados evidenciaram que os jerks podem ser explicados pela dinâmica do núcleo, que inclui oscilações torsionais (Capítulo 5) e que são fortemente dependentes do campo magnético local para a interface manto-núcleo e, portanto, observados somente numa região limitada da superfície da Terra.

A SAMA pode ter um papel importante na detecção de jerks. Isto pode acontecer pela sobreposição ou amplificação de sinais de menor comprimento de onda, como é o caso dos jerks.

\subsection{A deriva para oeste e as variações em intensidade}

A deriva para Oeste é uma das principais características do campo magnético principal. Quando Halley descobriu este fenômeno e propôs o modelo de rotação relativa entre duas esferas para interpretar a deriva para Oeste, muitas análises foram feitas usando vários dados e métodos. Diferentes resultados foram obtidos para épocas e componentes distintas, encontradas por vários pesquisadores. Porém, a deriva de $\sim 0,2 \%$ ano para o campo total é amplamente aceita [BULLARD et al., 1950; LANGEL, 1987].

O CMP possui certas vantagens quando comparado com outras componentes do campo para determinação da taxa de deriva para Oeste:

I. As diferentes taxas de deriva obtidas de diferentes componentes dificultam a determinação de uma única taxa de deriva.

II. O campo total mostra uma estrutura espacial relativamente simples e estável, enquanto que as componentes magnéticas $(X, Y, Z)$ geralmente possuem morfologias mais complicadas.

A deriva para Oeste é detectada não só pelo deslocamento dos focos do campo principal, mas também pelo deslocamento dos focos nos mapas da variação 
secular [LANGEL, 1987]. Wei e Xu (2003) determinaram taxas de deriva para Oeste do campo utilizando a variação secular do campo total e, componentes $X, Y$ e $Z$. Os resultados indicaram que a deriva para Oeste, calculada através da variação secular do campo principal, foi de 0,43\%ano obtida para o intervalo de 1900-2005, sendo bem superior à taxa de deriva obtida simplesmente pelo deslocamento do campo principal que foi de $0,15 \%$ ano. As componentes $X, Y$ e $Z$ apresentaram padrões de deriva complicados, com taxas de 0,51\%ano, 0,39\%ano e 0,43\%ano, respectivamente.

\subsubsection{A deriva do campo não-dipolar}

As grandes variações na direção do CMT durante os últimos 150 anos estão associadas com a parte não-dipolar do campo. Isto pode ser visualizado através do movimento para Oeste de vários focos isopóricos (máximos ou mínimos) para cartas isomagnéticas de diferentes épocas magnéticas. Bullard et al. (1950) verificou que para o período de 1907 á 1945, a velocidade média foi de 0,18\%/ano de deriva para Oeste do campo não-dipolar. A figura 4.4 mostra cartas magnéticas do campo nãodipolar para os anos de 1950 e 2000. A razão entre os campos não-dipolar e total são mostrados nas figuras do Apêndice $B$, e que dão uma idéia de como o campo não-dipolar tem derivado com o tempo.

Uma das maiores contribuições para o geomagnetismo nas últimas décadas tem sido o uso de dados históricos, inclusive dos navegadores, estendendo-se até a época de 1600 [BLOXHAM e GUBBINS, 1985; BARRACLOUGH, 1974]. Os valores do campo na interface manto-núcleo foram calculados utilizando-se para isso a técnica de inversão estocástica [BLOXHAM et al., 1989]. No entanto existem ainda algumas controvérsias, como a forma de resolução do campo e algumas interpretações dos dados. Por exemplo, o campo magnético pode mudar por causa da difusão de um ponto para outro ou por causa da advecção (arrastamento das linhas do campo pelos movimentos do fluido) e quando a difusão é desprezada, a chamada aproximação do "frozen flux" (fluxo congelado) é aplicada. Bloxham e Gubbins (1985) sugerem que ambos os processos ocorrem, nesse caso, pode haver problemas em usar os dados para calcular velocidades do fluido no núcleo. Entretanto, Constable et al. (1993), afirmam que os dados são compatíveis com a hipótese do frozen flux. Porém, não se pode descartar a possibilidade de que a 
difusão ocorra para a escala de tempo histórica de 400 anos, mas a difusão é pouco importante para harmônicos de graus inferiores nos modelos deste intervalo.

a)
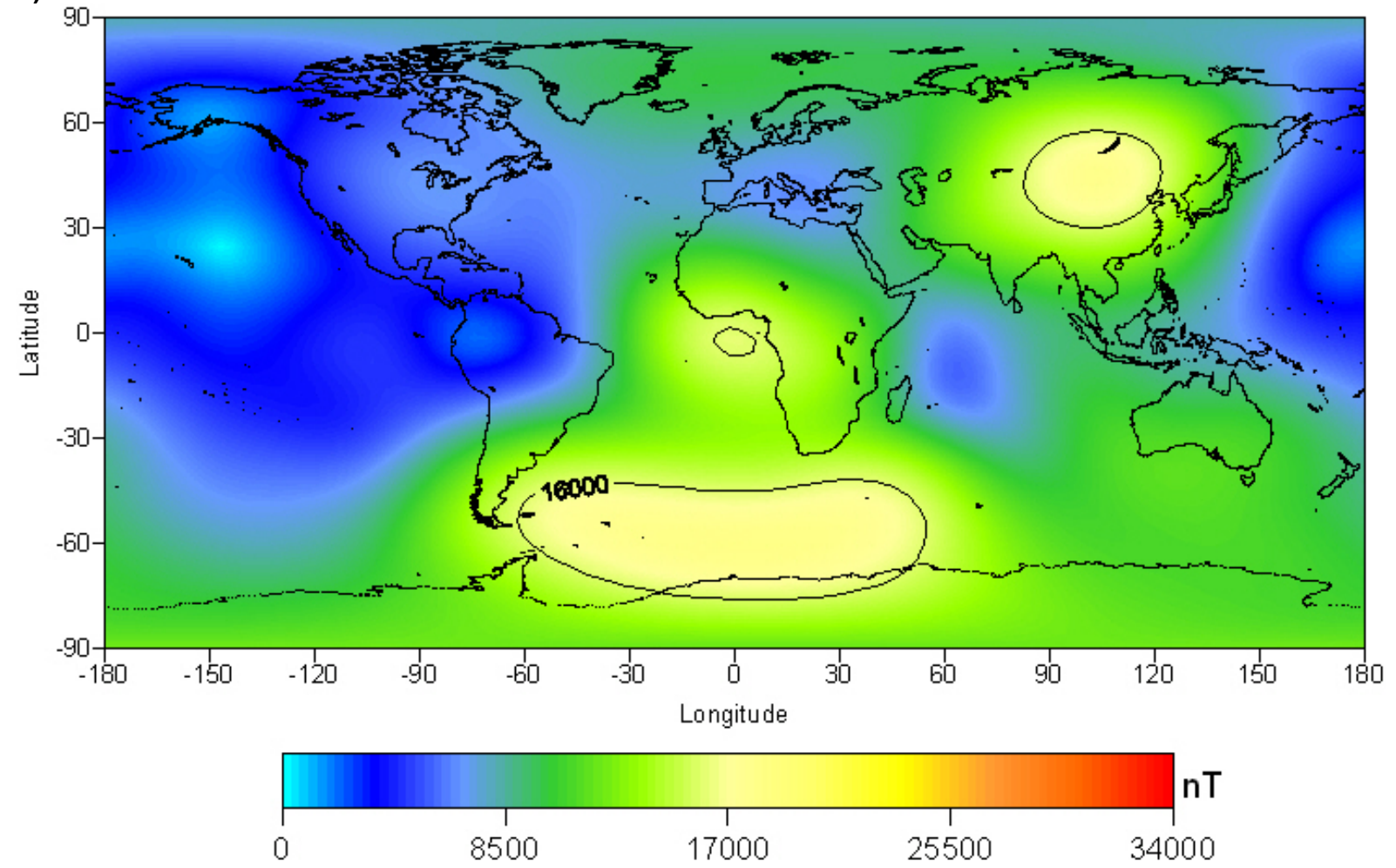

b)
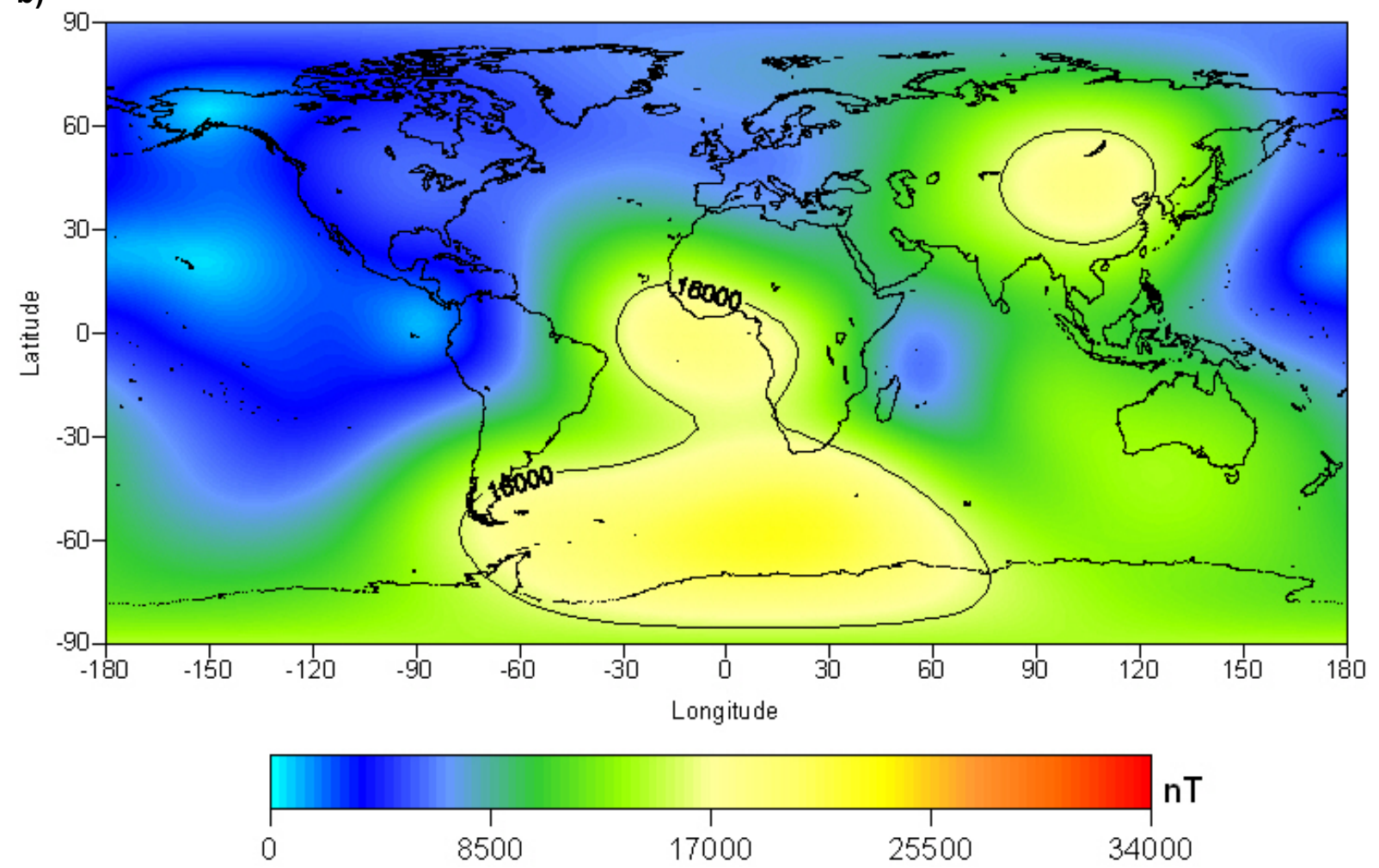

Figura 4.4: Mapas para o campo não-dipolar. Em (a) para o ano de 1950 e (b) 2000. O intervalo de contorno de 16000nT mostra a variação dos focos de maior intensidade para o campo não-dipolar. 
As análises destes dados indicam que a deriva para Oeste do campo nãodipolar é primariamente confinada à região do Atlântico. De fato, o campo nãodipolar é muito pequeno numa região do Oceano Pacífico que é referida como "janela dipolar do Pacífico", como pode ser notado na figura 4.4.

Existem dois tipos principais de anomalias não-dipolares: aquelas que claramente possuem deriva para Oeste (como a anomalia da África central) e aquelas que permanecem estacionárias e aumentam ou diminuem em magnitude (como a anomalia da Mongólia).

Vários modelos tentam essencialmente explicar os mesmos dados de variação secular: a deriva para Oeste do campo não-dipolar; os modelos de anomalias estacionárias e de deriva e suas variáveis; a deriva em direção aos pólos do campo não-dipolar; e as mudanças aleatórias no campo não-dipolar.

\subsubsection{Variações do campo dipolar em função do tempo}

O campo dipolar também varia com o tempo. A intensidade do campo dipolar tem diminuído a uma taxa de $5 \%$ por século desde o período das análises de Gauss em 1835. Com a análise por harmônicos esféricos para várias épocas, podese calcular também os momentos do dipolo equivalente, mostrados na figura $4.5 \mathrm{em}$ função do tempo.

Utilizando os modelos do IGRF e de Barraclough (1974), pode-se ter uma estimativa do decréscimo do campo dipolar desde 1600, quando o momento for calculado com os três primeiros coeficientes que descrevem o campo dipolar.

Nota-se que o momento de dipolo tem decrescido quase que linearmente nos últimos séculos e uma extrapolação indicaria campo nulo por volta de 3700 a 4000. Isto foi resolvido com o Arqueomagnetismo, isto é, medidas da magnetização de materiais cerâmicos fabricados pelo homem primitivo, adquirida ao cozinhar seus artefatos em fornos ou fogueiras. Métodos de laboratório permitem relacionar a magnetização desses materiais com a intensidade do campo geomagnético do lugar, na época da queima da cerâmica.

A fim de poder comparar resultados de várias procedências, os dados de intensidade foram utilizados para calcular o momento do dipolo equivalente. A figura 4.6 mostra a variação do momento do dipolo nos últimos 10.000 anos. O campo tem decrescido, desde aproximadamente 2500 anos atrás, quando passou por um 
máximo, e antes estava crescendo, há aproximadamente 6500 anos atrás, quando passou por um mínimo. Do mínimo ao máximo, o momento do dipolo quase dobrou.

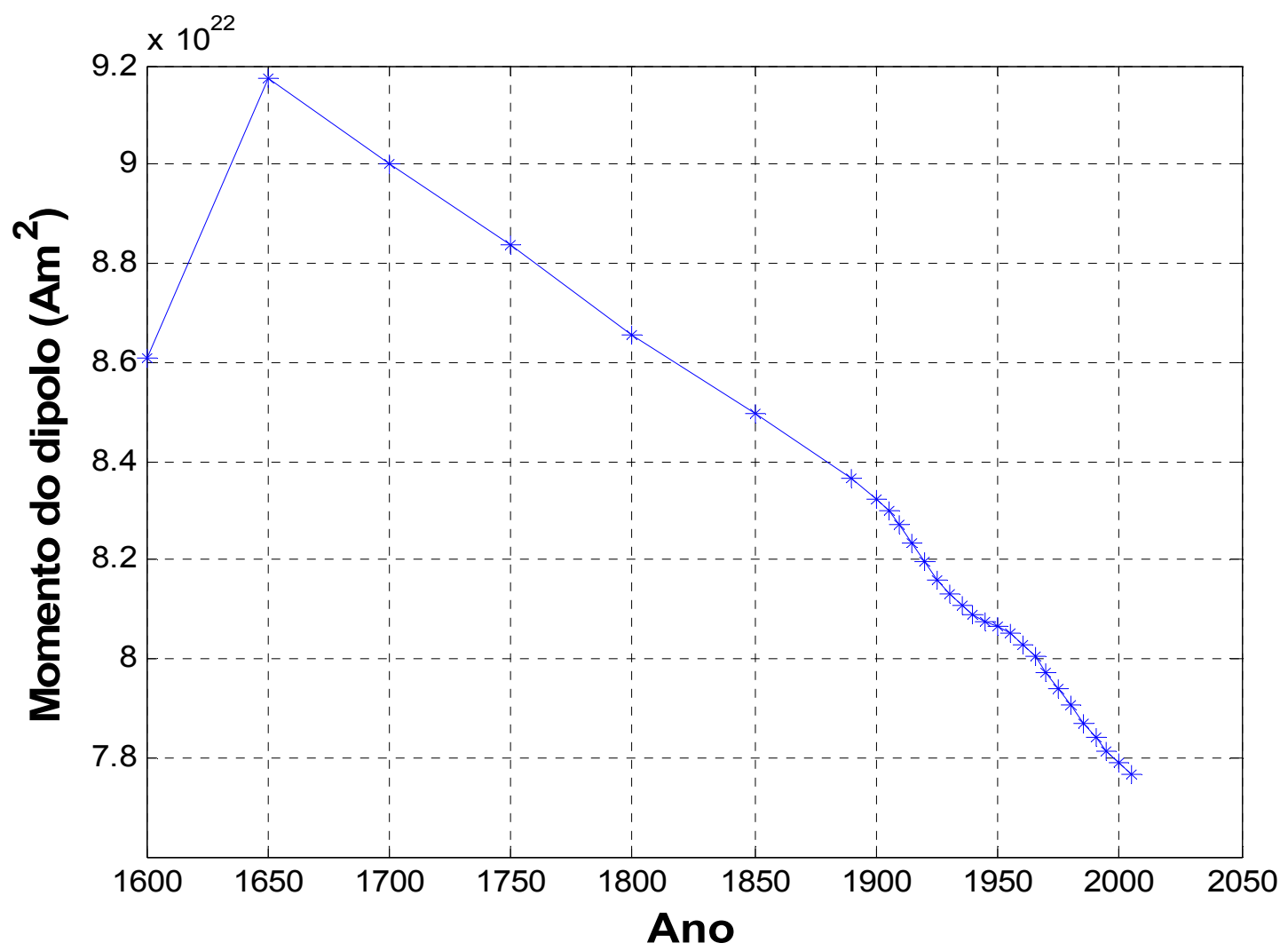

Figura 4.5: Variação do momento dipolar de 1600 a 2005 considerando os coeficientes de Gauss $g_{1}^{0}$, $g_{1}^{1}$ e $h_{1}^{1}$.

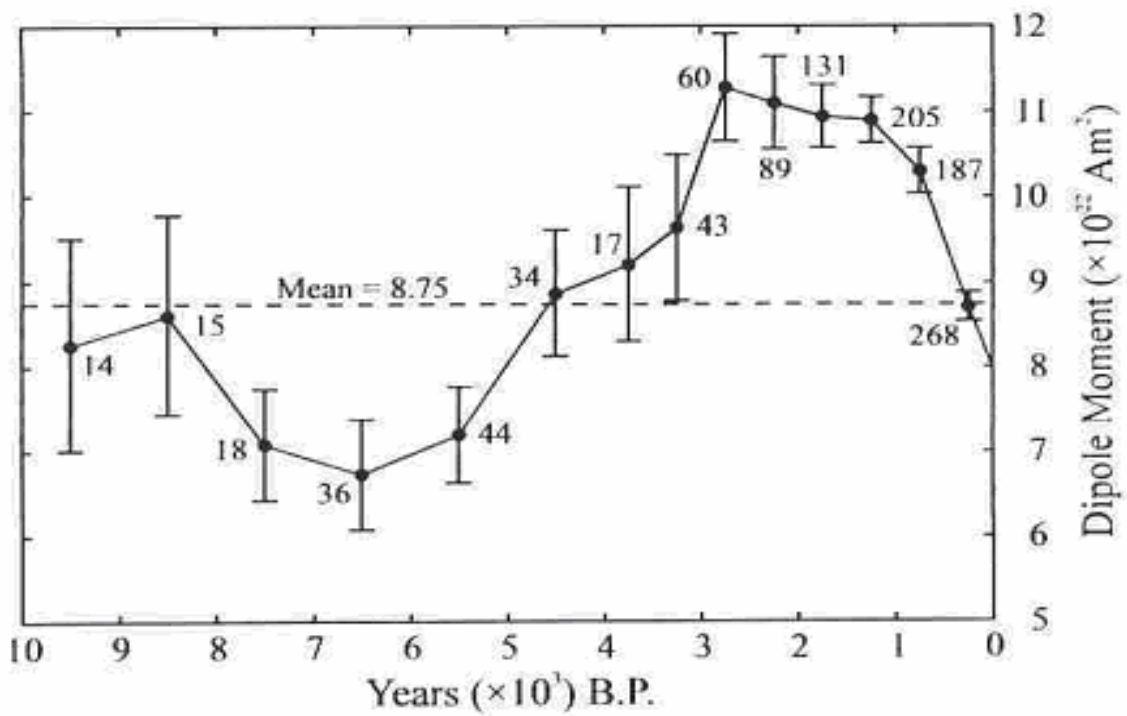

Figura 4.6: Momento do dipolo em função do tempo obtido em intervalos médios de 500 e 1000 anos. A barra de erros mostra um nível de confiança de 95\% (compilado de Merrill et al., 1998). 
Com isto, verifica-se que a escala de tempo dos observatórios não é adequada para conhecer essas variações de intensidade do campo. Para os últimos 150 anos, o dipolo parece ter lentamente mudado para Oeste em cerca de 0,05\%ano a 0,1\%ano, no ângulo azimutal, mas não houve movimento progressivo no ângulo polar.

Barraclough (1974) analisou o campo desde 1600. As estimativas das posições do pólo Norte mostram que o campo dipolar derivou para Oeste a uma taxa de $0,08^{\circ}$ por ano desde 1600 e mudou sua latitude a uma taxa de $0,01^{\circ}$ por ano.

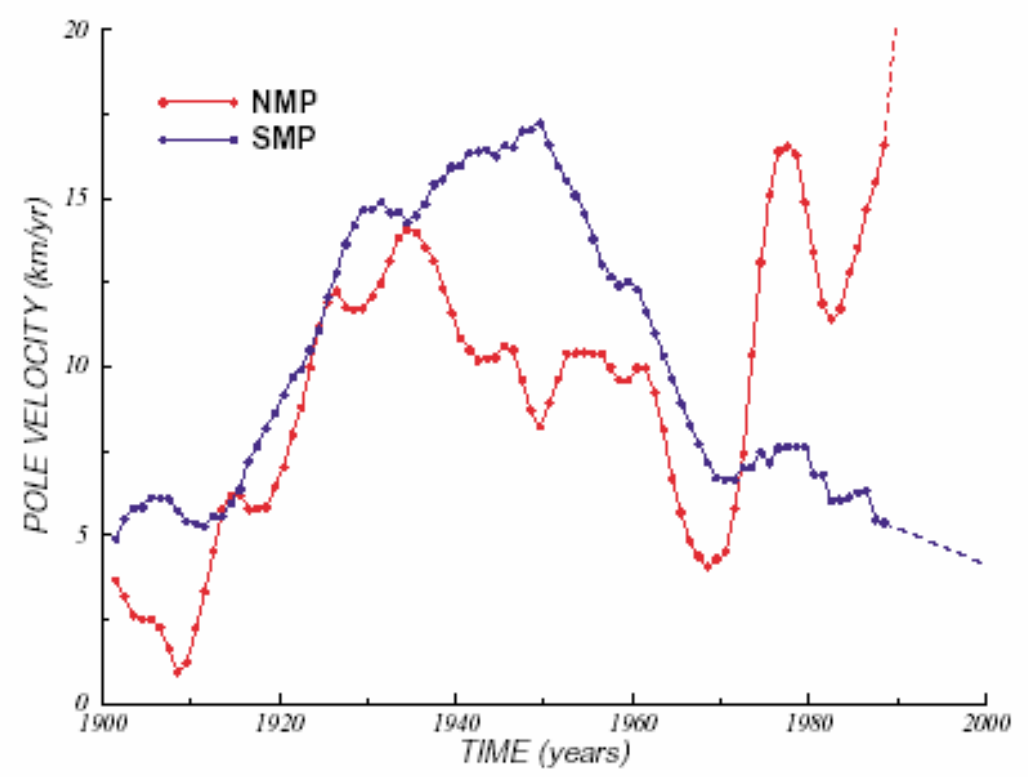

Figura 4.7: Velocidades de deslocamento dos pólos Norte e Sul obtidos através dos modelos do campo geomagnético para o período de 1900 a 2000. A linha em vermelho é a curva do pólo Norte magnético e a curva em azul o pólo Sul magnético (compilado de Mandea e Dormy, 2003).

Mandea e Dormy (2003) analisaram o comportamento assimétrico dos pólos de mergulho (dip poles) para o último século. Os resultados mostraram que a velocidade de deslocamento do pólo Norte magnético praticamente dobrou nos últimos 30 anos. A figura 4.7 mostra as velocidades dos pólos Norte e Sul com o tempo. Outro resultado importante indica que a posição do pólo Norte magnético é sensível a pequenas mudanças no campo, sendo que sua velocidade é afetada pelos jerks geomagnéticos do último século. 


\section{A geração do campo geomagnético no núcleo externo}

A abordagem deste assunto no trabalho procura mostrar como as principais feições do campo na superfície podem ser produzidas. Serão discutidos também alguns dos principais modelos de geração do campo, visando saber como eles descrevem a formação de anomalias observadas na superfície.

\subsection{Introdução}

O campo geomagnético é um campo magnético, portanto gerado por correntes elétricas, neste caso, no núcleo da Terra. Atualmente está bem estabelecido que o núcleo líquido da Terra é formado, fundamentalmente, por ferro e por uma fração de níquel, no estado líquido, além de elementos menos densos na sua composição. Assim, uma vez que a variação da temperatura no interior da Terra impede que se considere a possibilidade da existência de magnetização permanente, foram-se estabelecendo modelos de dínamo para a geração do campo geomagnético.

Um gerador elétrico ou dínamo é um aparelho que gera correntes elétricas através do movimento de materiais condutores na presença de um campo magnético. Muitos aspectos essenciais dos modelos de dínamo podem ser resumidos da seguinte forma: a energia magnética é produzida por conversão de energia mecânica, a partir de um campo magnético inicial. Quando este campo é gerado pelas próprias correntes é chamado de dínamo auto-excitado ou dínamo auto-sustentado. Para aumentar a energia magnética gerada pelo dínamo é necessário aumentar o momento que mantém a rotação, permitindo então a remoção do campo inicial.

O modelo mais simples de dínamo proposto é o chamado Dínamo de Disco, ou Disco Homopolar, sugerido por Larmor em 1917 e formalizado por Bullard em 1955, e que pode ser utilizado para ilustrar os aspectos físicos mais importantes dos modelos. As equações apropriadas que governam o sistema são: 


$$
\begin{aligned}
& L \frac{d I}{d t}+R I=M \Omega I \quad \text { (parte elétrica) } \\
& C \frac{d \Omega}{d t}=\mathrm{G}-M I^{2} \quad \text { (parte mecânica) }
\end{aligned}
$$

onde $L$ é a auto-indutância do circuito, $R$ a resistência do circuito, $M$ a indutância mútua entre a espira e a periferia, $I$ é a corrente, $\Omega$ é a velocidade angular, $t$ é o tempo, $C$ é o momento de inércia do disco e $\mathrm{G}$ é o momento do binário que gira o disco.

As equações (5.1) e (5.2) podem ser solucionadas em termos de $I$ e $\Omega$. A magnitude do campo magnético resultante pode ser facilmente encontrada desde que $I$ seja obtido para uma geometria particular escolhida.

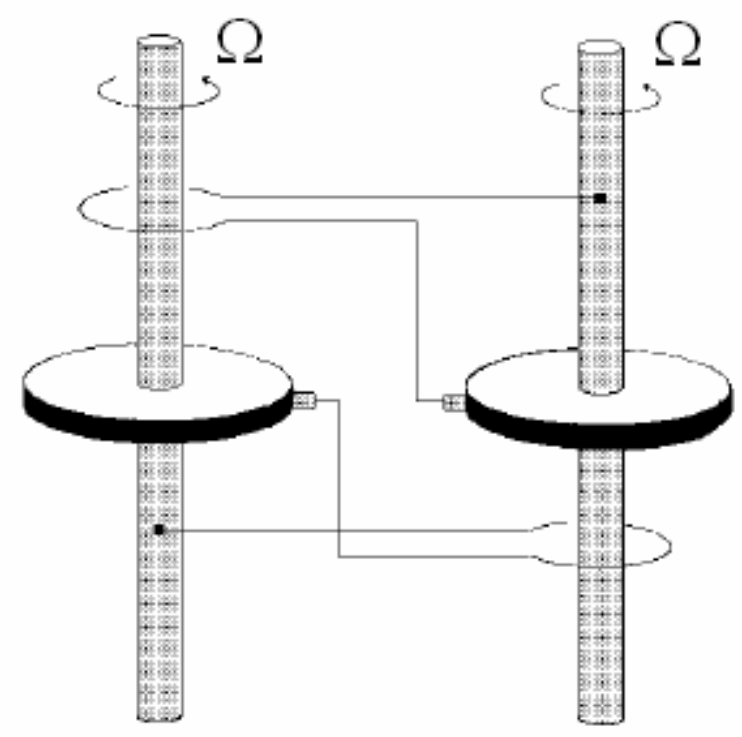

Figura 5.1: Dínamo duplo de Rikitake.

Cálculos mostraram que o dínamo de um único disco não era suficiente para produzir reversões do campo, a menos que a direção da rotação fosse revertida aplicando um torque externo de sinal oposto. Porém, um dínamo com dois discos acoplados entre si resolveu este problema (figura 5.1). Alterações freqüentes nos torques aplicados aos discos resultam em muitas variações de campo, inclusive reversões [RIKITAKE, 1966]. Além disso, os modelos de disco podem produzir reversões caóticas que exibem muitas das propriedades observadas nos registros de reversão da superfície da Terra. Entretanto, as analogias deste modelo com o 
núcleo da Terra não são boas. No caso do núcleo, a energia mecânica está associada com movimentos do fluido. Pode-se imaginar o núcleo como sendo um conjunto de vários dínamos funcionando ao mesmo tempo e diferentes dos Dínamos de Disco.

Apesar de que o modelo do Dínamo de Disco tenha sido importante para a teoria do dínamo terrestre, muitos modelos surgiram com o intuito de se aproximar mais do campo produzido e foram estabelecidas teorias apropriadas para a descrição da geração do campo em termos de movimentos do fluido e dos parâmetros do núcleo.

\subsection{O problema do geodínamo}

O processo de geração do CMT pela ação de um dínamo auto-sustentado no fluido do núcleo da Terra é chamado de geodínamo.

Os modelos de geodínamos mais utilizados baseiam-se não em análogos eletromecânicos semelhantes ao Dínamo de Disco, mas sim na resolução analítica e numérica de um conjunto de equações que governam a mecânica dos fluidos simultaneamente com equações do eletromagnetismo. A teoria utilizada é a magnetohidrodinâmica (MHD).

As equações que são utilizadas nos dínamos MHD são derivadas das leis de conservação da mecânica de fluidos, equações de Maxwell e a lei de Ohm do eletromagnetismo. O pressuposto magnetohidrodinâmico, é de que $\partial \mathbf{D} / \partial t=0$ e que o fluido é geralmente considerado como sendo incompressível, isto é, $\nabla \cdot \mathbf{v}=0$.

As forças de empuxo, que requerem compressibilidade, ainda assim conduzem a fenômenos como a convecção mas são incorporadas na aproximação de Boussinesq: o fluido é considerado como incompressível exceto para a expansão térmica.

A solução simultânea das equações (5.3) a (5.12), utilizando condições iniciais e de contorno apropriadas é conhecida como o problema do geodínamo. Contudo, muitas simplificações são feitas para solucionar uma parte do problema e mesmo assim a solução requer consideráveis análises matemáticas e intensos cálculos numéricos. 


$$
\begin{aligned}
& \nabla \times \mathbf{B}=\mu_{0}\left(\mathbf{J}+\frac{\partial \mathbf{D}}{\partial t}\right) \\
& \nabla \times \mathbf{E}=-\frac{\partial \mathbf{B}}{\partial t} \\
& \nabla \cdot \mathbf{E}=\rho_{e} \\
& \nabla \cdot \mathbf{B}=0 \\
& \mathbf{J}=\sigma \mathbf{E}+\sigma(\mathbf{v} \times \mathbf{B}) \\
& \rho\left(\frac{\partial}{\partial t}+\mathbf{v} \cdot \nabla\right) \mathbf{v}+2 \rho(\Omega \times \mathbf{v}) \\
& =-\nabla P+\eta \nabla^{2} \mathbf{v}+\frac{1}{3} \eta \nabla(\nabla \cdot \mathbf{v})-\rho \nabla \phi_{g}+\mathbf{J} \times \mathbf{B} \\
& \nabla \cdot(\rho \mathbf{v})+\frac{\partial \rho}{\partial t}=0 \\
& \nabla^{2} \phi_{g}=4 \pi G \rho \\
& \frac{\partial T}{\partial t}=\kappa \nabla^{2} T+(\nabla \kappa \cdot \nabla T)-v \cdot \nabla T+\varepsilon \\
& \rho=f(P, T, B)
\end{aligned}
$$$$
\text { Lei de Ampère }
$$

Equação de Navier-Stokes

Equação da continuidade

Equação de Poisson

Equação generalizada do calor

Equação de estado

Onde: B : campo magnético

$\mathbf{J}$ : corrente elétrica

D : corrente de deslocamento

$\mathbf{E}$ : campo elétrico

$\mathbf{v}$ : velocidade

$t$ : tempo

$\rho_{e}$ : densidade de carga elétrica

$\sigma$ : condutividade elétrica $\eta$ : viscosidade

$\rho:$ densidade do material

$T$ : temperatura

$P$ : pressão

$G$ : constante gravitacional

$\phi_{g}:$ potencial gravitacional

$\varepsilon$ : termo da fonte de calor

$\kappa$ : difusividade térmica

Uma das equações mais importantes no problema do geodínamo, pode ser derivada da equação (5.3) com a equação (5.7):

$$
\nabla \times \mathbf{B}=\sigma \mathbf{E}+\sigma(\mathbf{v} \times \mathbf{B})
$$


então, aplicando o rotacional em ambos os lados da equação e usando as equações (5.6) e (5.7), obtém-se a equação de indução magnética:

$$
\frac{\partial \mathbf{B}}{\partial t}=\frac{1}{\sigma \mu} \nabla^{2} \mathbf{B}+\nabla \times(\mathbf{v} \times \mathbf{B})
$$

quando $\mathbf{v}=0$ esta equação se reduz a equação difusão de $\mathbf{B}$. Na ausência de uma velocidade $\mathbf{v}$ para o campo, um campo magnético dado decai de acordo com o primeiro termo do lado direito da equação. O último termo fornece a interação do campo de velocidade com o campo magnético. Esta interação pode causar aumento ou colapso do campo, dependendo da natureza do campo de velocidade. A equação (5.14) não é solucionada de uma forma fechada, mas necessita de outras aproximações para uso em expansões e cálculos numéricos.

Nos modelos de dínamos cinemáticos, $\mathbf{v}$ é especificado de uma forma razoável (geralmente não tem fontes ou sorvedouros e é continuamente diferenciável), junto com um campo magnético inicial $\mathbf{B}_{\mathbf{0}}$. O problema é determinar se o campo de $\mathbf{v}$ pode suportar um campo $\mathbf{B}$ que não decai a zero quando o tempo tende para o infinito. Um subconjunto de problemas do dínamo cinemático envolve a procura de soluções do dínamo de estado estacionário (steady-state), isto é, soluções do tipo $\partial \mathbf{B} / \partial t=0$. O problema do dínamo cinemático não requer que o campo de velocidades satisfaça a equação de Navier-Stokes. Desta forma, um campo magnético que se aproxima do infinito, quando o tempo tende ao infinito é uma solução aceitável para um problema de dínamo cinemático. Um outro subconjunto dos modelos de dínamos cinemáticos envolve dínamos rápidos (fast dynamos), em que a difusão do campo magnético é desprezada para investigar a máxima taxa de aumento do campo através do processo de dínamo.

O problema de solucionar simultaneamente as equações (5.8) e (5.14) representa o problema do dínamo hidrodinâmico. Este problema é solucionado supondo que a força do corpo, proporcional a $(\mathbf{J} \times \mathbf{B})$ na equação (5.8), é uma perturbação. Então, pode-se resolver a equação de Navier-Stokes para uma determinada geometria, condições iniciais e de contorno desprezando o termo $(\mathbf{J} \times \mathbf{B})$. A solução para o campo de velocidade, $\mathbf{v}$, é então substituído na equação de indução (5.14), que é solucionada para uma determinada condição inicial e de 
contorno relativa a um campo magnético. Esta solução provém uma estimativa para B . Com isto é possível retornar para a equação de Navier-Stokes e usar este B no termo de força do corpo magnético e solucionar um novo $\mathbf{v}$. Este procedimento de iteração pode ser continuado ad infinitum (ilimitado) ou até o tempo computacional tornar-se também dispendioso. Para este procedimento ser válido, é necessário demonstrar que o procedimento de iteração conduz para uma convergência de $\mathbf{v}$ e B .

Esta aproximação requer uma força de Lorentz $(\mathbf{J} \times \mathbf{B})$ pequena relativa à força de Coriolis, $2(\Omega \times \mathbf{v})$, e o dínamo resultante é chamado de modelo de campo fraco. O modelo de campo forte implica que a magnitude da força de Lorentz seja igual ou maior que a força de Coriolis. A magnitude da força de Lorentz com relação à força de Coriolis, é conhecida como número de Elsasser, $\Lambda$, e é dada por:

$$
\Lambda=\frac{\mu B^{2}}{\rho k_{m} \omega}
$$

onde $k_{m}=1 /(\mu \sigma)$. Defensores da teoria do dínamo argumentam que os modelos de campo forte são necessários para descrever o campo terrestre, e portanto, que $\Lambda$ é igual ou maior que 1. $\Lambda$ é igual a 1 quando $B$ é aproximadamente 3 vezes o campo dipolar na interface manto-núcleo [MERRILL, et al., 1998].

Para compreensão física dos termos da equação (5.14), deve-se considerar separadamente os dois termos do lado direito da equação. O primeiro termo do lado direito é nulo para o caso hipotético de condutividade infinita. Neste caso, pode-se demonstrar que nenhuma f.e.m. (força eletromotriz) induzida ocorre num condutor perfeito, movendo-se num campo magnético. Este teorema é chamado de teorema de congelamento do campo ou hipótese do fluxo congelado (frozen flux). Isto possibilita entender como um condutor em movimento pode gerar ou colapsar um campo magnético. No caso de condutividade infinita, a equação (5.14) reduz-se:

$$
\frac{\partial \mathbf{B}}{\partial t}=\nabla \times(\mathbf{v} \times \mathbf{B})
$$

Considerando uma área, $\mathbf{S}$, fechada por uma linha $\mathbf{L}$ num fluido em movimento e considerando $\mathbf{n}$ um vetor normal a $\mathbf{S}$, temos que: 


$$
\int_{\mathbf{S}} \frac{\partial \mathbf{B}}{\partial t} \cdot \mathbf{n} d \mathbf{S}=\int_{\mathbf{S}} \nabla \times(\mathbf{v} \times \mathbf{B}) \cdot \mathbf{n} d \mathbf{S}=\int_{\mathbf{L}}(\mathbf{v} \times \mathbf{B}) \cdot d \mathbf{L}=-\int_{\mathbf{L}} \mathbf{B}(\mathbf{v} \times d \mathbf{L})
$$

neste caso, $(\mathbf{v} \times d \mathbf{L})$ é o incremento de área perpendicular a $\mathbf{L}$ que é varrido num intervalo de tempo $d t$. Portanto,

$$
\int_{\mathbf{S}} \frac{\partial \mathbf{B}}{\partial t} \cdot \mathbf{n} d \mathbf{S}=\int_{\mathbf{L}} \mathbf{B}(\mathbf{v} \times d \mathbf{L})=\frac{d}{d t} \int_{\mathbf{S}} \mathbf{B} \cdot \mathbf{n} d \mathbf{S}=0
$$

Desta forma, o fluxo magnético $\phi$, é definido como:

$$
\phi=\int_{\mathbf{S}} \mathbf{B} \cdot \mathbf{n} d \mathbf{S}=\mu_{0} \int_{\mathbf{S}} \mathbf{B} \cdot \mathbf{n} d \mathbf{S}
$$

e a f.e.m. induzida é igual a $-d \phi / d t$, portanto, as equações implicam que:

$$
\frac{d \phi}{d t}=0
$$

isso é interpretado como sendo referente ao fato de que o fluxo é congelado dentro de um condutor perfeito. E por causa disso o campo magnético é algumas vezes descrito como sendo "congelado internamente" em um condutor.

Se apenas o primeiro termo do lado direito da equação (5.14) está presente, a equação de indução do campo magnético é reduzida à equação de difusão do vetor. Isto explica porque $k_{m} \equiv(\sigma \mu)^{-1}$ é freqüentemente chamada de difusividade magnética. Isso ocorre se o campo de velocidades for nulo e neste caso o campo magnético poderá decair com o tempo. Para o núcleo, os dois termos do lado direito da equação estão presentes. Desta forma, poderá ocorrer tanto a difusão quanto a formação (ou colapso) do campo devido à interação de $\mathbf{v}$ com $\mathbf{B}$. A razão entre o segundo termo pelo primeiro termo do lado direito da equação (5.14) fornece uma estimativa do tempo de decaimento do campo. Um número adimensional $R_{m}$ (chamado de número de Reynolds magnético, por analogia com o número de Reynolds da mecânica de fluidos), caracteriza tal estimativa: 


$$
\frac{\nabla \times(\mathbf{v} \times \mathbf{B})}{k_{m} \nabla^{2} \mathbf{B}} \sim \frac{v L}{k_{m}} \equiv R_{m}
$$

onde $L$ é uma dimensão de comprimento apropriada. Pode-se notar que $R_{m}>1$ é uma condição necessária, mas não suficiente para que o dínamo seja autosustentado. Para números de Reynolds pequenos, o termo de decaimento dominará, e então não se pode ter um dínamo auto-sustentável. A questão de quais valores usar para $v$ e, para $L$, é difícil porque geralmente mais de uma escala de comprimento torna-se necessária.

Uma equação similar à equação (5.14) pode ser derivada para a vorticidade fluida, tomando-se o rotacional da equação de Navier-Stokes. Uma vez que as forças magnéticas e gravitacionais são conservativas (o rotacional delas é nulo), esta operação fornece a seguinte equação para a vorticidade $(\Omega=\nabla \times \mathbf{v})$ :

$$
\frac{\partial \Omega}{\partial t}=\frac{\eta}{\rho} \nabla^{2} \Omega+\nabla \times(\mathbf{v} \times \Omega)
$$

esta equação é da mesma forma da equação (5.14), com $\eta / \rho$ sendo semelhante a $k_{m}$ e, $\Omega$ a B . O entendimento sobre a origem do CMT pode ser obtido a partir de analogias com a mecânica de fluidos. A semelhança entre as equações (5.14) e (5.22) mostra que $k_{m}$ pode ser chamada também de viscosidade magnética. Entretanto, há limitações pois as condições de contorno para a interface mantonúcleo são diferentes para $\mathbf{B}$ e $\Omega$.

$\mathrm{Na}$ ausência de um campo de velocidades, a equação (5.14) fica da forma:

$$
\frac{\partial \mathbf{B}}{\partial t}=\frac{1}{\sigma \mu} \nabla^{2} \mathbf{B}=k_{m} \nabla^{2} \mathbf{B}
$$

esta é a equação do vetor de difusão para o campo magnético. O campo decai a $1 / e$ de sua intensidade inicial para um tempo $\tau$. Uma análise dimensional pode ser usada para obter uma estimativa aproximada deste tempo. Considerando $t \sim \tau$ e $\nabla^{2} \sim 1 / L^{2}$, onde $L$ têm aproximadamente $3 \times 10^{6} \mathrm{~m}$ para o raio do núcleo, então: 


$$
\tau \cong \frac{L^{2}}{k_{m}} \cong \frac{\left(3 \times 10^{6}\right)}{2} \mathrm{~S}
$$

o tempo de decaimento livre estimado por este método é da ordem de 100.000 anos. Entretanto, cálculos usando geometria esférica indicam que o tempo de decaimento livre da parte dipolar do campo é da ordem de 10.000 a 30.000 anos; e a parte nãodipolar ainda menor [MERRILL et al., 1998]. Contudo, o problema é mais complicado do que estas simplificações porque é um procedimento com um vetor de difusão para um caso geral.

\subsubsection{Os efeitos $\alpha$ e $\omega$ na teoria do Geodínamo}

\subsubsection{O Efeito $\alpha$}

As evidências observacionais e teóricas sugerem que os movimentos do núcleo são complexos e que correlações no campo de velocidade em dimensões moderadas podem ser pequenas ou desprezíveis. Um passo importante nos chamados dínamos turbulentos é simplesmente aplicar aproximações estatísticas para obter uma aproximação do campo médio (mean-field) do CMT.

Todos os modelos de dínamos turbulentos dependem do chamado efeito $\alpha$ para aumentar o campo magnético. A lei de Ohm é escrita em termos de uma densidade de corrente $\mathbf{J}$ :

$$
\mathbf{J}=\sigma \mathbf{E}+\sigma(\mathbf{v} \times \mathbf{B})
$$

onde $\mathbf{E}$ é um campo elétrico externamente aplicado. Um campo elétrico interno é definido por:

$$
\mathbf{E}_{i} \equiv \mathbf{v} \times \mathbf{B}
$$

Supondo que um sistema parcialmente turbulento seja descrito por $\mathbf{v}=\mathbf{v}_{0}+\mathbf{v}^{\prime}$ e $\mathbf{B}=\mathbf{B}_{0}+\mathbf{B}^{\prime}$, onde $\mathbf{v}_{0}$ e $\mathbf{B}_{0}$ denotam a parte constante e, $\mathbf{v}^{\prime}$ e $\mathbf{B}^{\prime}$ indicam a parte flutuante do campo. A média do campo interno é então:

$$
\left\langle\mathbf{E}_{\mathbf{i}}\right\rangle=\mathbf{v}_{\mathbf{0}} \times \mathbf{B}_{\mathbf{0}}+\left\langle\mathbf{v}^{\prime} \times \mathbf{B}^{\prime}\right\rangle
$$


desde que $\left\langle\mathbf{v}^{\prime}\right\rangle=\left\langle\mathbf{B}^{\prime}\right\rangle=0$. Uma f.e.m. adicional associada com $\mathbf{v}^{\prime} \times \mathbf{B}^{\prime}=\mathbf{E}^{\prime}$ ocorre quando $\mathbf{v}^{\prime}$ e $\mathbf{B}^{\prime}$ estão correlacionados. Pode-se escrever então que:

$$
\mathbf{E}^{\prime}=\alpha \mathbf{B}_{0}
$$

Neste caso o campo elétrico produzido a partir de partes flutuantes dos campos $\mathbf{v}$ e $\mathbf{B}$ está diretamente relacionado através da constante $\alpha$ com o campo constante $\mathbf{B}_{0}$.
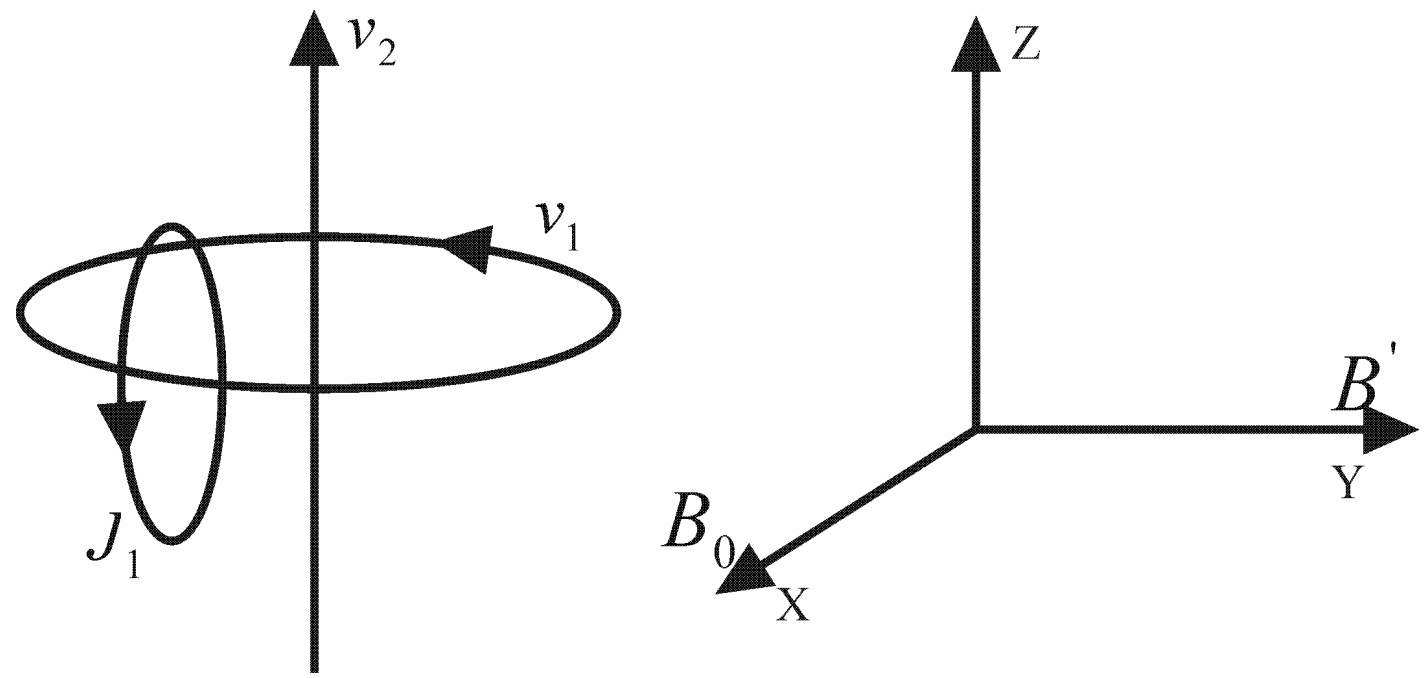

Figura 5.2: llustração do efeito $\alpha$. Modificado de Merrill et al. (1998).

A figura 5.2 mostra (hipoteticamente) como o efeito $\alpha$ pode ocorrer no núcleo. Supondo que $\mathbf{v}^{\prime}=\mathbf{v}_{1}+\mathbf{v}_{2}$, onde $\mathbf{v}_{2}$ é paralelo ao eixo $z, \mathbf{v}_{1}$ representa a rotação em torno de $z, \mathbf{v}^{\prime}$ é a velocidade helicoidal e $\mathbf{B}_{0}$ é uniforme na direção $x$; $\left(\mathbf{v}_{1} \times \mathbf{B}_{0}\right)$ produz a densidade de corrente $\mathbf{J}_{1}$, seguindo o plano perpendicular ao eixo $y$. Associado com $\mathbf{J}_{1}$ deverá haver um campo $\mathbf{B}^{\prime}$ na direção $y$. A interação de $\mathbf{B}^{\prime}$ com $\mathbf{v}_{2}$, produz um campo elétrico $\mathbf{E}^{\prime}$ paralelo a $\mathbf{B}_{0}$, como mostra a equação (5.27).

A equação (5.27) representa o efeito $\alpha$ na teoria dos dínamos turbulentos. Como um campo elétrico médio é produzido num sistema turbulento, análises deste tipo são freqüentemente conhecidas como eletrodinâmica do campo médio. Experimentalmente, um campo elétrico interno pode conduzir uma corrente, e se a corrente interna possui uma geometria adequada poderia reforçar um campo magnético inicial [MERRILL et al, 1998]. 
Entretanto, deve-se notar que uma condição necessária para a presença de um efeito $\alpha$ é a correlação entre vorticidade $(\nabla \times \mathbf{v})$, e a velocidade (isto é, a helicidade $\mathbf{v} \cdot(\nabla \times \mathbf{v}) \neq 0)$. O efeito $\alpha$ é essencialmente um mecanismo no qual a energia turbulenta é convertida em energia elétrica.

\subsubsection{O efeito $\omega$ e a hipótese do dínamo $\alpha \omega$}

A idéia básica do dínamo é de que um campo magnético inicial é alterado através de interações com um campo de velocidades assumido (cinemático) ou derivado (hidromagnético) de maneira que o campo magnético seja reforçado. $\mathrm{Na}$ ausência de um campo de velocidades no núcleo, o campo magnético deveria decair com o tempo. O campo de velocidades interage com o campo magnético através da lei de Lenz. Qualquer tentativa de movimentar um material eletricamente condutor num campo magnético deve induzir no condutor correntes que se opõe a este movimento e estas correntes induzidas devem alterar o campo magnético inicial. Se o condutor não é perfeito, o campo pode difundir dentro e fora do condutor. De fato, isto deve ocorrer porque seria impossível conseguir que as linhas de campo num condutor perfeito atuem primeiro. O processo de movimentar um condutor para intensificar o campo magnético mostra como a energia cinética pode ser convertida em energia de campo magnético [ROBERTS e GUBBINS, 1987].

A figura 5.3 ilustra como o campo magnético inicial, representado por uma simples linha de campo, pode ser alterado pelo movimento condutivo do fluido no núcleo. Em 5.3a, o campo magnético inicial tem uma componente radial $\mathbf{S}_{1}^{0}$ (esta notação refere-se ao vetor de harmônicos esféricos), que é o campo poloidal. E o campo de velocidades toroidal, $\mathbf{T}_{1}^{0}$, produz apenas um movimento simples (a definição de campo toroidal implica que não exista a componente radial). E em 4.3b, o campo toroidal $\mathbf{T}_{1}^{0}$ interage com o campo magnético $\mathbf{S}_{1}^{0}$, gerando um campo magnético toroidal mais complexo, $\mathbf{T}_{2}^{0}$, que possui sinais opostos nos dois hemisférios. Este processo é conhecido como o efeito $\omega$.

Um outro campo de velocidade com a componente radial (poloidal) pode ocorrer a fim de reforçar o campo original, desde que assumindo-se o pressuposto de que a convecção no núcleo exista. A figura 5.4 mostra como o campo toroidal seria afetado por um upwelling de fluido (ascensão de fluido) no hemisfério Norte. 
Uma protuberância ocorre na linha de campo, tendendo a representar um segmento de linha do campo toroidal que se move com o fluido. A força de Coriolis no hemisfério Norte deve agir produzindo uma rotação no sentido anti-horário na região de upwelling do fluido. As linhas de campo se retorcem com esta rotação e um loop de campo magnético poloidal é produzido a cada rotação de $90^{\circ}$.

a)

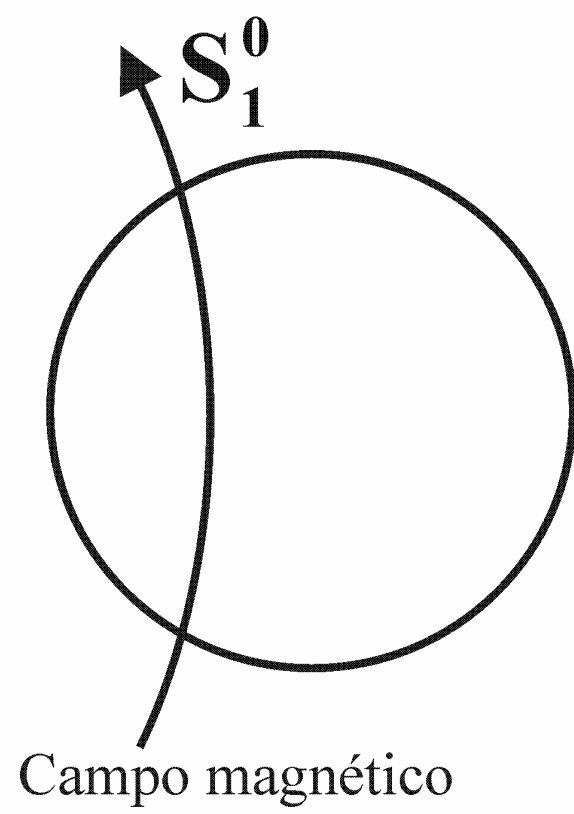

b)

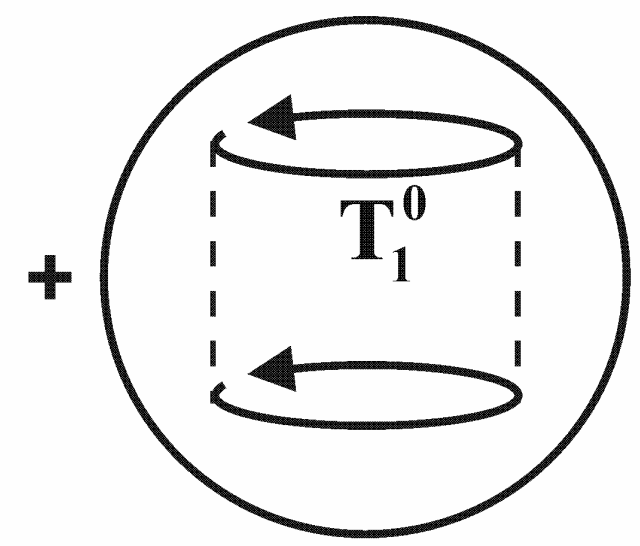

Campo de velocidade
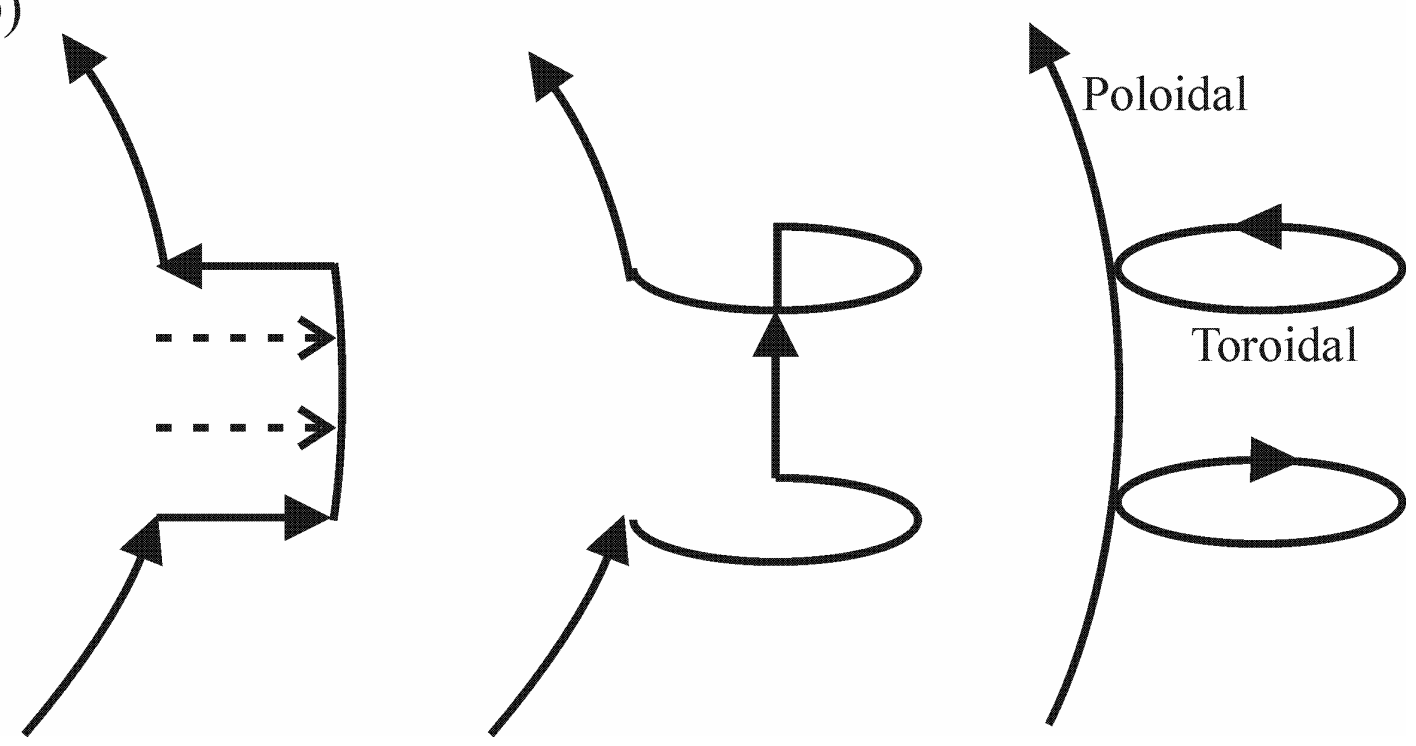

Figura 5.3: Geração de um campo magnético toroidal no núcleo. Em (a), a linha do campo magnético poloidal, $\mathbf{S}_{\mathbf{1}}^{\mathbf{0}}$, atravessa o núcleo da Terra e, um campo de velocidades cilíndrica $\mathbf{T}_{\mathbf{1}}^{\mathbf{0}}$. Em (b), a interação entre os campos magnético e de velocidade, em três períodos sucessivos, sendo que quando o circuito se completa, um novo campo toroidal $\left(\mathbf{T}_{2}^{\mathbf{0}}\right)$ de sinal oposto é gerado. Modificado de Merrill et al. (1998).

As regiões de downwelling (descida de fluxo) produzem loops poloidais de sinal oposto às regiões de upwelling, isto sugere que haja heterogeneidades nestas 
regiões. Este modelo hipotético de dínamo, combinando os efeitos $\alpha$ e $\omega$ é chamado de dínamo $\alpha \omega$.
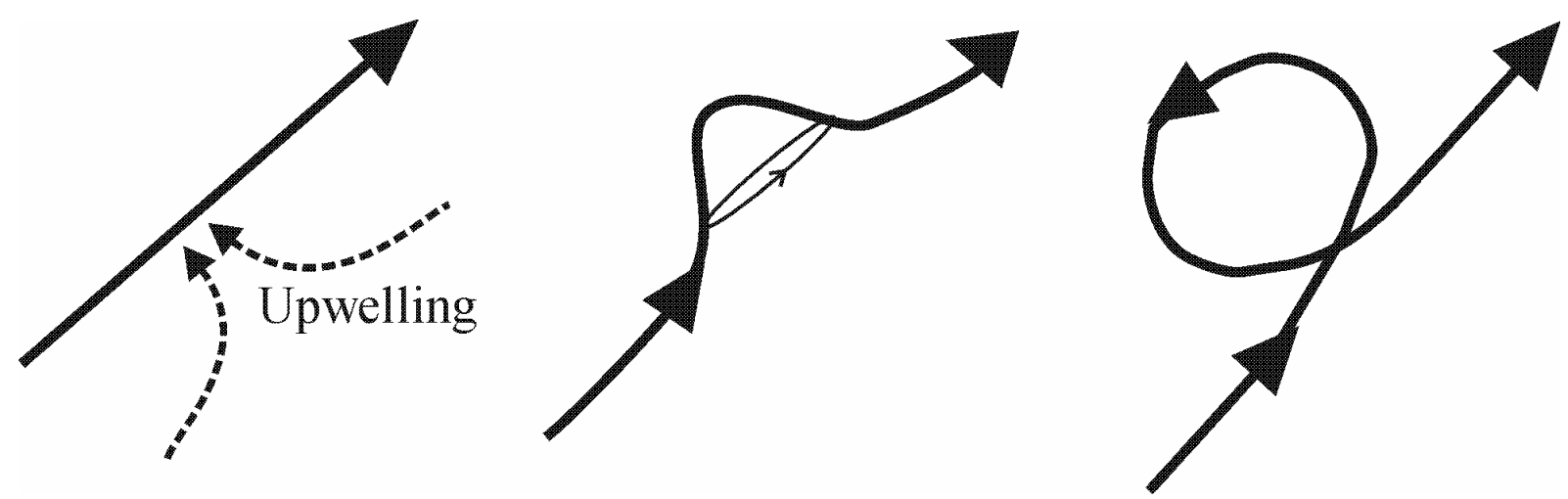

Figura 5.4: Geração de um campo poloidal a partir de um upwelling. Modificado de Merrill et al. (1998).

O campo toroidal nos dínamos pode ser formado por movimentos de pequena escala mais do que por movimentos de grande escala. Isto é, o campo toroidal pode se formar, via efeito $\alpha$ agindo sobre um campo poloidal. Quando um dínamo é formado por este processo, ele é chamado de dínamo $\alpha^{2}$. Em alguns modelos de dínamos os efeitos $\alpha^{2}$ e $\omega$ contribuem para a geração do campo magnético toroidal. Neste caso, o dínamo é chamado de dínamo $\alpha^{2} \omega$.

\subsubsection{Propriedades do núcleo da Terra e números adimensionais}

Nos modelos de geodínamo é importante que se tenha definido os parâmetros a serem utilizados. Em geral, na teoria do dínamo reescreve-se as equações que governam o sistema e as condições de contorno na forma adimensional porque, assim, o sistema sob estudo apresenta um número pequeno de parâmetros adimensionais.

A tabela 5.1 apresenta as principais propriedades do núcleo da Terra e, a tabela 5.2 sintetiza os números adimensionais utilizados nos modelos de geodínamo.

Os parâmetros do primeiro grupo da tabela 5.1 são bem determinados a partir de observações diretas. Os do segundo grupo, são menos conhecidos e determinados a partir de inferências indiretas baseadas nas propriedades de materiais que supostamente constituem o núcleo e que foram extrapoladas para pressões e temperaturas do núcleo. 
Tabela 5.1: Propriedades do núcleo da Terra.

\begin{tabular}{|c|c|c|c|}
\hline Propriedade & Símbolo & Valor & Unidade \\
\hline Densidade & $\rho$ & $9,9-12,2 \times 10^{3}$ & $\mathrm{~kg} \mathrm{~m}^{-3}$ \\
\hline Velocidade de onda $P$ & $v_{P}$ & $9 \times 10^{3}$ & $\mathrm{~m} \mathrm{~s}^{-1}$ \\
\hline Incompressibilidade & $\kappa_{s}$ & $10^{12}$ & $\mathrm{~Pa}$ \\
\hline Pressão & $P$ & $136-329 \times 10^{9}$ & $\mathrm{~Pa}$ \\
\hline Gravidade & $g$ & $10,7-4,4$ & $\mathrm{~m} \mathrm{~s}^{-2}$ \\
\hline Raio do núcleo & $c$ & $3,48 \times 10^{6}$ & $\mathrm{~m}$ \\
\hline Raio do núcleo interno & $r_{i}$ & $1,22 \times 10^{6}$ & $\mathrm{~m}$ \\
\hline Raio da Terra & $a$ & $6,37 \times 10^{6}$ & $\mathrm{~m}$ \\
\hline Viscosidade cinemática & $v$ & $10^{-6}$ & $\mathrm{~m} \mathrm{~s}^{-2}$ \\
\hline Condutividade elétrica & $\sigma$ & $4 \times 10^{5}$ & $S \mathrm{~m}^{-1}$ \\
\hline Condutividade térmica & $k$ & $6 \times 10^{-6}$ & $\mathrm{~J} \mathrm{~m}^{-1} \mathrm{~s}^{-1} \mathrm{~K}^{-1}$ \\
\hline Calor específico a pressão constante & $c_{P}$ & 840 & $\mathrm{~J} \mathrm{~kg}^{-1} \mathrm{~K}^{-1}$ \\
\hline Gradiente de temperatura & $\beta$ & $1 \times 10^{-12}$ & $\mathrm{~K} \mathrm{~m}^{-1}$ \\
\hline Temperatura & $T$ & 5000 & $\mathrm{~K}$ \\
\hline Coeficiente de expansão térmica & $\alpha$ & $10^{-5}$ & $\mathrm{~K}^{-1}$ \\
\hline Difusividade térmica & $\kappa$ & $5 \times 10^{-6}$ & $m^{2} s^{-1}$ \\
\hline Difusividade magnética & $\eta$ & 2 & $m^{2} s^{-1}$ \\
\hline
\end{tabular}

Tabela 5.2: Números adimensionais

\begin{tabular}{|c|c|c|c|}
\hline Nome & Símbolo & Definição & Razão \\
\hline Número de Rayleigh & $R_{a}$ & $\alpha \beta_{0} g_{0} R_{0}^{4} / v \kappa$ & Empuxo pela viscosidade \\
\hline Número de Ekman & $E$ & $v / 2 \Omega R_{0}^{2}$ & $\begin{array}{l}\text { Viscosidade pela força de } \\
\text { Coriolis }\end{array}$ \\
\hline Número de Prandtl & $\operatorname{Pr}$ & $v / \kappa$ & $\begin{array}{l}\text { Difusão viscosa pela difusão } \\
\text { térmica }\end{array}$ \\
\hline Número magnético de Prandtl & $P m$ & $v / \eta$ & $\begin{array}{l}\text { Difusão viscosa pela difusão } \\
\text { magnética }\end{array}$ \\
\hline Número de Taylor & $T a$ & $\left(2 \Omega R_{0}^{2} / v\right)^{2}$ & $\begin{array}{l}\text { Força de Coriolis pela força de } \\
\text { viscosidade }\end{array}$ \\
\hline Número de Rayleigh modificado & $R a_{M}$ & $\alpha \beta_{0} g_{0} R_{0}^{2} / 2 \Omega \kappa$ & Empuxo pela força de Coriolis \\
\hline Número magnético de Ekman & $E_{M}$ & $\eta / 2 \Omega R_{0}^{2}$ & $\begin{array}{l}\text { Escala de tempo magnético pelo } \\
\text { período de rotação }\end{array}$ \\
\hline Taxa de difusividade & $q$ & $\kappa / \eta$ & $\begin{array}{l}\text { Difusão térmica pela difusão } \\
\text { magnética }\end{array}$ \\
\hline Número magnético de Reynolds & $R_{M}$ & $V_{0} R_{0} / \eta$ & $\begin{array}{l}\text { Escala de tempo cinética pela } \\
\text { difusão maqnética }\end{array}$ \\
\hline Número de Elsasser & $\Lambda$ & $B_{0}^{2} / 2 \Omega \eta \mu_{0} \rho_{0}$ & $\begin{array}{l}\text { Força de Lorentz pela força de } \\
\text { Coriolis }\end{array}$ \\
\hline Número de Rossby & $R_{0}$ & $V_{0} / \Omega R_{0}$ & Inércia pela força de Coriolis \\
\hline
\end{tabular}

Na tabela 5.2, $V_{0}$ é a velocidade de fluxo e $B_{0}$ é a intensidade do campo no núcleo. Estas estimativas assumem valores apropriados para difusão molecular e, ignoram a possibilidade de núcleo turbulento. A turbulência é freqüentemente modelada para valores aumentados de difusividades. Este procedimento é considerado uma aproximação grosseira, mas que reflete algumas feições dos 
efeitos da turbulência. As difusividades térmica e viscosa turbulentas no núcleo podem ser muitas ordens de magnitude maiores do que as difusões moleculares [GUBBINS e ROBERTS, 1987].

\subsection{Os modelos de geração do campo}

Os atuais modelos de geodínamo são capazes de reproduzir uma fração importante dos fenômenos observados na superfície da Terra, como por exemplo, o caráter predominantemente dipolar, a variação secular e as reversões do campo. Esses modelos são comparados com as descrições do campo continuado para a interface manto-núcleo e com os resultados obtidos de estudos arqueomagnéticos e paleomagnéticos.

Modelos de geração bi e tridimensionais foram construídos com o objetivo de descrever as principais feições do campo na superfície. A proliferação de modelos tem, entretanto, causado alguns resultados aparentemente conflitantes. Isto pode ser parcialmente atribuído às diferentes formas como os grupos de modelagem têm modelado o núcleo, normalizado as equações, definido os parâmetros adimensionais, escolhido as condições de contorno e selecionado as fontes de energia [KONO e ROBERTS, 2002].

Embora existam grandes diferenças na maneira pela qual os modelos são definidos, os campos magnéticos gerados têm similaridades. Os campos são dominados pelo dipolo axial e a convecção ocorre na forma de cilindros, dentro dos quais o efeito $\alpha$ distorce as linhas de campo toroidal para geração de campo poloidal. As condições de contorno que definem o fluxo de energia influenciam bastante, pois alteram a freqüência e a forma das reversões bem como a razão nas taxas de intensidade dos momentos dipolar e não-dipolar.

Os modelos de geração tridimensionais requerem soluções não-lineares para as equações da MHD, que determinam simultaneamente o campo magnético e os movimentos do fluido. Essas soluções necessitam de suporte computacional avançado.

A tabela 5.3 relaciona nove grupos que realizaram simulações completamente tridimensionais e modelos não-lineares do CMT [KONO e ROBERTS, 2002], com as respectivas publicações. 
Tabela 5.3: Grupos de simulações tridimensionais do geodínamo (compilado de Kono e Roberts, 2002).

\begin{tabular}{|c|c|}
\hline Grupo & Publicações \\
\hline KS95 & $\begin{array}{l}\text { Kageyama et al. (1995), Kageyama e Sato (1997a, 1997b, 1997c), e } \\
\text { Ochi et al. (1999) }\end{array}$ \\
\hline GR95 & Glatzmaier e Roberts (1995a, 1995b) \\
\hline GR96 & $\begin{array}{l}\text { Glatzmaier e Roberts (1996a, 1996b, 1997), Coe et al. (2000), Roberts } \\
\text { e Glatzmaier (2000a) e Glatzmaier et al. (1999) }\end{array}$ \\
\hline KB97 & Kuang e Bloxham (1997, 1998, 1999), e Bloxham (2000a, 2000b) \\
\hline KAK97 & $\begin{array}{l}\text { Kida et al. (1997), Kida e Kitauchhi (1998a, 1998b), Kitauchi e Kida } \\
\text { (1998), e Ishihara e Kida (2000) }\end{array}$ \\
\hline COG98 & $\begin{array}{l}\text { Christensen et al. (1998, 1999, 2001), Olson et al. (1999), e Kutzner e } \\
\text { Christensen (2000) }\end{array}$ \\
\hline SK99 & Sakaruba e Kono (1999) e Kono et al. (2000b) \\
\hline GBT99 & Grote et al. (1999, 2000a, 2000b) \\
\hline KMH99 & Katayama et al. (1999) \\
\hline
\end{tabular}

A figura 5.5 mostra a relação entre os dois números adimensionais que caracterizam os modelos de geodínamo: o número de Rayleigh $(R a)$ e o número de Ekman ( $E$ ). Neste caso, a abscissa mede a velocidade de rotação (ou seja, quanto menor o $E$ maior a rotação), enquanto a ordenada fornece a quantidade de energia disponível para o sistema que impulsiona a convecção (logo, quanto maior o $R a$ mais impulsionado é o sistema). Para comparação, a relação $R a-E$ para o começo da convecção numa esfera em rotação é mostrada para diferentes números de Prandtl $(P r)$ pelas linhas sólidas e pontilhadas.

Pelo gráfico da figura 5.5 , nota-se que a relação $R a-E$ para os diferentes modelos de geração são bastantes diferentes do valor que seria apropriado para a Terra, e que nenhuma simulação, com exceção ao modelo GR95, é fortemente impulsionada, todos os modelos apresentam $R a<100$ vezes o valor crítico para o qual a convecção torna-se possível.

No entanto, dois modelos de geração tridimensionais conseguiram, com êxito, descrever bem o campo observado na superfície. Em 1995, Kageyama et al. (1995) e Glatzmaier e Roberts (1995a, 1995b) publicaram resultados de simulações de dínamos completamente tridimensionais. O primeiro deles forneceu informações sobre os processos do campo gerado: os mecanismos de geração do campo dipolar, a estrutura do movimento de convecção e os processos de geração do campo toroidal. O segundo foi projetado levando em conta as principais características do CMT, tendo alcançado resultados satisfatórios, pois conseguiu representar a variação secular e as reversões de polaridade. 


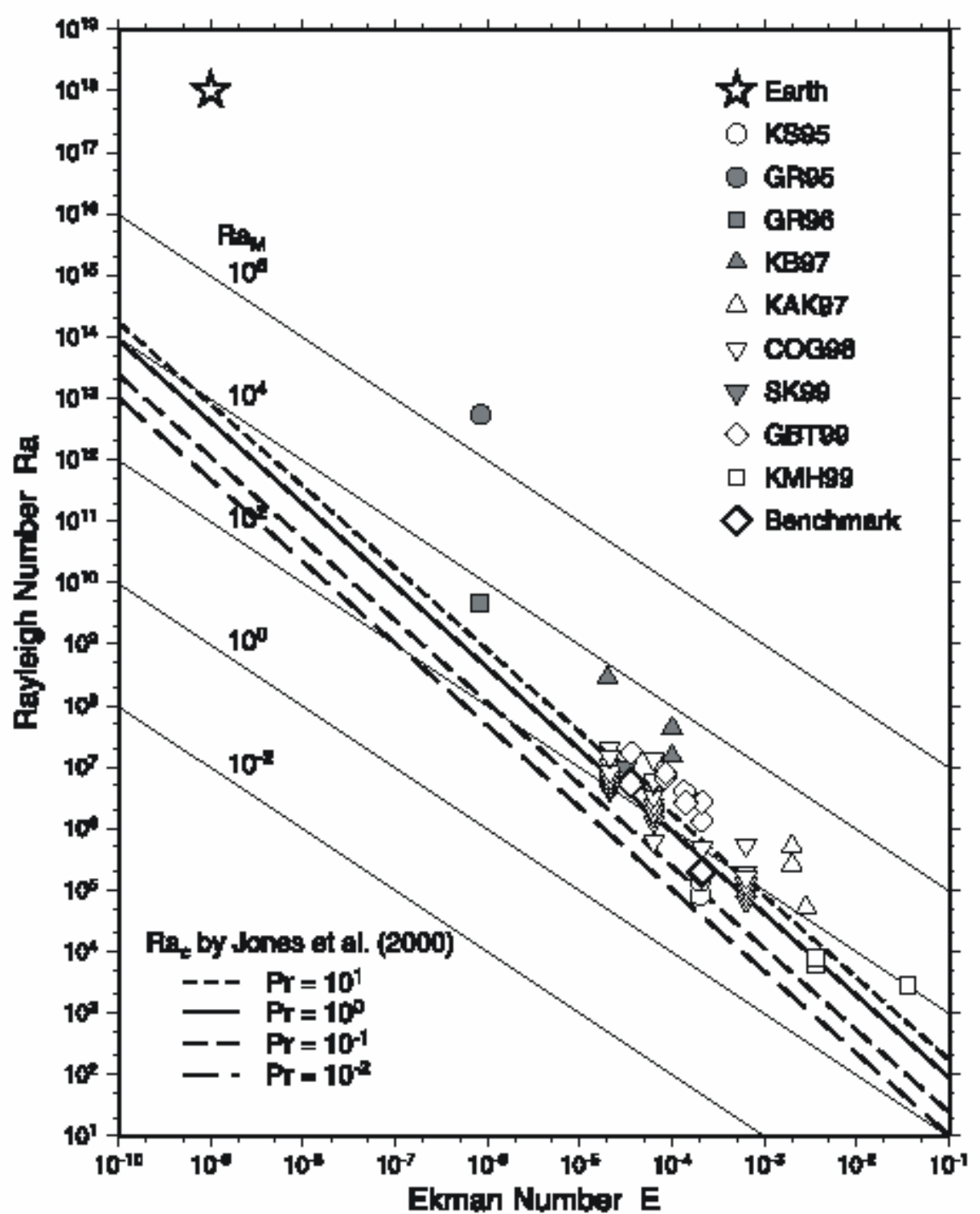

Figura 5.5: Relação entre o número de Ekman ( $E$ ) e o número de Rayleigh ( $R a$ ) em vários modelos de geodínamo. As linhas mais espessas indicam números de Rayleigh críticos e as linhas finas representam valores do número de Rayleigh modificado $\left(R a_{M}=E R a\right)$. O valor para a Terra é baseado numa viscosidade de $1 \mathrm{~m}^{2} \mathrm{~s}^{-1}$ (compilado de Kono e Roberts, 2002).

A comparação do campo na superfície continuado para a interface mantonúcleo (considerando o manto como um isolante), com o campo obtido através das simulações do geodínamo fornece um meio para se testar os modelos. A figura 5.6 mostra mapas da componente radial para a CMB (Core Mantle Boundary).

As projeções dos mapas da figura 5.6 foram feitas para a superfície (à esquerda na figura) e para a CMB (à direita na figura). O primeiro conjunto mostra o campo radial observado em superfície truncado até $n=12 \mathrm{e}$, o segundo e terceiro conjunto foram obtidos através das simulações de Roberts e Glatzmaier (2000), sendo que o segundo está truncado até $n=12$ e o terceiro até $n=95$. Pode-se notar 
que, embora se introduzam harmônicos de graus 13 a 95, na superfície não são produzidas diferenças detectáveis, no entanto, na $\mathrm{CMB}$ as diferenças são significativas na estrutura do campo. A grande concentração de pontos de fluxo magnético (pontos do núcleo) observada na $\mathrm{CMB}$ é, semelhante às manchas solares na superfície do Sol, que são interpretadas como erupções do campo toroidal [BLOXHAM e GUBBINS, 1985]. Estes mapas ilustram graficamente a dificuldade em inferir o campo na CMB a partir do campo observado na superfície da Terra.

\section{Radial Component of the Magnetic Field}

At surface

At core-mantle boundary

Geomagnetic field (1980) up to degree 12
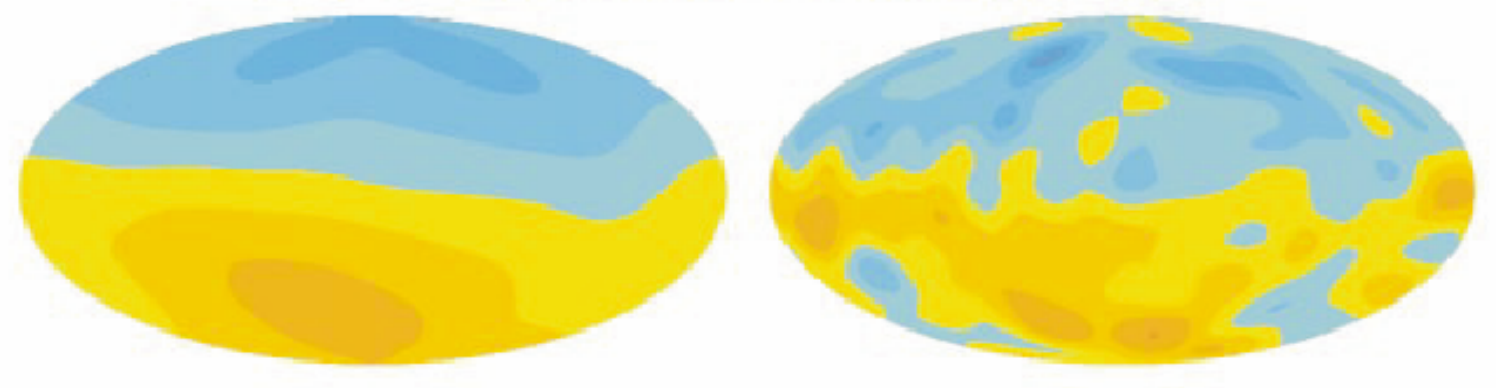

\section{G-R simulation plotted up to degree 12}
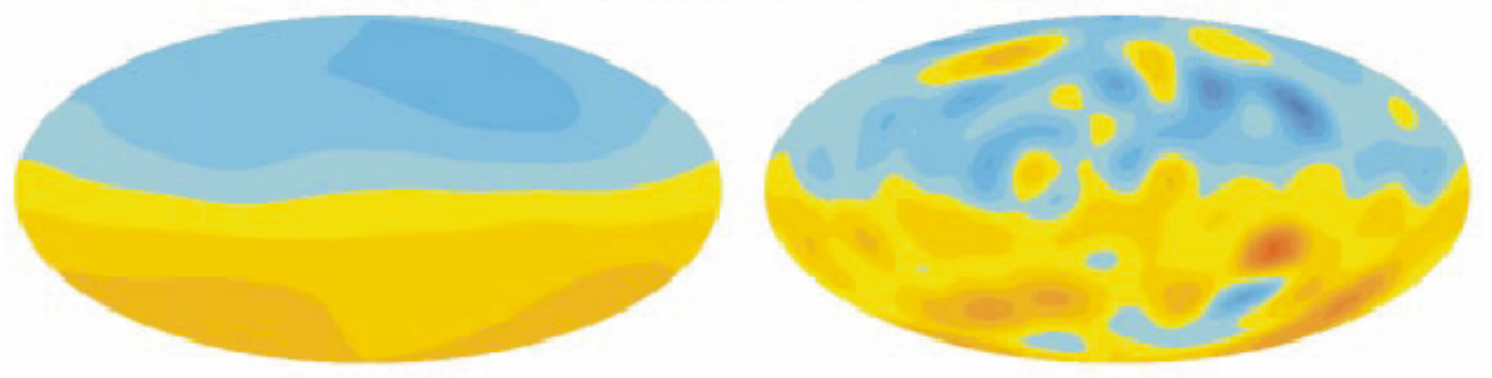

\section{G-R simulation up to degree 95}
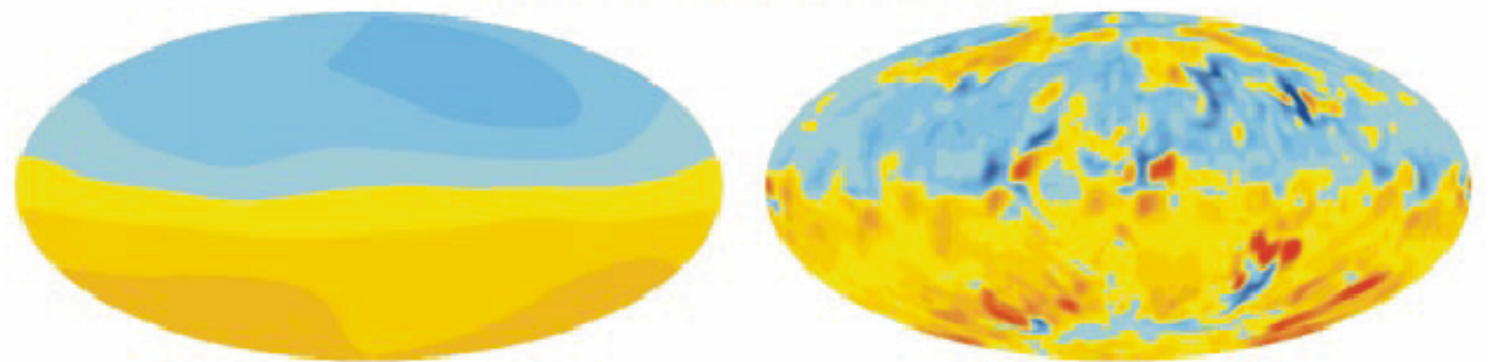

Figura 5.6: Componente radial do campo magnético mapeada na superfície e na CMB. Os focos tendendo para o vermelho indicam saída e os focos tendendo para o azul indicam entrada de fluxo magnético. A escala de cores na superfície foi multiplicada por 10 para se obter contrastes equivalentes (compilado de Roberts e Glatzmaier, 2000). 
A figura 5.7 mostra uma comparação entre os campos gerados na simulação de Kuang e Bloxham (1999) e Roberts e Glatzmaier (2000). Na figura 5.7 são mostrados mapas da componente radial na $\mathrm{CMB}$ e um corte através do núcleo mostra a simetria dos campos. Ambas soluções produziram campos magnéticos de predominância dipolar na CMB. A baixa difusão e alta resolução do modelo de Roberts e Glatzmaier (2000), produziu uma solução com feições magnéticas de pequena escala e efeitos dos cilindros tangentes. O campo zonal é principalmente confinado no interior dos cilindros tangentes, considerando que o campo meridional está principalmente externo ao campo zonal [ROBERTS e GLATZMAIER, 2000]. O modelo de baixa resolução de Kuang e Bloxham (1999) e o modelo truncado até $n=12$ (figura 5.6), são representados por feições de maior escala.

\section{Radial Field at Core-Mantle Boundary Mean Toroidal and Poloidal Fields}

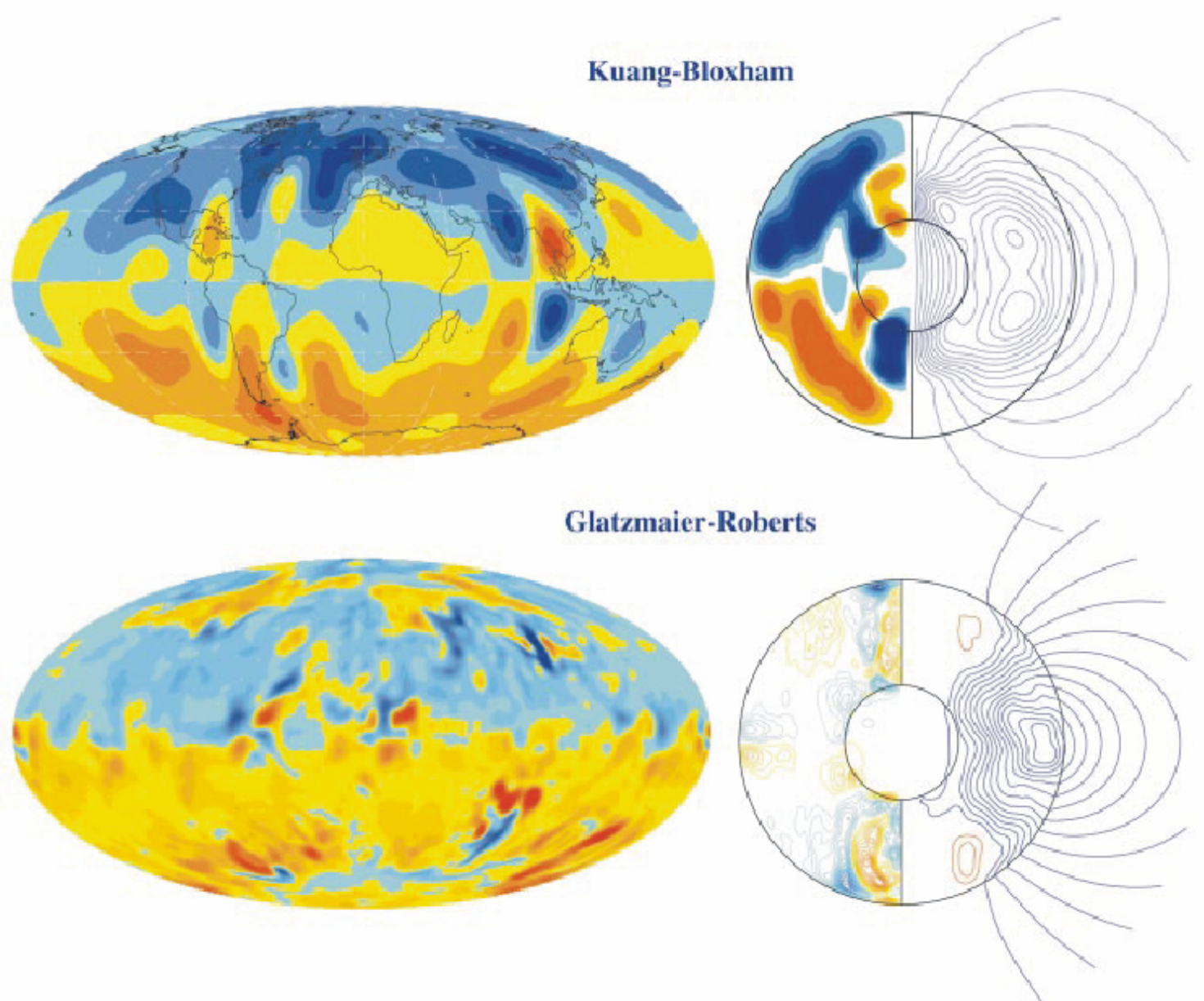

Figura 5.7: Mapas da componente radial do campo na CMB (à esquerda), e um corte longitudinal do núcleo (à direita) com os contornos do campo toroidal à esquerda e linhas de campo magnético poloidal à direita. O conjunto superior é do modelo de Kuang e Bloxham (1999) e o modelo inferior de Glatzmaier e Roberts (2000), (compilado de Roberts e Glatzmaier, 2000). 


\section{Metodologia de Análise dos Dados}

Este capítulo apresenta os modelos utilizados para análise, a metodologia para descrição das principais características da SAMA, e o software utilizado para o processamento dos dados.

\subsection{Modelos}

Para análise da SAMA foram utilizados modelos que contém os coeficientes de Gauss para várias épocas. Para isto, foram divididos em dois períodos: o primeiro para os anos de 1600 a 1890 e o segundo para os anos de 1900 a 2005.

Para o período de 1600 a 1890 (período histórico), os dados utilizados para construção dos modelos basearam-se em observações de navegadores. Já para o período dos últimos 105 anos, os dados para construção dos modelos baseiam-se em observatórios magnéticos, satélites e estações de repetição terrestres e marítimas.

\subsubsection{Modelos do campo para o período histórico}

Para a abordagem da SAMA, foram utilizados modelos para o período histórico de 1600 e 1890. Barraclough (1974) analisou o campo de 1600 a 1910. Para isto, foram utilizados os dados para as épocas de 1600, 1650, 1700, 1750, 1800, 1850 e, re-analisados os modelos de 1890 e 1910. Os dados usados na análise foram retirados do catálogo de Veinberg e Shibaev (1969) que continha valores de declinação $(D)$, inclinação $(I)$ e a componente horizontal $(H)$, reduzidos a 12 épocas entre 1550 e 1940, inclusive para posições onde latitude e longitude eram múltiplos de $10^{\circ}$. Dois conjuntos de modelos de harmônicos esféricos foram derivados, e dois métodos usados para superar a falta de dados de intensidade para as épocas iniciais da análise.

No primeiro conjunto de modelos (1600 a 1800), as razões dos harmônicos esféricos para $g_{1}^{0}$ são determinadas usando os dados de declinação e inclinação. Assim, quando somente se dispõe de dados de declinação, o método de Bauer pode 
ser usado para encontrar outras componentes do campo. Para qualquer ponto na superfície da Terra, a relação:

$$
X \sin D=Y \cos D
$$

pode ser reescrita expandindo $X$ e $Y$ em harmônicos esféricos. O campo é considerado como sendo derivável de um potencial escalar e as fontes são todas de origem interna. A relação resultante é:

$$
\begin{aligned}
& \sin D \sum_{n=1}^{K} \sum_{m=0}^{n}\left\{\left(\frac{a}{r}\right)^{n+2} A_{n}^{m}\left(g_{n}^{m} \cos m \phi+h_{n}^{m} \sin m \phi\right)\right\}- \\
& -\cos D \sum_{n=1}^{K} \sum_{m=0}^{n}\left\{\left(\frac{a}{r}\right)^{n+2}\left(\frac{m P_{n}^{m}}{\sin \theta}\right)\left(g_{n}^{m} \cos m \phi-h_{n}^{m} \sin m \phi\right)\right\}=0
\end{aligned}
$$

onde:

$$
A_{n}^{m}=n X_{n}^{m} \cos \delta-(n+1) P_{n}^{m} \sin \delta
$$

$K$ é o grau máximo das análises, $a$ é o raio médio da Terra (neste caso, $a=6371,2 \mathrm{~km}), r$ é a distância radial do centro da Terra, $\theta$ é a colatitude, $\delta$ é a diferença entre a colatitude geodésica e a colatitude geocêntrica, $\phi$ é a longitude medida a leste de Greenwich, $P_{n}^{m}(\cos \theta)$ são os polinômios associados de Legendre e $n X_{n}^{m}(\cos \theta)=d P_{n}^{m}(\cos \theta) / d \theta$. Substituindo, $\left\{g_{n}^{m}, h_{n}^{m}\right\}$ por $x_{j}$ e,

$$
\alpha_{j} \text { por }\left\{\begin{array}{l}
(a / r)^{n+2}\left[A_{n}^{m} \cos m \phi \sin D-\left(m P_{n}^{m} / \sin \theta\right) \sin m \phi \cos D\right] \\
(a / r)^{n+2}\left[A_{n}^{m} \sin m \phi \sin D+\left(m P_{n}^{m} / \sin \theta\right) \cos m \phi \cos D\right]
\end{array}\right.
$$

Então, a equação (6.2) pode ser reescrita,

$$
\sum_{j=1}^{K^{\prime}} x_{j} \alpha_{j}(\theta, \phi, D)=0
$$


onde $K^{\prime}=K(K+2)$ é o número de coeficientes $\left\{g_{n}^{m}, h_{n}^{m}\right\}$ a serem determinados. Desde que $x_{1}=g_{1}^{0} \neq 0$,

$$
x_{1} \alpha_{1}+\sum_{j=2}^{K^{\prime}} x_{j} \alpha_{j}=0
$$

ou dividindo por $x_{1}$,

$$
\sum_{j=2}^{K^{\prime}} x_{j} \alpha_{j}=-\alpha_{1}
$$

onde $y_{j}=x_{j} / x_{1}$. Se há $N$ valores de $D$, uma série resulta de $N$ equações nãohomogêneas e pode ser resolvida obtendo os valores dos coeficientes de Gauss:

$$
\sum_{j=2}^{K^{\prime}} y_{j} \alpha_{j i}=-\alpha_{1 i} \quad i=1,2, \ldots, N
$$

Se forem disponíveis valores de inclinação para pontos em que dados de declinação também existam, então o método de Bauer assume a relação:

$$
Z \cos I=H \sin I=\frac{X}{\cos D} \sin I
$$

Procedendo da mesma maneira e assumindo os mesmos pressupostos em consideração ao campo geomagnético, $X$ e $Z$ são expandidos em termos de harmônicos esféricos. A equação (6.9) fica:

$$
\begin{aligned}
& \frac{\sin I}{\cos D} \sum_{n=1}^{K} \sum_{m=0}^{n}\left\{\left(\frac{a}{r}\right)^{n+2} A_{n}^{m}\left(g_{n}^{m} \cos m \phi+h_{n}^{m} \sin m \phi\right)\right\}+ \\
& +\cos I \sum_{n=1}^{K} \sum_{m=0}^{n}\left\{\left(\frac{a}{r}\right)^{n+2} B_{n}^{m}\left(g_{n}^{m} \cos m \phi-h_{n}^{m} \sin m \phi\right)\right\}=0
\end{aligned}
$$

onde 


$$
B_{n}^{m}=(n+1) P_{n}^{m} \cos \delta+n X_{n}^{m} \sin \delta
$$

fazendo a substituição,

$$
\alpha_{j} \text { por }\left\{\begin{array}{l}
(a / r)^{n+2}\left[A_{n}^{m} \cos m \phi \sec D \sin I+B_{n}^{m} \cos m \phi \cos I\right] \\
(a / r)^{n+2}\left[A_{n}^{m} \sin m \phi \sec D \sin I+B_{n}^{m} \sin m \phi \cos I\right]
\end{array}\right.
$$

Assim, o número de $N$ pontos de dados é a soma do número dos valores de $D$, para cada valor há uma equação na forma descrita pelas equações (6.4) e (6.8), e o número de valores de I para os pontos em que há valores de $D$ disponíveis, para cada uma, há uma equação na forma descrita pelas equações (6.8) e (6.12).

O segundo método é usado para os dados de 1850, 1890 e 1910 que incluem substanciais quantidades de dados da componente horizontal. O método usado por Braginskii e Kulanin (1971), Braginsky (1972), Benkova et al. (1970), determina valores de $g_{1}^{0}$ pela extrapolação temporal de valores determinados desde a época de Gauss. Barraclough (1974) ajustou uma reta para $g_{1}^{0}$ de 170 modelos de harmônicos esféricos do campo entre 1829 e 1970 pela relação:

$$
g_{1}^{0}(t)=-31110,3+15,46(t-1914)
$$

onde $t$ é época em anos. Esta expressão foi ajustada por mínimos quadrados. Onde havia modelos para a mesma época, um procedimento de seleção foi usado para rejeitar qualquer valor de $g_{1}^{0}$ que diferisse do valor médio para a época.

Os valores iniciais dos coeficientes a serem corrigidos, para a época de 1910, utilizam o modelo de 1905 que é baseado nas análises da variação secular do campo [VESTINE et al., 1947].

Nas análises subseqüentes, os valores de $g_{1}^{0}$ encontrados usando a equação (6.13) foram fixados e as correções para todos os outros coeficientes determinadas. Foi atribuída uma forma esferoidal para a Terra e pesos iguais a 1,0, 0,25 e 1,0, respectivamente, para as equações de condição para $D, I$ e $H$.

Os modelos produzidos por Barraclough, usaram os métodos com grau e ordem máximos de $K=4 \quad\left(K^{\prime}=24\right)$, ou seja, truncados até ordem e grau 4 . Os 
valores e os respectivos desvios padrão dos coeficientes dos modelos são apresentados na Tabela do Anexo A. Nota-se que os desvios padrão e as diferenças tornam-se pequenas para as últimas épocas. Isto reflete $\mathrm{o}$ fato de que os harmônicos zonais não são bem determinados pelos dados de declinação somente.

Há quatro razões para a escolha dos modelos de Barraclough no presente estudo:

I. Os modelos de Benkova et al. (1970) analisaram dados para 1600, 1650, 1700 e 1750, mas foram publicados na forma de gráficos.

II. Adam et al. (1970), usaram os resultados destas análises e análises adicionais para 1550, 1800 e 1850 para investigar a dependência temporal de vários parâmetros do campo geomagnético, como a posição dos dipolos excêntricos, dos pólos geomagnéticos e dos pólos magnéticos, entretanto, os valores dos coeficientes dos harmônicos esféricos não foram publicados.

III. Braginskii e Kulanin (1971), analisaram os dados para 1600, 1650, 1700, 1750 e 1800 usando um método diferente e publicaram valores para os coeficientes resultantes e seus desvios padrão, contudo, Braginskii (1972) usou os mesmos dados, aumentados por dados de outras fontes, produzindo mais um conjunto de modelos diferentes para as mesmas épocas.

IV. Investigações de movimentos do fluido no núcleo da Terra para os últimos séculos requerem modelos que descrevam cuidadosamente o campo geomagnético. Bloxham e Gubbins (1985), Bloxham (1987), Bloxham et al. (1989), Bloxham e Jackson (1989; 1992) utilizaram estes dados para mapeamento do campo na interface manto-núcleo. Entretanto, os resultados publicados foram apenas os mapas de campo.

Apesar dos modelos para o período histórico apresentarem um truncamento baixo para os coeficientes, a representação do campo é satisfatória.

\subsubsection{Modelos do campo para os últimos 105 anos}

No último século, aumentou o número de observatórios magnéticos espalhados pelo mundo. Com isto os dados levantados tornaram-se mais confiáveis e precisos melhorando consideravelmente os modelos para representação do campo. Atualmente, cerca de 190 observatórios, estações de repetição terrestres e 
nos oceanos, além de dados de satélites contribuem com dados para construção dos modelos. Como o campo varia com o tempo, são construídos modelos a cada 5 anos. Para o presente estudo, os modelos do DGRF (Definitive Geomagnetic Reference Field) e IGRF (International Geomagnetic Reference Field) utilizam as técnicas de derivação apresentadas no Capítulo 3. Estes modelos foram construídos considerando somente o campo originado no núcleo da Terra. Conseqüentemente, campos magnéticos originados de fontes crustais, ionosfera e magnetosfera, foram removidos [MACMILLAN e QUINN, 2000].

Os modelos do IGRF são modelos internacionalmente harmonizados para mapeamento. A harmonia baseia-se numa média de diferentes modelos nacionais: IGRFs não são do ponto de vista estatístico os "melhores modelos". Eles contêm elementos preditivos porque os dados são aproximados de cinco anos anteriores para épocas posteriores. Os modelos do DGRF são baseados sobre dados corrigidos para as épocas centrais de cada modelo. O principal problema com o IGRF, DGRF e com os modelos de Barraclough (1974), é que eles são construídos para mapeamento preferivelmente da superfície do que para estudos do núcleo [BLOXHAM et al., 1989].

Para o estudo da SAMA, os coeficientes de Gauss dos modelos do IGRF utilizados estão apresentados na Tabela do Anexo B. Para os anos de 1900 a 2000, os modelos utilizados já encontram-se corrigidos (DGRF) pela IAGA. Os modelos para as épocas de 1900 a 1990 apresentam coeficientes do campo principal truncados até ordem e grau 10. Já os modelos de 2000 e 2005 apresentam coeficientes truncados até ordem e grau 13 e possuem uma precisão de $0,1 \mathrm{nT}$, refletidos pela melhoria na resolução dos instrumentos, principalmente dos dados adquiridos por satélites.

\subsection{Processamento dos dados}

Para o processamento dos coeficientes dos modelos, foi utilizado o programa Maggrid 3.0 desenvolvido pelo NGDC (National Geophysical Data Center). Inicialmente desenvolvido em Fortran, o programa foi posteriormente alterado para a 
linguagem $C$, sendo que os arquivos do código fonte são fornecidos gratuitamente pelo NGDC ${ }^{1}$.

O Maggrid 3.0, programa de modelagem do campo geomagnético, calcula a partir dos coeficientes de Gauss dos modelos para o período histórico e para os últimos 105 anos, as componentes do campo total, não-dipolar, vertical e horizontal, além da componente vertical para a interface manto-núcleo.

As opções e parâmetros de entrada do programa para realização dos cálculos são:

a) Arquivos de saída: nesta opção o usuário escolhe se prefere salvar ou não os dados de saída num arquivo. Se a opção for a de salvar os dados, o programa solicita o nome e a extensão do arquivo a ser salvo. No processamento, armazenamos os arquivos no formato ASCII com a extensão .dat;

b) Modelos de entrada: nesta opção escolhe-se o arquivo que contém os modelos a serem calculados. Neste caso, o arquivo original (com o nome: igrf) contém os modelos de 1900 a 2000. Este arquivo foi alterado acrescentando o modelo IGRF2005. O arquivo com os modelos históricos foi nomeado de igrf1. Neste arquivo encontram-se os modelos de 1600 a 1890. Para o cálculo do campo não-dipolar, foram retirados dos modelos os coeficientes $g_{1}^{0}, g_{1}^{1}$ e $h_{1}^{1}$;

c) Época: o terceiro parâmetro de entrada refere-se à escolha da data para o qual os dados serão calculados. Neste parâmetro, há duas opções de escolha: em décimos de anos (por exemplo: 1985.3) ou então em ano, mês e dia (por exemplo, Ano: 1978, Mês: 11 e Dia: 28). Nos cálculos foi utilizado a primeira opção, sendo escolhida a época inicial de cada ano (por exemplo, 1995.0);

d) Sistemas de coordenadas: o programa permite escolher o sistema de coordenadas, que podem ser geodésicas ou geocêntricas. Em ambas, é solicitado ao usuário a unidade de preferência: quilômetros, milhas ou pés. O parâmetro do raio foi alterado para o cálculo do campo na interface manto-núcleo. A versão original do programa efetua o cálculo tendo como entrada a distância radial de $6370,2 \mathrm{~km}$ a $6971,2 \mathrm{~km}$, ou seja,

\footnotetext{
${ }^{1}$ Disponível no site:

http://www.ngdc.noaa.gov/seg/geom util/geomutil.shtml
} 
efetua os cálculos para um alcance de até $600 \mathrm{~km}$. Para efetuar os cálculos da continuação para baixo, da superfície até a interface mantonúcleo, alterou-se o programa para calcular a partir do raio de $3450,2 \mathrm{~km}$ até 4050,2km;

e) Limites de Latitude e Longitude: nesta opção, deve-se indicar primeiro a latitude mais ao sul da área a ser calculada e depois a latitude mais ao norte, assim, de $-90^{\circ}$ para o hemisfério Sul e de $90^{\circ}$ para o hemisfério Norte. Em seguida, deve-se indicar a distância (em graus) para os pontos a serem calculados entre as duas latitudes (para esta opção, a resolução máxima alcançada foi com espaçamento de $1^{\circ}$ ). Procedimento idêntico é adotado para as longitudes, porém, $-180^{\circ}$ para o hemisfério Oeste e $180^{\circ}$ para o hemisfério Leste;

f) Componentes do Campo: esta opção permite o usuário escolher: 1) Declinação (D); 2) Intensidade Total (F); 3) Inclinação (I); 4) Componente Horizontal (H) e 5) Componente Vertical (Z). Feita a escolha da componente a ser calculada, o programa efetua os cálculos iterativamente e finaliza com o término dos cálculos;

Os cálculos efetuados são idênticos ao descrito pelas equações derivadas no Capítulo 3. O processo de cálculo fixa uma determinada latitude e calcula os pontos variando as longitudes. Efetuado os cálculos para uma latitude, inicia-se o cálculo para uma outra latitude e segue iterativamente até completar os limites da malha definida pelo usuário. São três as colunas de dados dos arquivos de saída: a primeira de longitude, a segunda de latitude e a terceira da componente escolhida para cálculo. A resolução máxima alcançada para os dados foi de $1^{\circ}$ para latitude e $1^{\circ}$ para longitude.

Para construção dos mapas das várias componentes, utilizou-se o Software Surfer 7.0 e Matlab 7.0 Release 14. Os dados foram interpolados usando o método "Nearest Neigbor" (próxima vizinhança), com espaçamento de 0,10 entre os pontos calculados, ou seja, com esta interpolação tem-se os nós da malha exatamente sobre os pontos calculados. Este procedimento foi usado por Heynderickx (1996).

Com base nos mapas é que serão extraídos os dados de posicionamento e os respectivos valores do campo, com o intuito de descrever as principais características da SAMA, como o deslocamento para o Sul, a deriva para Oeste e as variações em magnitude. 


\subsection{Método de análise}

\subsubsection{Principais características}

Para descrever as principais características da SAMA adotou-se um método de extração dos dados. A SAMA varia continuamente em extensão e magnitude. Para tanto é necessário conhecer as variações em intensidade e deriva da SAMA. Heynderickx (1996) propôs três formas para se obter o centro geográfico da SAMA:

a) A localização geográfica do "ponto espelho" da posição do dipolo excêntrico para o campo geomagnético;

b) A localização geográfica do foco do mínimo valor do campo geomagnético total;

c) Lócus do máximo fluxo de partículas na região (dependente da energia das partículas).

Estes três métodos fornecem a localização do centro da SAMA. Entretanto, a diferença na localização pode variar bastante, porque os três métodos utilizam diferentes características do campo. Segundo Henderickx (1996) as diferenças podem variar em até $30^{\circ}$ de latitude e $10^{\circ}$ em longitude, dependendo do método utilizado. A figura 6.1 mostra a localização geográfica usando os três métodos em função do tempo.

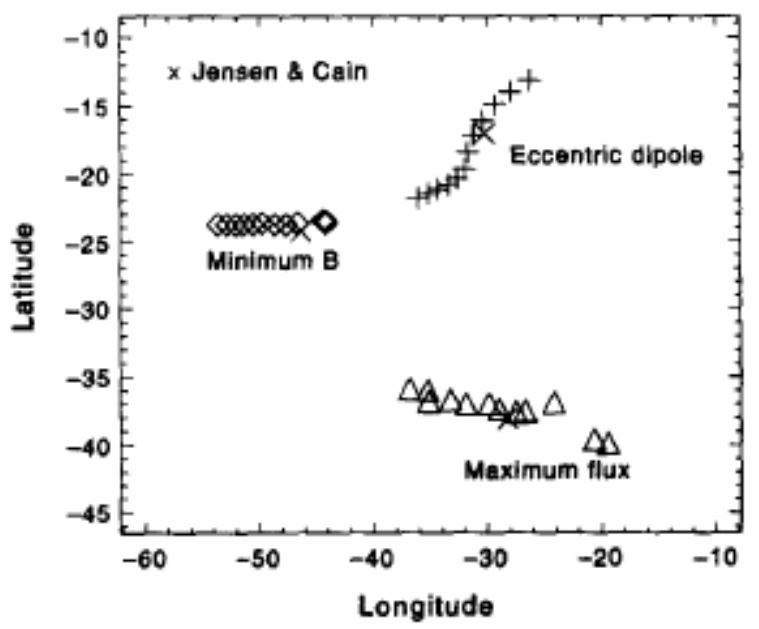

Figura 6.1: Localização geográfica das três aproximações para o centro da SAMA para o período de 1945 a 2000 (compilado de Henderickx, 1996).

Para descrição do comportamento espacial e temporal da SAMA, e de outras anomalias do campo, adotou-se método de localização que utiliza as medidas do valor mínimo do campo total, ou seja, aquele que fornece como resposta em 
superfície o campo produzido, portanto, mais adequado ao estudo. Os outros métodos não foram adotados pelas seguintes razões:

I. O dipolo excêntrico é uma aproximação matemática do dipolo que melhor representa o campo geomagnético. Este dipolo é inclinado e deslocado do centro da Terra, portanto, não necessariamente deve responder às feições produzidas pelo campo do núcleo na superfície.

II. O lócus de máximo fluxo de partículas é localizado pela entrada de partículas na região da SAMA. Embora o fluxo seja maior porque o campo possui menor intensidade nesta região, ele pode ser alterado pela densidade e energia das partículas, correntes ionosféricas, variação diurna ou por tempestades magnéticas. Conseqüentemente, a posição pode ser amplamente alterada.

Além disso, a região da SAMA possui as intensidades mais baixas do campo, fazendo com que o seu centro seja facilmente encontrado. Conhecendo o menor valor do campo, encontra-se a localização geográfica da SAMA. Esses dados são importantes para descrição das principais características em superfície da SAMA.

No processo de cálculo para as diferentes componentes do campo, foi adotado um raio terrestre de $6371,2 \mathrm{~km}$, ou seja, calculado na superfície da Terra. Para o período histórico adotou-se os limites para o cálculo de $-30^{\circ}$ a $0^{\circ} \mathrm{em}$ latitude e de $60^{\circ}$ a $-40^{\circ}$ em longitude e, para os modelos do último século, os limites foram de $-15^{\circ}$ a $-30^{\circ}$ em latitude e de $-30^{\circ}$ a $-60^{\circ}$ em longitude. A figura 6.2 é um exemplo de como os resultados foram extraídos.

a)

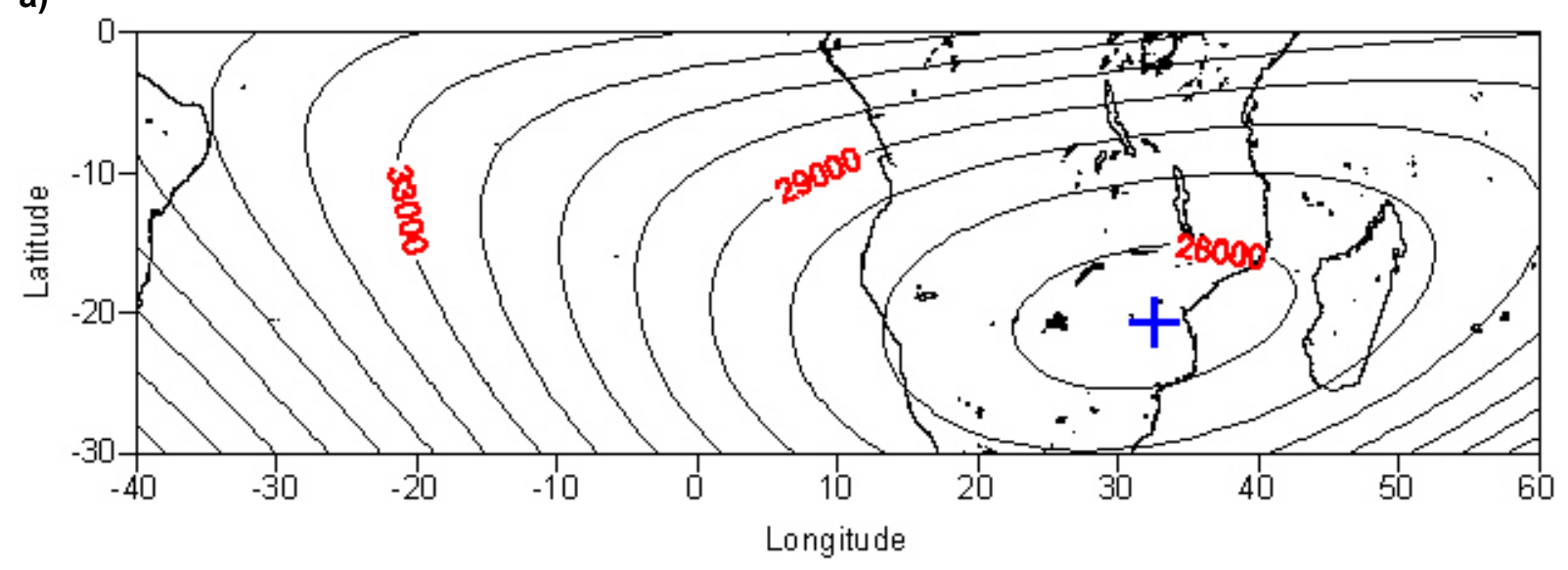


b)

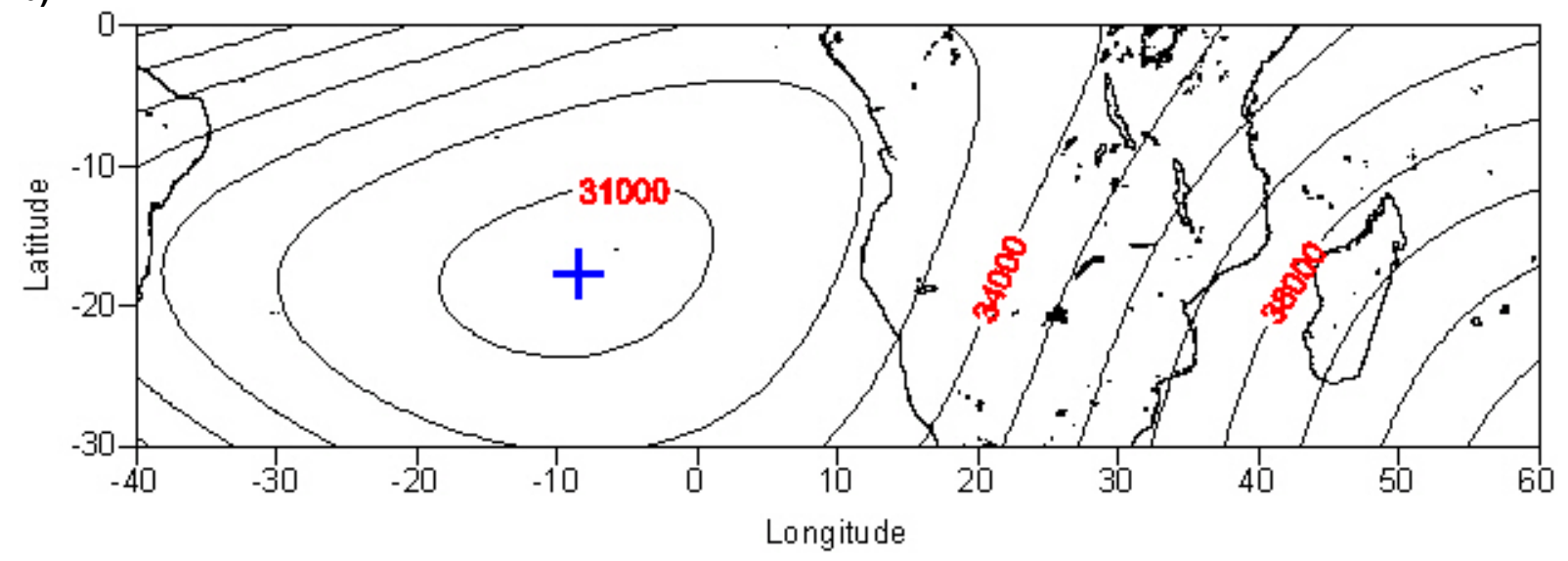

c)

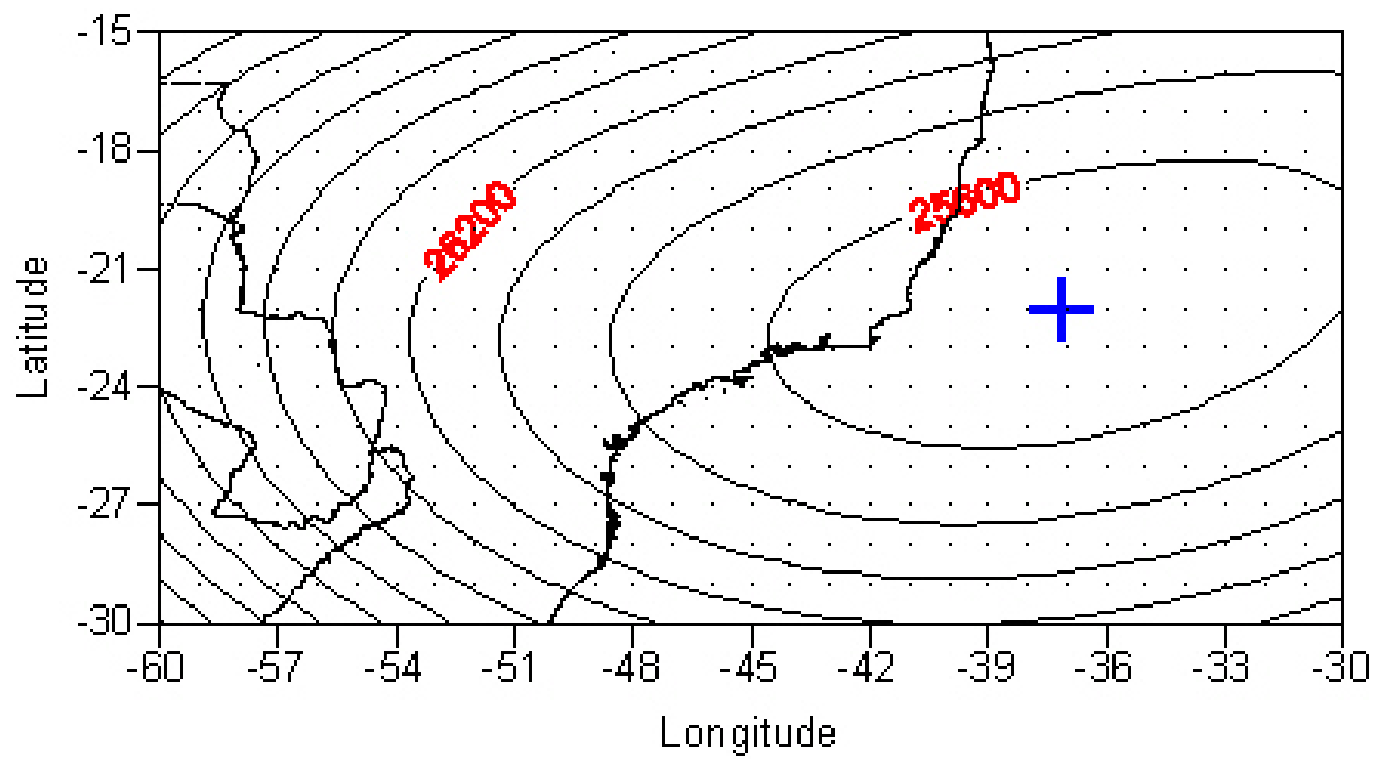

d)

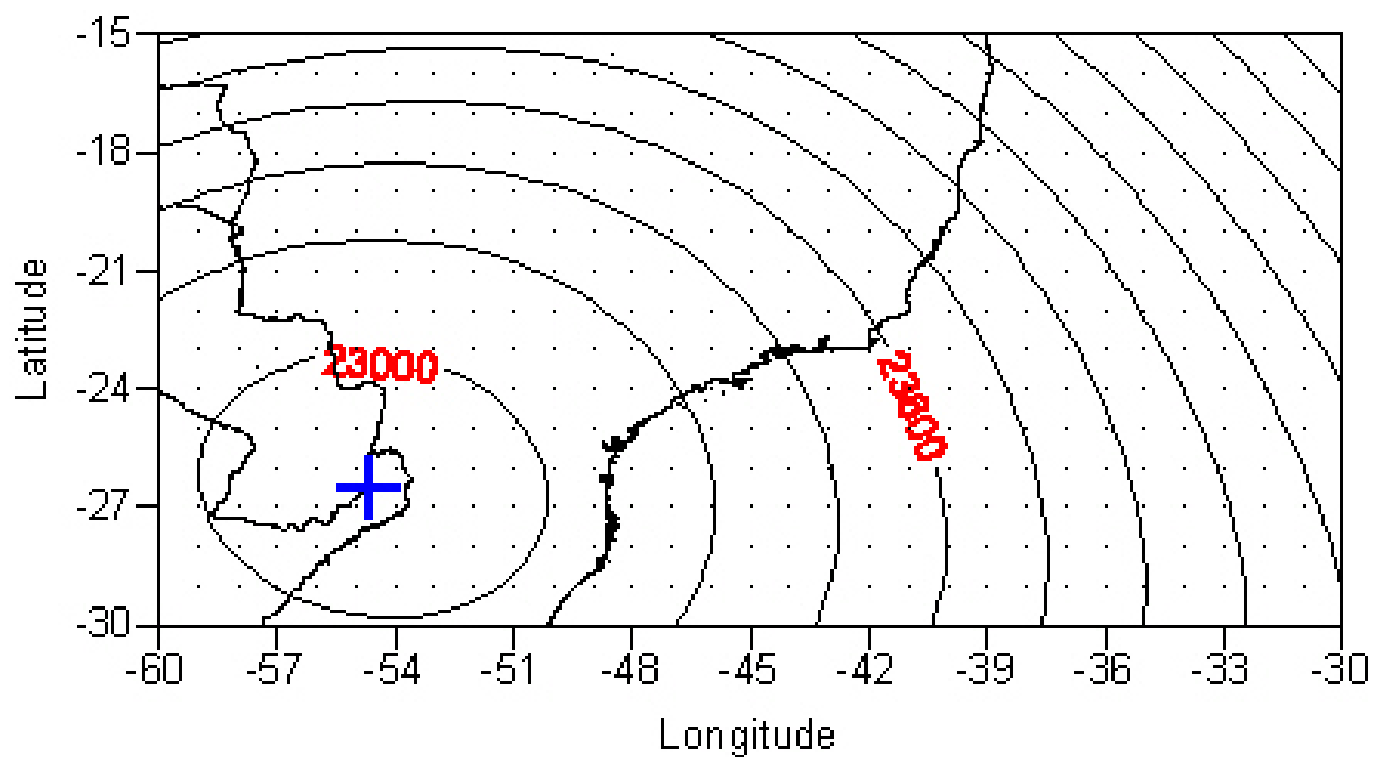

Figura 6.2: Mapas do campo total que mostram a variação da SAMA. Para o período histórico: em (a) para a época de 1600 e (b) para a época de 1800; o intervalo de contorno é de 1000nT. Para o último século: em (c) para 1900 e em (d) para 2000; o intervalo de contorno é de 200nT e os pontos representam a malha dos dados calculados, espaçados em $1^{\circ}$. Em todos os mapas a cruz em azul representa a localização geográfica para o valor da intensidade mais baixa do campo. 
Além da construção de mapas para a região da SAMA foram construídos mapas magnéticos globais, pelo fato de que outras anomalias influenciam 0 comportamento da SAMA.

\subsubsection{Continuação para baixo do campo geomagnético}

Uma forma de entender a SAMA e outras anomalias do campo é o mapeamento na interface manto-núcleo (em inglês, CMB - Core Mantle Boundary), que pode ser determinado a partir de medidas feitas sobre a superfície da Terra, não assumindo campos de origem externa e considerando o manto como um isolante. Para mapeamento do campo na CMB, geralmente utiliza-se a componente vertical, não sendo necessário considerar as outras componentes pelo fato de que na CMB tem-se a blindagem eletromagnética para campos horizontais.

Bloxham (1987), Bloxham e Jackson (1989, 1992), Bloxham et al. (1989), Jackson et al. (2000) e Jackson (2003) têm afirmado que a melhor forma de mapear o campo magnético na interface manto-núcleo é utilizando a técnica de inversão estocástica dos dados de superfície. Há dois problemas fundamentais inerentes ao problema inverso: convergência e estabilidade. Para determinar o campo na CMB, hipóteses adicionais ou condições de regularização, podem ser introduzidas para garantir a convergência das séries para a equação (3.30) e estabelecer a continuação para baixo. No caso da técnica de inversão estocástica, geralmente as séries são truncadas até ordem e grau 14 [JACKSON et al., 2000].

Numa análise convencional do campo principal, como a usada para obter o IGRF, as séries em (3.30) são truncadas e os coeficientes geomagnéticos encontrados como parâmetros em um ajuste por mínimos quadrados das observações. Esta regularização não é necessariamente restritiva, porém, conduz a problemas similares àqueles em truncar séries de Fourier.

Embora a inversão seja o método mais apropriado para análise do campo na $\mathrm{CMB}$, neste trabalho foi utilizada a continuação para baixo dos modelos para o período histórico e do IGRF. Para isso, adota-se o mesmo sistema de coordenadas esféricas $(r, \theta, \lambda)$ da superfície para a CMB, onde $r$ é o raio, $\theta$ a colatitude e $\lambda$ a longitude. O raio da Terra e o raio do núcleo são indicados por $a$ e $c$, respectivamente, sendo $a=6371,2 \mathrm{~km} \mathrm{e} c=3485 \mathrm{~km}$, e assumindo o manto como um isolante. O cálculo do campo para a CMB procede da maneira descrita pela seção 6.2 , sendo que o parâmetro de entrada neste caso é o raio do núcleo. 


\section{Análise dos Resultados: Discussão e Conclusões}

Este capítulo contempla as principais características da SAMA e a possível relação com as anomalias na interface manto-núcleo, que podem ser interpretadas como as possíveis causas para a SAMA.

\subsection{Principais características}

A variação temporal e espacial da SAMA depende em grande parte do comportamento morfológico de todo o campo geomagnético. São comparadas as trajetórias e mudanças de intensidade da SAMA com outras anomalias do campo, como os pólos magnéticos e o Alto da Sibéria e, também, com medidas realizadas por observatórios geomagnéticos na América do Sul.

Com os dados de mínima intensidade para o centro da SAMA, pode-se descrever a mudança de posição e as variações de intensidade.

\subsubsection{Trajetória}

Com base nos dados extraídos a partir dos modelos de diferentes épocas, pode-se verificar a trajetória da SAMA na superfície da Terra. O gráfico da figura 7.1 ilustra a trajetória do centro da SAMA em função do tempo para os últimos 405 anos. Para o último século, a trajetória foi extraída ano a ano; enquanto que para os modelos de Barraclough (1974) os dados da trajetória estão eqüiespaçados em 50 anos. O erro atribuído aos dados é $\pm 0,1^{\circ}$ em latitude e longitude, que é equivalente ao espaçamento dos pontos da malha nos mapas. Foi feita uma curva de ajuste polinomial de grau 6 para os dados, que apresentou um bom ajuste, com o valor de R-quadrado ${ }^{2}$ satisfatório.

A partir destes dados, pode-se verificar diferentes variações para diferentes épocas com mesmo intervalo de tempo. A semelhança encontra-se em períodos de deslocamento para o Norte ou Sul, cujas taxas alternam-se em períodos de

\footnotetext{
${ }^{2}$ R-quadrado ou coeficiente de determinação: é um indicador que revela o grau de correspondência entre os dados estimados para curva de ajuste e os dados reais, sendo que a curva ajustada é mais confiável quando o valor de R-quadrado é 1 ou próximo de 1.
} 
deslocamento mais "rápido" ou mais "lento". As taxas de deriva estão apresentadas na tabela 7.1.

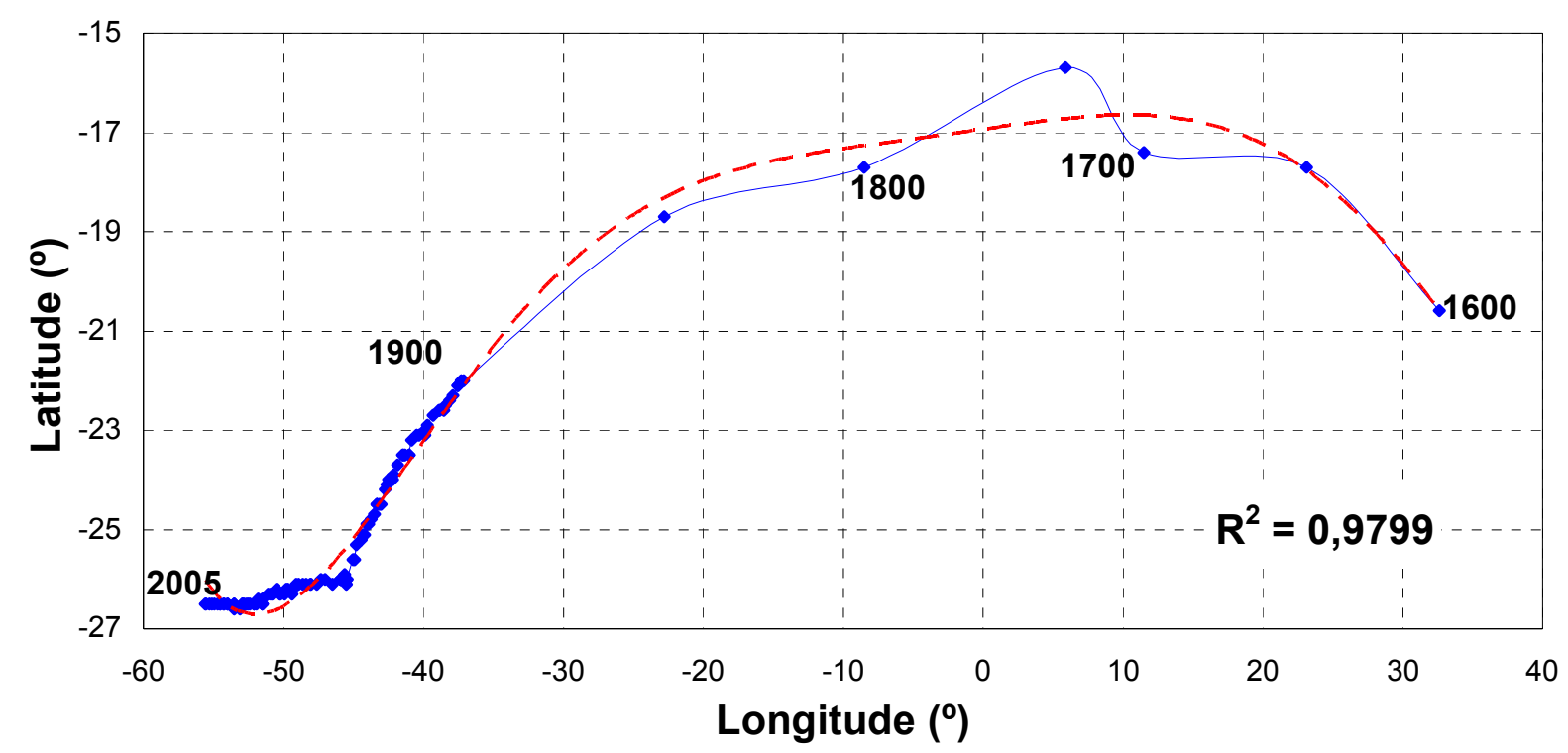

Figura 7.1: Trajetória do centro da SAMA em função do tempo. A curva em vermelho é um ajuste polinomial de grau 6, o valor de R-quadrado é adequado para o ajuste.

Tabela 7.1: Taxas de deriva aproximadas para o centro da SAMA.

\begin{tabular}{c|c|c}
\hline Intervalo & Deriva Leste-Oeste (\%/ano) & $\begin{array}{c}\text { Deslocamento Norte-Sul } \\
\text { (\%/ano) }\end{array}$ \\
\hline $1600-1650$ & $-0,2$ & 0,06 \\
\hline $1650-1700$ & $-0,23$ & 0,006 \\
\hline $1700-1750$ & $-0,11$ & 0,03 \\
\hline $1750-1800$ & $-0,29$ & $-0,04$ \\
\hline $1800-1850$ & $-0,29$ & $-0,02$ \\
\hline $1850-1900$ & $-0,29$ & $-0,07$ \\
\hline $1900-1950$ & $-0,17$ & $-0,08$ \\
\hline $1950-2000$ & $-0,18$ & $-0,01$ \\
\hline Média & $-\mathbf{0 , 2 2}$ & $-\mathbf{0 , 0 1 5}$ \\
\hline
\end{tabular}

Entre 1600 e 1750, a SAMA desloca-se para o Norte, alternando com um período de pequena variação em latitude entre 1650 e 1700 . A partir de 1750 a SAMA desloca-se predominantemente para o Sul, sendo que entre os períodos de 1800-1850 e 1950-2000, há pequena variação em latitude. A latitude varia em menos de $1^{\circ}$ para os intervalos de 1650-1700, 1800-1850 e 1950-2000.

Pelos resultados, a SAMA possui deriva para Oeste, intercalando taxas diferenciadas para certos períodos. As taxas mais constantes correspondem ao período de 1750-1900. Embora exista alguma diferença para as taxas entre os 
modelos anteriores e posteriores a 1900, as feições de longo comprimento de onda dos modelos anteriores a 1900 são observadas em superfície, conforme mapas do campo total no Apêndice A.

Os dados da figura 7.2 mostram a deriva da SAMA para os últimos 105 anos, pois para este período os dados são mais confiáveis e fornecem mais detalhes do campo. A figura mostra também a localização geográfica de quatro observatórios geomagnéticos próximos ao centro da SAMA.

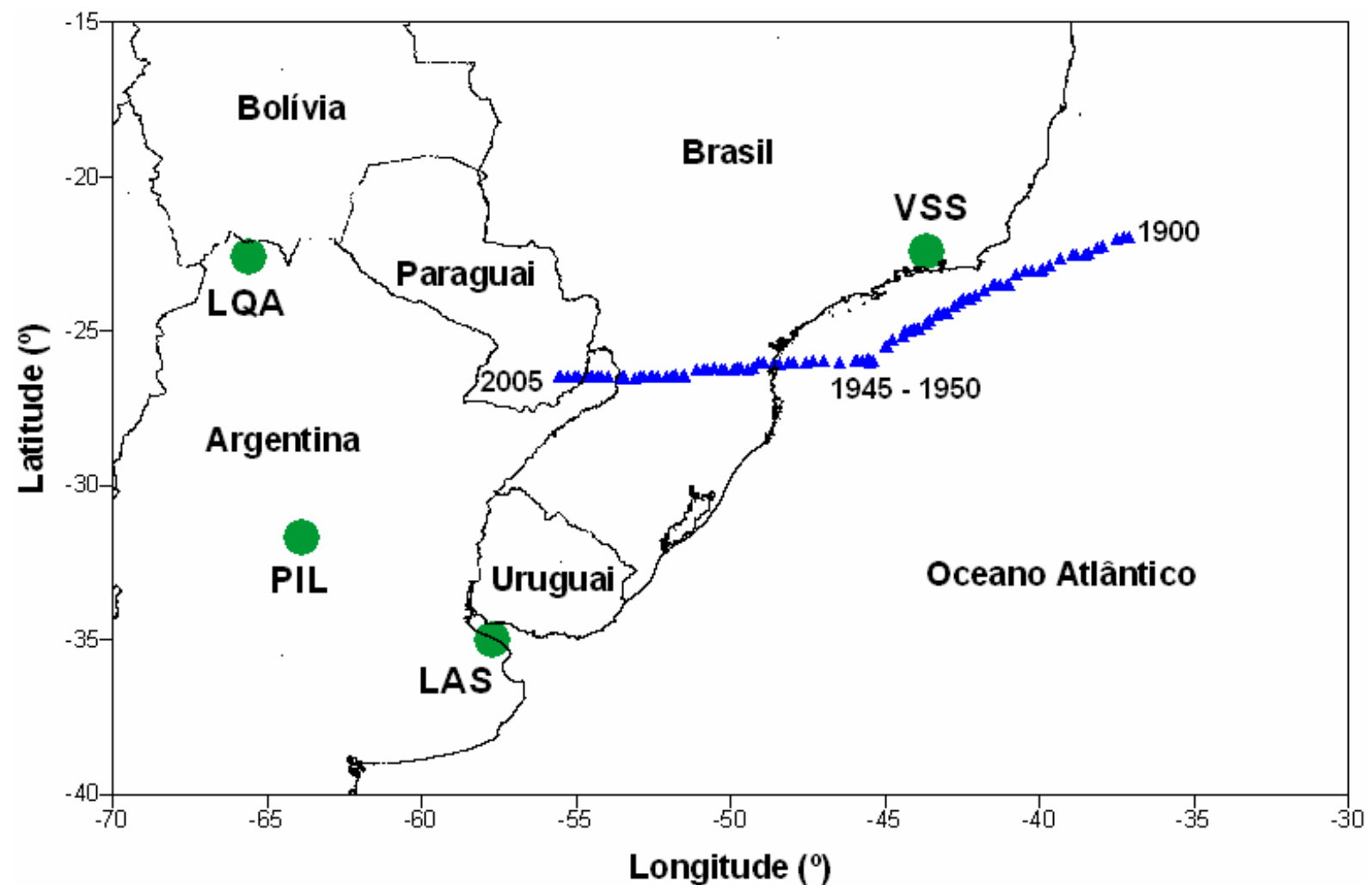

Figura 7.2: Trajetória do centro da SAMA em função do tempo e a localização de quatro observatórios geomagnéticos: Vassouras (VSS), Las Acacias (LAS), La Quiaca (LQA) e Pilar (PIL).

Tabela 7.2: Taxas de deriva do centro da SAMA para os últimos 105 anos.

\begin{tabular}{c|c|c}
\hline Intervalo & Deriva para Oeste (\%/ano) & $\begin{array}{c}\text { Deslocamento para o Sul } \\
\text { (\%/ano) }\end{array}$ \\
\hline $1900-1945$ & $-0,19$ & $-0,09$ \\
\hline $1945-2005$ & $-0,17$ & $-0,008$ \\
\hline Média & $-\mathbf{0 , 1 8}$ & $\mathbf{0 , 0 5}$ \\
\hline
\end{tabular}

O deslocamento da SAMA para o Sul pode ser separado em duas épocas para o último século, conforme a tabela 7.2. A partir de 1945-1950, a variação em latitude foi menor que para o período de 1900-1945. A taxa média para os últimos 60 anos foi muito pequena, praticamente não houve variação em latitude. $E$, a deriva 
para Oeste foi praticamente constante, e praticamente deixou de haver o deslocamento para o Sul.

As taxas de deriva para Oeste para o centro da SAMA obtidas pelo fluxo de partículas (seção 2.4.1) são, aproximadamente, 0,1\%ano maiores do que as taxas obtidas através da mínima intensidade do campo na superfície para os últimos 105 anos e, enquanto as taxas de variação em latitude indicaram um deslocamento para o Norte, as taxas de mínima intensidade do campo indicam um deslocamento para o Sul.

Xu $(2000,2002)$ revisou os coeficientes de grau e ordem igual ou superior a 6 para os modelos de 1945, 1950 e 1955, isto porque para estes modelos, os coeficientes têm valores muito diferentes do que seria esperado. Coincidentemente, são os anos em que a SAMA apresenta uma mudança de trajetória em termos de latitude.

\subsubsection{Intensidade}

Assim como todo o campo geomagnético varia de intensidade com o tempo, a SAMA também varia, apresentando diferentes taxas de variação para diferentes épocas. O gráfico da figura 7.3 mostra as intensidades do centro da SAMA para os últimos 405 anos. A maior densidade de pontos corresponde ao último século com os modelos do IGRF. A curva de ajuste polinomial de grau 6 ajustou-se bem aos dados apresentando um valor de R-quadrado satisfatório. A curva pode sugerir uma ciclicidade para as intensidades da SAMA. No entanto, o intervalo de tempo abordado é insuficiente para inferir um ciclo.

As taxas de variação da intensidade para o período de 400 anos são mostradas na tabela 7.3. Nota-se que as taxas são completamente diferentes para os vários períodos. O maior gradiente é para o período de 1650-1700, e o menor para o período de 1700-1800. A partir de 1800 as taxas apresentam valores negativos, fazendo com que a SAMA diminua de intensidade e aumente em área de abrangência.

O gráfico da figura 7.4 mostra os dados de intensidade para os últimos 105 anos. A variação pode ser analisada em três épocas distintas que correspondem a diferentes valores. O maior gradiente ocorre para o intervalo de 1940-1970. Outro ponto a ser destacado é o fato de coincidir com o período em que a SAMA 
apresenta sua mudança na trajetória. A tabela 7.4 apresenta as taxas para os três períodos.

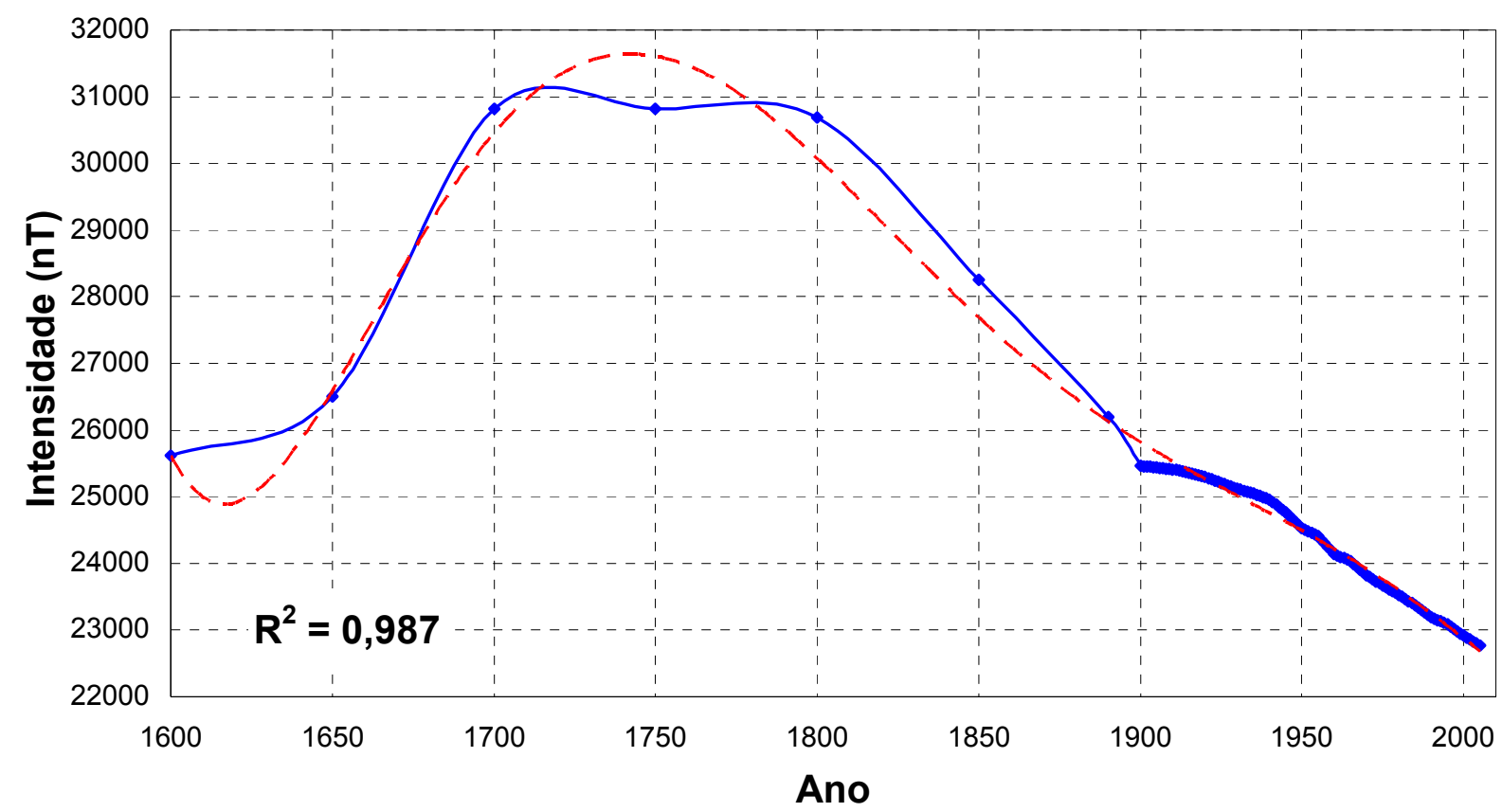

Figura 7.3: Intensidade total do centro da SAMA para o período de 405 anos. A curva em vermelho é um ajuste polinomial de grau 6 e o valor de R-quadrado é adequado para o ajuste.

Tabela 7.3: Variação de intensidade do centro da SAMA para os últimos 400 anos.

\begin{tabular}{c|c}
\hline Intervalo & Variação (nT/ano) \\
\hline $1600-1650$ & 17,8 \\
\hline $1650-1700$ & 86,2 \\
\hline $1700-1750$ & 0,11 \\
\hline $1750-1800$ & $-2,7$ \\
\hline $1800-1850$ & $-48,7$ \\
\hline $1850-1900$ & $-55,8$ \\
\hline $1900-1950$ & $-18,6$ \\
\hline $1950-2000$ & $-32,3$ \\
\hline Média & $-\mathbf{6 , 7 5}$
\end{tabular}

Apesar das variações para os intervalos de 1940-1970 e 1970-2005 apresentarem valores próximos, há diferenças de variações que podem ser observadas na segunda derivada dos dados de intensidade (figura 7.5).

Os picos e vales de variação na segunda derivada definem a resolução temporal de 5 anos para os modelos do IGRF e mostram os três patamares de variação: 1900-1940, 1940-1970 e, 1970-2005. O período crítico (1940-1970) mostra as maiores variações, podendo sugerir que os coeficientes de grau maior que 6 são importantes para o comportamento morfológico da SAMA. 


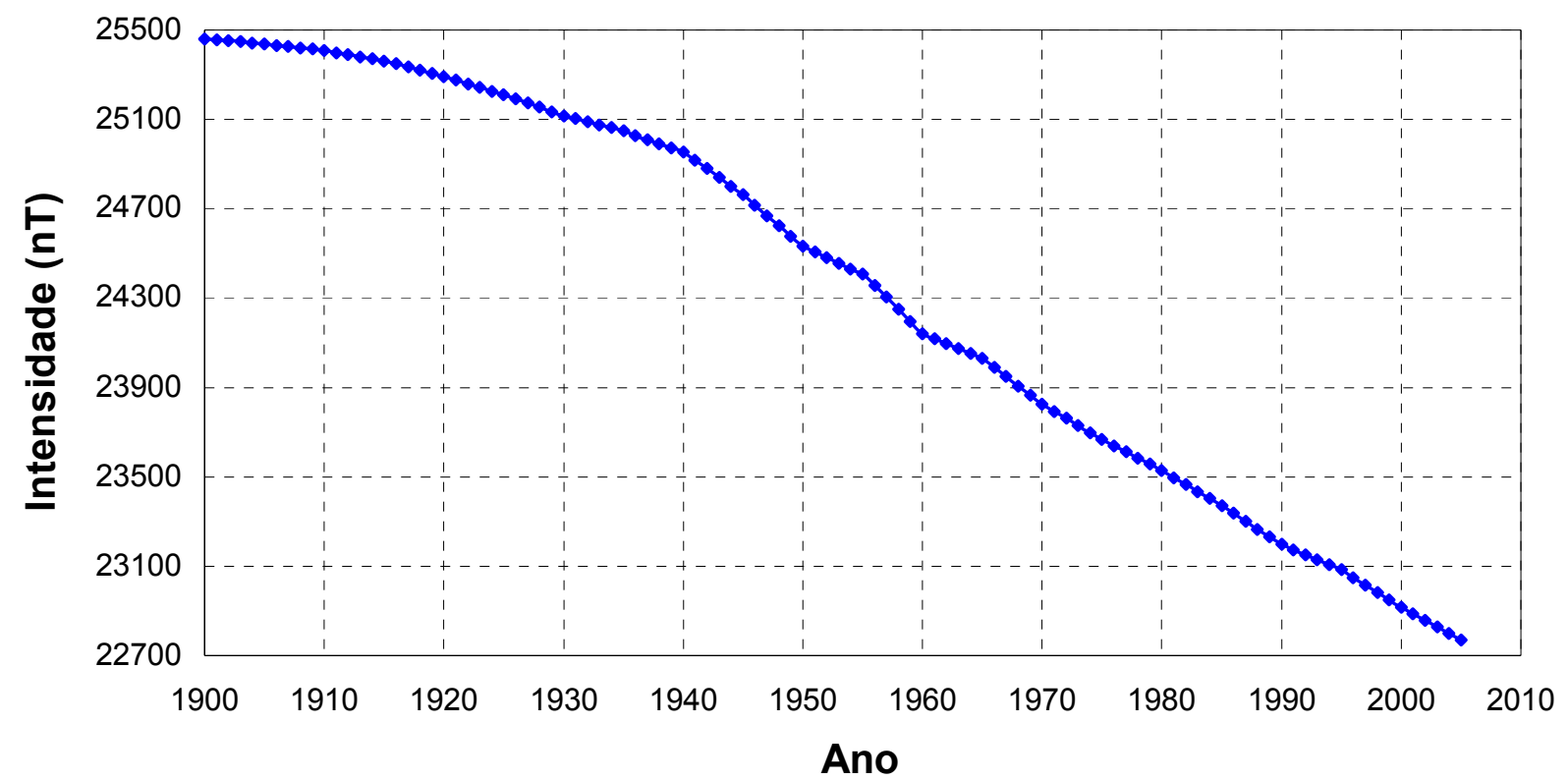

Figura 7.4: Intensidades do centro da SAMA para os últimos 105 anos.

Tabela 7.4: Variação em intensidade do centro da SAMA para os últimos 105 anos.

\begin{tabular}{c|c}
\hline Intervalo & Variação (nT/ano) \\
\hline $1900-1940$ & $-12,7$ \\
\hline $1940-1970$ & $-37,6$ \\
\hline $1970-2005$ & $-30,1$ \\
\hline Média & $\mathbf{- 2 6 , 8}$
\end{tabular}

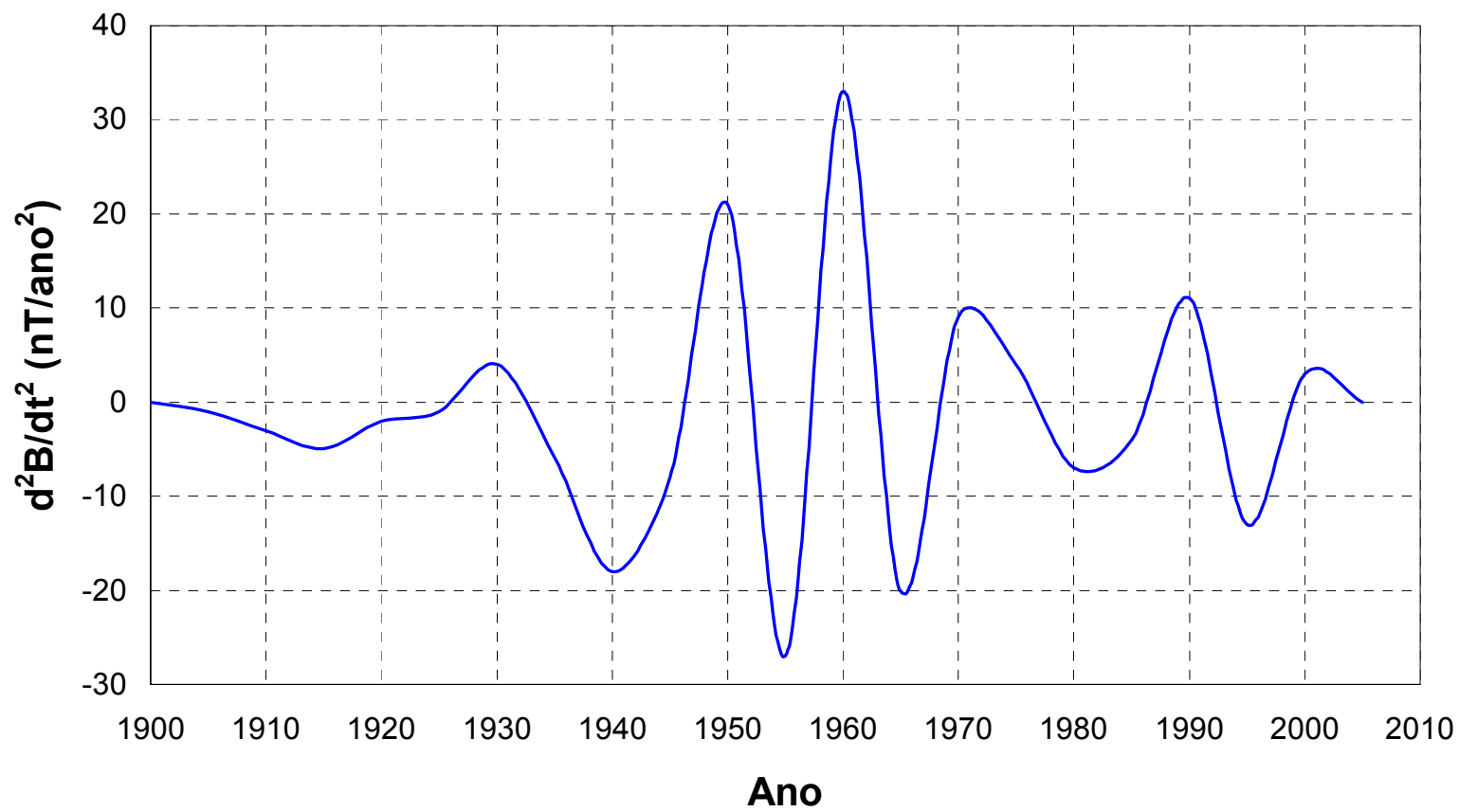

Figura 7.5: Segunda derivada para os dados de intensidade da SAMA. 
Apesar da SAMA ser caracterizada como uma anomalia de longo comprimento de onda, as variações negativas e positivas para os dados de intensidade mostram que a SAMA é sensível a mudanças sutis nos dados dos modelos.

\subsubsection{Campo não-dipolar}

O campo não-dipolar vem aumentando com o tempo. Analisá-lo separadamente do campo total pode indicar possíveis relações com a SAMA.

O gráfico da figura 7.6 mostra a soma dos módulos dos coeficientes dos campos dipolar e não-dipolar em função do tempo. Os coeficientes dipolares utilizados no gráfico foram os de grau e ordem 1 e do campo não-dipolar de grau e ordem superiores. O gráfico da figura 7.7 mostra a razão entre os campos dipolar e total. Atualmente, o campo não-dipolar representa aproximadamente $17 \%$ do campo total, sendo que para o último século o campo não-dipolar apresentou um aumento de $5 \%$ e o campo dipolar um decréscimo da mesma ordem.
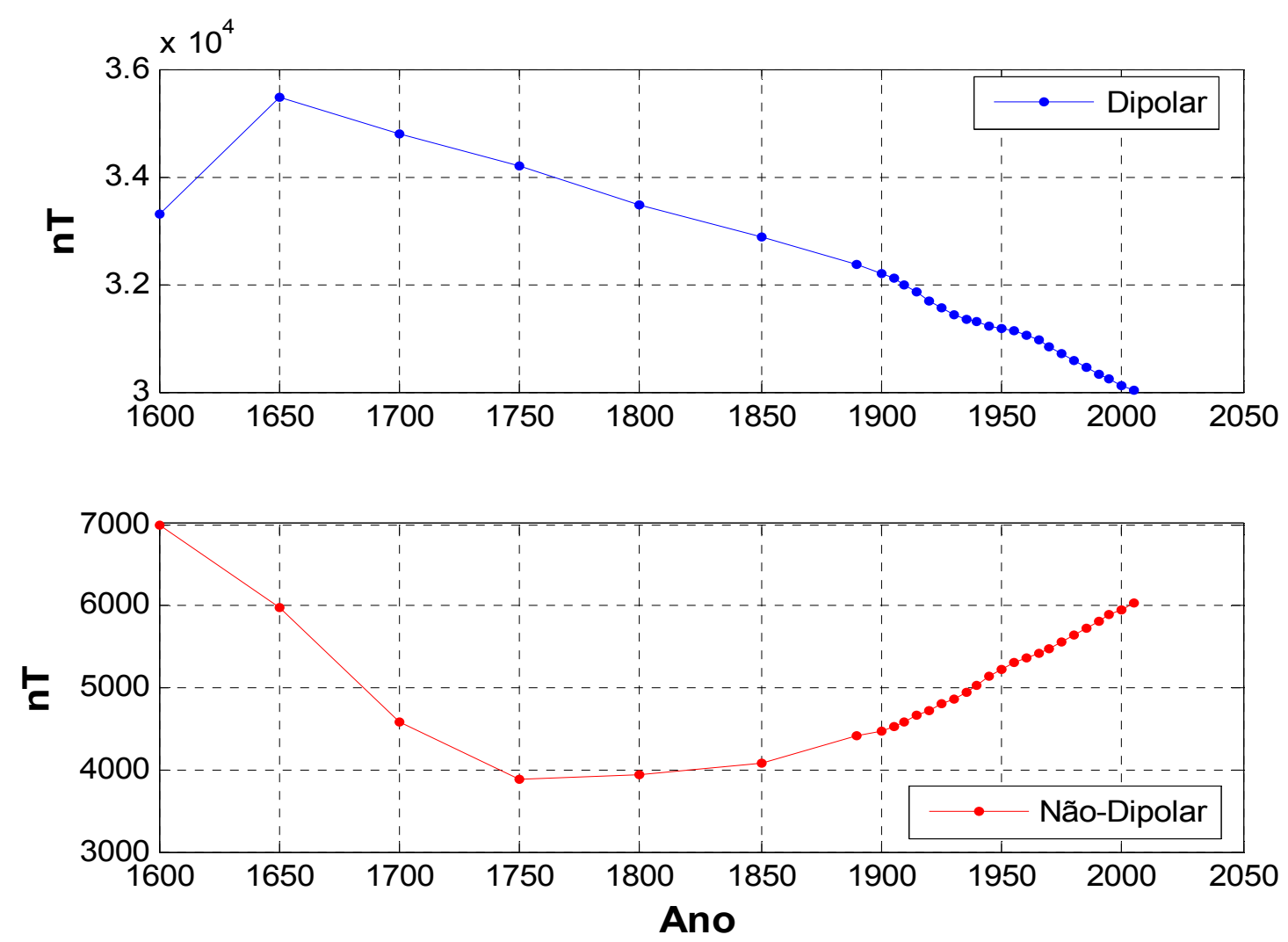

Figura 7.6: Variação em módulo dos coeficientes dipolares e não-dipolares em função do tempo. 


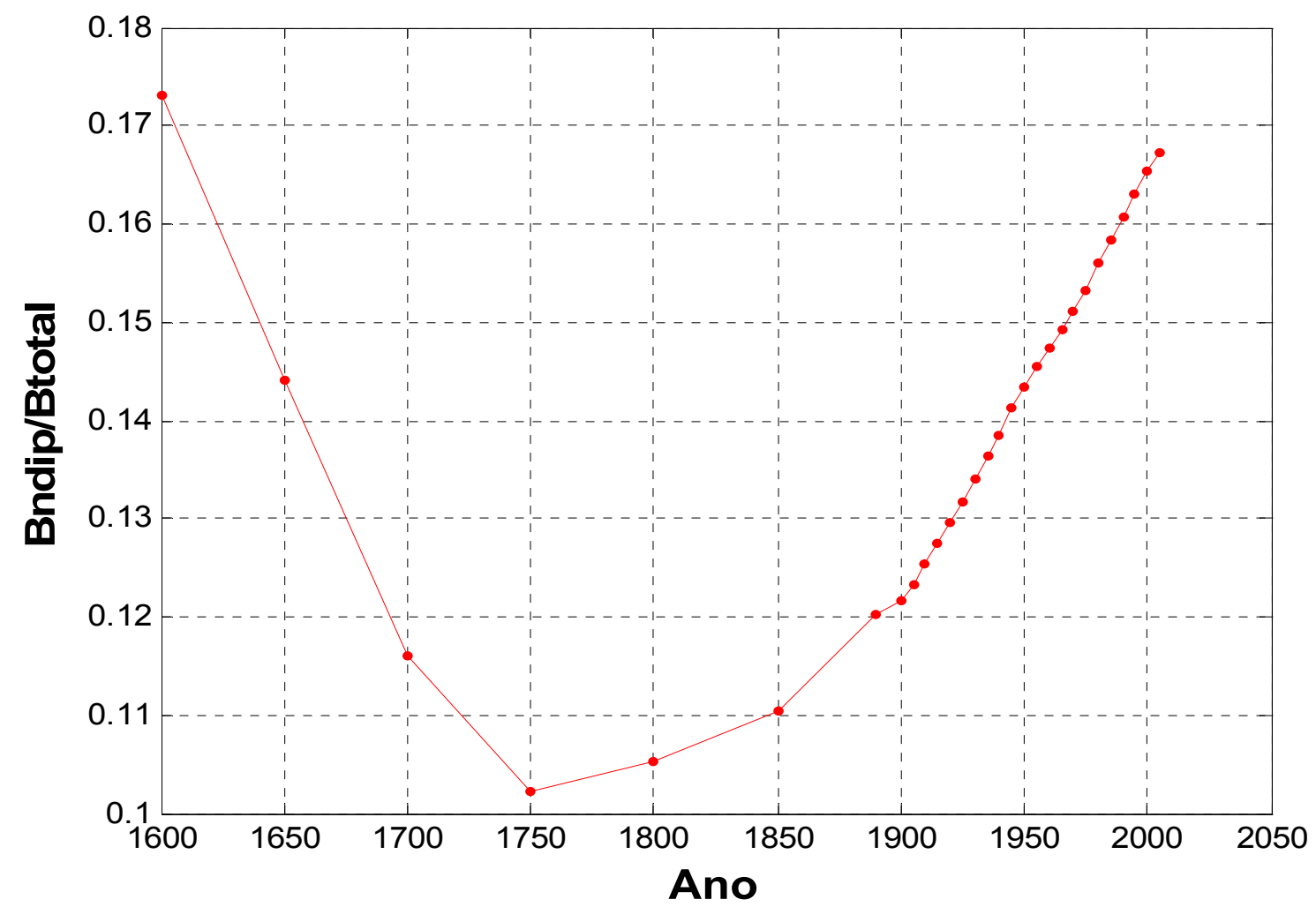

Figura 7.7: Razão entre o campo não-dipolar (Bndip) e total (Btotal) em função do tempo.

As características do campo não-dipolar diferem muito em relação ao campo total. Entretanto, há feições que têm persistido com o tempo e que localizam-se sobre o Atlântico Sul. Os mapas do Apêndice B mostram a razão entre os campos não-dipolar e total. Pelos mapas, observa-se que o ponto de máximo na razão entre os campos não-dipolar e total para a superfície, localiza-se predominantemente no Atlântico Sul. Este foco tem derivado para Oeste, do Sul da África à América do Sul, de 1600 até aproximadamente 1965, quando passou a intensificar-se mais à Leste, alcançando novamente o Sul da África. O gráfico da figura 7.8 mostra a razão entre os campos não-dipolar e total entre 1600 e 2005 do ponto de máximo campo nãodipolar. As menores taxas para o ponto de máximo campo não-dipolar são maiores do que as obtidas diretamente dos coeficientes dos modelos.

De 1850 até o período atual, praticamente todo o Atlântico Sul apresenta altas taxas de campo não-dipolar, conforme ilustrado pelas figuras do Apêndice B.

Com isto, nota-se que os coeficientes de mais alto grau que representam o campo não-dipolar, têm aumentado significativamente. No entanto, analisá-los somente em função dos modelos não fornece informações suficientes a respeito da SAMA. A razão entre os campos não-dipolar e total, do ponto de vista analítico é 
mais representativo para interpretar a SAMA porque mostra as variações do campo não-dipolar com a localização geográfica.

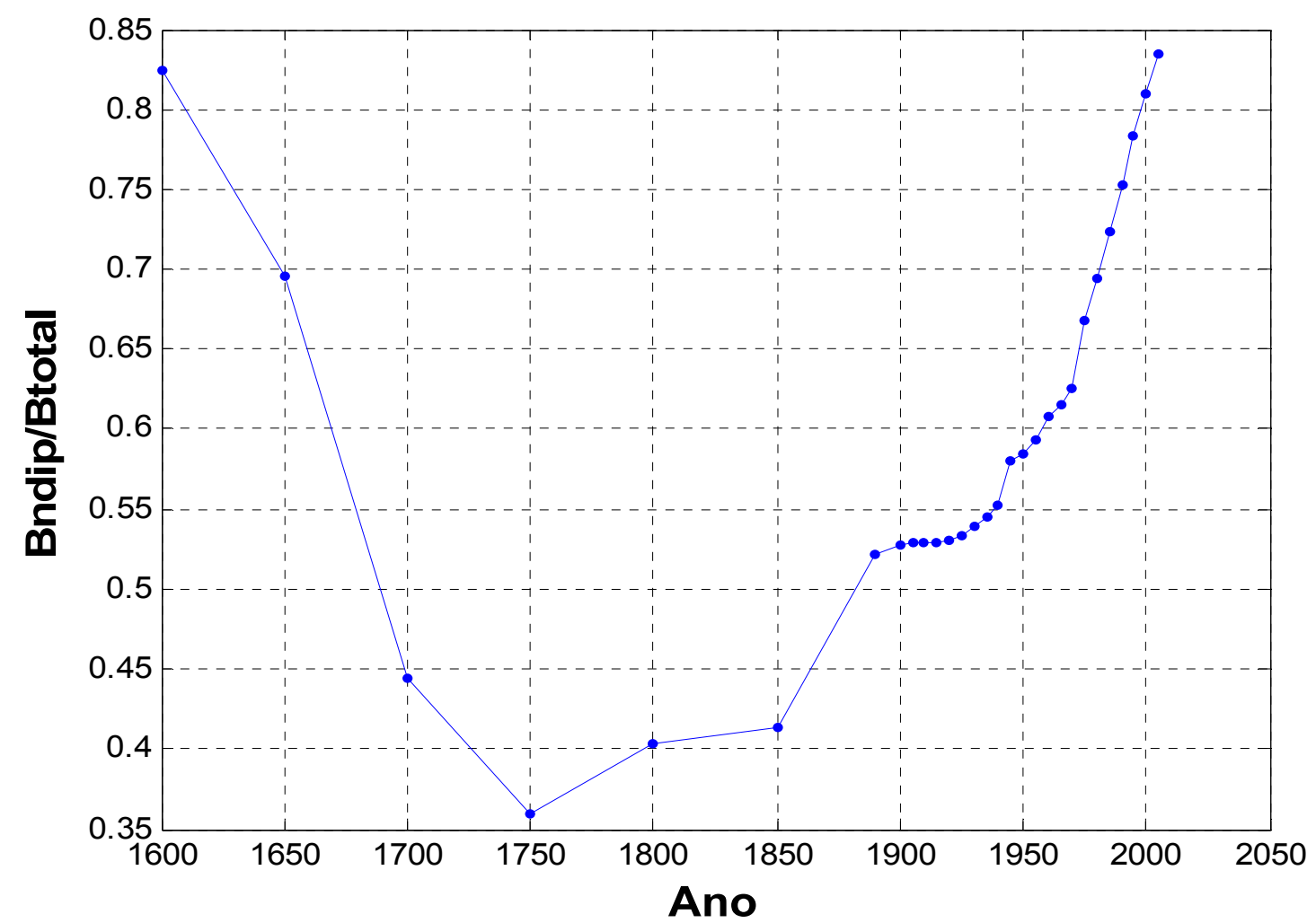

Figura 7.8: Razão entre o campo não-dipolar (Bndip) e o campo total (Btotal) em função do tempo para o foco de máximo campo não-dipolar no Atlântico Sul.

\subsubsection{Comparação com observatórios geomagnéticos}

Os observatórios de Vassouras - RJ (VSS), Pilar (PIL), Las Acacias (LAS) e La Quiaca (LQA) (estes três últimos localizados na Argentina) apresentam dados pelos quais pode-se observar a influência da SAMA.

Para esta comparação, foram utilizadas as médias anuais de intensidade

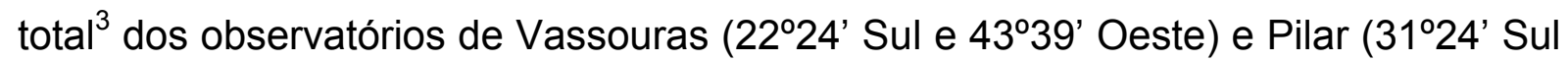
e 6353' Oeste) para o período de 1915 a 2001; Las Acacias ( $35^{\circ}$ Sul e $57^{\circ} 42^{\prime}$

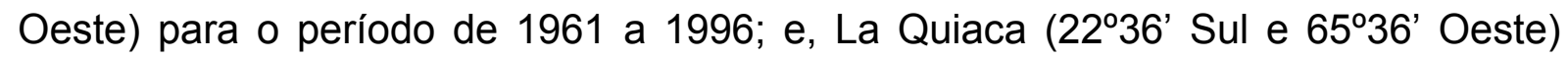
para o período de 1920 a 1992. A figura 7.2 mostra a deriva da SAMA para os últimos 105 anos e a posição geográfica dos observatórios.

As intensidades dos observatórios e da SAMA são comparadas no gráfico da figura 7.9. Os dados mostram um comportamento de diminuição da intensidade

\footnotetext{
${ }^{3}$ Dados obtidos no site do Britsh Geological Survey: http://www.geomag.bgs.ac.uk/gifs/annual_means.shtml.
} 
total dos quatro observatórios e do centro da SAMA. E diminui à medida que a SAMA aproxima-se dos observatórios.

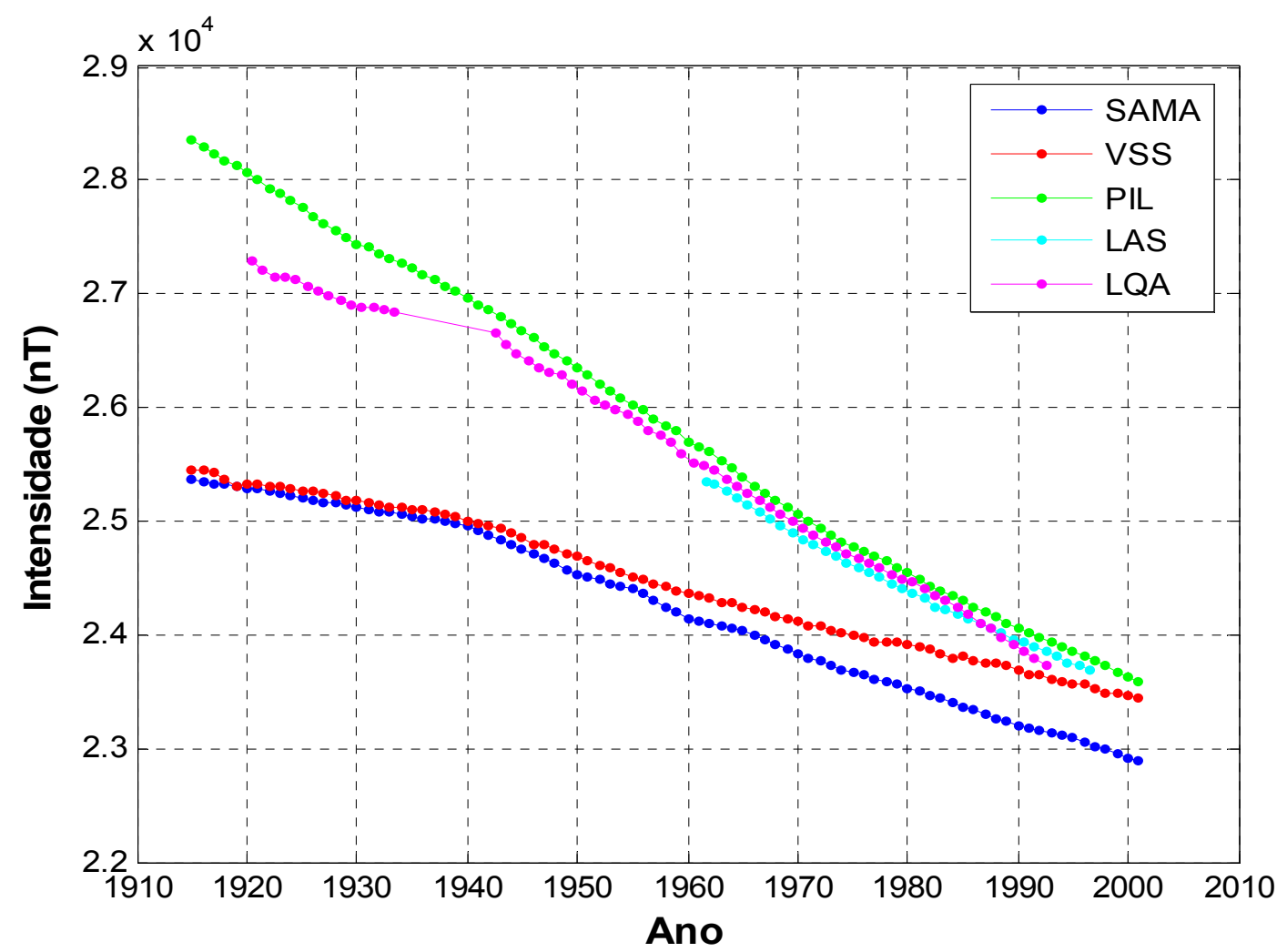

Figura 7.9: Intensidade total para a SAMA e para observatórios VSS, PIL, LAS e LQA em função do tempo.

O gráfico da figura 7.10 mostra a segunda derivada dos dados de intensidade. As variações dos observatórios são derivadas das médias anuais, enquanto que para a SAMA a resolução é qüinqüenal. As maiores variações ocorrem no período de 1940-1960 para a SAMA e os observatórios, sendo que os maiores picos de variação ocorrem em PIL e LQA por volta de 1960.

A influência da SAMA sobre PIL e LQA pode ser notada pois as variações tornam-se menores antes e após esse período. O início das atividades do VSS é coincidente com os anos em que o centro da SAMA estava aproximando-se de VSS, e que correspondem às maiores variações registradas pelo observatório. VSS e LQA apresentam grandes variações para o período de 1940-1950, porém o mesmo não ocorre em PIL. Este período é crítico porque coincide com o período de mudança de trajetória e de variações significativas para o centro da SAMA. Pode-se observar que tanto as posições de VSS, LQA e do centro da SAMA, encontram-se numa faixa de latitude que é inferior a $2^{\circ}$. Isto pode sugerir que um fenômeno, aparentemente mais 
localizado, possa ter afetado as medidas realizadas pelos observatórios, e conseqüentemente alterado a trajetória do centro da SAMA.

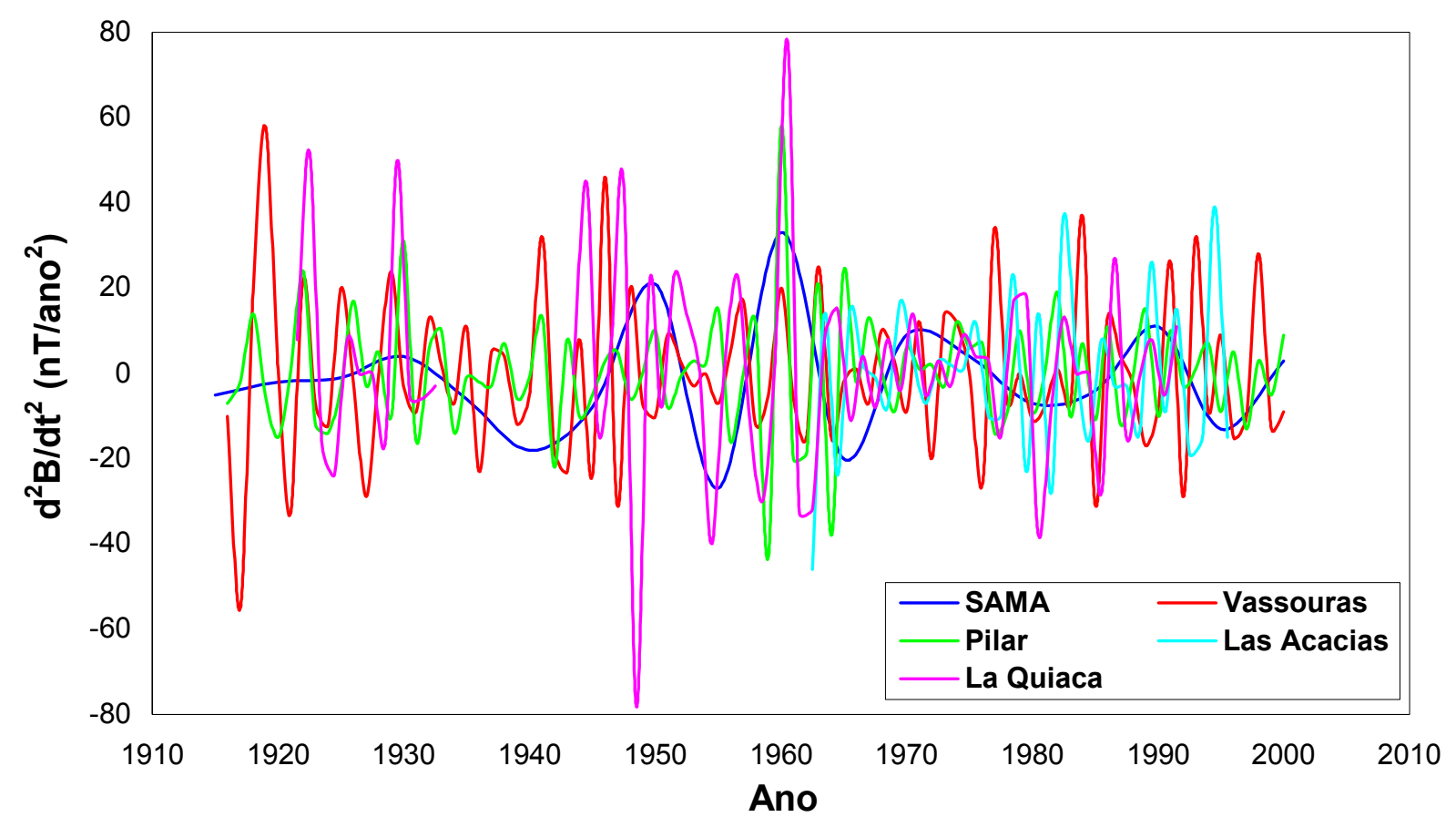

Figura 7.10: Segunda derivada dos dados de intensidade total da SAMA, VSS, PIL, LAS e LQA em função do tempo.

Os gráficos da figura 7.11 mostram as intensidades medidas pelos observatórios em função da distância ao centro da SAMA. O período em que a SAMA muda de trajetória (1945-1950) e apresenta as maiores variações, mostram diminuições abruptas de intensidade para os observatórios de VSS, PIL e LQA. Apesar do intervalo de LAS ser menor que o dos outros três, observa-se que a inclinação na curva de intensidade (figura 7.9) é semelhante á de PIL, provavelmente porque estes dois observatórios estão localizados mais ao Sul.

Entre os anos de 1915 e 1940, aproximadamente, a SAMA estava muito próxima de VSS (menos de $500 \mathrm{~km}$ ). Atualmente o centro da SAMA está aproximadamente num ponto eqüidistante aos quatro observatórios. Embora os observatórios apresentem diminuições em intensidades, mesmo com a SAMA afastando-se, como é o caso de VSS, deve-se atentar para o fato de que a SAMA, além de apresentar baixas intensidades, aumenta em área de abrangência. Este aumento em área pode ser observado nos mapas do Apêndice A pelo contorno de $28000 \mathrm{nT}$. 
a)

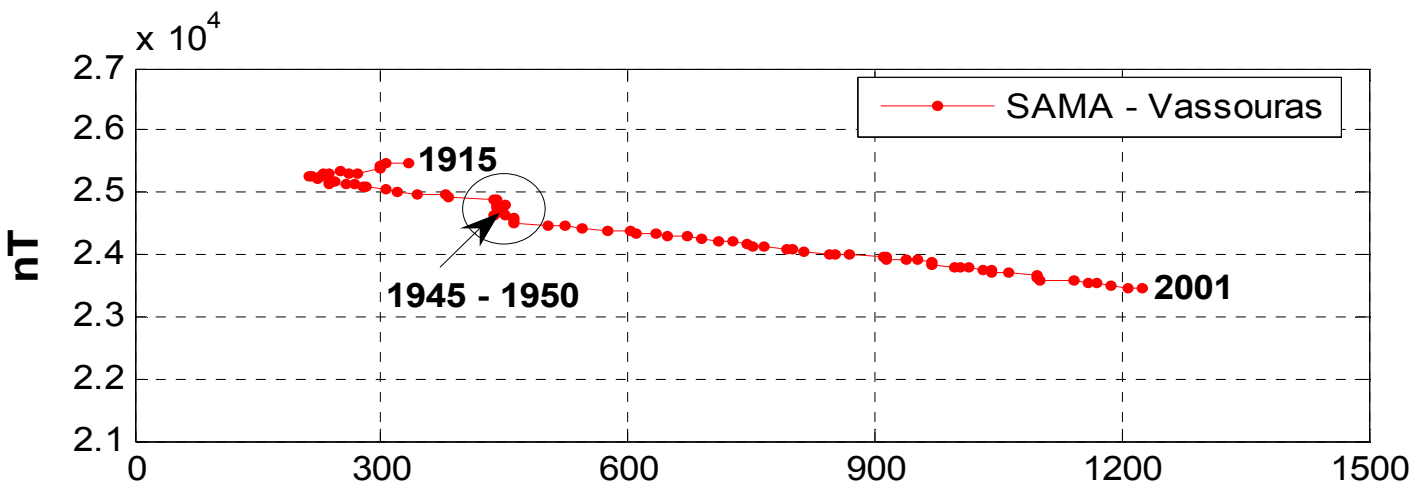

b)

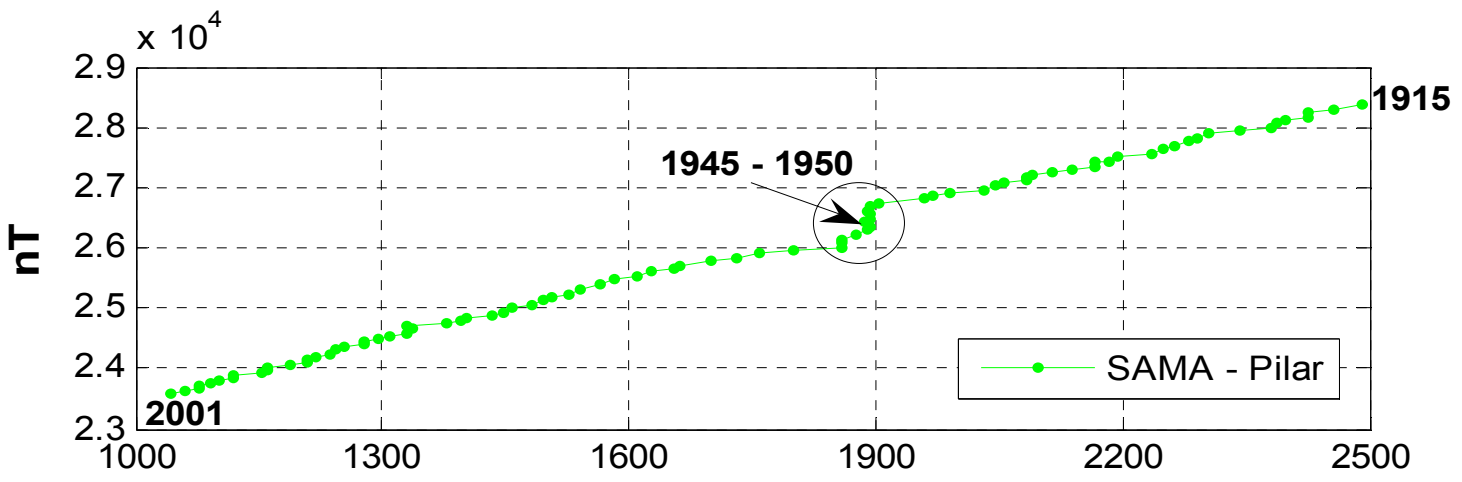

c)

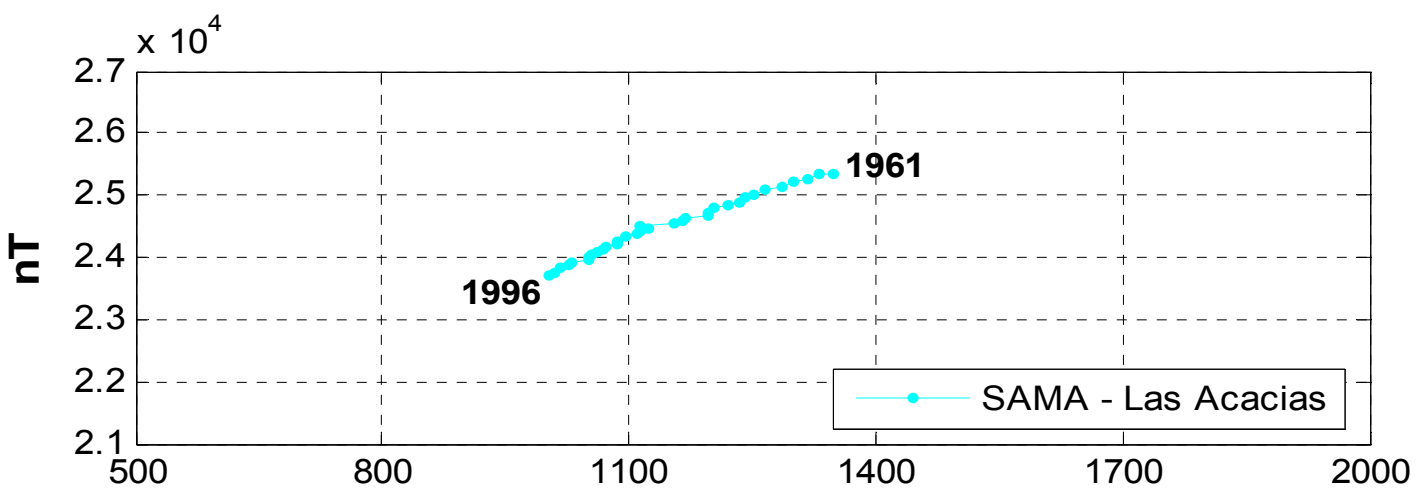

d)

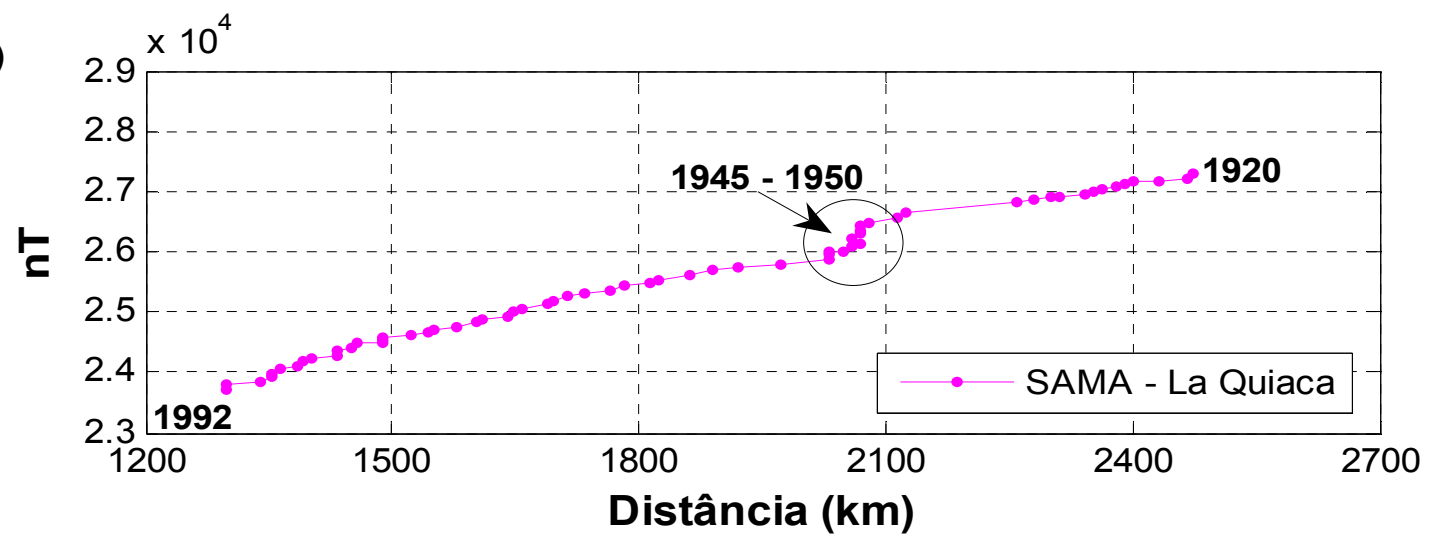

Figura 7.11: Variação de intensidade total dos observatórios em função da distância ao centro da SAMA. Em (a) para Vassouras, (b) para Pilar, (c) Las Acacias e (d) La Quiaca. 


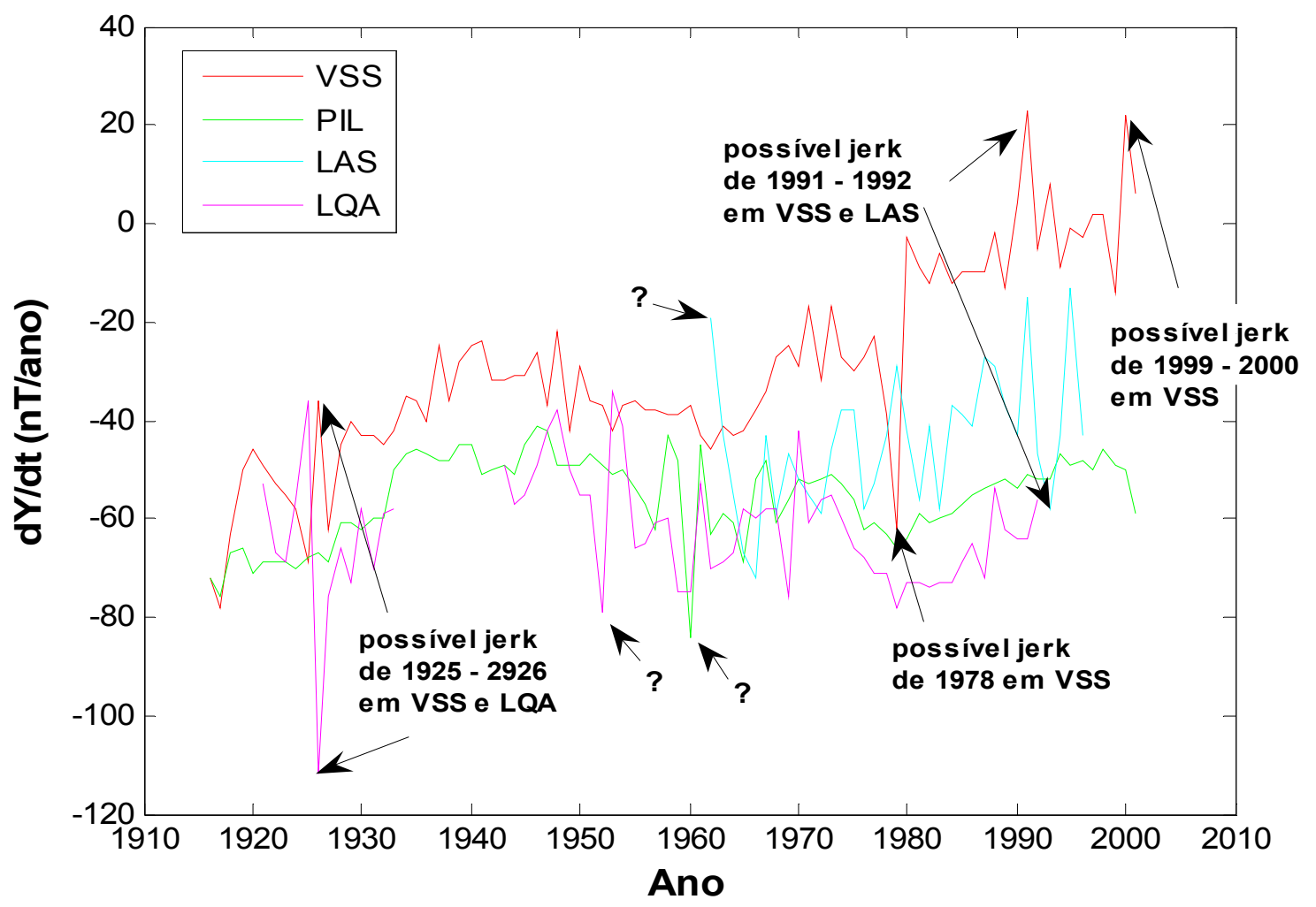

Figura 7.12: Primeira derivada da componente Y em VSS, PIL, LAS e LQA em função do tempo.

A comparação de dados de observatórios com a SAMA são interessantes porque pode fornecer informações sobre fenômenos como os jerks geomagnéticos. Nem todos os jerks descritos pela literatura são detectados nestes observatórios quando comparados com os observatórios europeus, e outras variações rápidas são observadas isoladamente em alguns observatórios. Apesar dos jerks apresentarem características mais locais e possivelmente poderem ser explicados por oscilações torcionais no núcleo externo [BLOXHAM et al., 2002], observa-se que quatro possíveis jerks podem ser detectados: o jerk de 1925-1926 é observado em VSS e LQA; de 1978 em VSS; de 1991-1992 em VSS e LAS e, de 1999-2000 em VSS apenas. Nota-se também, que variações rápidas são observadas em LQA em 1952, PIL em 1960 e LAS em 1962. Embora esses possíveis jerks não sejam descritos na literatura são coincidentes com as maiores variações apresentadas pela SAMA. Isto pode sugerir que um comportamento magnético de longo comprimento de onda, como é o caso da SAMA, pode se sobrepor a sinais menores como os jerks. A derivada primeira da componente $Y$ para VSS, LAS, LQA e PIL são mostradas na figura 7.12 . 


\subsubsection{Comparação com outras anomalias do campo}

Como a SAMA é caracterizada por apresentar baixas intensidades do campo geomagnético total, pode-se observar, neste contexto, outras anomalias na superfície terrestre como os pólos geomagnéticos e o Alto da Sibéria. Comparar estas anomalias com a SAMA pode indicar possíveis relações entre elas.

O gráfico da figura 7.13 mostra um comparativo das intensidades e a figura 7.14 a posição geográfica dos pontos de máxima intensidade entre a SAMA e os pólos Norte e Sul geomagnético entre 1600 e 2000. Aparentemente, observa-se que tanto os pólos quanto a SAMA são anomalias independentes e que não apresentam relação direta entre si.

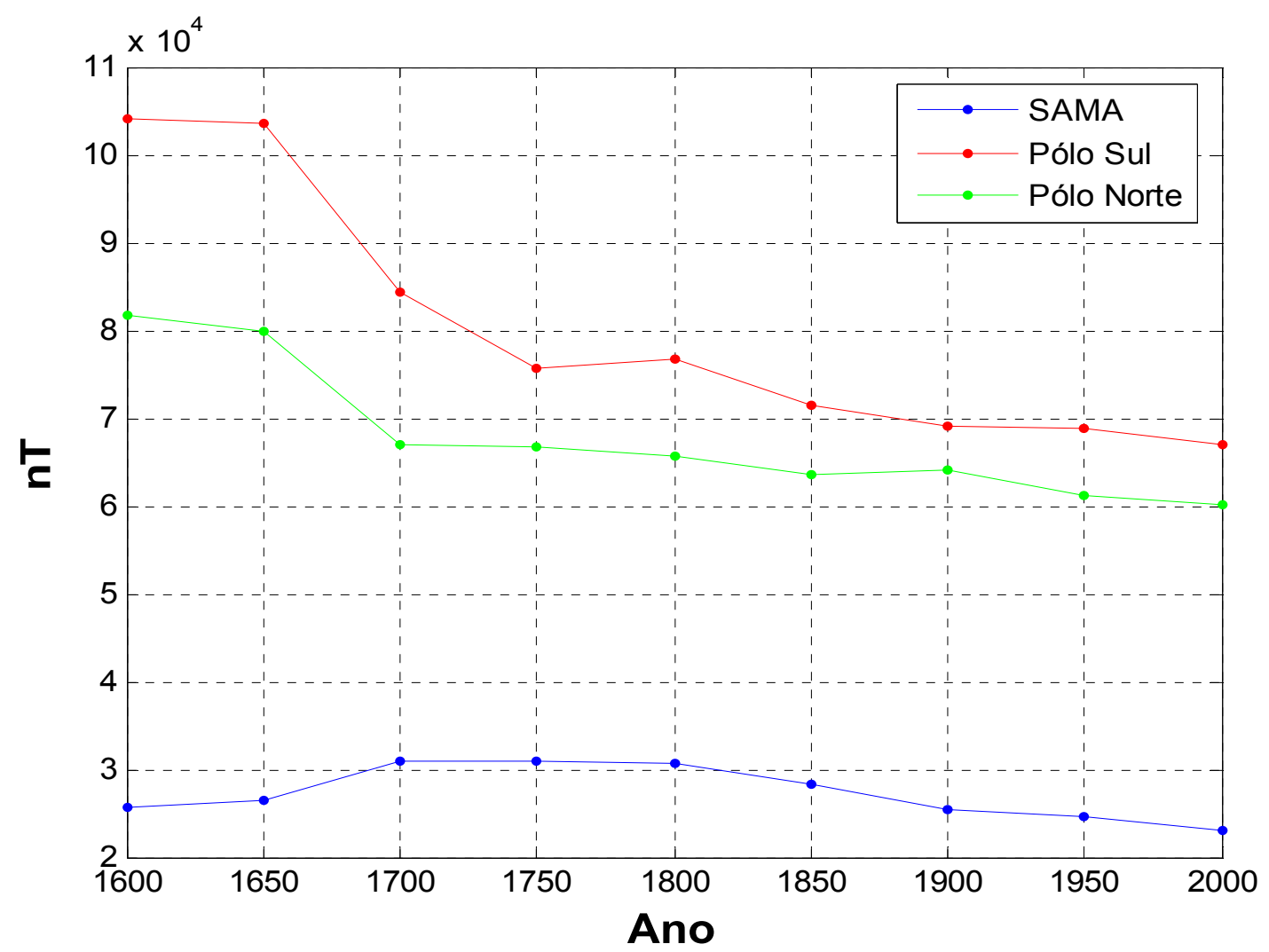

Figura 7.13: Intensidade total para a SAMA e para os pólos Norte e Sul em função do tempo.

As intensidades do pólo Norte são menores do que as intensidades do pólo Sul na escala do período histórico (1600-2000), embora ambos apresentem diminuição nas intensidades. Para os últimos 200 anos, aproximadamente, a SAMA e os pólos apresentam queda nos valores de intensidade. Isso sugere que a queda do momento dipolar é importante para todo o campo e não somente para os pólos. 


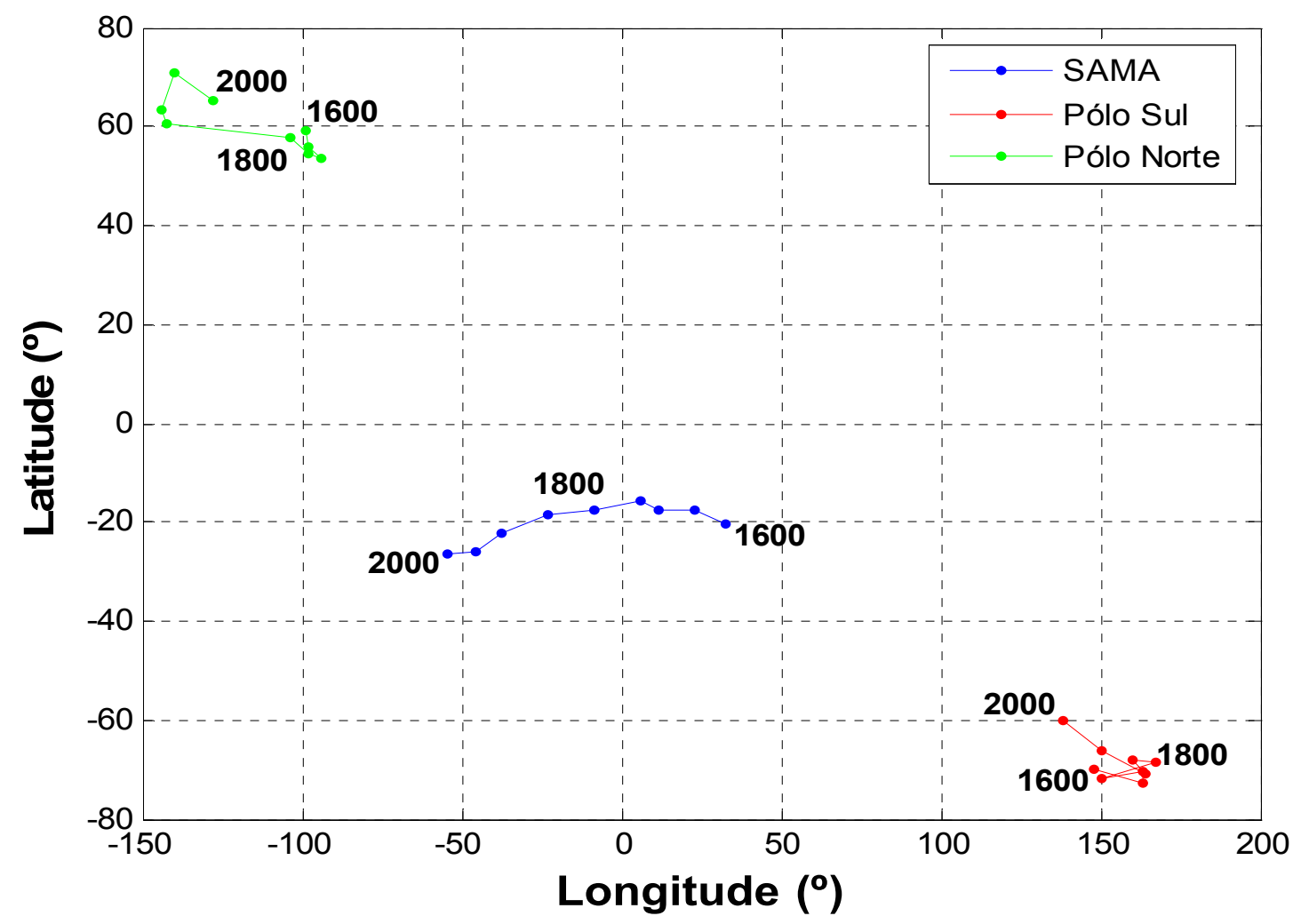

Figura 7.14: Deriva da SAMA e dos pólos Norte e Sul em função do tempo.

No entanto, o campo não-dipolar é mais significativo para a região de abrangência da SAMA porque de 1600 a 1700 as intensidades cresciam com o tempo e o período coincide com a diminuição do campo não-dipolar. Entre 1700 e 1800, as variações são mais estáveis, quando a partir de 1800 a intensidade começa a diminuir e, o campo não-dipolar começa a aumentar, como pode ser constatado pelos resultados da seção 7.1.3.

Os pólos apresentam deslocamentos independentes quanto às derivas e a SAMA parece ter um comportamento de deriva mais equatorial (por se encontrar em baixas latitudes), e está relativamente mais próxima do pólo Sul. Embora seja uma aproximação, os deslocamentos independentes não sugerem alguma relação direta para a deriva das três anomalias.

O Alto da Sibéria é caracterizado por apresentar campo total de intensidade elevada. Esta anomalia fica evidente nos mapas de campo total a partir de aproximadamente 1890-1900 (como pode ser verificado nos mapas do Apêndice A). Atualmente, as intensidades do Alto da Sibéria são superiores às do pólo Norte. Os gráficos da figura 7.15 mostram as intensidades do centro da SAMA, do Alto da Sibéria e dos pólos Norte e Sul a partir de 1900. 
A semelhança de intensidades entre o pólo Norte e o Alto da Sibéria pode sugerir uma possível mudança de localização, onde atualmente encontra-se o pólo Norte geomagnético para a posição do Alto da Sibéria [MANDEA e DORMY, 2003]. A época de 1945-1950, mostra que as intensidades do Alto da Sibéria passam a ser superiores, porém, próximas às do pólo Norte. Isso perdura até 1980, aproximadamente, quando as intensidades do pólo Norte diminuem mais rapidamente, enquanto para o Alto da Sibéria se mantém estável.

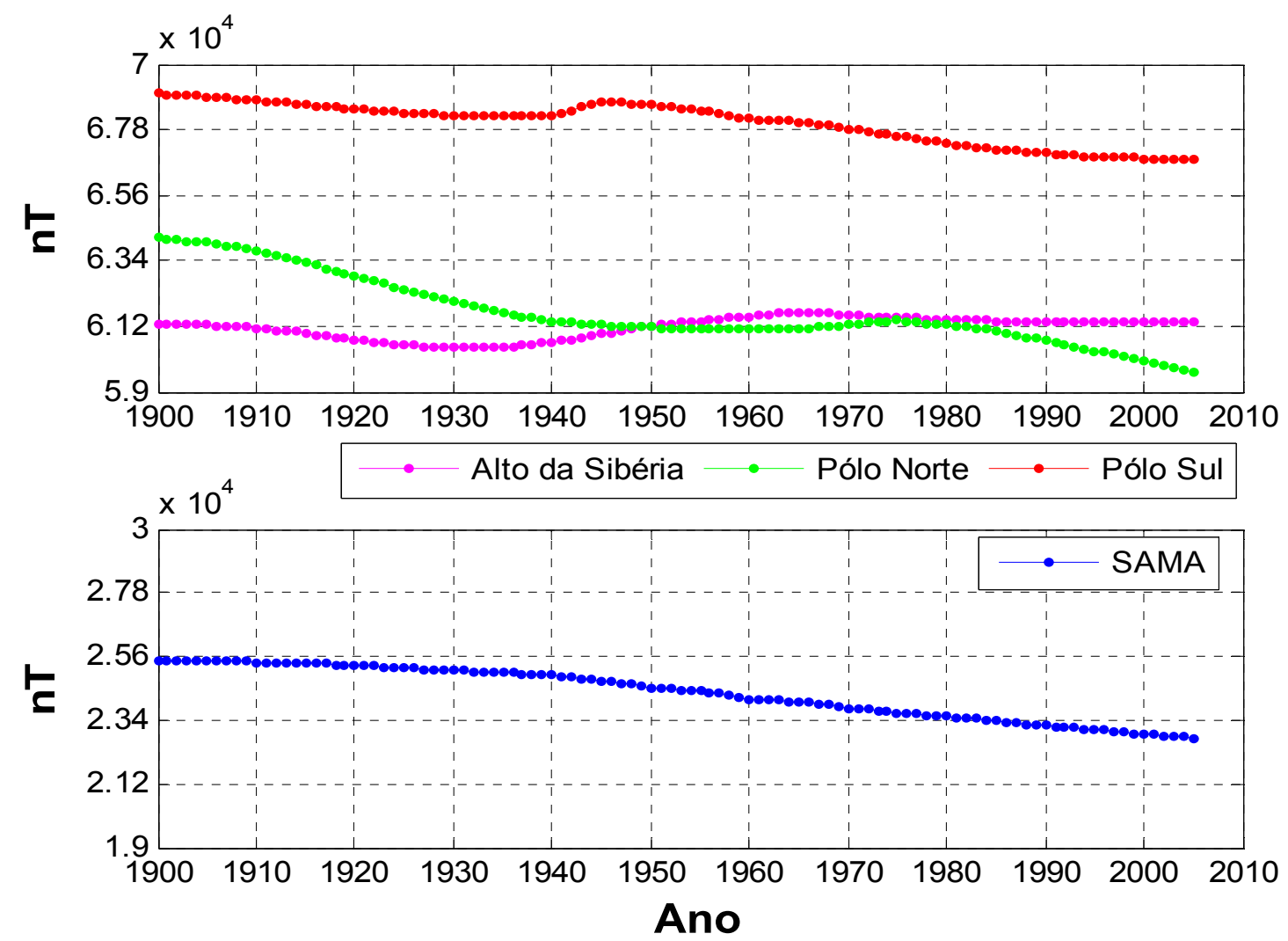

Figura 7.15: Intensidades para as quatro anomalias do campo em função do tempo.

Para o período de 1940-1970, nota-se um comportamento de maior variação para as quatro anomalias, sendo que as maiores variações ocorrem no pólo Sul, conforme a segunda derivada das intensidades (figura 7.16). Os picos e vales mostram a resolução temporal de cinco anos dos modelos do IGRF.

As maiores variações do pólo Sul ocorrem para o período de 1940-1960. A variação para a época de 1945 corresponde a variações menores para a SAMA, o Alto da Sibéria e o pólo Norte. Pode-se sugerir então, que as contribuições nãodipolares são significativas também para o pólo Sul. A proximidade da SAMA ao 
pólo Sul pode favorecer a essas grandes variações. Os mapas de intensidade total do Apêndice A mostram a evolução das quatro anomalias.

O pico de maior variação do pólo Norte coincide com a época em que as intensidades começam a diminuir mais rapidamente. De um modo geral, o comportamento das quatro anomalias apresentam três patamares de variação: para 1900-1940, 1940-1970 e 1970-2005. Quando comparada com as variações das outras anomalias, a SAMA, apresenta variações relativamente menores sendo comparáveis em alguns períodos somente.

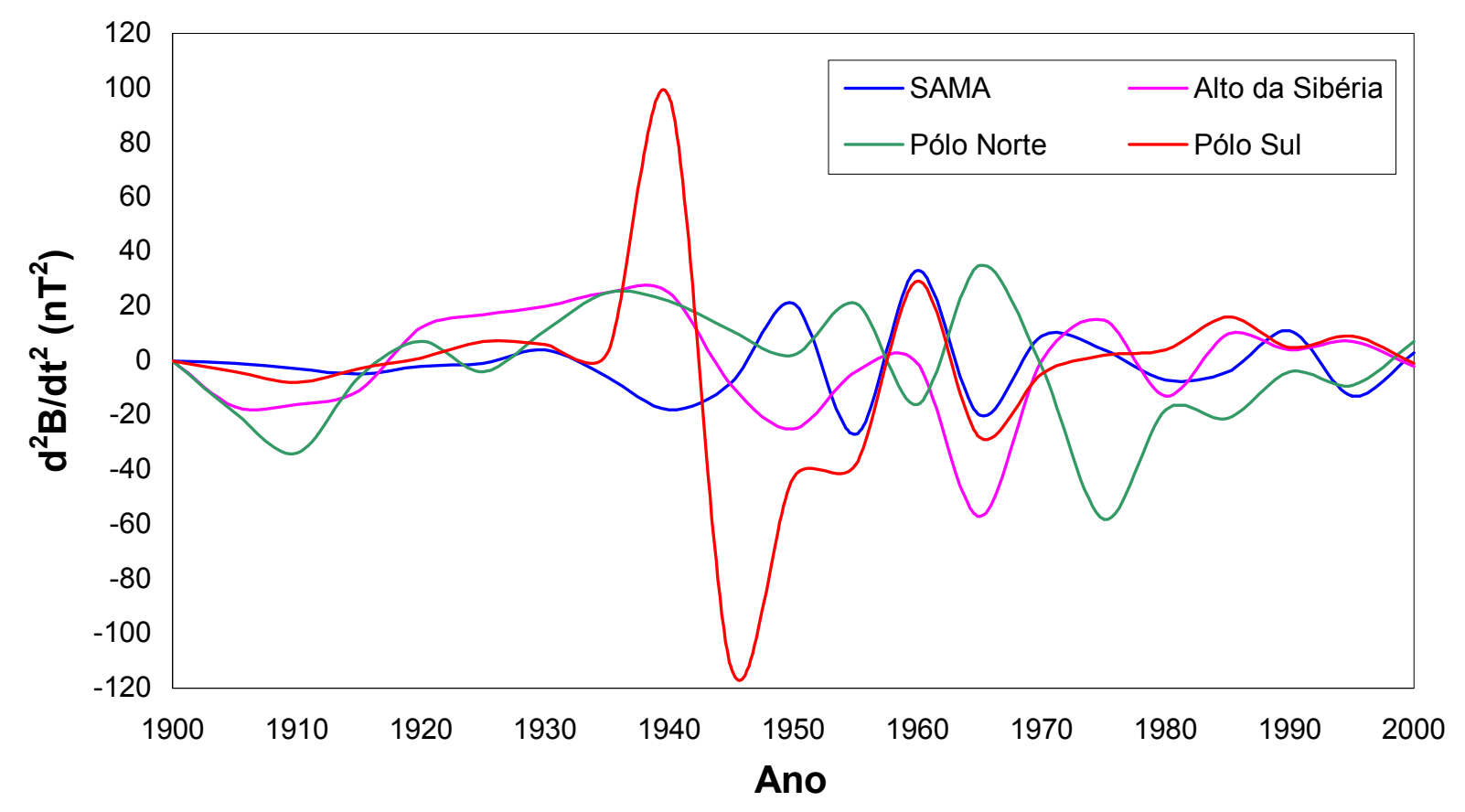

Figura 7.16: Segunda derivada das intensidades para as quatro anomalias do campo em função do tempo.

$\mathrm{Xu}(2000,2002)$ tem sugerido que os coeficientes de Gauss com $n \geq 6$ pouco afetam as principais feições do campo principal na superfície. No entanto, variações maiores, como a dos pólos, são observadas e estas mostram que o campo não-dipolar pode ser significativo. Mesmo as variações da SAMA são consideráveis, até porque a morfologia é alterada.

A figura 7.17 é um comparativo de derivas da SAMA, do Alto da Sibéria e dos pólos Norte e Sul. As quatro anomalias apresentam deriva para Oeste e um comportamento diferenciado de trajetória para a época de 1940-1950. Todas anomalias apresentam características particulares neste período, isso evidencia que o campo, para este período, foi realmente diferenciado das demais épocas e sugere 
que pode ter ocorrido um fenômeno de abrangência global e de origem interna do campo.

O pólo Norte e o Alto da Sibéria apresentam um período de deriva para Leste. A hipótese de que estas duas anomalias podem estar interconectadas, é reforçada pelo fato das variações ocorrerem praticamente numa mesma latitude e, aproximadamente opostas em longitude. O pólo Sul apresenta variações maiores de longitude (relativas à posição em latitude) do que o pólo Norte e o Alto da Sibéria.
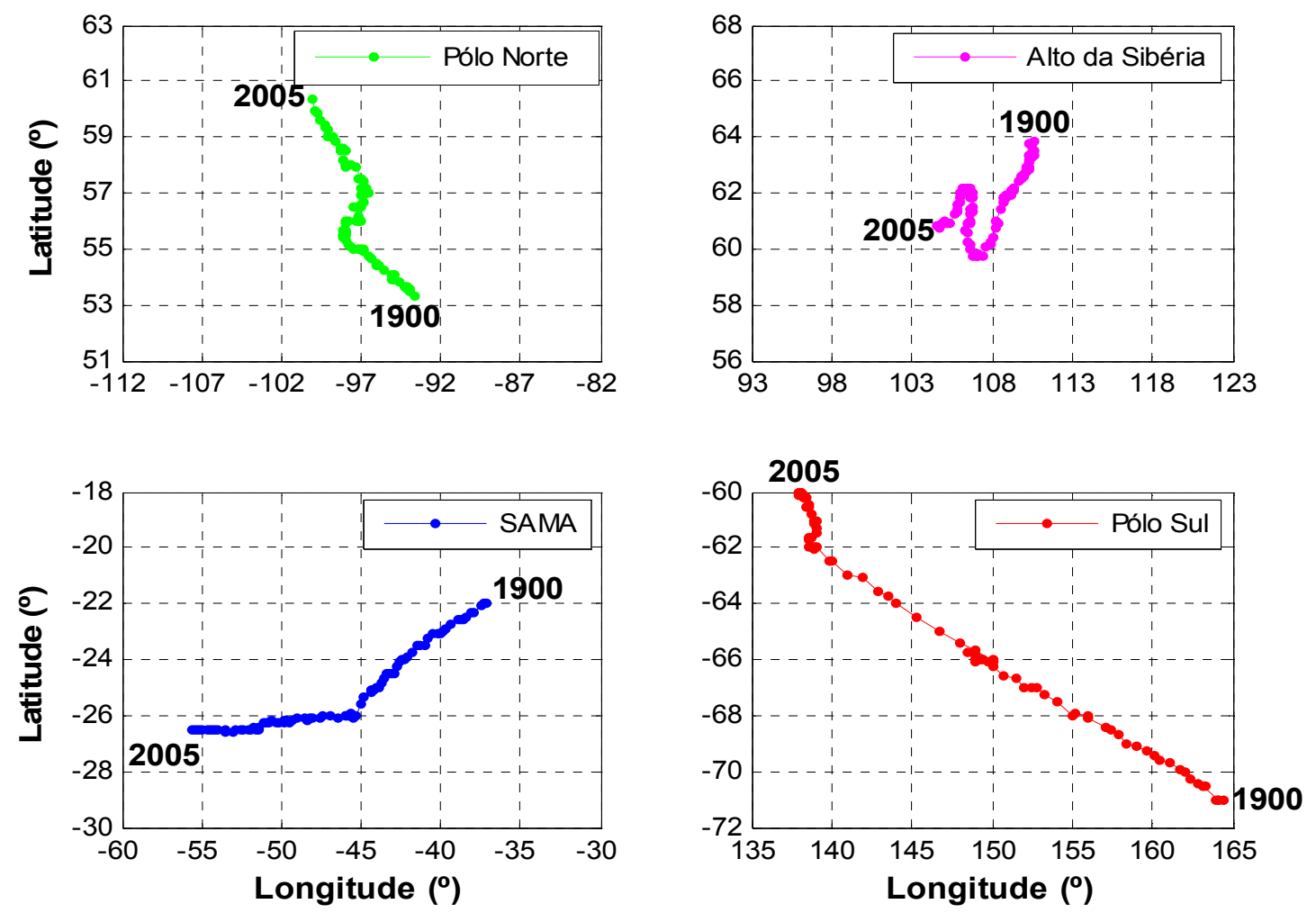

Figura 7.17: Localização geográfica para as quatro anomalias do campo em função do tempo.

Contudo, pode-se verificar que o movimento independente da SAMA com relação às outras anomalias do campo é evidente e constata-se que o comportamento é predominantemente devido ao campo não-dipolar.

\subsection{Anomalias do campo magnético na interface manto-núcleo}

O campo magnético na interface manto-núcleo pode, de certa forma, revelar as causas da morfologia do campo na superfície. Muitos trabalhos foram realizados 
neste sentido, e técnicas utilizadas para este tipo de mapeamento, foram elaboradas. O mapeamento do campo na CMB é demonstrado com a componente vertical do campo e parte do pressuposto de que o manto é um isolante, ou seja, que as correntes elétricas do manto inferior possam ser desprezadas (seção 4.2).

Uma técnica utilizada para este tipo de mapeamento é a chamada "Técnica de Inversão Estocástica" [BLOXHAM e GUBBINS, 1985; BLOXHAM, 1987; BLOXHAM e JACKSON, 1989; BLOXHAM et al., 1989; BLOXHAM e JACKSON, 1992; JACKSON, et al., 2000; JACKSON, 2003], que utiliza dados de levantamentos magnéticos terrestres, marítimos e de satélite para inversão. A técnica é bem estabelecida e consegue fornecer modelos adequados para interpretação.

Neste trabalho não foi utilizada a técnica de inversão estocástica para mapeamento do campo na CMB. Para fins de comparação e representação, adotouse, simplesmente, a continuação para baixo de todos os modelos utilizados. Os resultados do mapeamento são mostrados nos mapas do Apêndice $C$.

A figura 7.18 compara mapas na CMB para a época de 1990, obtidos utilizando a continuação para baixo com um mapa usando a inversão estocástica do trabalho de Jackson et al. (2000). As diferenças aparentes ocorrem devido à convenção do campo vertical: valores negativos em um mapa correspondem aos positivos no outro e vice-versa. Porém, os mapas apresentam gradientes aproximadamente idênticos e as maiores feições do campo são mostradas em ambos. Os fluxos obtidos são compatíveis com os valores esperados e semelhantes aos de modelagem por inversão.

Os coeficientes de alto grau descrevem feições magnéticas de pequena escala. As intensidades destas feições sobre a superfície são baixas quando comparadas com os coeficientes de baixo grau. Porém, para profundidades da CMB, os coeficientes de alto grau contribuem significativamente nos fluxos magnéticos. Isto pode ser avaliado através da equação (3.30) (potencial magnético), em que um coeficiente de grau $n$ é proporcional a razão $(a / r)^{n+1}$. Na superfície, esta razão é igual a 1 para qualquer grau $n$, enquanto que na $\mathrm{CMB}$ a razão aumenta com o aumento de $n$. Por exemplo, para o modelo do IGRF2000, na superfície o somatório dos coeficientes com $n=4$ é 1534,1nT e na CMB é 31295,6nT; para os coeficientes com $n=10$ na superfície é $-9,2 \mathrm{nT}$ e na CMB é $-7014,1 \mathrm{nT}$. De todos os modelos analisados, os fluxos dos modelos para o período de 1940-1960 apresentam valores 
maiores do que seria esperado. Para este período, os modelos possuem coeficientes com $n>6$ que mudaram drasticamente de valor [XU, 2000].

a)

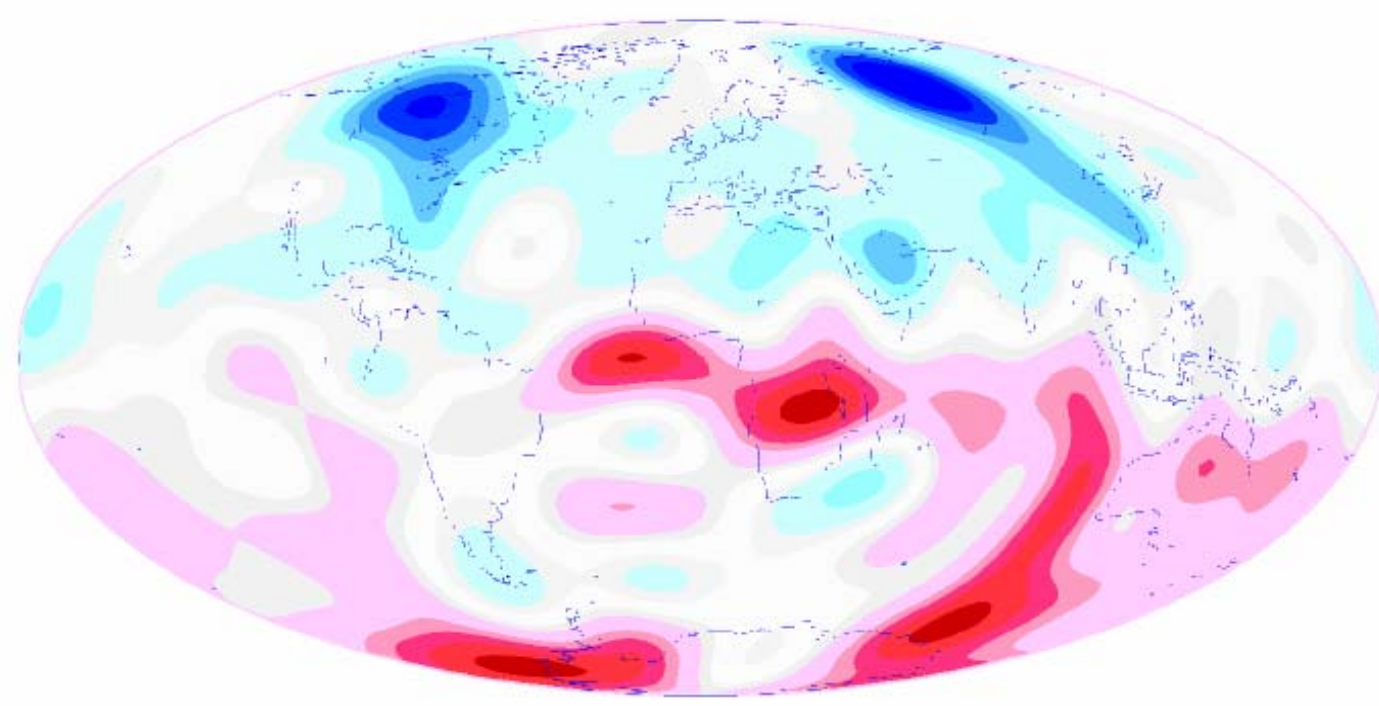

b)
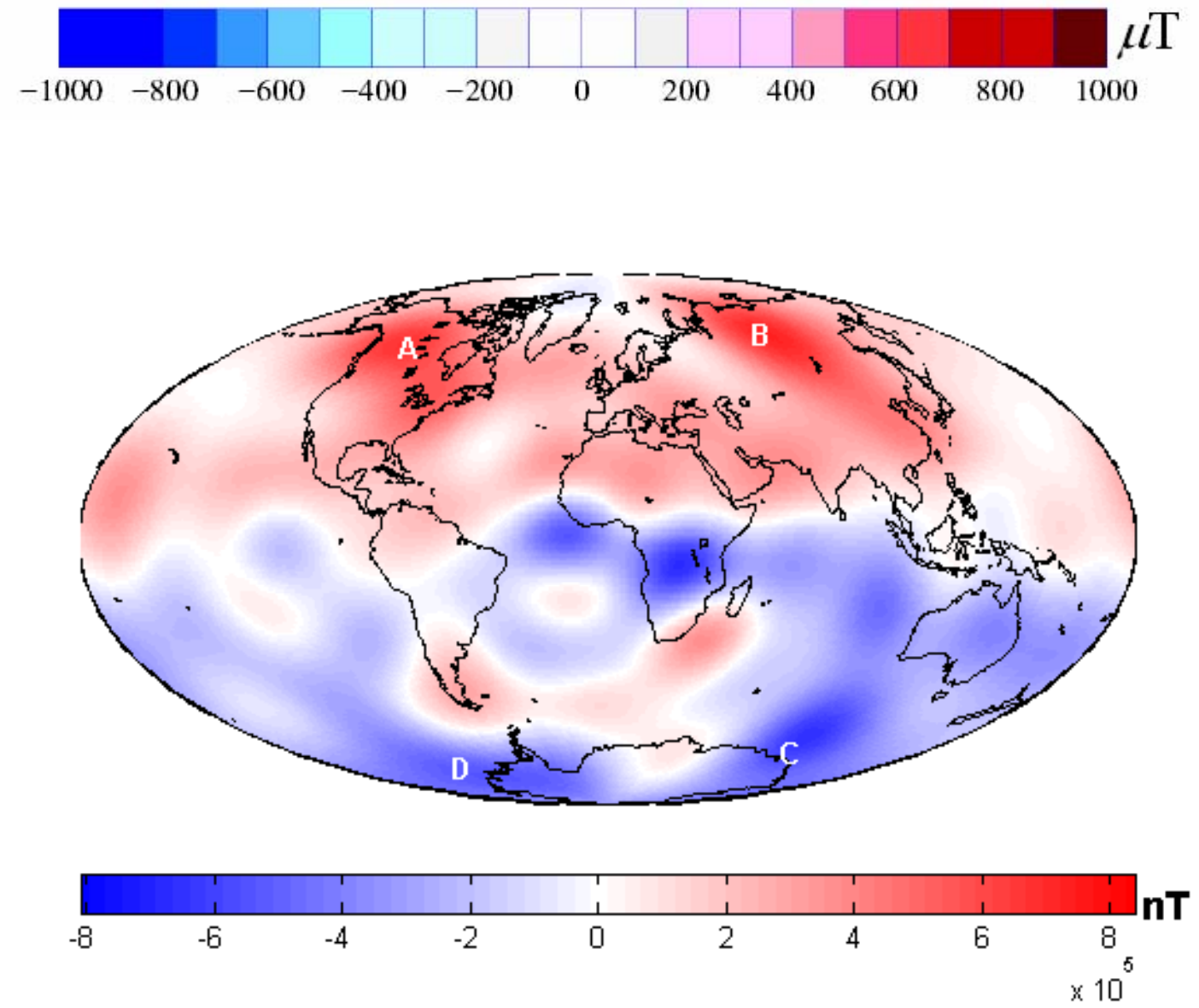

Figura 7.18: Mapas da componente radial na CMB. Em (a), modelo de Jackson et al. (2000), truncado até $n=14$ e em (b) usando a continuação para baixo, truncado até $n=10$. Os gradientes de intensidades são compatíveis. Ambos os mapas estão na projeção Aitoff. 
O aumento de fluxo magnético observado dos modelos iniciais até o período atual, deve-se em parte à expansão dos modelos (figuras do Apêndice $\mathrm{C}$ ). Os modelos para o período histórico (1600-1890) estão truncados até $n=4$ e os modelos para o último século até $n=10$ (1900-1995) e $n=13$ (2000-2005), o que dá um ganho significativo de feições aos mapas. As feições de maior amplitude são mostradas em todos os modelos, como por exemplo os pólos. No entanto, os modelos de mais alto grau contribuem para os mapas mostrando o campo com mais detalhes. Partindo desse pressuposto, pode-se atentar para os "lóbulos" (anomalias) de fluxo magnético que aparecem na CMB.

As regiões polares apresentam características peculiares. As feições que parecem estar caracterizando os pólos observados em superfície, apresentam também anomalias "próximas", que podem estar alterando os movimentos das linhas de campo. Um exemplo que se pode citar sobre isso é o Alto da Sibéria. Suas características em superfície podem sugerir uma conexão com o pólo Norte. Situação semelhante ocorre no pólo Sul para os mapas da CMB mas, ao contrário do Alto da Sibéria, esta anomalia ainda não é observada na superfície. No entanto, o rápido movimento do pólo Sul na superfície sugere que feições semelhantes às do hemisfério Norte possam ocorrer também no hemisfério Sul.

A análise destes "lóbulos principais" na CMB pode sugerir algo nessa direção. Os quatro lóbulos ( $A, B, C$ e $D$ ), ora mostrados na figura $7.18 \mathrm{~b}$, estão aproximadamente na região dos pólos. Uma tentativa de análise do comportamento desses lóbulos é mostrada na figura $7.19 \mathrm{com}$ a razão entre as intensidades aproximadas para as regiões dos quatro lóbulos.

As razões entre os lóbulos dos pólos indicam uma forte correspondência de características do campo na superfície. As variações observadas na superfície para o período de 1940-1960 são percebidas também nos mapas da CMB. O gradiente do fluxo varia muito para esse período, provocando grandes mudanças morfológicas do campo na CMB (Apêndice $C$ ). Essas variações são comparadas na razão entre as intensidades dos lóbulos que supostamente representam os pólos ( $A$ e $C$ ) e, dos lóbulos que podem indicar o Alto da Sibéria e uma outra anomalia (B e $D)$, que poderá vir a surgir em superfície, se for suposto algo semelhante ao que vem ocorrendo com o Alto da Sibéria. 


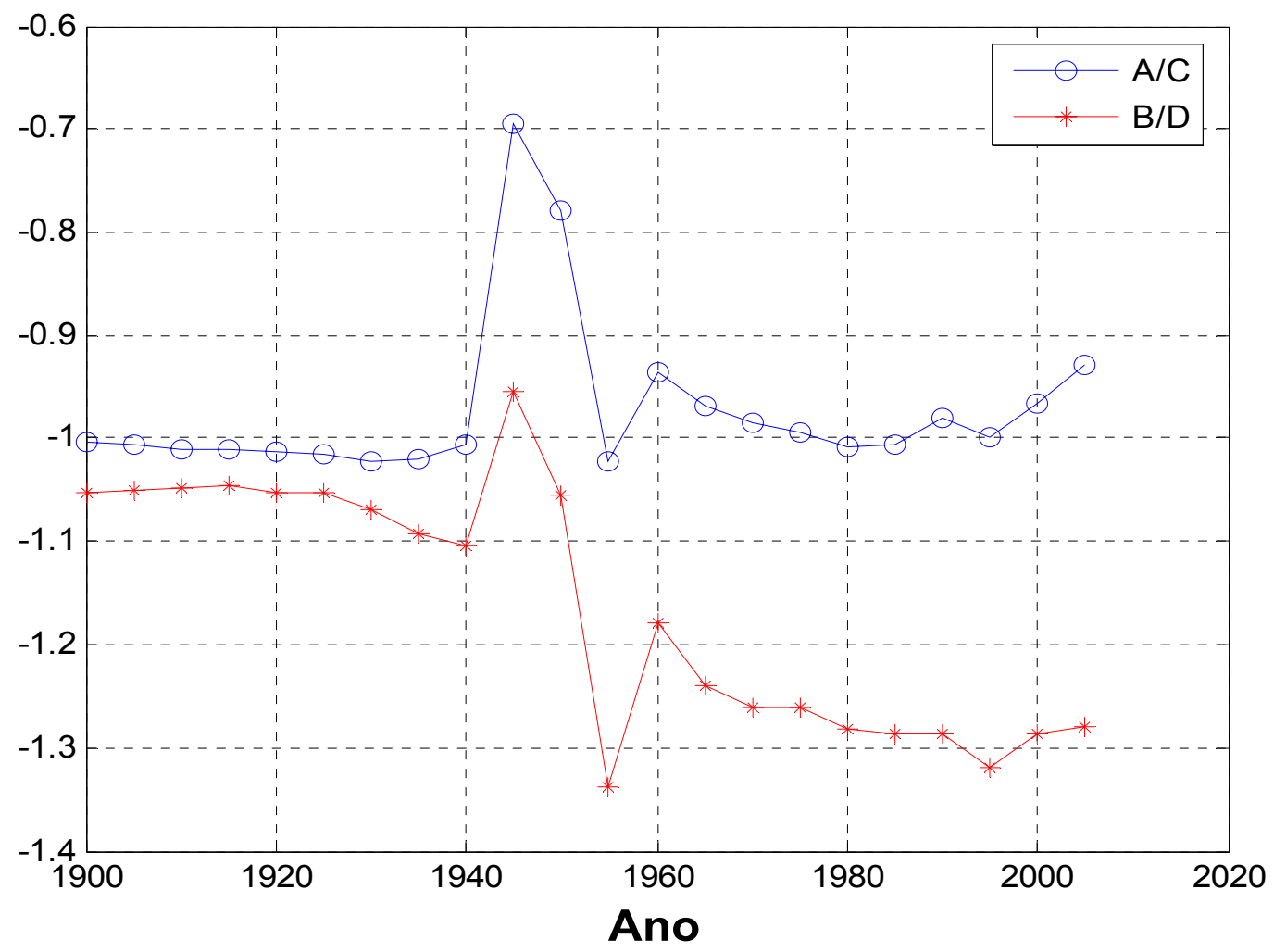

Figura 7.19: Razão entre as intensidades dos lóbulos principais do núcleo em função do tempo.

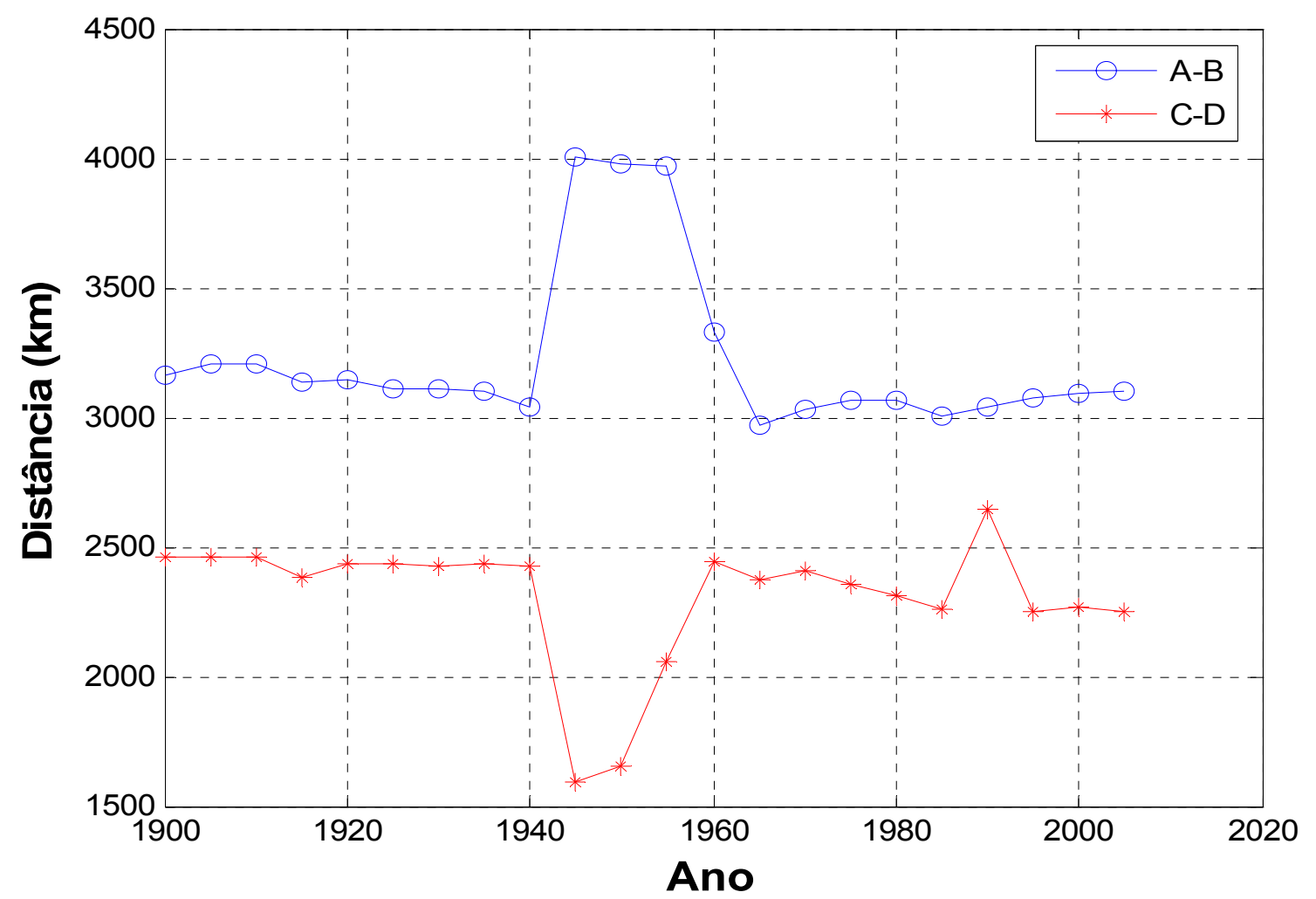

Figura 7.20: Distância aproximada entre os lóbulos principais do núcleo em função do tempo. 
A figura 7.20 compara as distâncias aproximadas entre os lóbulos A-B e CD. Os afastamentos e aproximações entre os lóbulos podem indicar uma possível interconexão entre os lóbulos. Observa-se que enquanto os lóbulos A e B afastamse, os lóbulos C e D aproximam-se. Este movimento relativo entre os lóbulos pode indicar grandes movimentos de fluido no núcleo externo.

Uma hipótese nesta direção indica que o núcleo externo está essencialmente em balanço geostrófico. Isto significa que a força de Coriolis é balanceada com a força de pressão. Considera-se que as outras forças, como empuxo, inércia, viscosidade e força de Lorentz, não interferem no fluxo geostrófico. Neste caso, uma conseqüência destas suposições seria de que os campos poloidal e toroidal no núcleo teriam magnitudes semelhantes.

Um aspecto importante do fluxo geostrófico é o que envolve as colunas de convecção e os campos magnéticos associados (seção 5.3). Estes campos magnéticos devem ser principalmente toroidais (assumindo a hipótese do frozen flux), exceto próximo das interfaces. Nas interfaces, a sucção de Ekman produz um campo poloidal, que em princípio, é observado na superfície da Terra. A sucção de Ekman refere-se ao fluxo radial secundário que é "sugado" (ou ejetado) proveniente da borda da camada (ou de dentro) do "corpo principal" do fluido do núcleo [MERRILL et al., 1998].

As distâncias relativas entre os lóbulos são da ordem do diâmetro do núcleo interno. As aproximações e afastamentos dos lóbulos do núcleo são aproximadamente proporcionais, ou seja, enquanto os lóbulos A e B afastam-se, os lóbulos C e D aproximam-se na mesma proporção. O gráfico da figura 7.20 pode confirmar a idéia de Bloxham e Gubbins (1985) de que os dois pares estacionários de focos magnéticos estariam associados com colunas de convecção do núcleo. Neste caso, cada par estaria em hemisférios opostos e separados aproximadamente em $120^{\circ}$. As colunas de convecção adotadas para cada par seriam tangentes ao núcleo interno da Terra e estariam posicionadas paralelas à direção do eixo $z$, assim, os lóbulos A e D seriam produzidas por uma coluna e os lóbulos B e C por outra coluna. Bloxham e Gubbins (1985) especularam ainda que um terceiro par poderia estar presente nesta simetria, mas que talvez este par não seria observado porque uma estrutura adicional poderia estar presente na convecção do núcleo. Assim, se os quatro lóbulos são estacionários, e se forem manifestações das colunas de convecção no núcleo, estas colunas também devem ser estacionárias. 
$\mathrm{O}$ equador magnético na $\mathrm{CMB}$ difere bastante do equador na superfície. As feições próximas ao equador na $\mathrm{CMB}$ são de anomalias de menor comprimento de onda e se apresentam em maior número do que os lóbulos próximos aos pólos. De um modo geral, os dois hemisférios são separados pelo equador magnético. Há predominância das polaridades em cada hemisfério: no Norte o campo é positivo e no Sul o campo é negativo. Embora exista essa distinção entre os hemisférios, devese notar que o hemisfério Sul apresenta alguns lóbulos de polaridade positiva. Isto significa que nesses lóbulos o campo é oposto ao que seria esperado para o hemisfério.

Os modelos de geração do campo em conjunto com análises observacionais, sugerem que nessas regiões o fluxo seja reverso. Neste caso, o movimento predominante é o downwelling do material do núcleo (seção 5.2.1.2).

A comparação de anomalias produzidas na $\mathrm{CMB}$, pelo movimento do núcleo externo, com as feições do campo não-dipolar observadas na superfície, pode indicar que em praticamente todo o Atlântico Sul o fluxo reverso seja predominante. Isto pode ser observado comparando-se os mapas do Apêndice B com os mapas do Apêndice $C$.

Baseando-se na hipótese de que os pólos e o Alto da Sibéria possam ter seus correspondentes nos lóbulos do núcleo, pode-se atribuir o mesmo para o restante do campo. Os "pontos do núcleo" ou "regiões de fluxo reverso" no Atlântico Sul, podem causar feições do campo na superfície.

As duas colunas de convecção do núcleo externo, que podem ser a causa maior para os quatro lóbulos principais do núcleo, podem estar alterando também os movimentos do fluido no hemisfério Sul. Pode-se sugerir isto, pelo fato de que as colunas de convecção poderiam se encontrar inclinadas em relação ao eixo de rotação, estando mais "próximas" no hemisfério Sul do que no hemisfério Norte (conforme gráfico 7.20). É sugestivo, portanto, a hipótese de que a SAMA poderia ser causada pela combinação de movimentos das colunas de convecção no hemisfério Sul, com os movimentos de fluxo reverso no Atlântico Sul.

No entanto, na análise das anomalias do núcleo não foram levados em consideração outros fatores que podem causar ou interferir na formação destas anomalias como a topografia da interface manto-núcleo e, as convecções termal e composicional, que poderiam alterar as hipóteses feitas. 
As comparações de anomalias de superfície com movimentos do fluido do núcleo não são tão triviais quanto parecem. As observações nem sempre refletem o que os modelos de geração sugerem e vice-versa.

A fenomenologia do campo é muito complexa e, várias proposições são feitas para os modelos de geração. A idéia de que existam anomalias interligadas aos pólos é forte e que algo semelhante ocorra no Atlântico Sul também. No caso dos modelos de geração, estas anomalias indicam que possam existir outras formas de movimentos no núcleo ou então que os movimentos previstos pelos modelos sejam mais complexos e combinados com outros movimentos. As evidências observacionais e fenomenológicas para as anomalias de superfície, podem contribuir como vínculos para a construção dos modelos de geração do campo. Entretanto, o pouco conhecimento sobre o campo toroidal também é uma séria limitação para estas suposições.

\subsection{Sumário}

Este trabalho teve por objetivo descrever as características da SAMA durante os últimos 405 anos, utilizando para isso modelos que foram construídos com dados de navegadores e de antigos observatórios (para o período de 1600 a 1890) e com os modelos do IGRF (para os anos de 1900 a 2005). Conjuntamente, o levantamento dos efeitos da SAMA nas pesquisas espaciais motivou o desenvolvimento desta pesquisa.

Pode-se sumarizar as conclusões da seguinte forma:

1. Os resultados mostram que a taxa de $0,18 \%$ ano de deriva para Oeste, obtida por Heynderickx (1996) para o período de 1945-2000, é igual á taxa média obtida neste trabalho para os últimos 105 anos. As taxas obtidas pela posição do "ponto espelho" do dipolo excêntrico (Heynderickx, 1996) mostram valores semelhantes, porém, a localização do dipolo excêntrico é uma aproximação para a localização da SAMA, e neste caso, os coeficientes de multipolo influenciam na localização e extensão da SAMA. As taxas obtidas pelo fluxo de partículas são pelo menos $0,1 \%$ ano maiores do que as taxas de mínima intensidade (conforme seção 2.4.1 e figura 6.1). Desta forma, pode-se concluir que a forma adotada para se encontrar as taxas de deriva e de intensidade da SAMA foi adequada. 
2. A SAMA apresenta deriva predominantemente á Oeste, como todo o campo geomagnético. Os valores encontrados para o período histórico, cujos modelos são truncados até $n=4$, são semelhantes às taxas encontradas para os modelos do último século, com exceção do período de 1700-1750, que apresentou uma taxa equivalente à metade da taxa média para o período de 400 anos (conforme tabela 7.1). As taxas de deslocamento para o Sul são diferentes, alternando deslocamentos para o Norte e para o Sul. O ajuste dos dados da trajetória sugere que o deslocamento da SAMA ocorra dentro de uma faixa de latitude, no entanto, o intervalo de tempo utilizado é insuficiente para inferir tal afirmação (figura 7.1). Para o último século, a SAMA apresenta uma mudança de trajetória por volta de 1945-1950, que é um período particularmente crítico para os modelos, porque apresentam valores discrepantes para os coeficientes com $n>6$. A partir de 1945-1950, a SAMA praticamente não se desloca para o Sul. As taxas de deriva da SAMA para o último século, diferem dos valores encontrados para as taxas obtidas pelo fluxo de partículas (seção 2.4.1), o que é coerente, porque são relativas a componentes distintas do campo.

3. As variações em intensidade para o centro da SAMA diferem muito de período para período mas, na média, as variações são negativas. No período de 1600-1750 as variações são positivas e coincidem com o período em que a SAMA se desloca para o Norte (conforme figuras 7.1 e 7.3). A partir de 1750 as variações são negativas e a SAMA apresenta deslocamento para o Sul. A comparação de variações de intensidade positiva com o deslocamento para o Norte pode sugerir que a SAMA seja uma anomalia cíclica, com respeito à intensidade e trajetória, no entanto, o período estudado é insuficiente para supor esta hipótese.

4. A segunda derivada de intensidades para o centro da SAMA no último século, mostrou três épocas de variações distintas. Isto acontece porque os coeficientes com $n>6$ são importantes para o comportamento morfológico da SAMA, ao contrário do que afirmou Xu $(2000,2002)$ na revisão dos coeficientes com $n>6$ para os modelos de 1945, 1950 e 1955, de que as principais feições do campo magnético na superfície não são alteradas pelos coeficientes com $n>6$.

5. A comparação entre os campos dipolar e não-dipolar utilizando os coeficientes dos modelos, mostram que o campo não-dipolar vem aumentando com o tempo e que, atualmente, o campo não-dipolar representa aproximadamente $17 \%$ do campo total. No entanto, quando se compara o campo não-dipolar e o campo 
total com a localização geográfica, nota-se que taxas elevadas do campo nãodipolar em todo o Atlântico Sul, sugerem fortemente o caráter não-dipolar para a SAMA, como ilustrado pelas figuras do Apêndice B.

6. A comparação dos dados da SAMA com os dados de quatro observatórios na América do Sul, suporta a metodologia aplicada para a descrição das características da SAMA. A influência da SAMA nas medidas realizadas por observatórios da América do Sul aparece nas variações de intensidade, pela aproximação da SAMA. A inclinação das curvas de intensidade dos observatórios torna-se mais semelhante á curva da SAMA, quanto mais próxima a Anomalia encontrar-se dos observatórios, conforme mostra a figura 7.9.

7. Fenômenos de menor comprimento de onda, como os jerks geomagnéticos, nem sempre são detectados pelos observatórios e, outras variações maiores são observadas, mas não descritas pela literatura como sendo jerks nestes observatórios. Possivelmente, as rápidas variações da componente $Y$ podem estar sendo sobrepostas ou amplificadas pela SAMA em determinados observatórios, conforme mostra a figura 7.12.

8. A comparação da SAMA com os pólos magnéticos para o período histórico mostra que a diminuição do momento dipolar é importante para a diminuição de intensidade nos pólos e na SAMA. O deslocamento para as três anomalias é independente, mesmo porque a SAMA apresenta um movimento com características mais equatoriais. O Alto da Sibéria é uma anomalia que fica evidente nos mapas do campo total entre 1850-1890. Na comparação entre os pólos, a SAMA e o Alto da Sibéria para o último século, novamente fica evidente a sensibilidade aos coeficientes com $n>6$ através do comportamento anômalo de mudança de trajetória para as quatro anomalias. As variações de intensidade, observadas na segunda derivada, mostram os mesmos três patamares de variação encontrados para a SAMA, o que é um forte indício de que movimentos muito significativos do núcleo externo tenham ocorrido dentro do período de 1940-1970.

9. A continuação do campo geomagnético até a CMB, utilizando simplesmente os modelos, forneceu suporte para análise das feições observadas em superfície com os modelos de geração do campo. Apesar de que o método utilizado não é o mais preciso para este tipo de mapeamento, os resultados obtidos para a análise são satisfatórios quando comparados com os modelos que utilizaram a inversão estocástica (figura 7.18). Para o período de 1900-2005, a comparação 
mostra que os gradientes de fluxos são idênticos e as principais feições do campo são mostradas com ambos os métodos. Somente os modelos do período histórico não mostram o campo na CMB com muitos detalhes, até porque os modelos estão truncados até $n=4$, o que dá apenas a noção das feições de maior comprimento de onda na CMB.

10. A tentativa de analisar os quatro lóbulos principais do núcleo é apoiada pela idéia inicial de Bloxham e Gubbins (1985) de que eles são estacionários e correspondem a colunas de convecção no núcleo e que o balanço geostrófico é predominante no núcleo externo. As distâncias relativas entre os lóbulos principais são indícios de que esta idéia seja coerente.

11. Baseado na hipótese de que os quatro lóbulos principais seriam produzidos por duas colunas de convecção (aproximadamente paralelas ao eixo de rotação), e que estes lóbulos estariam mais próximos no hemisfério Sul do que no hemisfério Norte, as colunas também poderiam se encontrar mais próximas no hemisfério Sul. Assim, a proximidade destas colunas no hemisfério Sul, combinada com movimentos de fluxo reverso no Atlântico Sul, poderia ser a causa maior para os movimentos que originam a SAMA. No entanto, deve-se considerar esta idéia apenas como uma hipótese, pelo fato de que se está excluindo outros possíveis fatores que podem originar anomalias na $\mathrm{CMB}$, como a topografia e as convecções térmica e composicional.

Apesar dos modelos de Barraclough (1974) terem os coeficientes truncados até $n=4$, a descrição do campo para o período histórico é satisfatória e forneceu bons resultados para a descrição da SAMA e dos pólos. O truncamento para graus maiores, utilizando os dados de navegadores, poderia incluir informações aos modelos que podem não condizer com o campo para a época, porque a distribuição dos dados é desigual e muitas vezes os mesmos dados são utilizados em mais de um modelo.

Para os modelos do último século, recomenda-se a análise dos modelos de 1945, 1950 e 1955 revisados por Xu $(2000,2002)$ para verificação da sensibilidade das principais feições do campo na superfície e na CMB aos coeficientes com $n>6$.

A análise dos lóbulos principais no núcleo, baseada nos mecanismos de geração, foi apenas observacional. Portanto, há a necessidade de se testar estas hipóteses como vínculos nos modelos de geração do campo. 


\section{Referências Bibliográficas}

ADAM, N. V.; BARRANOVA, T. N.; BENKOVA, N. P. e CHEREVKO, T. N. Spherical Harmonic Analysis of Declination and Secular Geomagnetic Variation 15501960, Earth and Planetary Science Letters, 9, 61-67, 1970.

AKASOFU, S. e CHAPMAN, S. Solar-Terrestrial Physics, 889p., Oxford at the Claredon Press, Oxford, 1972.

ALEXANDRESCU, M.; GIBERT, D.; HULOT, G.; Le MÖUEL, J. e SARACCO G.

Detection of geomagnetic jerks using wavelet analysis. Journal of Geophysical Research, vol. 100, B7, 12,557-12,572, 1995.

ALEXANDRESCU, M.; GIBERT, D.; HULOT, G.; Le MÖUEL, J. e SARACCO G. Worldwide wavelet analysis of geomagnetic jerks. Journal of Geophysical Research, vol. 101, B10, 21,975-21,994, 1996.

ALLDREDGE, L. R. e HURWITZ, L. Radial dipoles as the sources of the earth's main magnetic field. Journal of Geophysical Research, vol. 74, 6583-6593, 1964.

BACKUS, G. E. Application of mantle filter theory to the magnetic jerk of 1969. Geophys. J. R. Astr. Soc., 74, 713-746, 1983.

BADHWAR, G. D. Drift rate of the South Atlantic Anomaly. Journal of Geophysical Research, vol. 102, A2, 2343-2349, 1997.

BADHWAR, G. D.; ATWELL, W.; REITZ, G.; BEUJEAN, R. e HEINRICH W. Radiation measurements on the Mir Orbital Station, Radiation Measurements, 35, 393-422, 2002.

BARDE, S.; CUETO, J.; ECOFFET, R.; FALGUĖRE, D.; NUNS, T.; DUZELLIER, S.; BOSCHER, D.; BOURDARIE, S. e TSOURILO, I. Radiation Environment Measurements with SPICA On-Board the MIR Station. IEEE Transactions on Nuclear Science, vol. 49, 3, 2002.

BARRACLOUGH, D. R. Spherical Harmonic Analyses of the Geomagnetic Field for Eight Epochs between 1600 and 1910. Geophys. J. R. Astron. Soc., 36, 497$513,1974$. 
BENKOVA, N. P.; ADAM, N.V. e CHEREVKO, T. N. Application of spherical harmonic analysis to magnetic declination data. Geomag. Aeron., USSR, 10(4), 673-680, (527-532 in English translation), 1970.

BLOXHAM, J. e GUBBINS, D. The secular variation of Earth's magnetic field. Nature, vol. 317, 777-781, 1985.

BLOXHAM, J. e JACKSON A. Simultaneous Stochastic Inversion for Geomagnetic Main Field and Secular Variation 2. 1820-1980. Journal of Geophysical Research, vol. 94, n. B11: 15,753-15,769, 1989.

BLOXHAM, J. e JACKSON A. Time-Dependent Mapping of the Magnetic Field at the Core-Mantle Boundary. Journal of Geophysical Research, vol. 97, n. B13: 19,537-19,563, 1992.

BLOXHAM, J. Simultaneous Stochastic Inversion for Geomagnetic Main Field and Secular Variation 1. A Large-Scale Inverse Problem. Journal of Geophysical Research, vol. 92, n. B11: 11597-11608, 1987.

BLOXHAM, J.; GUBBINS, D. e JACKSON, A. Geomagnetic Secular Variation. Phil. Trans. Royal Soc. London. A 329: 415-502, 1989.

BLOXHAM, J.; ZATMAN, S. e DUMBERRY M. The origin of geomagnetic jerks. Nature, vol. 420, 65-68, 2002.

BRAGINSKII, S. I. e KULANIN, N. V. Spherical analysis of the geomagnetic field from angular data and the extrapoled $g_{1}^{0}$ value, II. Geomag. Aeron., USSR, 11(5), 931-933 (786-788 in English translation), 1971.

BRAGINSKII, S. I. Spherical analyses of the main geomagnetic field, 1550-1800. Geomag. Aeron., USSR, 12(3), 524-529 (464-468 in English translation), 1972.

BÜHLER, P.; ZEHNDER, A.; KRUGLANSKI, M.; DALY, E. e ADAMS, L. The highenergy proton fluxes in the SAA observed with REM aboard the MIR Orbital Station, Radiation Measurements, 35, 489-497, 2002.

BULLARD, E. C.; FREEDEMAN, C.; GELLMAN, H. e NIXON, J. The westward drift of the Earth's magnetic field. Phil. Trans. Roy. Soc., A243, 67-92, 1950.

CHAPMAN, S. e BARTELS, J. Geomagnetism, vol 2, 1049p. University Press, Oxford, 1940.

CONSTABLE, C. G., PARKER, R. L. e STARK, P. Geomagnetic field models incorporating frozen-flux constraints. Geophysical Journal International, 113, 419-433, 1993. 
COURTILLOT, V., MOUËL, J. L. e DUCRUIX, J. On Backus' mantle filter theory and the 1969 geomagnetic impulse. Geophys. J. R. Astr. Soc., 78, 619-925, 1984.

DEME, S.; APÁTHY I.; HÉJJA, I.; LÁNG, E. e FEHÉR, I. Extra dose due to extravehicular activity during the NASA4 mission measured by an on-board TLD system. Radiation Protection Dosimetry, vol. 85, n 1-4, 121-124, 1999a.

DEME, S.; APÁTHY I.; HÉJJA, I.; LÁNG, E. e FEHÉR, I. Dose due to South Atlantic Anomaly during the EUROMIR'95 mission measured by an on-board TLD system. Radiation Protection Dosimetry, vol. 85, n 1-4, 301-304, 1999b.

FIANDRINI, E.; ESPOSITO, G.; BERTUCCI, B.; ALPAT, G.; AMOBROSI, G.; BATTISTON, R.; BURGER, W. J.; CARAFFINI, D.; Di MASSO, L.; DINU, N.; IONICA, M.; IONICA, R.; PAULUZZI, M.; MENICHELLI, M. e ZUCCON P. Protons with kinetic energy $\mathrm{E}>70 \mathrm{MeV}$ trapped in the Earth's radiation belts. Journal of Geophysical Research, vol. 109, A102014, 2004.

FRASER-SMITH, A. C. Centered and Eccentric Geomagnetic Dipoles and Their Poles, 1600-1985, Reviews of Geophysics, 25, 1-16, 1987.

GLATZMAIER, G. A. e ROBERTS, P. H. A three-dimensional convective dynamo solution with rotating and finitely conducting inner core and mantle, Physics of the Earth and Planetary Interiors, 91, 63-75, 1995a.

GLATZMAIER, G. A. e ROBERTS, P. H. A three-dimensional self-consistent computer simulation of a geomagnetic field reversal. Nature, 377, 203-209, 1995b.

GUBBINS, D. e ROBERTS, P. H. Magnetohydrodinamics of the Earth's Core. In: Geomagnetism, vol. 2, J. A. Jacobs, ed., cap. 1, pp. 1-183, Academic Press, New York, 1987.

HEIRTZLER, J. R. The Future of the South Atlantic Anomaly and implications for radiation damage in space, Journal of Atmospheric and Solar-Terrestrial Physics, 64, 1701-1708, 2002.

HEYNDERICKX, D. Comparison between methods to compensate for the secular motion of the South Atlantic Anomaly, Radiation Measurements, 26: 369-373, 1996.

JACKSON, A. Intense equatorial flux spots on the surface of the Earth's core. Nature, vol. 424, 760-763, 2003. 
JACKSON, A.; JONKERS, A. R. T. e WALKER M. Four centuries of geomagnetic secular variation from historical records. Phil. Trans. R. Soc. London, A 358, 957-990, 2000.

KAGEYAMA, A.; SATO, T. e COMPLEXITY SIMULATION GROUP. Computer simulation of a magnetohydrodynamic dynamo II, Phys. Plasmas, 2, 14211431, 1995.

KIRCHHOFF, V. W. J. H. Introdução à Geofísica Espacial. Nova Stella, Editora da Universidade de São Paulo: FAPESP, 1991.

KONO, M. e ROBERTS, P. Recent Geodynamo Simulations and Observations of the Geomagnetic Field, Reviews of Geophysics, 40, 1-53, 2002.

KUANG, W. e BLOXHAM, J. Numerical modeling of magnetohydrodynamic convection in a rapidly rotating spherical shell: weak and strong field dynamo action. Journal of Computational Physics, 153, 51-81, 1999.

LANGEL, R. A. The main field. In: Geomagnetism, vol 1, J. A. Jacobs, ed, cap. 4, pp. 249-512, Academic Press, New York, 1987.

Le MÖUEL, J. L.; DUCRUIX, J. e DUYEN, C. The world-wide character of the 1969-1970 impulse of the secular acceleration rate. Physics of the Earth and Planetary Interiors, 28, 337-350, 1982.

Le HUY, M.; ALEXANDRESCU, M.; HULOT, G. e LeMOUËL J. On the characteristic of successive geomagnetic jerks. Earth Planets Space, 50, 723732, 1998.

MACMILLAN S. e QUINN J.M. The 2000 revision of the joint UK/US geomagnetic field models and an IGRF 2000 candidate model, Earth Planets Space, 52, 1149-1162, 2000.

MANDEA, M. e DORMY, E. Asymetric behavior of magnetic dip poles. Earth Planets Space, 55, 153-157, 2003.

MERRIL R. T., McELHINNY M. W. e McFADDEN P. L. The Magnetic Field of the Earth: Palemagnetism, the Core, and the Deep Mantle. International Geophysics Series, vol 63, Academic Press, 1998.

NICHITIU, F.; DRUMMOND, J. R.; ZOU, J. e DESCHAMBAULT, R. Solar particle events seen by the MOPITT instrument. Journal of Atmospheric and SolarTerrestrial Physics, 66, 1797-1803, 2004. 
PADILHA, A. Distortions in Magentotelluric fields possibly due to ULF activity at the South Atlantic Magnetic Anomaly Region. J. Geomag. Geoelectr., 47, 1311-1323, 1995.

PINTO Jr., O.; GONZALEZ, W. D. e PAES LEME, N. M. VLF disturbances at the South Atlantic Magnetic Anomaly following magnetic storms. Planet. Space Sci., vol. 38, n5, 633-636, 1990.

PINTO Jr., O.; GONZALEZ, W. D.; PINTO, I. R. C. A.; GONZALEZ, A. L. C. e MENDES JR. O. The South Atlantic Magnetic Anomaly: three decades of research, Journal of Atmospheric and Solar-Terrestrial Physics, 54, 1129-1134, 1992.

PINTO Jr., O.; MENDES, O.; PINTO, I. R. C. A.; GONZALEZ, W. D.; HOLZWORTH, R. H. e HU, H. Atmospheric X-rays in the Southern hemisphere. Journal of Atmospheric and Solar-Terrestrial Physics, vol. 59, nº 12, 1381-1390, 1997.

PINTO, Jr. O. e GONZALEZ, W. D. X ray measurements at the South Atlantic Magnetic Anomaly. Journal of Geophysical Research, vol. 91, A6, 7072-7078, 1986.

PINTO, Jr. O. e GONZALEZ, W. D. Energetic electron precipitation at the South Atlantic Magnetic Anomaly: a review. Journal of Atmospheric and Terrestrial Physics, vol. 51, n 5, 351-365, 1989.

PINTO, Jr. O.; GONZALEZ, W. D. e GONZALEZ, A. L. C. Time variations of X Ray fluxes at the South Atlantic Magnetic Anomaly in association with a strong geomagnetic storm. Journal of Geophysical Research, vol. 94, A12, 1727517280, 1989.

PINTO, L. M. V. G.; SZCZUPAK, J.; DRUMMOND, M. A. e MACEDO, L. H. Um novo olhar sobre a segurança de sistemas elétricos. Engenho Pesquisa, 2004.

RIKITAKE, T. Eletromagnetism and the Earth's interior. Amsterdam: Elsevier, 1966.

ROBERTS, P. H. e GLATZMAIER, G. A. Geodynamo theory and simulations. Reviews of Modern Physics, vol. 72, n.4, 1081-1123, 2000.

ROBERTS, P. H. e GUBBINS, D. Origin of the Main Field: Kinematics. In: Geomagnetism, vol 2, J. A. Jacobs, ed., cap. 2, pp. 185-249, Academic Press, New York, 1987. 
RUNCORN, S. K. The electrical conductivity of the earth's mantle. Trans. Amer. Geophys. Union, 36:191-198, 1955.

TRICHTCHENKO, L. e BOTELER, D. H. Modeling geomagnetically induced currents using geomagnetic indices and data. IEE Transactions on Plasma Science, vol. 32, n 4, 2004.

VEINBERG, B. P. e SHIBAEV, V. P. (Editor-in-Chief: A. Pushkov). Catalogue. The results of magnetic determinations at equidistant points and epochs, 15001940. IZMIRAN, Moscow. Translation: N. 0031 by Canadian Department of the Secretary of State, Translation Bureau, 1969.

VESTINE, E. H., LANGE, I., LaPORTE, L. e SCOTT, W. E. The geomagnetic field, its description and analysis. Carnegie Inst. Washington Rept. n 580, 1947.

WEI, Z. e XU, W. Westward drift in secular variation of the main geomagnetic field inferred from IGRF. Earth Planets Space, 55, 131-137, 2003.

WILLIS, P.; HAINES B.; BERTHIAS, J. P.; SENGENES, P. e Le MOUËL, J. L. Comportement de l'oscillateur DORIS/Jason au passage de l'anomalie sudatlantique. Comptes Rendus Geoscience, Jul.: 1-8, 2004.

XU, W. Unusual behavior of the IGRF during 1945-1955 period, Earth Planets Space, 52, 1227-1233, 2000.

XU, W. Revision of the high-degree Gauss coefficients in the IGRF 1945-1955 models by using natural orthogonal analysis, Earth Planets Space, 54, 753761, 2002. 


\section{Apêndices}

\section{Apêndice A - Mapas do campo total}

Este apêndice mostra mapas de intensidade total para algumas épocas utilizadas no trabalho. São apresentados os mapas de intensidade total para os modelos de Barraclough (1974) para os anos de 1600, 1650, 1700, 1750, 1800, 1850 e 1890; e, para os modelos do IGRF de 1900, 1920, 1940, 1950, 1960, 1980, 2000 e 2005. Os mapas estão na projeção Mercator. A escala de cores é a mesma para todas as épocas testadas e os intervalos de contorno são de 10.000nT. O intervalo de 28000 nT mostra a evolução da SAMA no tempo.

\section{a) 1600}

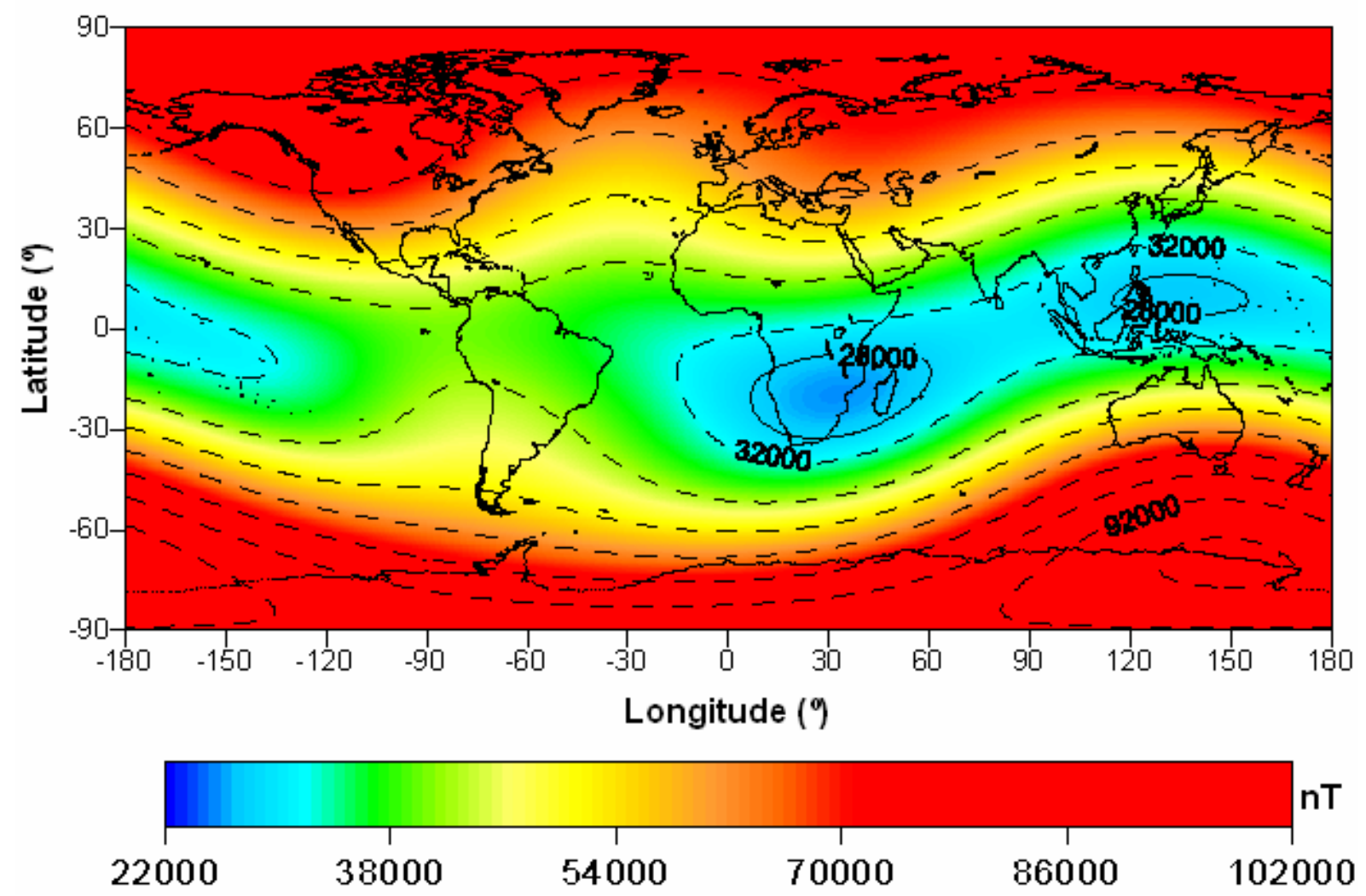




\section{b) 1650}
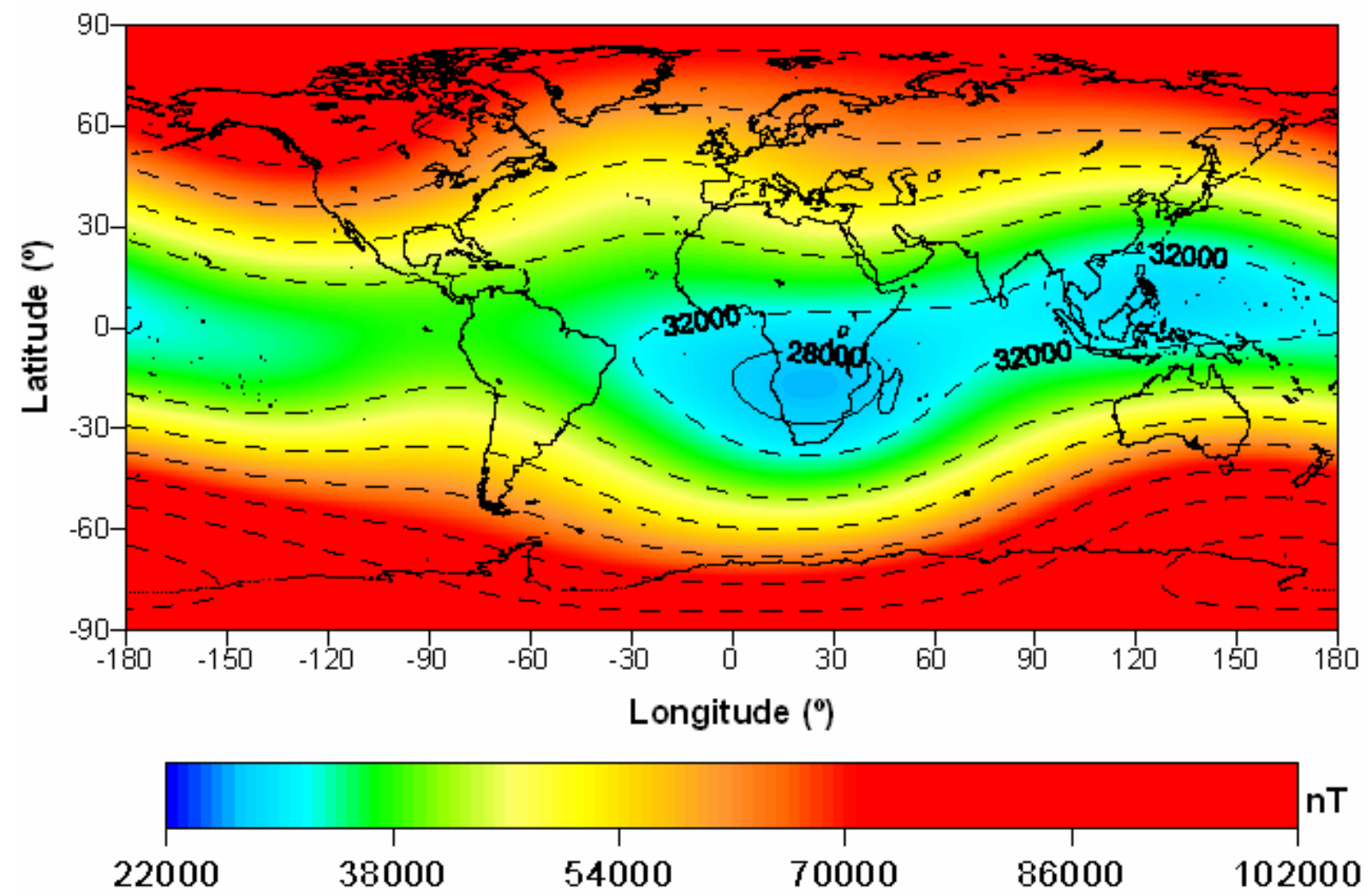

c) 1700
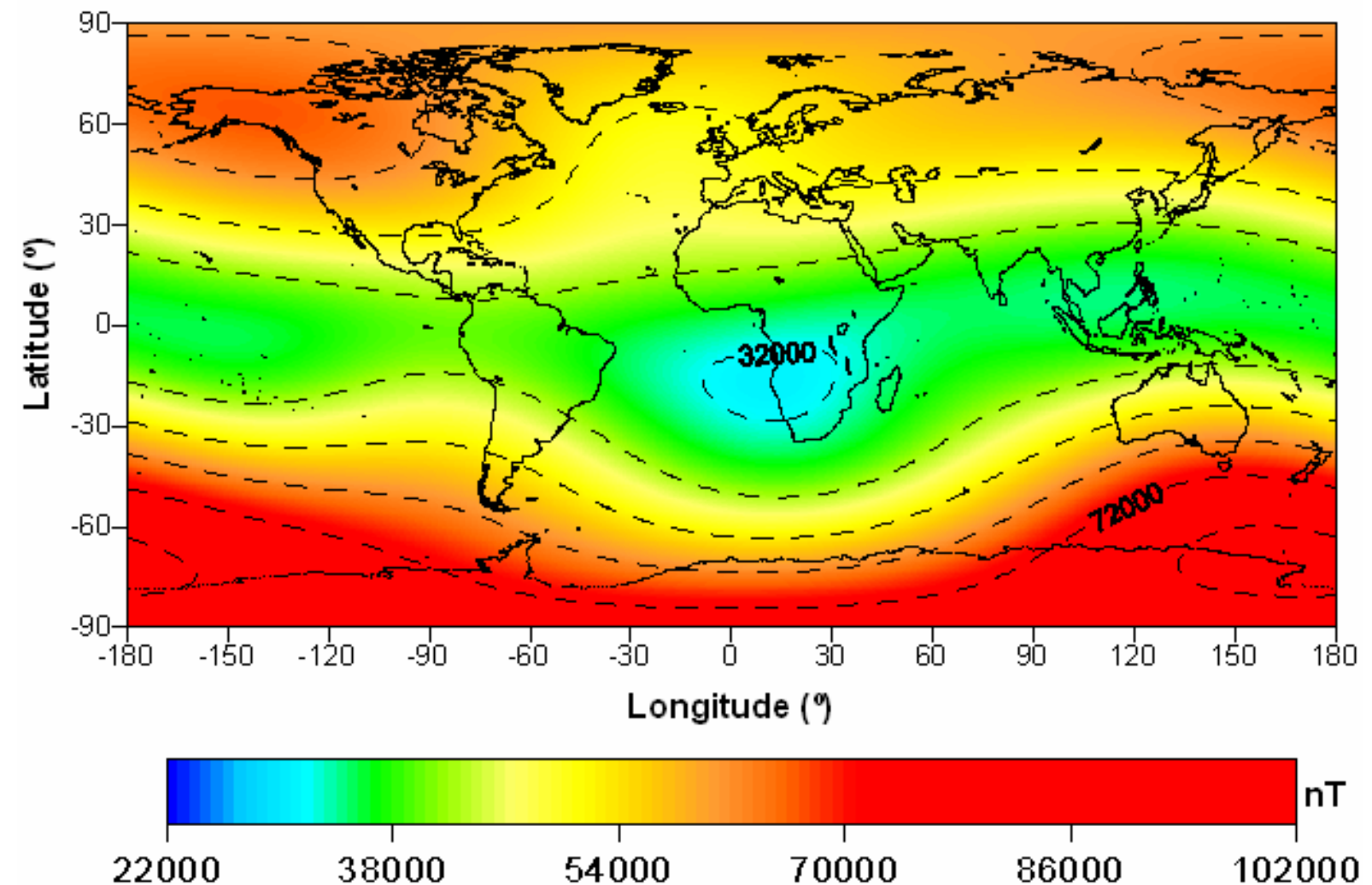

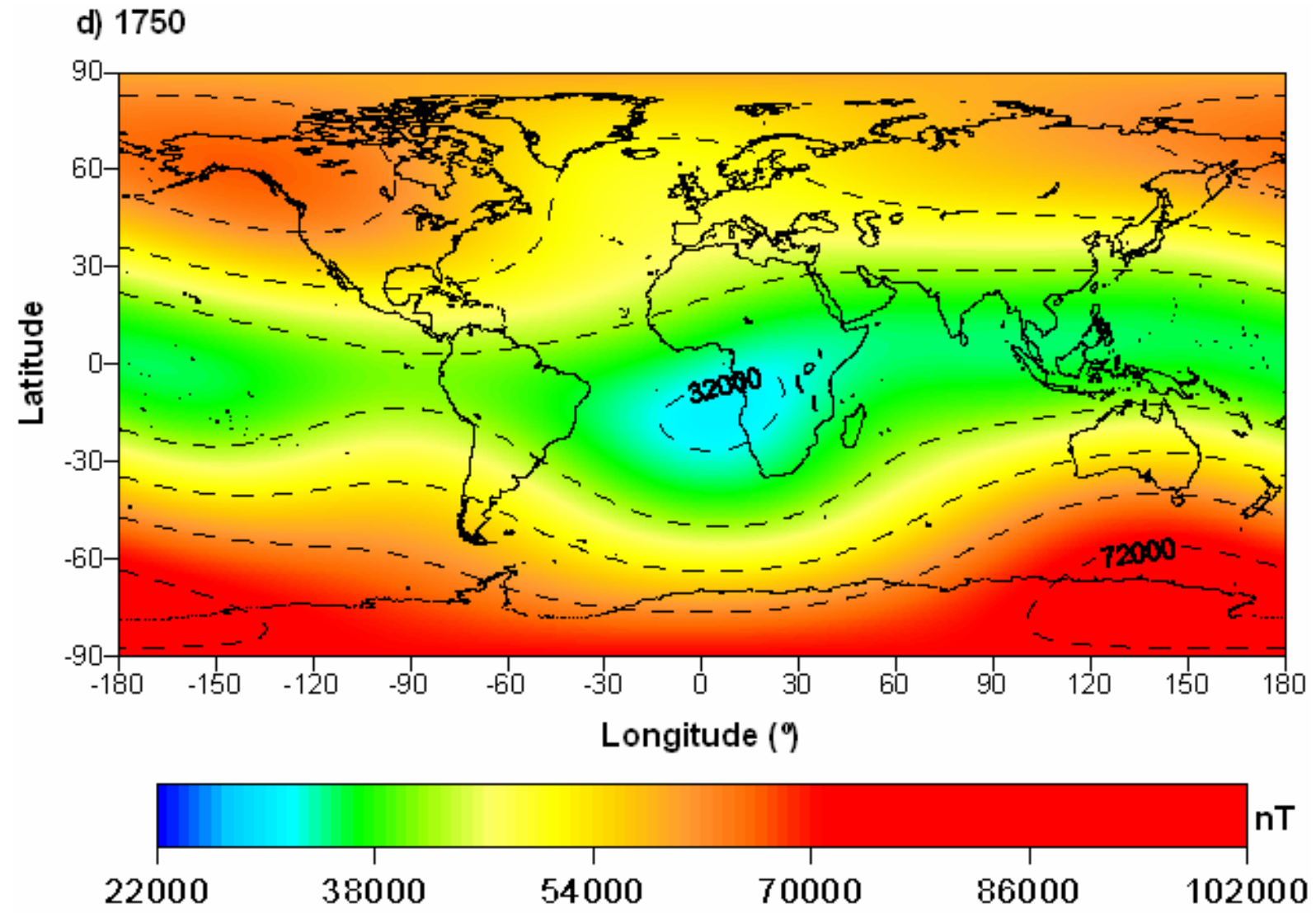

e) 1800
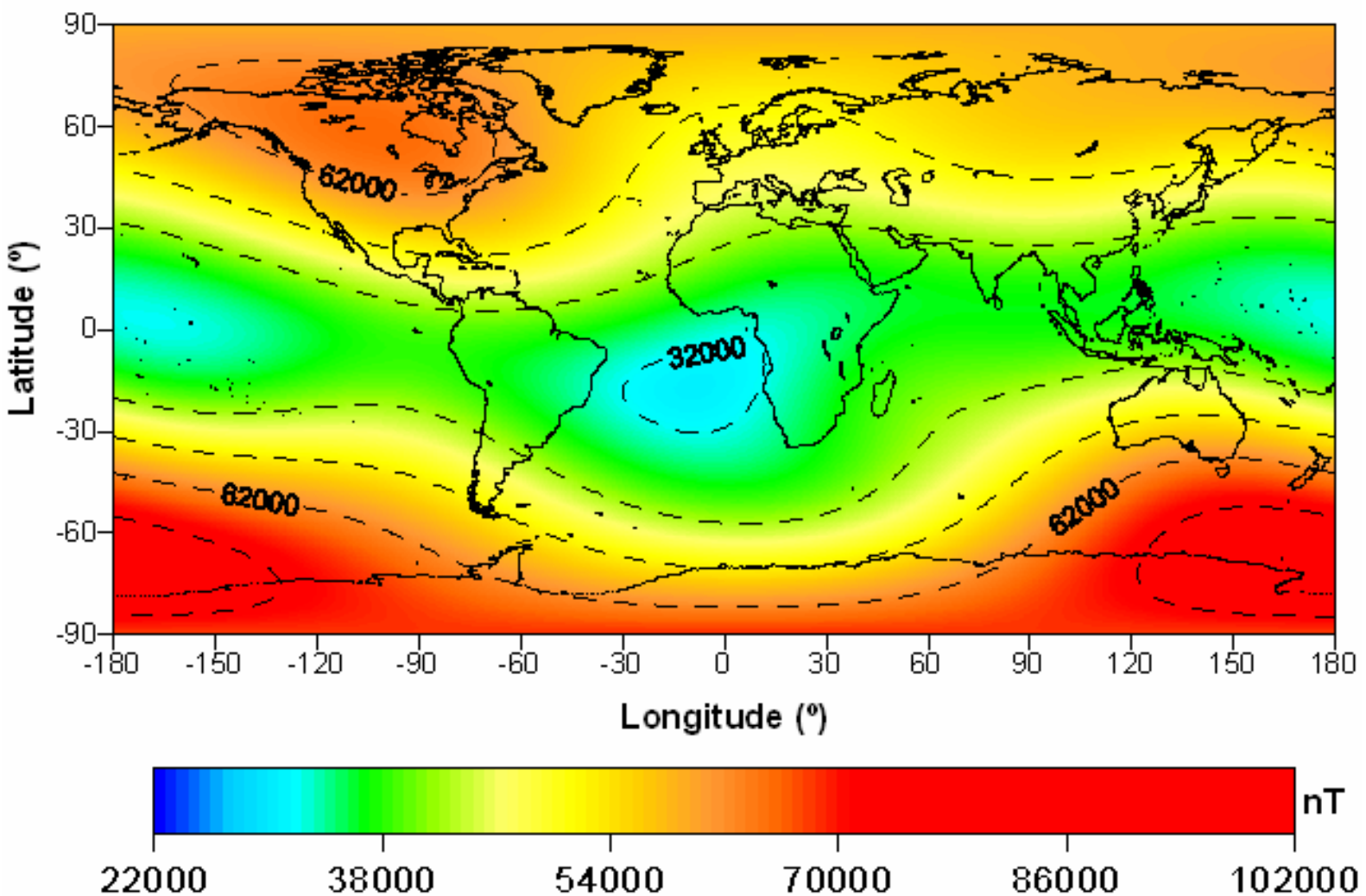


\section{f) 1850}
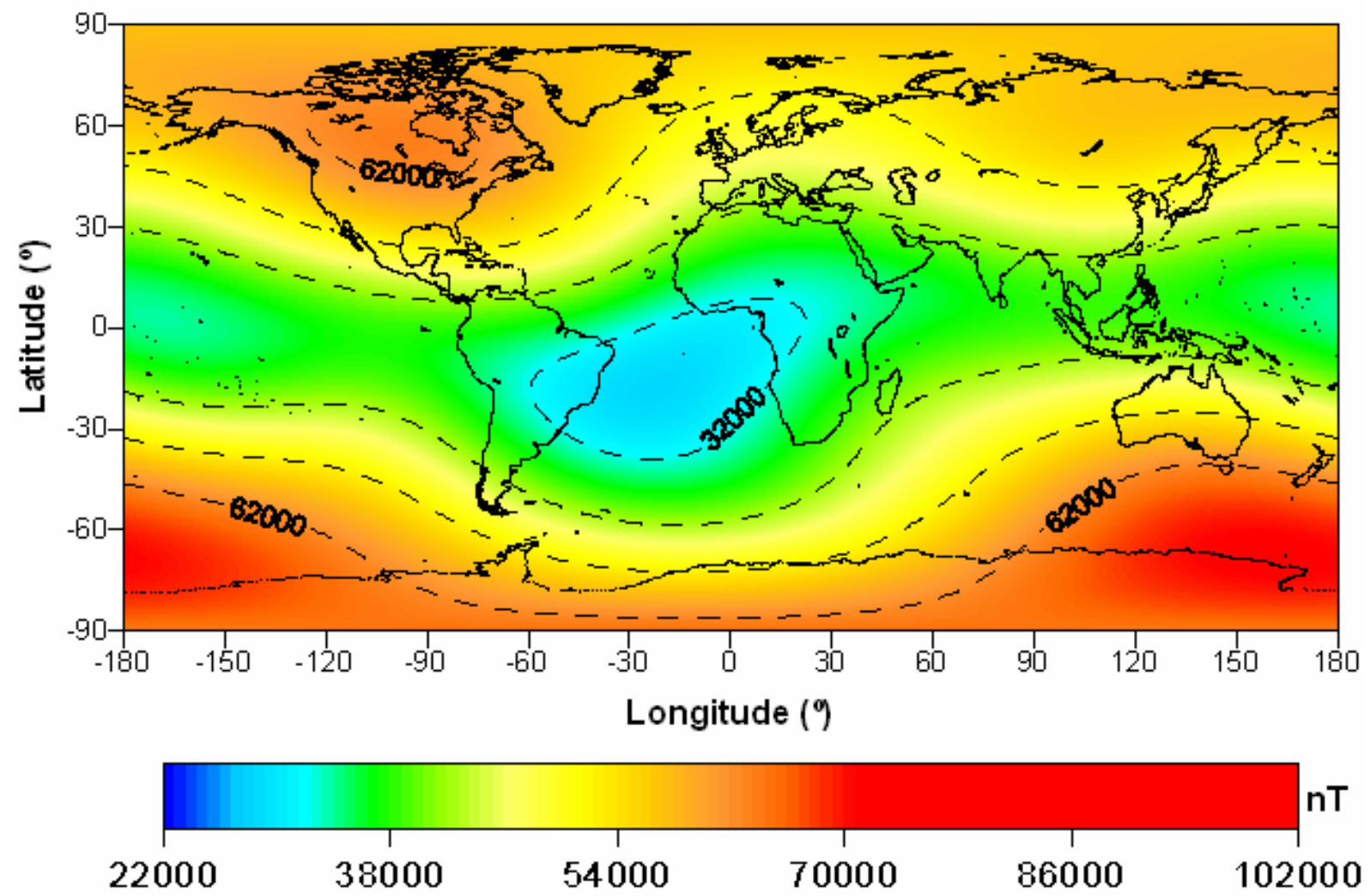

g) 1890
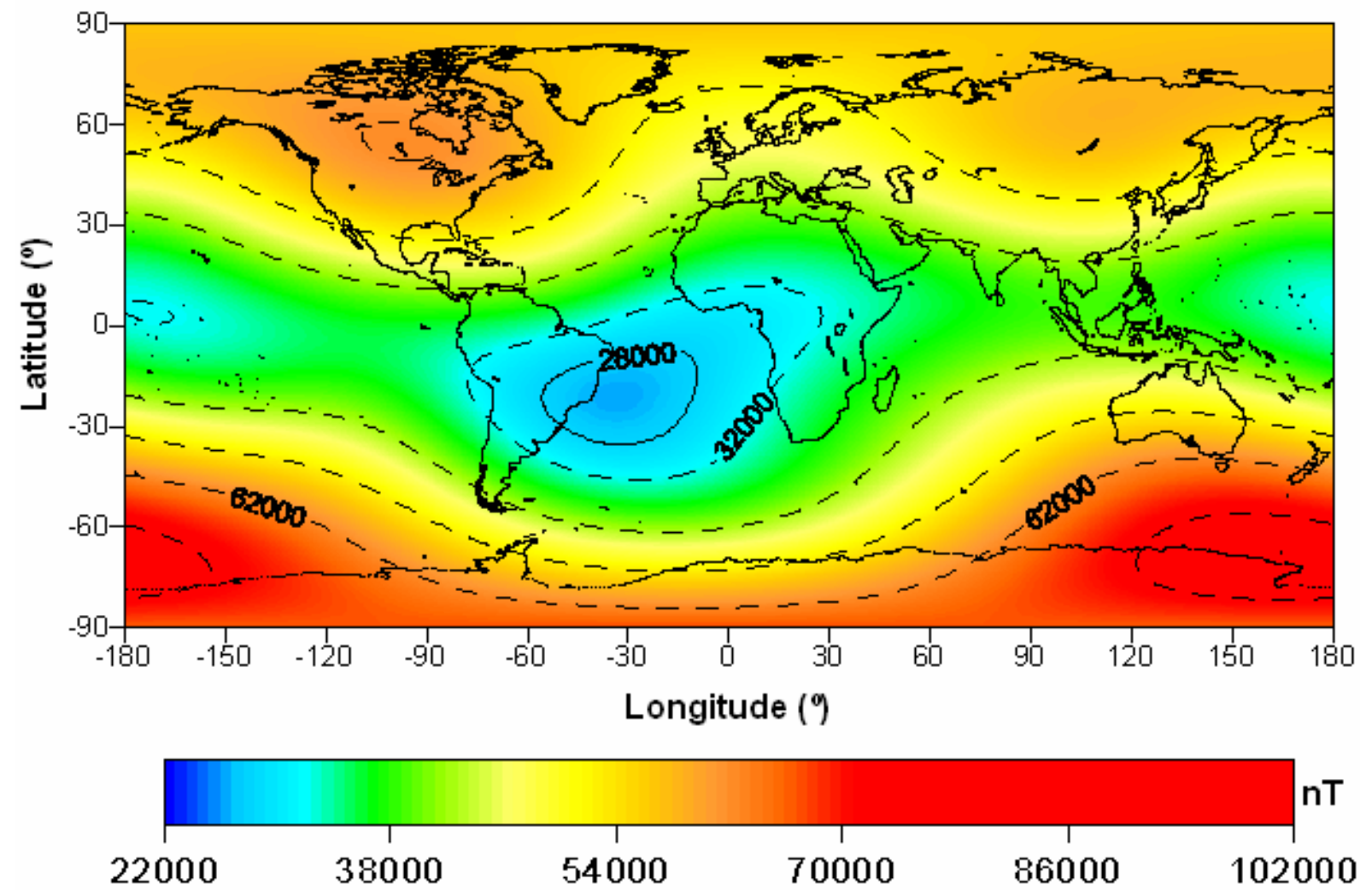
h) 1900
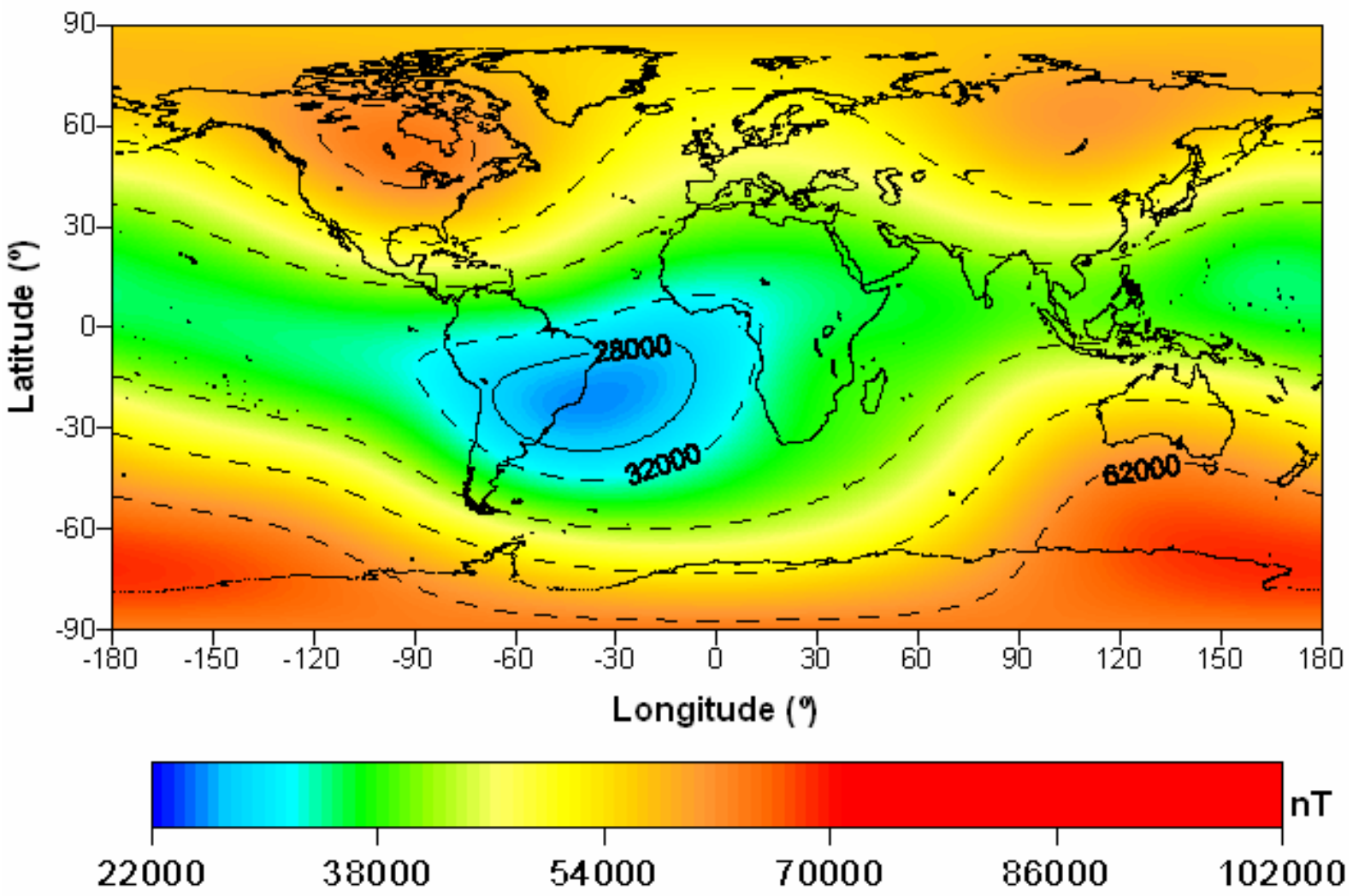

i) 1920
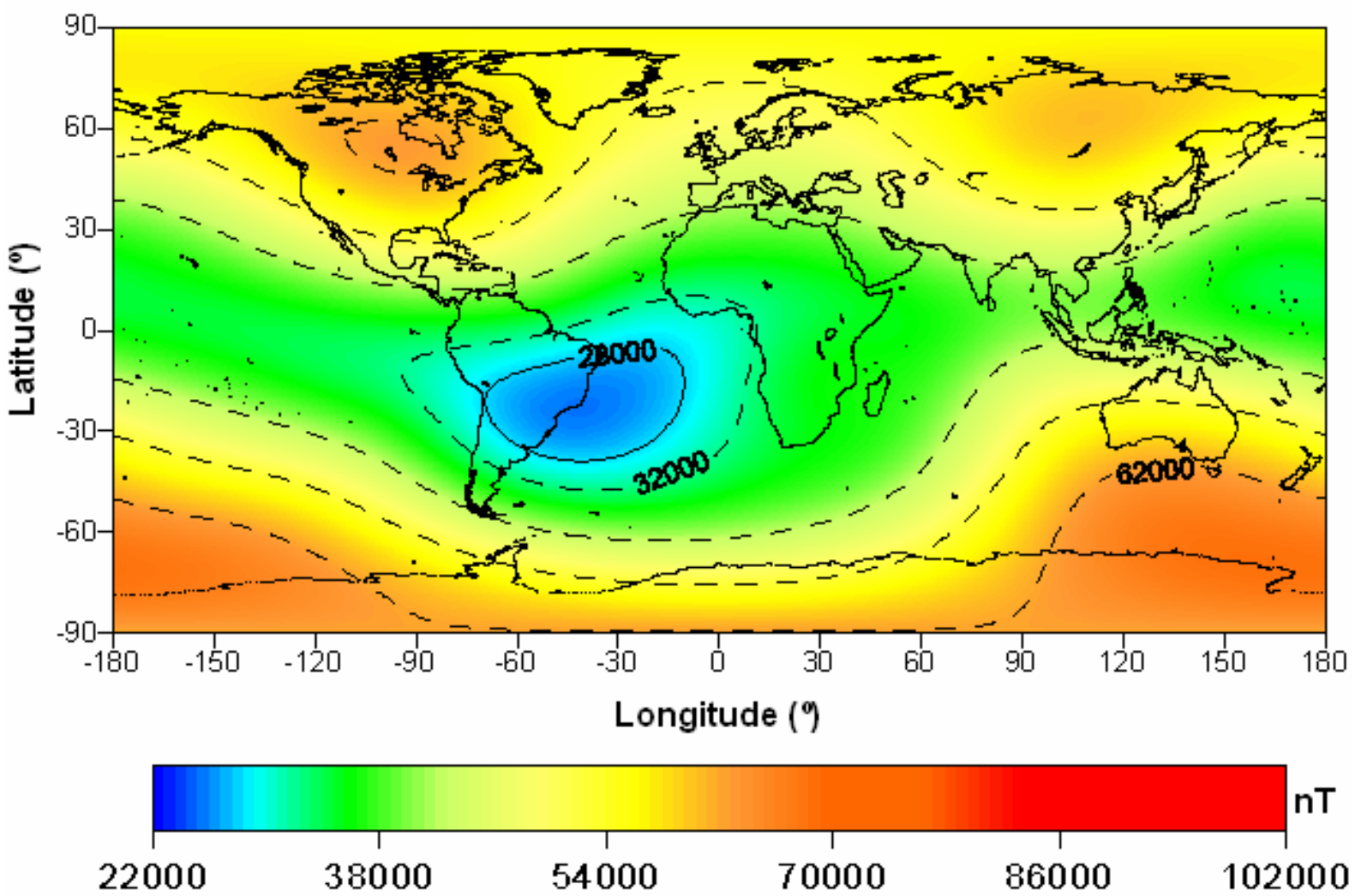

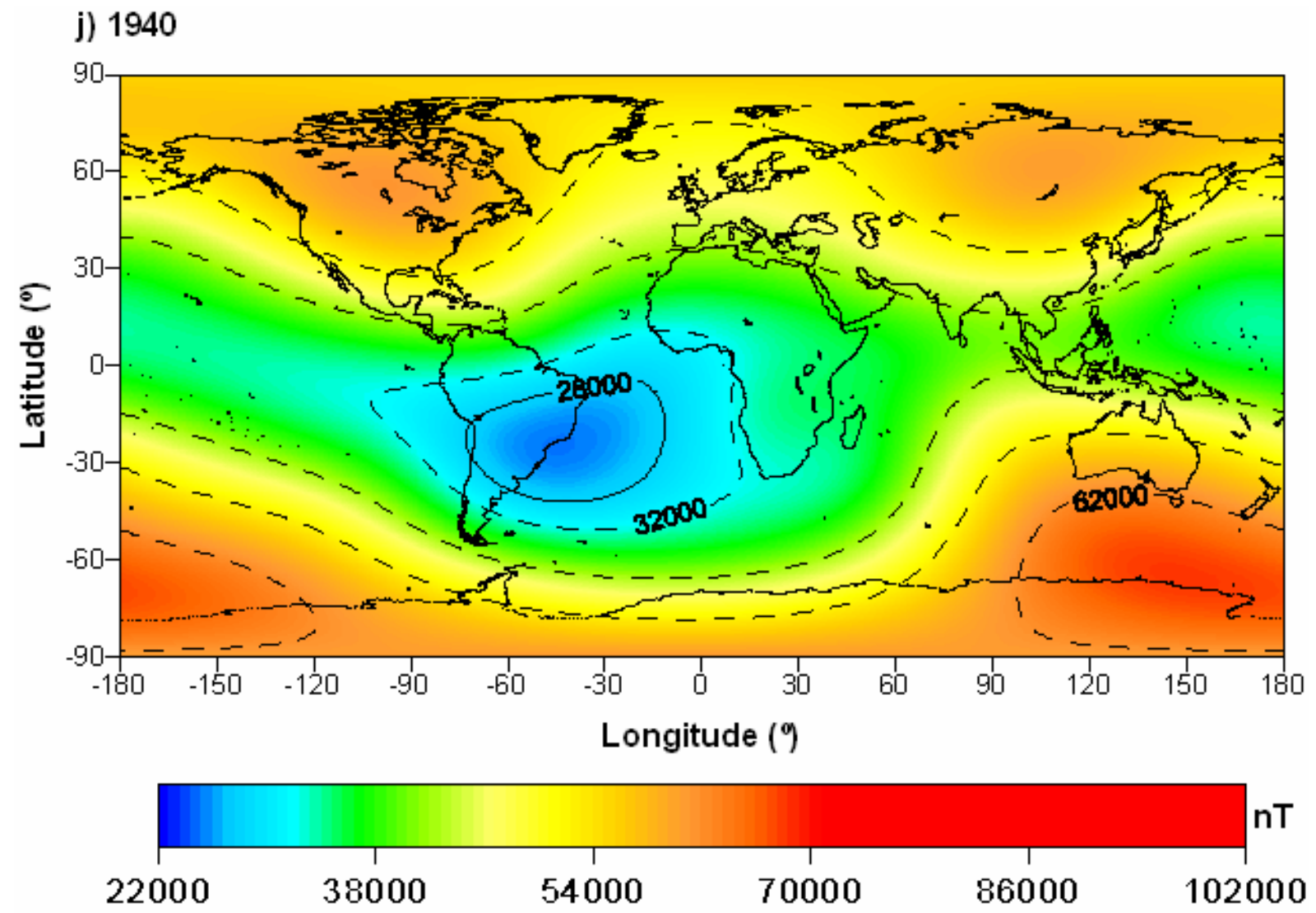

k) 1950
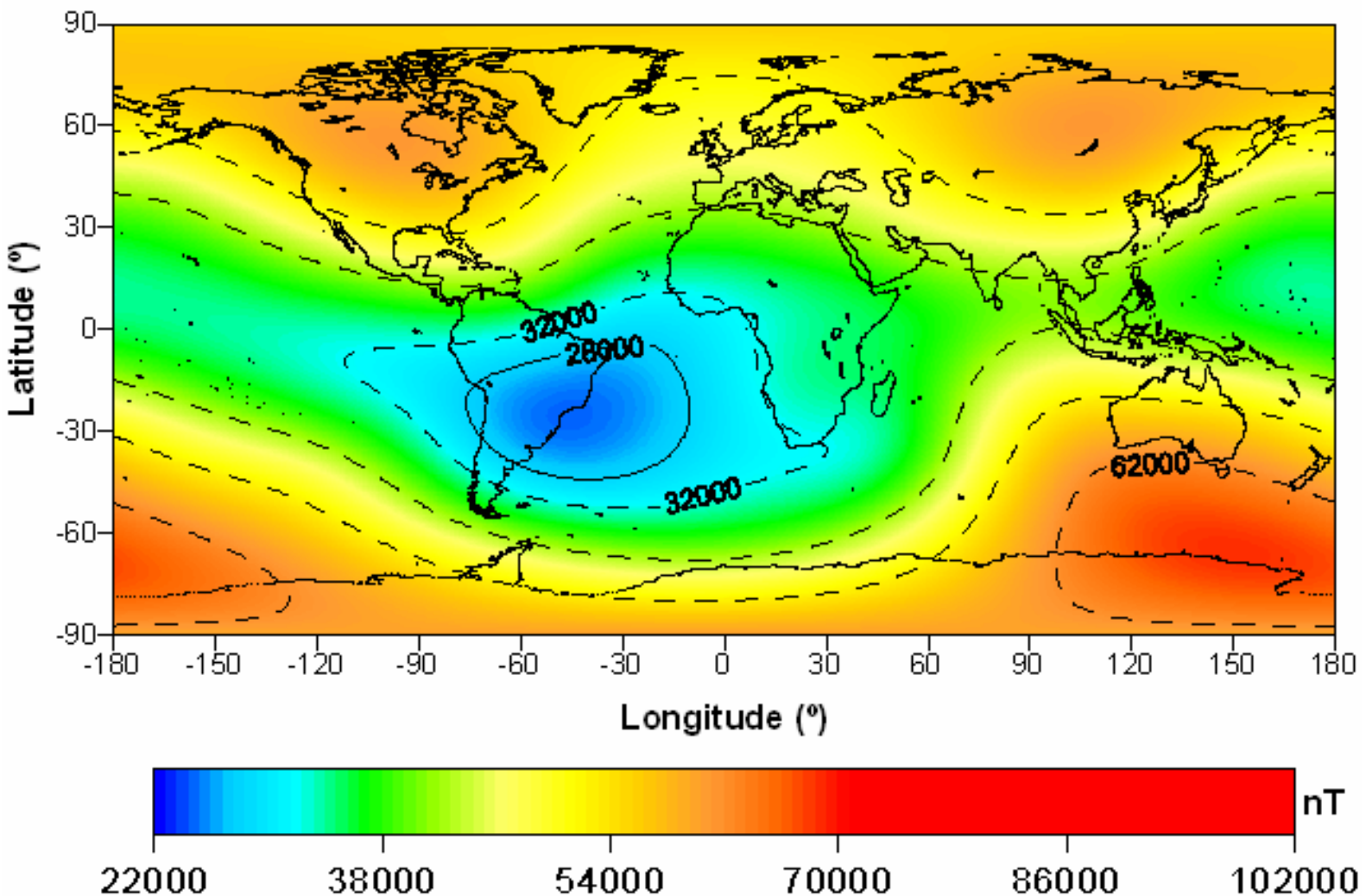

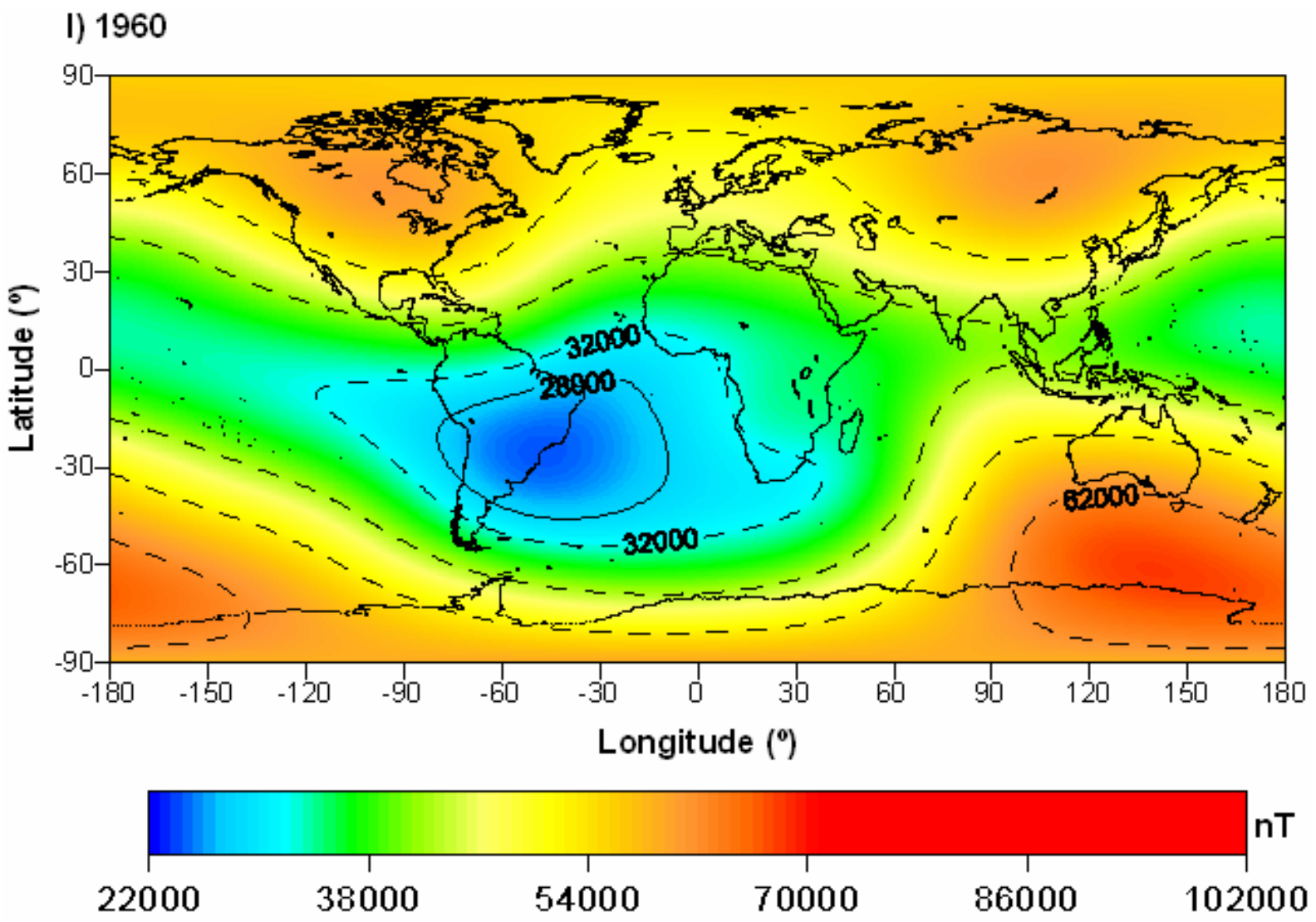

m) 1980
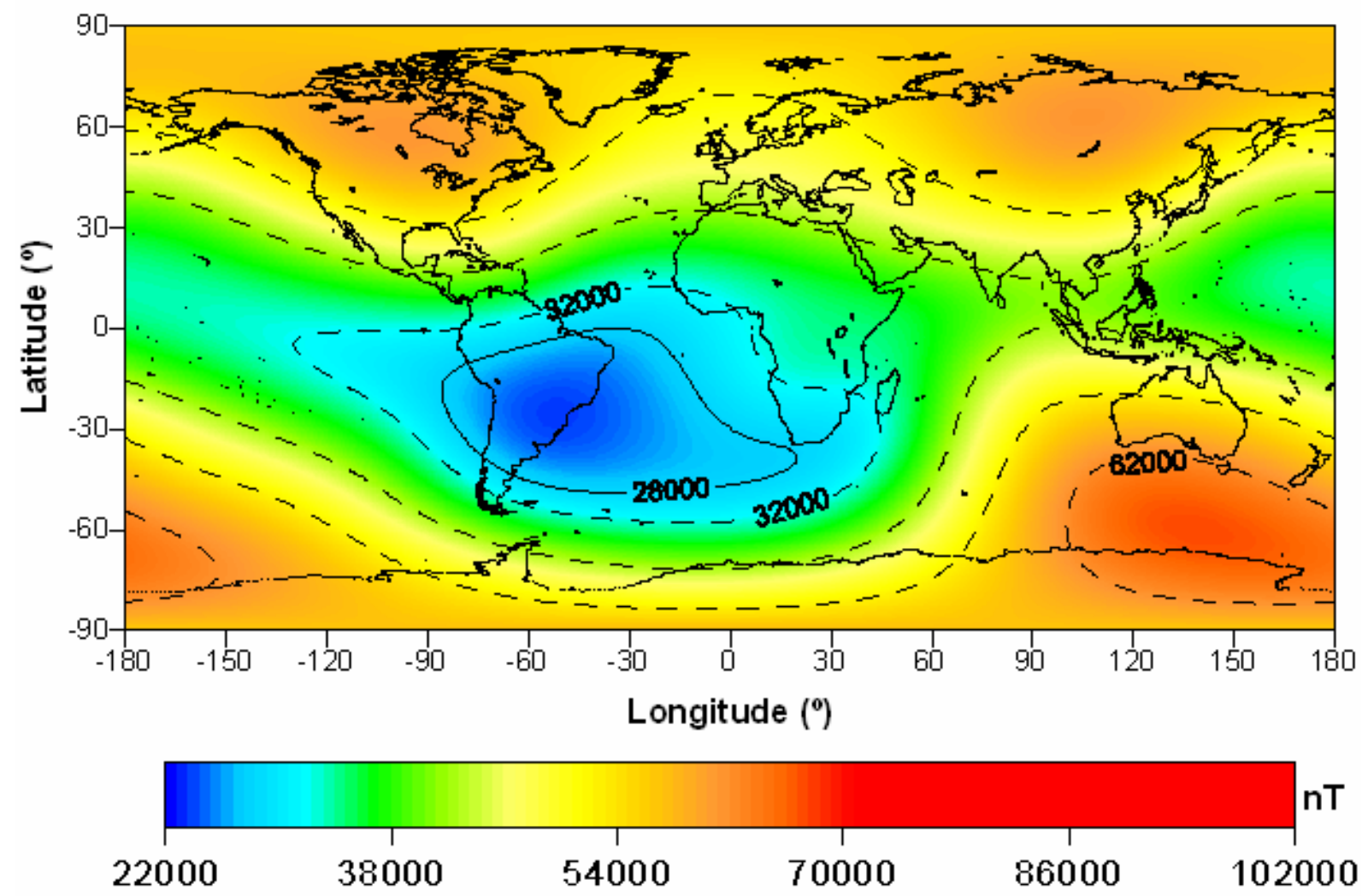

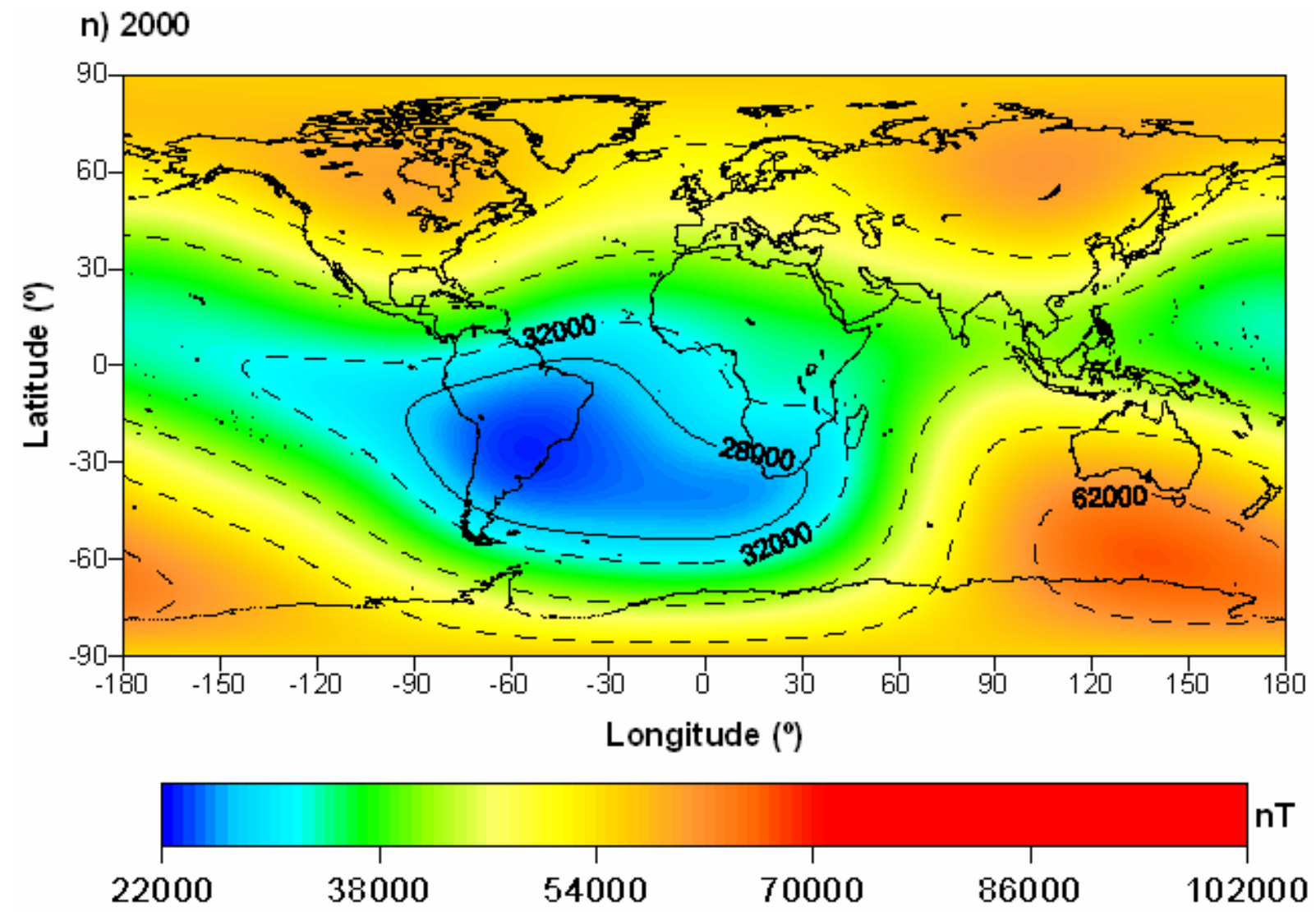

ㅇ) 2005
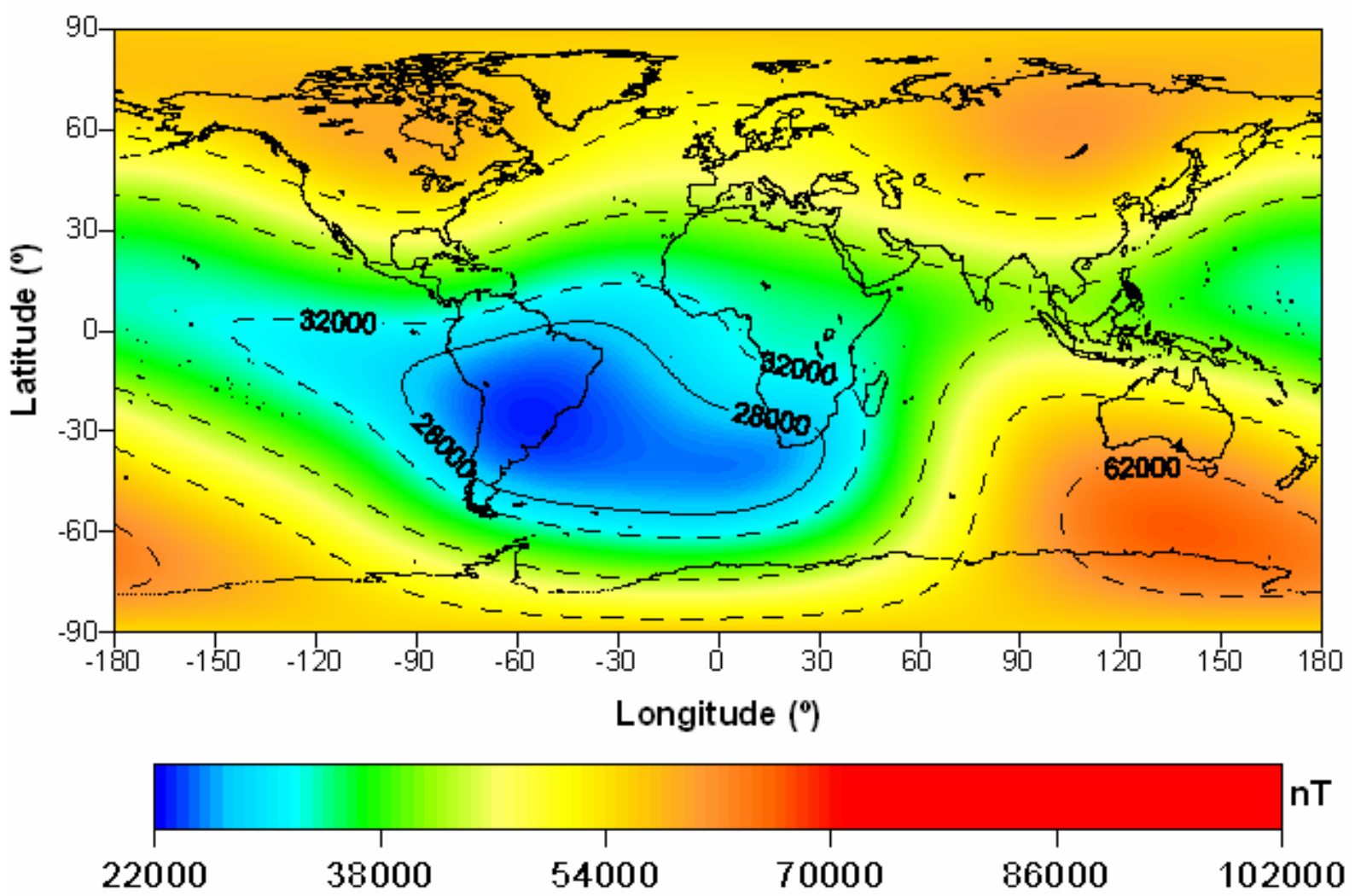


\section{Apêndice B - Mapas da razão entre os campos não-dipolar e total}

Neste apêndice são mostrados mapas da razão entre os campos não-dipolar e total, utilizando os modelos de Barraclough (1974) para os anos de 1600, 1650, 1700, 1750, 1800, 1850 e 1890; e, para os modelos do IGRF de 1900, 1920, 1940, 1950, 1960, 1980, 2000 e 2005. Os mapas estão na projeção Aitoff. A escala de cores é própria para cada mapa.
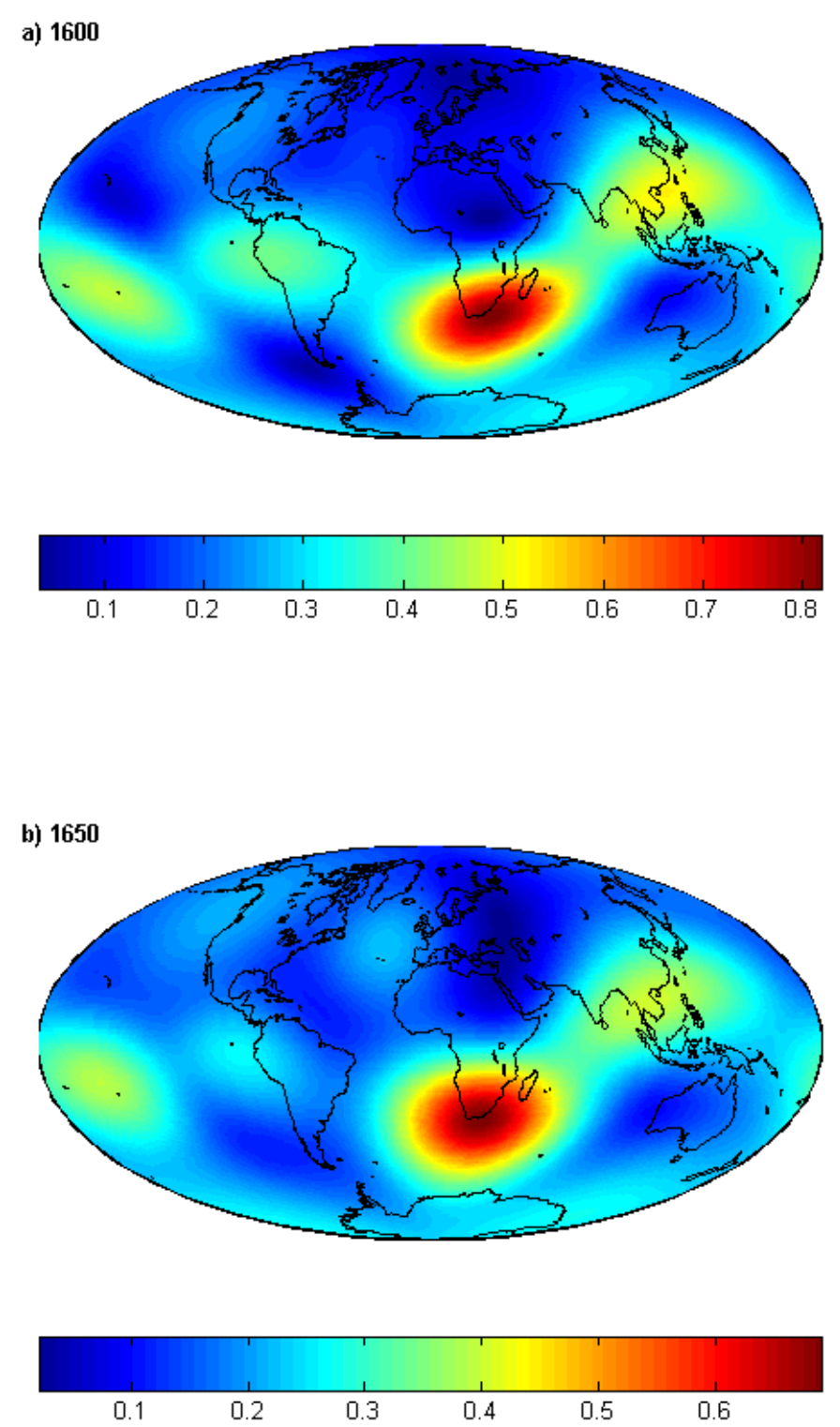

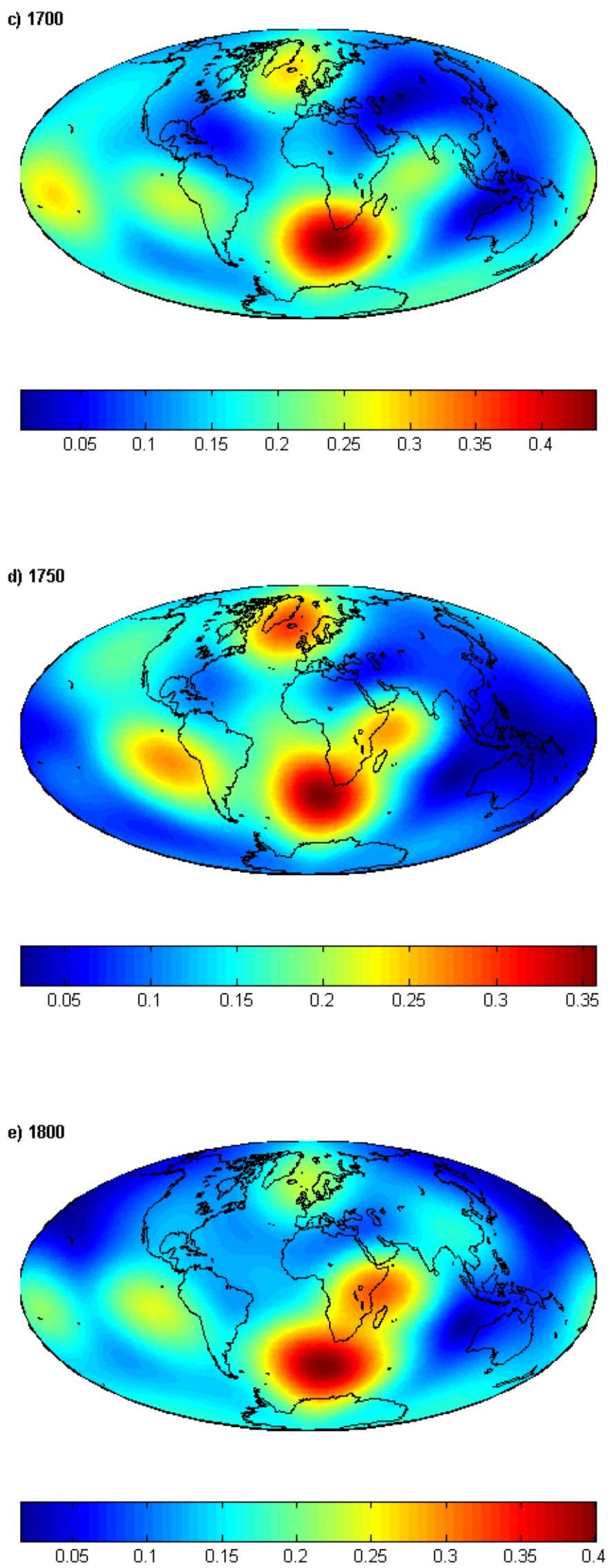

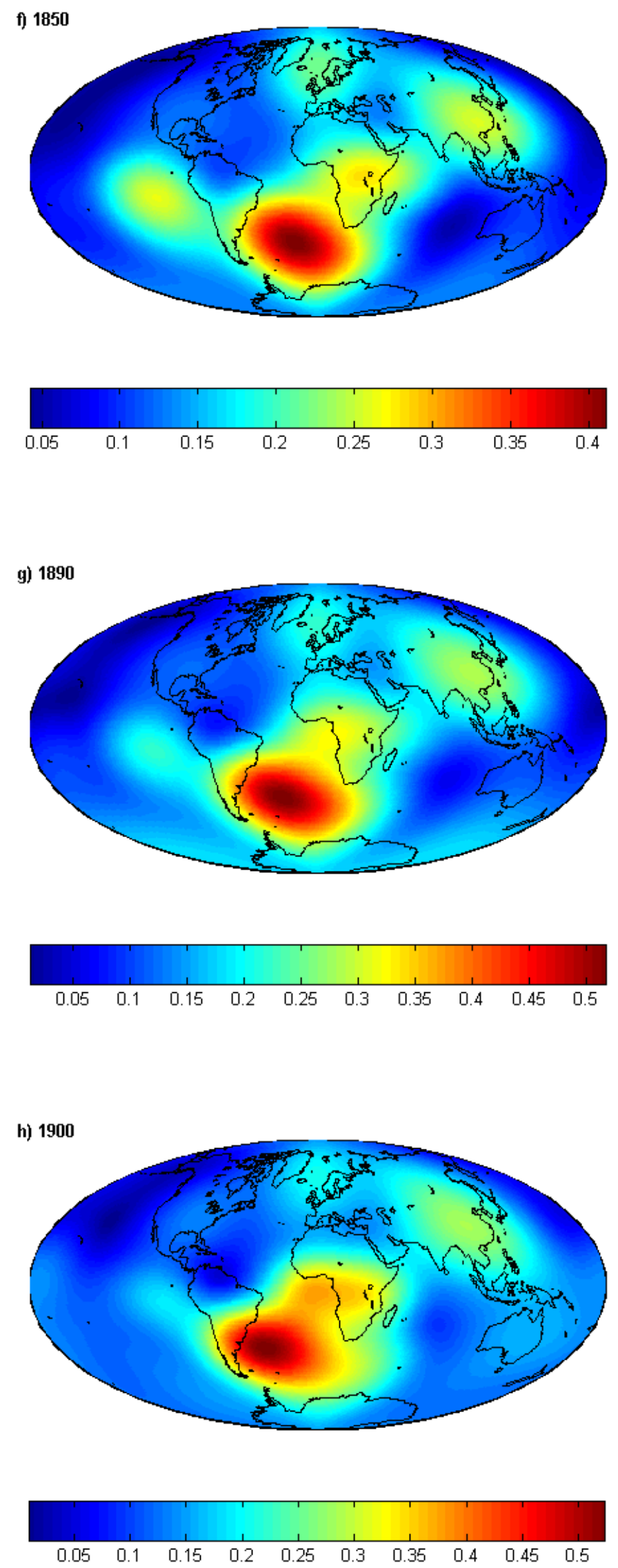

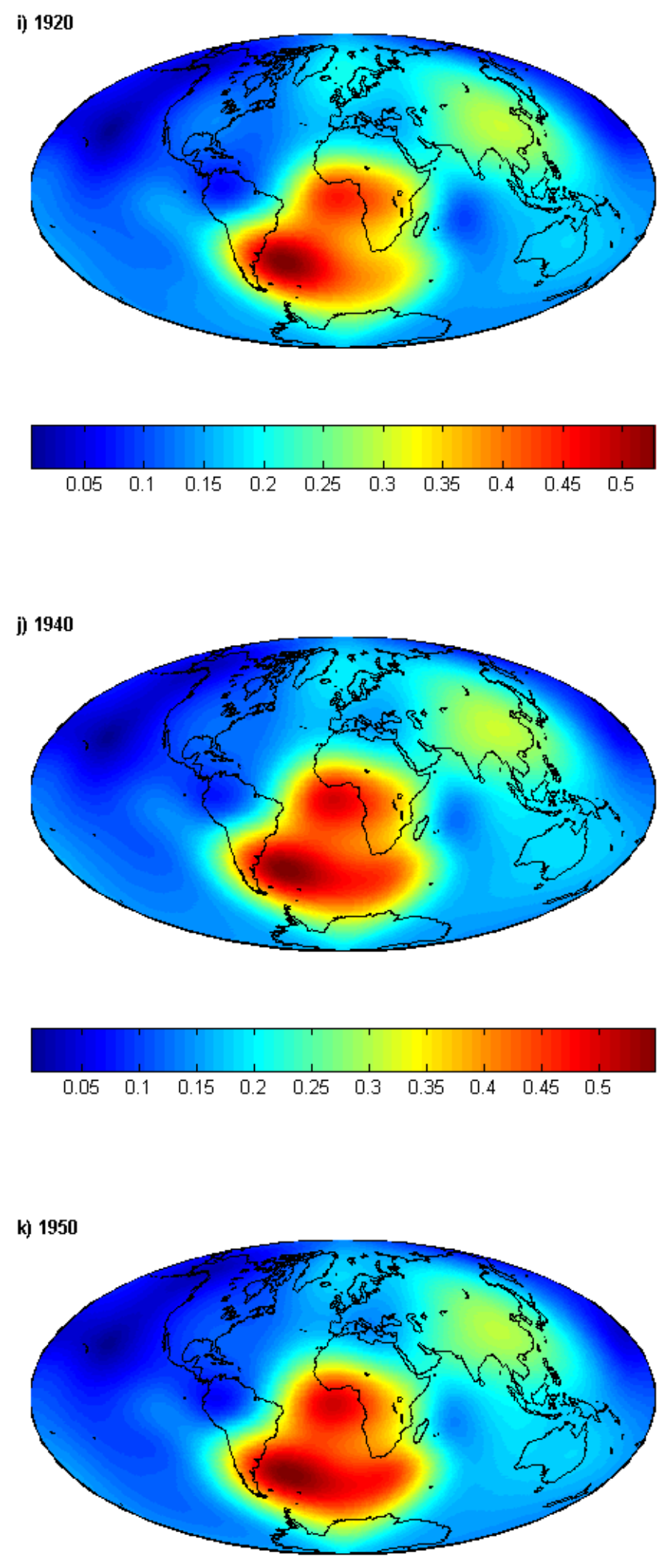

$\begin{array}{lllllllllll}0.05 & 0.1 & 0.15 & 0.2 & 0.25 & 0.3 & 0.35 & 0.4 & 0.45 & 0.5 & 0.55\end{array}$ 

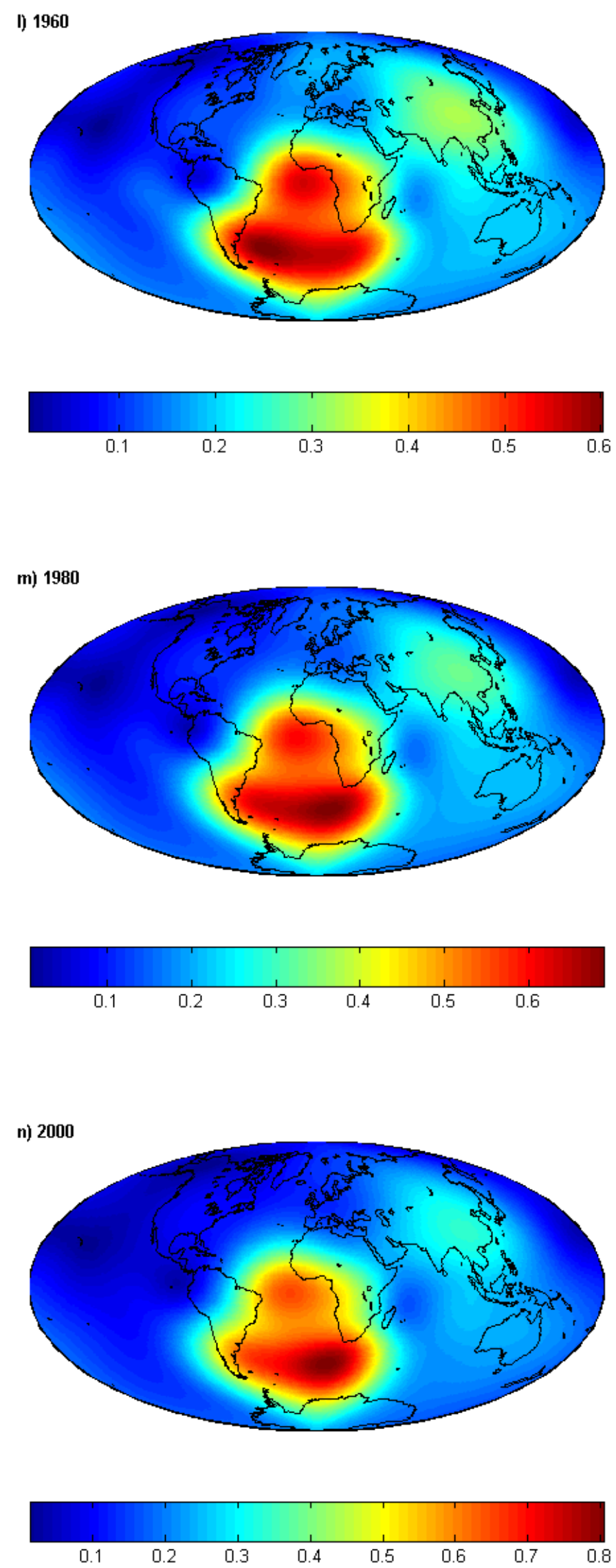

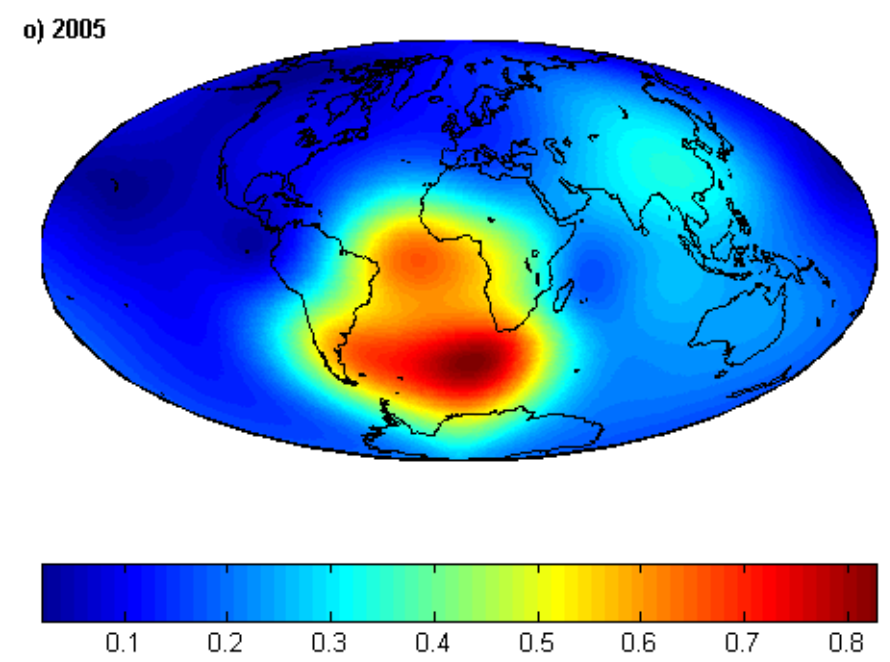


\section{Apêndice C - Mapas do campo radial na interface manto-núcleo}

Neste apêndice são mostrados os mapas da componente radial para a interface manto-núcleo, com $c=3485 \mathrm{~km}$. Os modelos apresentados são de Barraclough (1974) para os anos de 1600, 1650, 1700, 1750, 1800, 1850 e 1890; e, para os modelos do IGRF de 1900, 1920, 1940, 1950, 1960, 1980, 2000 e 2005. Os mapas estão na projeção Aitoff, as intensidades estão em nT e os valores são indicados na escala de cores.
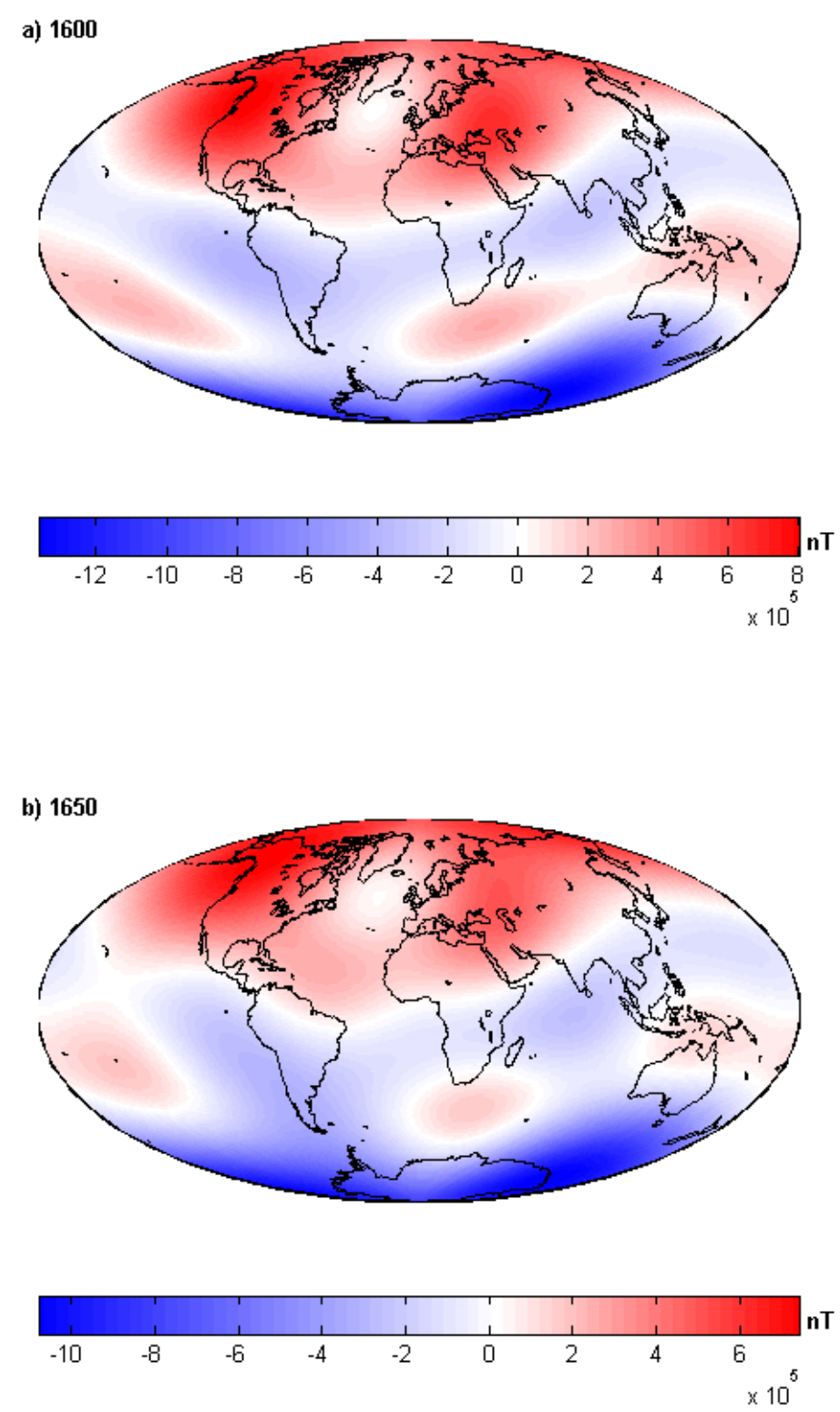

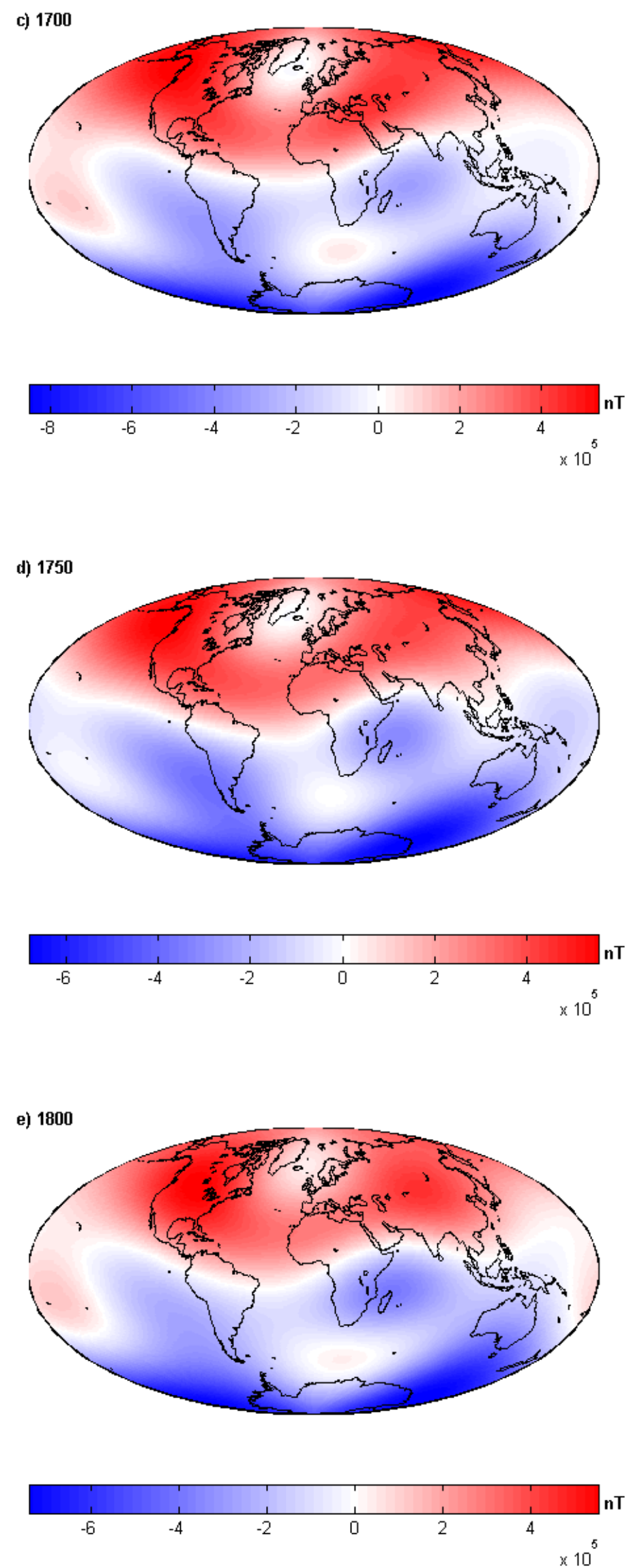

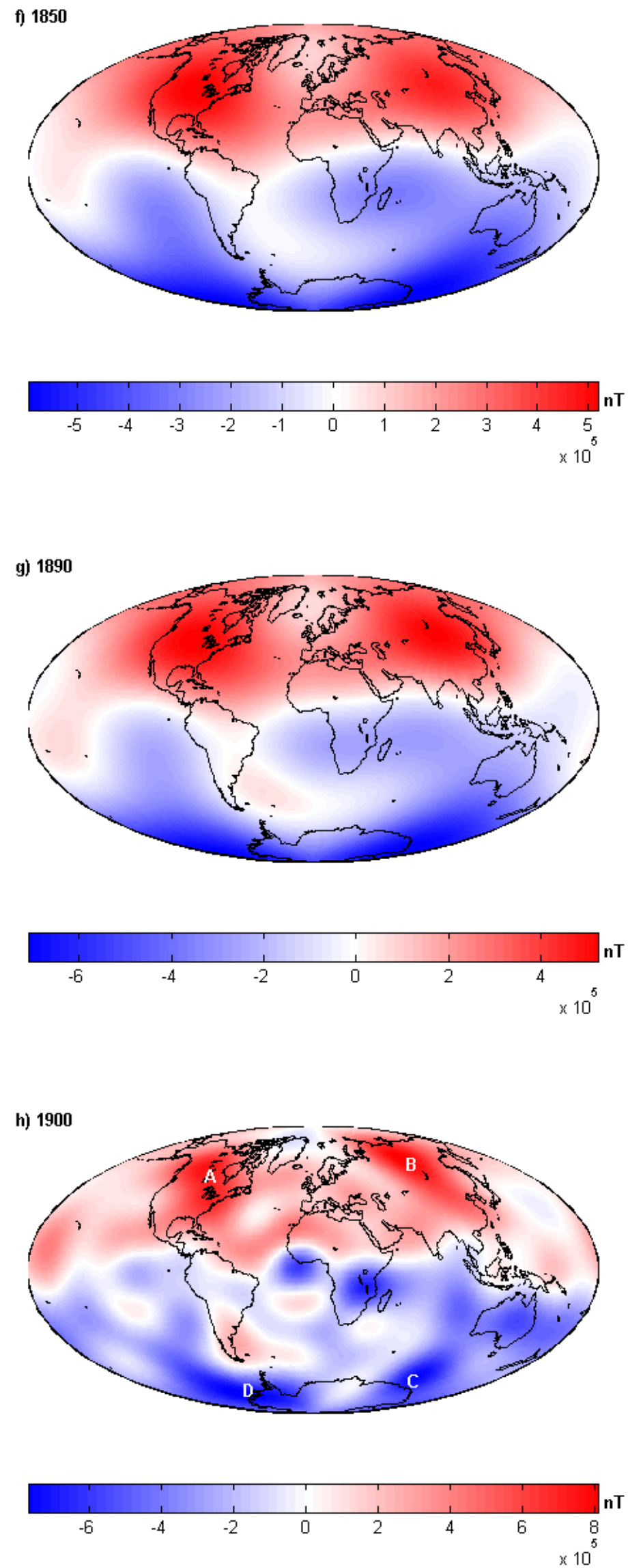

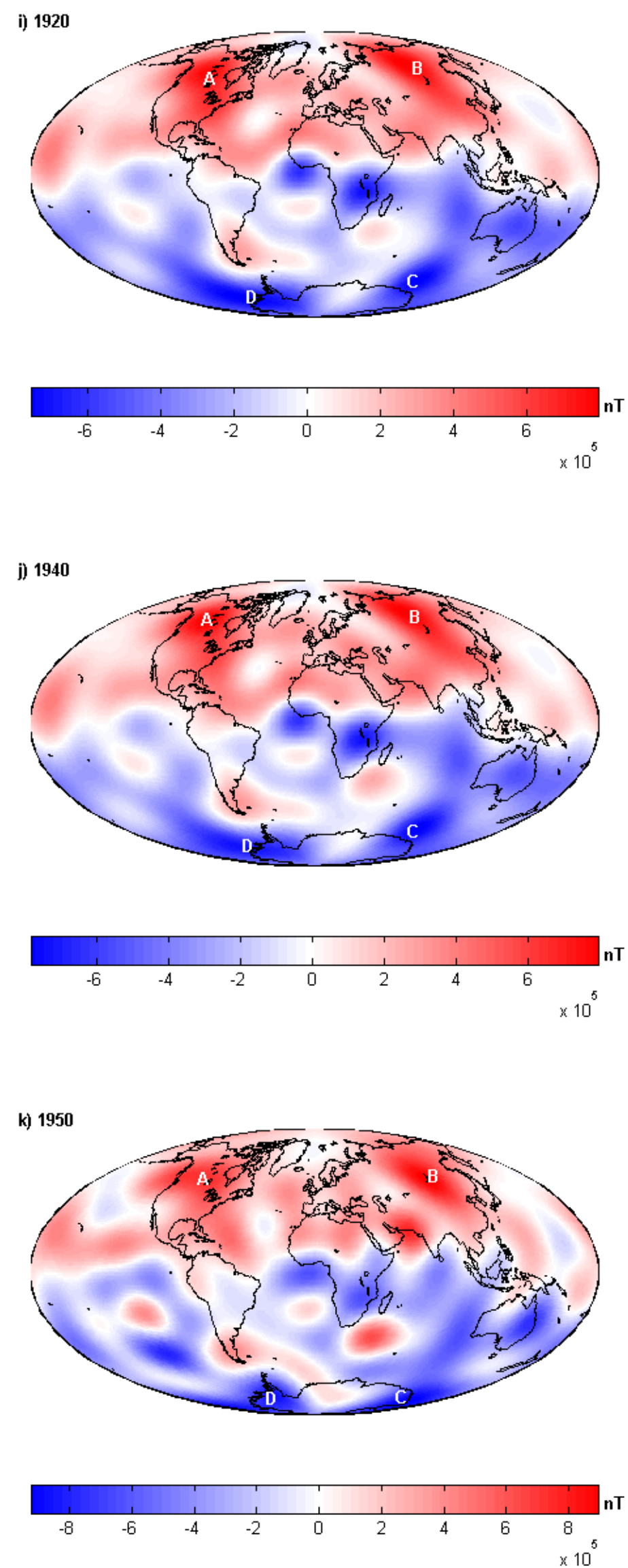

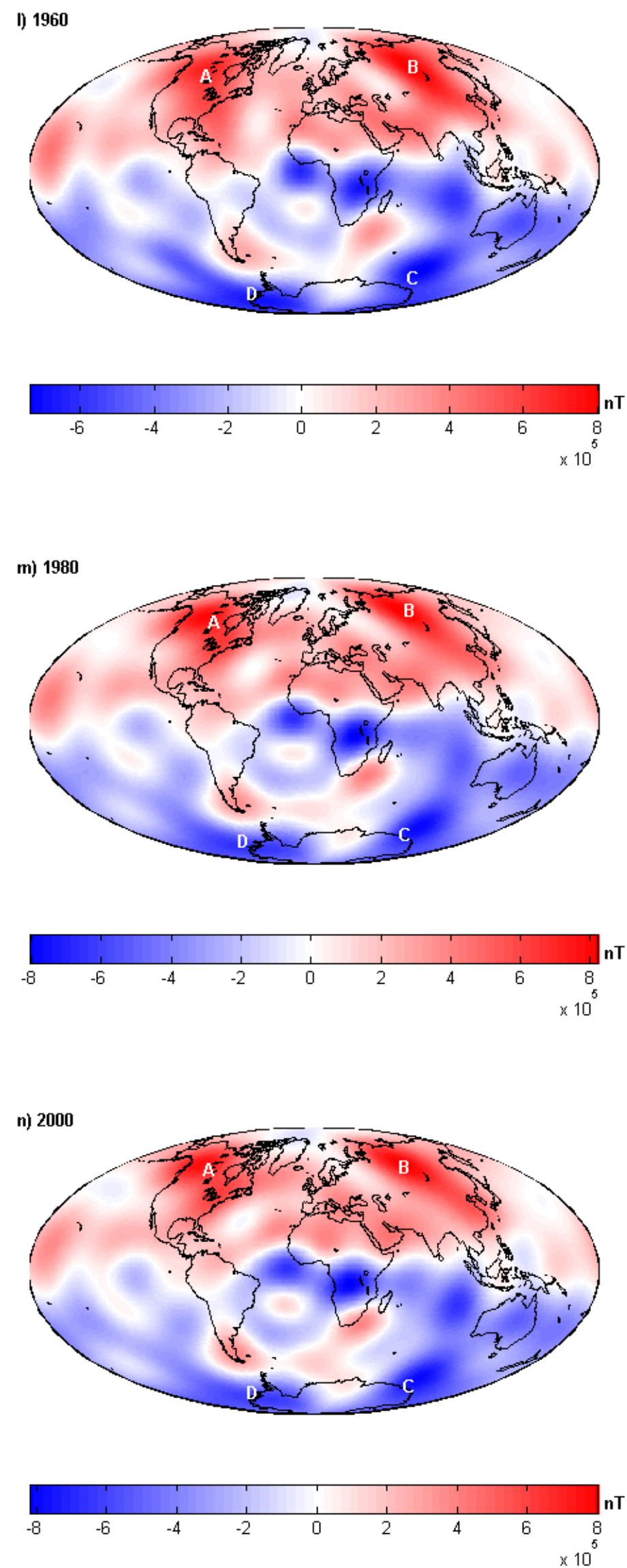


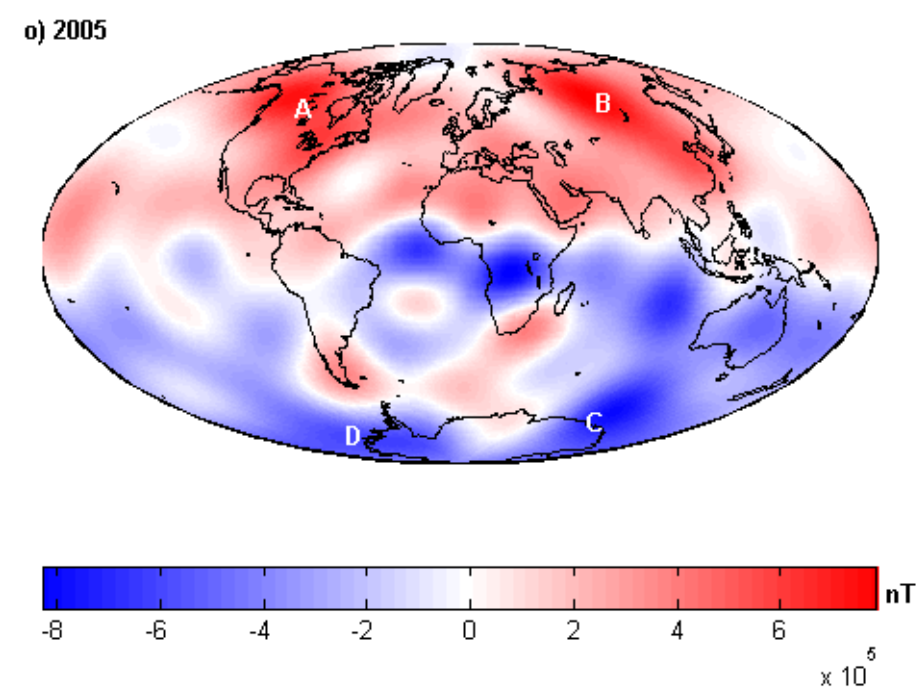




\section{Anexos}

\section{Anexo A - Tabela dos coeficientes de Gauss para o período histórico (modelos de Barraclough, 1974)}

\begin{tabular}{|c|c|c|c|c|c|c|c|c|c|c|c|c|c|c|c|}
\hline$g / h$ & $\mathrm{n} \mathrm{m}$ & 600 & $\sigma$ & 650 & $\sigma$ & 1700 & 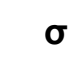 & 1750 & 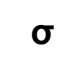 & 1800 & $\sigma$ & 1850 & $\boldsymbol{\sigma}$ & & \\
\hline$g$ & 10 & -32965 & 0 & -35192 & 0 & -34419 & 0 & -33646 & 0 & -32873 & & -32222 & 94 & -31718 & 99 \\
\hline $\mathrm{g}$ & 11 & -3421 & 32 & -3396 & 228 & -3497 & 126 & -3622 & 110 & -3339 & \pm 74 & -2823 & 48 & -2664 & \\
\hline h & 11 & 3055 & 293 & 2936 & 205 & 3761 & 108 & 4763 & 76 & 5282 & 67 & 5787 & 49 & 5764 & \\
\hline $\mathrm{g}$ & 20 & -193 & 3618 & 614 & 2570 & 1094 & 807 & 490 & 148 & 150 & 102 & -192 & 41 & -244 & \\
\hline $\mathrm{g}$ & 21 & 2026 & 753 & 2799 & 564 & 2668 & 264 & 2452 & 123 & 2309 & 89 & 2791 & 48 & 2972 & \\
\hline h & 21 & 1542 & 479 & 1902 & 297 & 1151 & 210 & 1075 & 90 & 717 & 82 & -193 & 48 & -834 & \\
\hline g & 22 & -1980 & 230 & -2053 & 167 & -2060 & 101 & -1178 & 65 & -522 & 47 & 154 & 37 & 704 & 62 \\
\hline h & 22 & -3282 & 184 & -2147 & 172 & -872 & 69 & 294 & 64 & 1108 & 53 & 1472 & 37 & 1303 & 6 \\
\hline$g$ & 30 & -2664 & 1663 & -2500 & 1332 & 251 & 676 & 696 & 151 & 732 & 108 & 1130 & 36 & 700 & \\
\hline $\mathrm{g}$ & 31 & -2320 & 798 & -1335 & 630 & -755 & 330 & 171 & 112 & -1111 & 81 & -930 & 38 & -1408 & \\
\hline h & 31 & 1381 & 553 & -29 & 451 & -596 & 302 & -568 & 90 & -576 & 84 & -274 & 38 & -239 & \\
\hline$g$ & 3 & 512 & 381 & 655 & 202 & 656 & 133 & 1151 & 75 & 1332 & 52 & 1466 & 37 & 1471 & 58 \\
\hline h & 32 & 185 & 570 & -134 & 304 & 312 & 110 & 140 & 66 & 363 & 57 & 28 & 35 & 13 & \\
\hline$g$ & 3 & -226 & 142 & -192 & 121 & -236 & 55 & -448 & 49 & 83 & 39 & 248 & 32 & 14 & 3 \\
\hline n & 3 & -43 & 144 & 8 & 118 & 4 & 51 & 2 & 51 & 4 & 40 & 802 & 33 & 551 & 5 \\
\hline 9 & 4 & 1317 & 655 & 30 & 469 & 07 & 334 & 800 & 84 & 24 & 75 & 734 & 32 & 975 & 3 \\
\hline$g$ & 4 & 88 & 419 & 1803 & 411 & 1497 & 312 & 1087 & 102 & 1332 & 67 & 784 & 31 & 1047 & 3 \\
\hline h & 4 & -1207 & 381 & -412 & 330 & -377 & 220 & -540 & 78 & 86 & 76 & 10 & 30 & -73 & 38 \\
\hline g & 4 & 583 & 235 & 355 & 164 & $3 / 6$ & 112 & -69 & 63 & 581 & 40 & 75 & 32 & 501 & ר \\
\hline h & 4 & -2089 & 309 & -1444 & 227 & -939 & 116 & -933 & $6^{-}$ & -664 & 5 & -193 & 32 & -99 & \\
\hline g & 4 & -6 & 144 & 166 & 88 & 165 & 64 & -1 & 45 & -106 & 38 & -247 & 29 & -422 & 38 \\
\hline h & 4 & -559 & 160 & -298 & 77 & -413 & 57 & -254 & 46 & -339 & 41 & -292 & 30 & -192 & 38 \\
\hline & 44 & 289 & 85 & 416 & 86 & -34 & 39 & -129 & 38 & -214 & 34 & 44 & 29 & 149 & 39 \\
\hline
\end{tabular}




\section{Anexo B - Tabela dos modelos do DGRF e IGRF a partir de 1900}

\begin{tabular}{|c|c|c|c|c|c|c|c|c|c|c|c|c|c|}
\hline g/h & $\mathbf{n}$ & m & 1900,0 & 1905,0 & 1910,0 & 1915,0 & 1920,0 & 1925,0 & 1930,0 & 1935,0 & 1940,0 & 1945,0 & 1950,0 \\
\hline g & 1 & 0 & -31543 & -31464 & -31354 & -31212 & -31060 & -30926 & -30805 & -30715 & -30654 & -30594 & -30554 \\
\hline 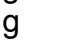 & 1 & 1 & -2298 & -2298 & -2297 & -2306 & -2317 & -2318 & -2316 & -2306 & -2292 & -2285 & -225 \\
\hline & 1 & 1 & 5922 & 5909 & 5898 & 5875 & 5845 & 5817 & 5808 & 5812 & 5821 & 5810 & 581 \\
\hline g & 2 & 0 & -677 & -728 & -769 & -802 & -839 & -893 & -951 & -1018 & -1106 & -1244 & -134 \\
\hline & 2 & 1 & 2905 & 2928 & 2948 & 2956 & 2959 & 2969 & 2980 & 2984 & 2981 & 2990 & 299 \\
\hline $\mathrm{h}$ & 2 & 1 & -1061 & -1086 & -1128 & -1191 & -1259 & -1334 & -1424 & -1520 & -1614 & -1702 & -181 \\
\hline g & 2 & 2 & 924 & 1041 & 1176 & 1309 & 1407 & 1471 & 1517 & 1550 & 1566 & 1578 & 157 \\
\hline n & 2 & 2 & 1121 & 1065 & 1000 & 917 & 823 & 728 & 644 & 586 & 528 & 477 & 38 \\
\hline g & 3 & 0 & 1022 & 1037 & 1058 & 1084 & 1111 & 1140 & 1172 & 1206 & 1240 & 1282 & 129 \\
\hline & 3 & 1 & -1469 & -1494 & -1524 & -1559 & -1600 & -1645 & -1692 & -1740 & -1790 & -1834 & -188 \\
\hline$n$ & 3 & 1 & -330 & -357 & -389 & -421 & -445 & -462 & -480 & -494 & -499 & -499 & -47 \\
\hline g & 3 & 2 & 1256 & 1239 & 1223 & 1212 & 1205 & 1202 & 1205 & 1215 & 1232 & 1255 & 127 \\
\hline$\pi$ & 3 & 2 & 3 & 34 & 62 & 84 & 103 & 119 & 133 & 146 & 163 & 186 & 20 \\
\hline g & 3 & 3 & 572 & 635 & 705 & 778 & 839 & 881 & 907 & 918 & 916 & 913 & 89 \\
\hline 11 & 3 & 3 & 523 & 480 & 425 & 360 & 293 & 229 & 166 & 101 & 43 & -11 & -4 \\
\hline g & 4 & 0 & 876 & 880 & 884 & 887 & 889 & 891 & 896 & 903 & 914 & 944 & 95 \\
\hline $\mathrm{g}$ & 4 & 1 & 628 & 643 & 660 & 678 & 695 & 711 & 727 & 744 & 762 & 776 & 79 \\
\hline n & 4 & 1 & 195 & 203 & 211 & 218 & 220 & 216 & 205 & 188 & 169 & 144 & 13 \\
\hline$g$ & 4 & 2 & 660 & 653 & 644 & 631 & 616 & 601 & 584 & 565 & 550 & 544 & 52 \\
\hline II & 4 & 2 & -69 & -77 & -90 & -109 & -134 & -163 & -195 & -226 & -252 & -276 & $-27 \varepsilon$ \\
\hline g & 4 & 3 & -361 & -380 & -400 & -416 & -424 & -426 & -422 & -415 & -405 & -421 & -408 \\
\hline $\mathrm{h}$ & 4 & 3 & -210 & -201 & -189 & -173 & -153 & -130 & -109 & -90 & -72 & -55 & -37 \\
\hline g & 4 & 4 & 134 & 146 & 160 & 178 & 199 & 217 & 234 & 249 & 265 & 304 & 303 \\
\hline h & 4 & 4 & -15 & -65 & -55 & -51 & -57 & -70 & -90 & -114 & -141 & -178 & -21 \\
\hline g & 5 & 0 & -184 & -192 & -201 & -211 & -221 & -230 & -237 & -241 & -241 & -253 & -24 \\
\hline y & 5 & 1 & 328 & 328 & 327 & 327 & 326 & 326 & 327 & 329 & 334 & 346 & 34 \\
\hline h & 5 & 1 & -210 & -193 & -172 & -148 & -122 & -96 & -72 & -51 & -33 & -12 & \\
\hline g & 5 & 2 & 264 & 259 & 253 & 245 & 236 & 226 & 218 & 211 & 208 & 194 & 21 \\
\hline $\mathrm{h}$ & 5 & 2 & 53 & 56 & 57 & 58 & 58 & 58 & 60 & 64 & 71 & 95 & 10 \\
\hline g & 5 & 3 & 5 & -1 & -9 & -16 & -23 & -28 & -32 & -33 & -33 & -20 & -2 \\
\hline $\mathrm{h}$ & 5 & 3 & -33 & -32 & -33 & -34 & -38 & -44 & -53 & -64 & -75 & -67 & -8 \\
\hline g & 5 & 4 & -86 & -93 & -102 & -111 & -119 & -125 & -131 & -136 & -141 & -142 & -14 \\
\hline $\mathrm{h}$ & 5 & 4 & -124 & -125 & -126 & -126 & -125 & -122 & -118 & -115 & -113 & -119 & -12 \\
\hline g & 5 & 5 & -16 & -26 & -38 & -51 & -62 & -69 & -74 & -76 & -76 & -82 & -7 \\
\hline$h$ & 5 & 5 & 3 & 11 & 21 & 32 & 43 & 51 & 58 & 64 & 69 & 82 & \\
\hline g & 6 & 0 & 63 & 62 & 62 & 61 & 61 & 61 & 60 & 59 & 57 & 59 & \\
\hline g & 6 & 1 & 61 & 60 & 58 & 57 & 55 & 54 & 53 & 53 & 54 & 57 & 5 \\
\hline $\mathrm{h}$ & 6 & 1 & -9 & -7 & -5 & -2 & 0 & 3 & 4 & 4 & 4 & 6 & \\
\hline g & 6 & 2 & -11 & -11 & -11 & -10 & -10 & -9 & -9 & -8 & -7 & 6 & \\
\hline $\mathrm{h}$ & 6 & 2 & 83 & 86 & 89 & 93 & 96 & 99 & 102 & 104 & 105 & 100 & 9 \\
\hline g & 6 & 3 & -217 & -221 & -224 & -228 & -233 & -238 & -242 & -246 & -249 & -246 & -24 \\
\hline $\mathrm{h}$ & 6 & 3 & 2 & 4 & 5 & 8 & 11 & 14 & 19 & 25 & 33 & 16 & \\
\hline g & 6 & 4 & -58 & -57 & -54 & -51 & -46 & -40 & -32 & -25 & -18 & -25 & -16 \\
\hline $\mathrm{n}$ & 6 & 4 & -35 & -32 & -29 & -26 & -22 & -18 & -16 & -15 & -15 & -9 & -1 \\
\hline g & 6 & 5 & 5 & 57 & 54 & 49 & 44 & 39 & 32 & 25 & 18 & 21 & \\
\hline h & 6 & 5 & 3 & 3 & 28 & 23 & 18 & 13 & 8 & 4 & 0 & -16 & -1 \\
\hline$g$ & 6 & 6 & -90 & -92 & -95 & -98 & -101 & -103 & -104 & -106 & -107 & -104 & -10 \\
\hline $\mathrm{h}$ & 6 & 6 & -69 & -67 & -65 & -62 & -57 & -52 & -46 & -40 & -33 & -39 & -3 \\
\hline$g$ & 7 & 0 & 7 & 7 & 71 & 72 & 73 & 73 & 74 & 74 & 74 & 70 & \\
\hline$g$ & 7 & 1 & -55 & -54 & -54 & -54 & -54 & -54 & -54 & -53 & -53 & -40 & -5 \\
\hline h & 7 & 1 & -45 & -46 & -47 & -48 & -49 & -50 & -51 & -52 & -52 & -45 & -3 \\
\hline$g$ & 7 & 2 & 0 & 0 & 1 & 2 & 2 & 3 & 4 & 4 & 4 & 0 & \\
\hline h & 7 & 2 & -13 & -14 & -14 & -14 & -14 & -14 & -15 & -17 & -18 & -18 & -1 \\
\hline$g$ & 7 & 3 & 3 & 33 & 32 & 31 & 29 & 27 & 25 & 23 & 20 & 0 & \\
\hline $\mathrm{h}$ & 7 & 3 & -10 & -11 & -12 & -12 & -13 & -14 & -14 & -14 & -14 & 2 & \\
\hline g & 7 & 4 & -41 & -41 & -40 & -38 & -37 & -35 & -34 & -33 & -31 & -29 & -4 \\
\hline $\mathrm{h}$ & 7 & 4 & -1 & 0 & 1 & 2 & 4 & 5 & 6 & 7 & 7 & 6 & 1 \\
\hline g & 7 & 5 & -21 & -20 & -19 & -18 & -16 & -14 & -12 & -11 & -9 & -10 & \\
\hline h & 7 & 5 & 28 & 28 & 28 & 28 & 28 & 29 & 29 & 29 & 29 & 28 & 3 \\
\hline g & 7 & 6 & 18 & 18 & 18 & 19 & 19 & 19 & 18 & 18 & 17 & 15 & \\
\hline $\mathrm{h}$ & 7 & 6 & -12 & -12 & -13 & -15 & -16 & -17 & -18 & -19 & -20 & -17 & -1 \\
\hline$g$ & 7 & 7 & 6 & 6 & 6 & 6 & 6 & 6 & 6 & 6 & 5 & 29 & 1 \\
\hline h & 7 & 7 & -22 & -22 & -22 & -22 & -22 & -21 & -20 & -19 & -19 & -22 & \\
\hline
\end{tabular}


continuação da tabela

\begin{tabular}{|c|c|c|c|c|c|c|c|c|c|c|c|c|c|}
\hline g/h & $\mathbf{n}$ & $\mathbf{m}$ & 1900,0 & 1905,0 & 1910,0 & 1915,0 & 1920,0 & 1925,0 & 1930,0 & 1935,0 & 1940,0 & 1945,0 & 1950,0 \\
\hline$g$ & 8 & 0 & 11 & 11 & 11 & 11 & 11 & 11 & 11 & 11 & 11 & 13 & 22 \\
\hline g & 8 & 1 & 8 & 8 & 8 & 8 & 7 & 7 & 7 & 7 & 7 & 7 & 15 \\
\hline $\mathrm{h}$ & 8 & 1 & 8 & 8 & 8 & 8 & 8 & 8 & 8 & 8 & 8 & 12 & 5 \\
\hline g & 8 & 2 & -4 & -4 & -4 & -4 & -3 & -3 & -3 & -3 & -3 & -8 & -4 \\
\hline $\mathrm{h}$ & 8 & 2 & -14 & -15 & -15 & -15 & -15 & -15 & -15 & -15 & -14 & -21 & -22 \\
\hline g & 8 & 3 & -9 & -9 & -9 & -9 & -9 & -9 & -9 & -9 & -10 & -5 & -1 \\
\hline $\mathrm{h}$ & 8 & 3 & 7 & 7 & 6 & 6 & 6 & 6 & 5 & 5 & 5 & -12 & 0 \\
\hline g & 8 & 4 & 1 & 1 & 1 & 2 & 2 & 2 & 2 & 1 & 1 & 9 & 11 \\
\hline $\mathrm{h}$ & 8 & 4 & -13 & -13 & -13 & -13 & -14 & -14 & -14 & -15 & -15 & -7 & -21 \\
\hline g & 8 & 5 & 2 & 2 & 2 & 3 & 4 & 4 & 5 & 6 & 6 & 7 & 15 \\
\hline $\mathrm{h}$ & 8 & 5 & 5 & 5 & 5 & 5 & 5 & 5 & 5 & 5 & 5 & 2 & -8 \\
\hline g & 8 & 6 & -9 & -8 & -8 & -8 & -7 & -7 & -6 & -6 & -5 & -10 & -13 \\
\hline $\mathrm{h}$ & 8 & 6 & 16 & 16 & 16 & 16 & 17 & 17 & 18 & 18 & 19 & 18 & 17 \\
\hline g & 8 & 7 & 5 & 5 & 5 & 6 & 6 & 7 & 8 & 8 & 9 & 7 & 5 \\
\hline $\mathrm{h}$ & 8 & 7 & -5 & -5 & -5 & -5 & -5 & -5 & -5 & -5 & -5 & 3 & -4 \\
\hline g & 8 & 8 & 8 & 8 & 8 & 8 & 8 & 8 & 8 & 7 & 7 & 2 & -1 \\
\hline $\mathrm{h}$ & 8 & 8 & -18 & -18 & -18 & -18 & -19 & -19 & -19 & -19 & -19 & -11 & -17 \\
\hline g & 9 & 0 & 8 & 8 & 8 & 8 & 8 & 8 & 8 & 8 & 8 & 5 & 3 \\
\hline g & 9 & 1 & 10 & 10 & 10 & 10 & 10 & 10 & 10 & 10 & 10 & -21 & -7 \\
\hline $\mathrm{h}$ & 9 & 1 & -20 & -20 & -20 & -20 & -20 & -20 & -20 & -20 & -21 & -27 & -24 \\
\hline g & 9 & 2 & 1 & 1 & 1 & 1 & 1 & 1 & 1 & 1 & 1 & 1 & -1 \\
\hline $\mathrm{h}$ & 9 & 2 & 14 & 14 & 14 & 14 & 14 & 14 & 14 & 15 & 15 & 17 & 19 \\
\hline g & 9 & 3 & -11 & -11 & -11 & -11 & -11 & -11 & -12 & -12 & -12 & -11 & -25 \\
\hline $\mathrm{h}$ & 9 & 3 & 5 & 5 & 5 & 5 & 5 & 5 & 5 & 5 & 5 & 29 & 12 \\
\hline g & 9 & 4 & 12 & 12 & 12 & 12 & 12 & 12 & 12 & 11 & 11 & 3 & 10 \\
\hline h & 9 & 4 & -3 & -3 & -3 & -3 & -3 & -3 & -3 & -3 & -3 & -9 & 2 \\
\hline g & 9 & 5 & 1 & 1 & 1 & 1 & 1 & 1 & 1 & 1 & 1 & 16 & 5 \\
\hline $\mathrm{h}$ & 9 & 5 & -2 & -2 & -2 & -2 & -2 & -2 & -2 & -3 & -3 & 4 & 2 \\
\hline g & 9 & 6 & -2 & -2 & -2 & -2 & -2 & -2 & -2 & -2 & -2 & -3 & -5 \\
\hline h & 9 & 6 & 8 & 8 & 8 & 8 & 9 & 9 & 9 & 9 & 9 & 9 & 8 \\
\hline g & 9 & 7 & 2 & 2 & 2 & 2 & 2 & 2 & 3 & 3 & 3 & -4 & -2 \\
\hline $\mathrm{h}$ & 9 & 7 & 10 & 10 & 10 & 10 & 10 & 10 & 10 & 11 & 11 & 6 & 8 \\
\hline g & 9 & 8 & -1 & 0 & 0 & 0 & 0 & 0 & 0 & 0 & 1 & -3 & 3 \\
\hline $\mathrm{h}$ & 9 & 8 & -2 & -2 & -2 & -2 & -2 & -2 & -2 & -2 & -2 & 1 & -11 \\
\hline g & 9 & 9 & -1 & -1 & -1 & -1 & -1 & -1 & -2 & -2 & -2 & -4 & 8 \\
\hline $\mathrm{h}$ & 9 & 9 & 2 & 2 & 2 & 2 & 2 & 2 & 2 & 2 & 2 & 8 & -7 \\
\hline g & 10 & 0 & -3 & -3 & -3 & -3 & -3 & -3 & -3 & -3 & -3 & -3 & -8 \\
\hline g & 10 & 1 & -4 & -4 & -4 & -4 & -4 & -4 & -4 & -4 & -4 & 11 & 4 \\
\hline $\mathrm{h}$ & 10 & 1 & 2 & 2 & 2 & 2 & 2 & 2 & 2 & 2 & 2 & 5 & 13 \\
\hline g & 10 & 2 & 2 & 2 & 2 & 2 & 2 & 2 & 2 & 2 & 2 & 1 & -1 \\
\hline $\mathrm{h}$ & 10 & 2 & 1 & 1 & 1 & 1 & 1 & 1 & 1 & 1 & 1 & 1 & -2 \\
\hline g & 10 & 3 & -5 & -5 & -5 & -5 & -5 & -5 & -5 & -5 & -5 & 2 & 13 \\
\hline $\mathrm{h}$ & 10 & 3 & 2 & 2 & 2 & 2 & 2 & 2 & 2 & 2 & 2 & -20 & -10 \\
\hline g & 10 & 4 & -2 & -2 & -2 & -2 & -2 & -2 & -2 & -2 & -2 & -5 & -4 \\
\hline $\mathrm{h}$ & 10 & 4 & 6 & 6 & 6 & 6 & 6 & 6 & 6 & 6 & 6 & -1 & 2 \\
\hline g & 10 & 5 & 6 & 6 & 6 & 6 & 6 & 6 & 6 & 6 & 6 & -1 & 4 \\
\hline $\mathrm{h}$ & 10 & 5 & -4 & -4 & -4 & -4 & -4 & -4 & -4 & -4 & -4 & -6 & -3 \\
\hline g & 10 & 6 & 4 & 4 & 4 & 4 & 4 & 4 & 4 & 4 & 4 & 8 & 12 \\
\hline h & 10 & 6 & 0 & 0 & 0 & 0 & 0 & 0 & 0 & 0 & 0 & 6 & 6 \\
\hline g & 10 & 7 & 0 & 0 & 0 & 0 & 0 & 0 & 0 & 0 & 0 & -1 & 3 \\
\hline h & 10 & 7 & -2 & -2 & -2 & -2 & -2 & -2 & -2 & -1 & -1 & -4 & -3 \\
\hline g & 10 & 8 & 2 & 2 & 2 & 1 & 1 & 1 & 1 & 2 & 2 & -3 & 2 \\
\hline h & 10 & 8 & 4 & 4 & 4 & 4 & 4 & 4 & 4 & 4 & 4 & -2 & 6 \\
\hline g & 10 & 9 & 2 & 2 & 2 & 2 & 3 & 3 & 3 & 3 & 3 & 5 & 10 \\
\hline h & 10 & 9 & 0 & 0 & 0 & 0 & 0 & 0 & 0 & 0 & 0 & 0 & 11 \\
\hline g & 10 & 10 & 0 & 0 & 0 & 0 & 0 & 0 & 0 & 0 & 0 & -2 & 3 \\
\hline h & 10 & 10 & -6 & -6 & -6 & -6 & -6 & -6 & -6 & -6 & -6 & -2 & 8 \\
\hline
\end{tabular}


continuação da tabela

\begin{tabular}{|c|c|c|c|c|c|c|c|c|c|c|c|c|}
\hline$g / h$ & $\mathrm{n} \mathrm{m}$ & 1955,0 & 1960,0 & 1965,0 & 1970,0 & 1975,0 & 1980,0 & 1985,0 & 1990,0 & 1995,0 & 2000,0 & 2005,0 \\
\hline$g$ & 10 & -30500 & -30421 & -30334 & -30220 & -30100 & -29992 & -29873 & -29775 & -29692 & $-29619,4$ & $-29556,8$ \\
\hline $\mathrm{g}$ & 11 & -2215 & -2169 & -2119 & -2068 & -2013 & -1956 & -1905 & -1848 & -1784 & $-1728,2$ & $-1671,8$ \\
\hline $\mathrm{h}$ & 11 & 5820 & 5791 & 5776 & 5737 & 5675 & 5604 & 5500 & 5406 & 5306 & 5186,1 & 5080,0 \\
\hline $\mathrm{g}$ & 20 & -1440 & -1555 & -1662 & -1781 & -1902 & -1997 & -2072 & -2131 & -2200 & $-2267,7$ & $-2340,5$ \\
\hline $\mathrm{g}$ & 21 & 3003 & 3002 & 2997 & 3000 & 3010 & 3027 & 3044 & 3059 & 3070 & 3068,4 & 3047,0 \\
\hline $\mathrm{h}$ & 21 & -1898 & -1967 & -2016 & -2047 & -2067 & -2129 & -2197 & -2279 & -2366 & $-2481,6$ & $-2594,9$ \\
\hline $\mathrm{g}$ & 22 & 1581 & 1590 & 1594 & 1611 & 1632 & 1663 & 1687 & 1686 & 1681 & 1670,9 & 1656,9 \\
\hline $\mathrm{h}$ & 22 & 291 & 206 & 114 & 25 & -68 & -200 & -306 & -373 & -413 & $-458,0$ & $-516,7$ \\
\hline$g$ & 30 & 1302 & 1302 & 1297 & 1287 & 1276 & 1281 & 1296 & 1314 & 1335 & 1339,6 & 1335,7 \\
\hline$g$ & $\begin{array}{ll}3 & 1\end{array}$ & -1944 & -1992 & -2038 & -2091 & -2144 & -2180 & -2208 & -2239 & -2267 & $-2288,0$ & $-2305,3$ \\
\hline $\mathrm{h}$ & $\begin{array}{ll}3 & 1\end{array}$ & -462 & -414 & -404 & -366 & -333 & -336 & -310 & -284 & -262 & $-227,6$ & $-200,4$ \\
\hline$g$ & 32 & 1288 & 1289 & 1292 & 1278 & 1260 & 1251 & 1247 & 1248 & 1249 & 1252,1 & 1246,8 \\
\hline $\mathrm{h}$ & 32 & 216 & 224 & 240 & 251 & 262 & 271 & 284 & 293 & 302 & 293,4 & 269,3 \\
\hline$g$ & 33 & 882 & 878 & 856 & 838 & 830 & 833 & 829 & 802 & 759 & 714,5 & 674,4 \\
\hline $\mathrm{h}$ & 33 & -83 & -130 & -165 & -196 & -223 & -252 & -297 & -352 & -427 & $-491,1$ & $-524,5$ \\
\hline$g$ & 40 & 958 & 957 & 957 & 952 & 946 & 938 & 936 & 939 & 940 & 932,3 & 919,8 \\
\hline $\mathrm{g}$ & 41 & 796 & 800 & 804 & 800 & 791 & 782 & 780 & 780 & 780 & 786,8 & 798,2 \\
\hline $\mathrm{h}$ & 41 & 133 & 135 & 148 & 167 & 191 & 212 & 232 & 247 & 262 & 272,6 & 281, \\
\hline $\mathrm{g}$ & 42 & 510 & 504 & 479 & 461 & 438 & 398 & 361 & 325 & 290 & 250,0 & 211,5 \\
\hline $\mathrm{h}$ & 42 & -274 & -278 & -269 & -266 & -265 & -257 & -249 & -240 & -236 & $-231,9$ & $-225,8$ \\
\hline$g$ & 43 & -397 & -394 & -390 & -395 & -405 & -419 & -424 & -423 & -418 & $-403,0$ & $-379,5$ \\
\hline h & 43 & -23 & 3 & 13 & 26 & 39 & 53 & 69 & 84 & 97 & 119,8 & 145,7 \\
\hline g & 44 & 290 & 269 & 252 & 234 & 216 & 199 & 170 & 141 & 122 & 111,3 & 100,2 \\
\hline $\mathrm{h}$ & 44 & -230 & -255 & -269 & -279 & -288 & -297 & -297 & -299 & -306 & $-303,8$ & $-304,7$ \\
\hline $\mathrm{g}$ & 50 & -229 & -222 & -219 & -216 & -218 & -218 & -214 & -214 & -214 & $-218,8$ & $-227,6$ \\
\hline$g$ & $\begin{array}{ll}5 & 1\end{array}$ & 360 & 362 & 358 & 359 & 356 & 357 & 355 & 353 & 352 & 351,4 & 354,4 \\
\hline $\mathrm{h}$ & $\begin{array}{ll}5 & 1\end{array}$ & 15 & 16 & 19 & 26 & 31 & 46 & 47 & 46 & 46 & 43,8 & 42,7 \\
\hline $\mathrm{g}$ & 52 & 230 & 242 & 254 & 262 & 264 & 261 & 253 & 245 & 235 & 222,3 & 208,8 \\
\hline $\mathrm{h}$ & 52 & 110 & 125 & 128 & 139 & 148 & 150 & 150 & 154 & 165 & 171,9 & 179,8 \\
\hline $\mathrm{g}$ & 53 & -23 & -26 & -31 & -42 & -59 & -74 & -93 & -109 & -118 & $-130,4$ & $-136,6$ \\
\hline $\mathrm{h}$ & 53 & -98 & -117 & -126 & -139 & -152 & -151 & -154 & -153 & -143 & $-133,1$ & $-123,0$ \\
\hline $\mathrm{g}$ & $\begin{array}{ll}5 & 4\end{array}$ & -152 & -156 & -157 & -160 & -159 & -162 & -164 & -165 & -166 & $-168,6$ & $-168,3$ \\
\hline $\mathrm{h}$ & 54 & -121 & -114 & -97 & -91 & -83 & -78 & -75 & -69 & -55 & $-39,3$ & -19, \\
\hline $\mathrm{g}$ & 55 & -69 & -63 & -62 & -56 & -49 & -48 & -46 & -36 & -17 & $-12,9$ & $-14,1$ \\
\hline $\mathrm{h}$ & 55 & 78 & 81 & 81 & 83 & 88 & 92 & 95 & 97 & 107 & 106,3 & 103, \\
\hline$g$ & 60 & 47 & 46 & 45 & 43 & 45 & 48 & 53 & 61 & 68 & 72,3 & 72,9 \\
\hline$g$ & 6 & 57 & 58 & 61 & 64 & 66 & 66 & 65 & 65 & 67 & 68,2 & 69,6 \\
\hline $\mathrm{h}$ & 6 & -9 & -10 & -11 & -12 & -13 & -15 & -16 & -16 & -17 & $-17,4$ & $-20,2$ \\
\hline$g$ & 62 & 3 & 1 & 8 & 15 & 28 & 42 & 51 & 59 & 68 & 74,2 & 76 \\
\hline $\mathrm{h}$ & 62 & 96 & 99 & 100 & 100 & 99 & 93 & 88 & 82 & 72 & 63,7 & 54,7 \\
\hline $\mathrm{g}$ & 63 & -247 & -237 & -228 & -212 & -198 & -192 & -185 & -178 & -170 & $-160,9$ & $-151,1$ \\
\hline $\mathrm{h}$ & 63 & 48 & 60 & 68 & 72 & 75 & 71 & 69 & 69 & 67 & 65,1 & 63,7 \\
\hline$g$ & $\begin{array}{ll}64 \\
\text {. }\end{array}$ & -8 & -1 & 4 & 2 & 1 & 4 & 4 & 3 & -1 & $-5,9$ & $-15,0$ \\
\hline h & $\begin{array}{ll}64 \\
\end{array}$ & -16 & -20 & -32 & -37 & -41 & -43 & -48 & -52 & -58 & $-61,2$ & $-63,4$ \\
\hline$g$ & 65 & 7 & -2 & 1 & 3 & 6 & 14 & 16 & 18 & 19 & 16,9 & 14,7 \\
\hline $\mathrm{h}$ & 65 & -12 & -11 & -8 & -6 & -4 & -2 & -1 & 1 & 1 & 0,7 & 0,0 \\
\hline$g$ & 66 & -107 & -113 & -111 & -112 & -111 & -108 & -102 & -96 & -93 & $-90,4$ & $-86,4$ \\
\hline h & 66 & -24 & -17 & -7 & 1 & 11 & 17 & 21 & 24 & 36 & 43,8 & 50 \\
\hline$g$ & 70 & 65 & 67 & 75 & 72 & 71 & 72 & 74 & 77 & 77 & 79,0 & 79,8 \\
\hline$g$ & $\begin{array}{ll}7 & 1\end{array}$ & -56 & -56 & -57 & -57 & -56 & -59 & -62 & -64 & -72 & $-74,0$ & -74 \\
\hline h & $\begin{array}{ll}7 & 1\end{array}$ & -50 & -55 & -61 & -70 & -77 & -82 & -83 & -80 & -69 & $-64,6$ & $-61,4$ \\
\hline$g$ & $\begin{array}{ll}72 \\
\end{array}$ & 2 & 5 & 4 & 1 & 1 & 2 & 3 & 2 & 1 & 0,0 & -1, \\
\hline $\mathrm{h}$ & $\begin{array}{ll}7 & 2\end{array}$ & -24 & -28 & -27 & -27 & -26 & -27 & -27 & -26 & -25 & $-24,2$ & -22 \\
\hline $\mathrm{g}$ & 73 & 10 & 15 & 13 & 14 & 16 & 21 & 24 & 26 & 28 & 33,3 & 38,6 \\
\hline $\mathrm{h}$ & 73 & -4 & -6 & -2 & -4 & -5 & -5 & -2 & 0 & 4 & 6,2 & 6 \\
\hline g & 74 & -32 & -32 & -26 & -22 & -14 & -12 & -6 & -1 & 5 & 9,1 & 12 \\
\hline $\mathrm{h}$ & 74 & 8 & 7 & 6 & 8 & 10 & 16 & 20 & 21 & 24 & 24,0 & 25 \\
\hline$g$ & 75 & -11 & -7 & -6 & -2 & 0 & 1 & 4 & 5 & 4 & 6,9 & 9 \\
\hline h & 75 & 28 & 23 & 26 & 23 & 22 & 18 & 17 & 17 & 17 & 14,8 & 10 \\
\hline$g$ & 76 & 9 & 17 & 13 & 13 & 12 & 11 & 10 & 9 & 8 & 7,3 & 5 , \\
\hline $\mathrm{h}$ & 76 & -20 & -18 & -23 & -23 & -23 & -23 & -23 & -23 & -24 & $-25,4$ & -26 \\
\hline $\mathrm{g}$ & 77 & 18 & 8 & 1 & -2 & -5 & -2 & 0 & 0 & -2 & $-1,2$ & 2 , \\
\hline & 77 & -18 & -17 & -12 & -11 & -12 & -10 & -7 & -4 & -6 & $-5,8$ & -4 \\
\hline
\end{tabular}


continuação da tabela

\begin{tabular}{|c|c|c|c|c|c|c|c|c|c|c|c|c|c|}
\hline$g / h$ & $\mathbf{n}$ & m & 1955,0 & 1960,0 & 1965,0 & 1970,0 & 1975,0 & 1980,0 & 1985,0 & 1990,0 & 1995,0 & 2000,0 & 2005,0 \\
\hline$g$ & 8 & 0 & 11 & 15 & 13 & 14 & 14 & 18 & 21 & 23 & 25 & 24,4 & 24,8 \\
\hline $\mathrm{g}$ & 8 & 1 & 9 & 6 & 5 & 6 & 6 & 6 & 6 & 5 & 6 & 6,6 & 7,7 \\
\hline $\mathrm{h}$ & 8 & 1 & 10 & 11 & 7 & 7 & 6 & 7 & 8 & 10 & 11 & 11,9 & 11,2 \\
\hline g & 8 & 2 & -6 & -4 & -4 & -2 & -1 & 0 & 0 & -1 & -6 & $-9,2$ & $-11,4$ \\
\hline $\mathrm{h}$ & 8 & 2 & -15 & -14 & -12 & -15 & -16 & -18 & -19 & -19 & -21 & $-21,5$ & $-21,0$ \\
\hline g & 8 & 3 & -14 & -11 & -14 & -13 & -12 & -11 & -11 & -10 & -9 & $-7,9$ & $-6,8$ \\
\hline$h$ & 8 & 3 & 5 & 7 & 9 & 6 & 4 & 4 & 5 & 6 & 8 & 8,5 & 9,7 \\
\hline g & 8 & 4 & 6 & 2 & 0 & -3 & -8 & -7 & -9 & -12 & -14 & $-16,6$ & $-18,0$ \\
\hline $\mathrm{h}$ & 8 & 4 & -23 & -18 & -16 & -17 & -19 & -22 & -23 & -22 & -23 & $-21,5$ & $-19,8$ \\
\hline g & 8 & 5 & 10 & 10 & 8 & 5 & 4 & 4 & 4 & 3 & 9 & 9,1 & 10,0 \\
\hline h & 8 & 5 & 3 & 4 & 4 & 6 & 6 & 9 & 11 & 12 & 15 & 15,5 & 16,1 \\
\hline g & 8 & 6 & -7 & -5 & -1 & 0 & 0 & 3 & 4 & 4 & 6 & 7,0 & 9,4 \\
\hline $\mathrm{h}$ & 8 & 6 & 23 & 23 & 24 & 21 & 18 & 16 & 14 & 12 & 11 & 8,9 & 7,7 \\
\hline g & 8 & 7 & 6 & 10 & 11 & 11 & 10 & 6 & 4 & 2 & -5 & $-7,9$ & $-11,4$ \\
\hline $\mathrm{h}$ & 8 & 7 & -4 & 1 & -3 & -6 & -10 & -13 & -15 & -16 & -16 & $-14,9$ & $-12,8$ \\
\hline g & 8 & 8 & 9 & 8 & 4 & 3 & 1 & -1 & -4 & -6 & -7 & $-7,0$ & $-5,0$ \\
\hline h & 8 & 8 & -13 & -20 & -17 & -16 & -17 & -15 & -11 & -10 & -4 & $-2,1$ & $-0,1$ \\
\hline g & 9 & 0 & 4 & 4 & 8 & 8 & 7 & 5 & 5 & 4 & 4 & 5,0 & 5,6 \\
\hline g & 9 & 1 & 9 & 6 & 10 & 10 & 10 & 10 & 10 & 9 & 9 & 9,4 & 9,8 \\
\hline $\mathrm{h}$ & 9 & 1 & -11 & -18 & -22 & -21 & -21 & -21 & -21 & -20 & -20 & $-19,7$ & $-20,1$ \\
\hline g & 9 & 2 & -4 & 0 & 2 & 2 & 2 & 1 & 1 & 1 & 3 & 3,0 & 3,6 \\
\hline $\mathrm{h}$ & 9 & 2 & 12 & 12 & 15 & 16 & 16 & 16 & 15 & 15 & 15 & 13,4 & 12,9 \\
\hline g & 9 & 3 & -5 & -9 & -13 & -12 & -12 & -12 & -12 & -12 & -10 & $-8,4$ & $-7,0$ \\
\hline $\mathrm{h}$ & 9 & 3 & 7 & 2 & 7 & 6 & 7 & 9 & 9 & 11 & 12 & 12,5 & 12.7 \\
\hline g & 9 & 4 & 2 & 1 & 10 & 10 & 10 & 9 & 9 & 9 & 8 & 6,3 & 5,0 \\
\hline $\mathrm{h}$ & 9 & 4 & 6 & 0 & -4 & -4 & -4 & -5 & -6 & -7 & -6 & $-6,2$ & $-6,7$ \\
\hline g & 9 & 5 & 4 & 4 & -1 & -1 & -1 & -3 & -3 & -4 & -8 & $-8,9$ & $-10,8$ \\
\hline h & 9 & 5 & -2 & -3 & -5 & -5 & -5 & -6 & -6 & -7 & -8 & $-8,4$ & $-8,1$ \\
\hline g & 9 & 6 & 1 & -1 & -1 & 0 & -1 & -1 & -1 & -2 & -1 & $-1,5$ & $-1,3$ \\
\hline $\mathrm{h}$ & 9 & 6 & 10 & 9 & 10 & 10 & 10 & 9 & 9 & 9 & 8 & 8,4 & 8,1 \\
\hline g & 9 & 7 & 2 & -2 & 5 & 3 & 4 & 7 & 7 & 7 & 10 & 9,3 & 8,7 \\
\hline $\mathrm{h}$ & 9 & 7 & 7 & 8 & 10 & 11 & 11 & 10 & 9 & 8 & 5 & 3,8 & 2,9 \\
\hline g & 9 & 8 & 2 & 3 & 1 & 1 & 1 & 2 & 1 & 1 & -2 & $-4,3$ & $-6,7$ \\
\hline h & 9 & 8 & -6 & 0 & -4 & -2 & -3 & -6 & -7 & -7 & -8 & $-8,2$ & $-7,9$ \\
\hline g & 9 & 9 & 5 & -1 & -2 & -1 & -2 & -5 & -5 & -6 & -8 & $-8,2$ & $-9,2$ \\
\hline $\mathrm{h}$ & 9 & 9 & 5 & 5 & 1 & 1 & 1 & 2 & 2 & 2 & 3 & 4,8 & 5,9 \\
\hline g & 10 & 0 & -3 & 1 & -2 & -3 & -3 & -4 & -4 & -3 & -3 & $-2,6$ & $-2,2$ \\
\hline g & 10 & 1 & -5 & -3 & -3 & -3 & -3 & -4 & -4 & -4 & -6 & $-6,0$ & $-6,3$ \\
\hline $\mathrm{h}$ & 10 & 1 & -4 & 4 & 2 & 1 & 1 & 1 & 1 & 2 & 1 & 1,7 & 2,4 \\
\hline g & 10 & 2 & -1 & 4 & 2 & 2 & 2 & 2 & 3 & 2 & 2 & 1,7 & 1,6 \\
\hline $\mathrm{h}$ & 10 & 2 & 0 & 1 & 1 & 1 & 1 & 0 & 0 & 1 & 0 & 0,0 & 0,2 \\
\hline g & 10 & 3 & 2 & 0 & -5 & -5 & -5 & -5 & -5 & -5 & -4 & $-3,1$ & $-2,5$ \\
\hline h & 10 & 3 & -8 & 0 & 2 & 3 & 3 & 3 & 3 & 3 & 4 & 4,0 & 4,4 \\
\hline g & 10 & 4 & -3 & -1 & -2 & -1 & -2 & -2 & -2 & -2 & -1 & $-0,5$ & $-0,1$ \\
\hline h & 10 & 4 & -2 & 2 & 6 & 4 & 4 & 6 & 6 & 6 & 5 & 4,9 & 4,7 \\
\hline g & 10 & 5 & 7 & 4 & 4 & 6 & 5 & 5 & 5 & 4 & 4 & 3,7 & 3,0 \\
\hline h & 10 & 5 & -4 & -5 & -4 & -4 & -4 & -4 & -4 & -4 & -5 & $-5,9$ & $-6,5$ \\
\hline$g$ & 10 & 6 & 4 & 6 & 4 & 4 & 4 & 3 & 3 & 3 & 2 & 1,0 & 0,3 \\
\hline $\mathrm{h}$ & 10 & 6 & 1 & 1 & 0 & 0 & -1 & 0 & 0 & 0 & -1 & $-1,2$ & $-1,0$ \\
\hline g & 10 & 7 & -2 & 1 & 0 & 1 & 1 & 1 & 1 & 1 & 2 & 2,0 & 2,1 \\
\hline h & 10 & 7 & -3 & -1 & -2 & -1 & -1 & -1 & -1 & -2 & -2 & $-2,9$ & $-3,4$ \\
\hline$g$ & 10 & 8 & 6 & -1 & 2 & 0 & 0 & 2 & 2 & 3 & 5 & 4,2 & 3,9 \\
\hline $\mathrm{h}$ & 10 & 8 & 7 & 6 & 3 & 3 & 3 & 4 & 4 & 3 & 1 & 0,2 & $-0,9$ \\
\hline g & 10 & 9 & -2 & 2 & 2 & 3 & 3 & 3 & 3 & 3 & 1 & 0,3 & $-0,1$ \\
\hline $\mathrm{h}$ & 10 & 9 & -1 & 0 & 0 & 1 & 1 & 0 & 0 & -1 & -2 & $-2,2$ & $-2,3$ \\
\hline g & 10 & 10 & 0 & 0 & 0 & -1 & -1 & 0 & 0 & 0 & 0 & $-1,1$ & $-2,2$ \\
\hline$h$ & 10 & 10 & -3 & -7 & -6 & -4 & -5 & -6 & -6 & -6 & -7 & $-7,4$ & $-8,0$ \\
\hline
\end{tabular}


continuação da tabela

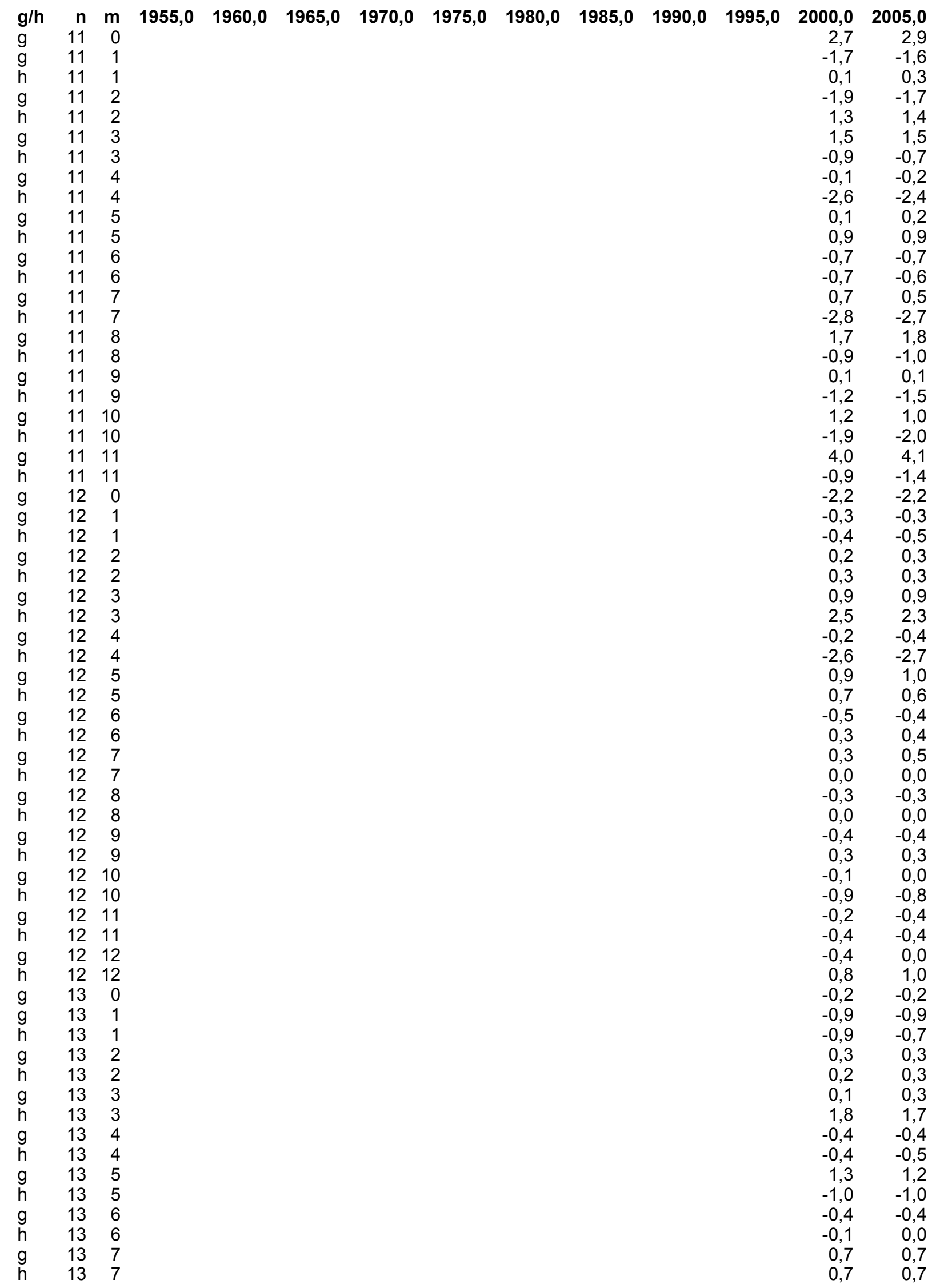




\section{continuação da tabela}

\begin{tabular}{|c|c|c|c|c|c|c|c|c|c|c|c|c|c|}
\hline$g / h$ & $n$ & m & 1955,0 & 1960,0 & 1965,0 & 1970,0 & 1975,0 & 1980,0 & 1985,0 & 1990,0 & 1995,0 & 2000,0 & 2005,0 \\
\hline g & 13 & 8 & & & & & & & & & & $-0,4$ & $-0,3$ \\
\hline $\mathrm{h}$ & 13 & 8 & & & & & & & & & & 0,3 & 0 \\
\hline g & 13 & 9 & & & & & & & & & & 0,3 & 0,4 \\
\hline $\mathrm{h}$ & 13 & 9 & & & & & & & & & & 0,6 & 0 , \\
\hline g & 13 & 10 & & & & & & & & & & $-0,1$ & -0 \\
\hline $\mathrm{h}$ & 13 & 10 & & & & & & & & & & 0,3 & 0 , \\
\hline g & 13 & 11 & & & & & & & & & & 0,4 & 0 \\
\hline $\mathrm{h}$ & 13 & 11 & & & & & & & & & & $-0,2$ & -0 \\
\hline g & 13 & 12 & & & & & & & & & & 0,0 & -0 \\
\hline h & 13 & 12 & & & & & & & & & & $-0,5$ & -0 , \\
\hline g & 13 & 13 & & & & & & & & & & 0,1 & $-c$ \\
\hline
\end{tabular}

